San Jose State University

SJSU ScholarWorks

Master's Theses

Master's Theses and Graduate Research

Fall 2019

\title{
Phreatomagmatic Eruption Deposits on the Seafloor Record Cataclysmic Caldera Formation on Axial Seamount, Juan de Fuca Mid-Ocean Ridge
}

Jacob Danielsen

San Jose State University

Follow this and additional works at: https://scholarworks.sjsu.edu/etd_theses

\section{Recommended Citation}

Danielsen, Jacob, "Phreatomagmatic Eruption Deposits on the Seafloor Record Cataclysmic Caldera Formation on Axial Seamount, Juan de Fuca Mid-Ocean Ridge" (2019). Master's Theses. 5060.

DOI: https://doi.org/10.31979/etd.sw2y-a7hc

https://scholarworks.sjsu.edu/etd_theses/5060

This Thesis is brought to you for free and open access by the Master's Theses and Graduate Research at SJSU ScholarWorks. It has been accepted for inclusion in Master's Theses by an authorized administrator of SJSU ScholarWorks. For more information, please contact scholarworks@sjsu.edu. 


\title{
PHREATOMAGMATIC ERUPTION DEPOSITS ON THE SEAFLOOR RECORD CATACLYSMIC CALDERA FORMATION ON AXIAL SEAMOUNT, JUAN DE FUCA MID-OCEAN RIDGE
}

\author{
A Thesis \\ Presented to \\ The Faculty of the Department of Geology \\ San José State University \\ In Partial Fulfillment \\ of the Requirements for the Degree \\ Master of Science
}

by

Jacob M. Danielsen

December, 2019 
(C) 2019

Jacob M. Danielsen

ALL RIGHTS RESERVED 
The Designated Thesis Committee Approves the Thesis Titled

\title{
PHREATOMAGMATIC ERUPTION DEPOSITS ON THE SEAFLOOR RECORD CATACLYSMIC CALDERA FORMATION ON AXIAL SEAMOUNT, JUAN DE FUCA MID-OCEAN RIDGE
}

\author{
by \\ Jacob M. Danielsen \\ APPROVED FOR THE DEPARTMENT OF GEOLOGY \\ SAN JOSÉ STATE UNIVERSITY
}

December, 2019

\begin{abstract}
Ryan Portner, Ph.D. Department of Geology
Jonathan Miller, Ph.D. Department of Geology

Ellen Metzger, Ph.D. Department of Geology
\end{abstract}




\begin{abstract}
PHREATOMAGMATIC ERUPTION DEPOSITS ON THE SEAFLOOR RECORD CATACLYSMIC CALDERA FORMATION ON AXIAL SEAMOUNT, JUAN DE FUCA MID-OCEAN RIDGE
\end{abstract}

by Jacob M. Danielsen

The physical and compositional characteristics of a unique ash-rich hydrothermal sediment, hydrothermal muddy tuff (HMT), on Axial Seamount, Juan de Fuca Ridge, suggest that it formed by phreatomagmatic eruptions during caldera formation. Deposit thickness trends away from the seamount summit and the presence of $68 \%$ primary volcaniclasts and $32 \%$ secondary lithics suggest a source from along caldera ring-faults deep in the crust. Lithic geothermometry indicates that the source was subject to low-temperature $\left(<150^{\circ} \mathrm{C}\right)$ alteration, consistent with a provenance as deep as $600-800 \mathrm{~m}$ below the seafloor. At this depth, just above the critical point of seawater, the brittle fragmentation of magma upon interaction with deep-circulating hydrothermal fluids triggered molten fuel coolant interaction (MFCl) and the production of highly angular and very fine grained $(100 \mu \mathrm{m})$ glass shards. The resulting phreatomagmatic eruption was dispersed over $3.5 \mathrm{~km}$ away from the caldera by eruption plume fall-out, ocean bottom currents, and dilute gravity-flows. The result is a unique volcaniclastic deposit that has never been described in mid-ocean ridge settings. This study provides the framework for future studies to further explore fragmentation and dispersal mechanisms within the context of deep-marine volcanic setting. 


\section{ACKNOWLEDGMENTS}

First and foremost, l'd like to thank Ryan Portner, Jonathan Miller, and Ellen Metzger for their guidance and support as advisors throughout this project. l'd like to thank Beth Johnson, Destiny kapule, Arran Murch, and Dave Clague, who assisted with this study in various capacities. Special thanks are due to those who helped with data collection and analysis including Ivano Aiello, Mike Torresan, Angela Tan, Jim Hein, and Lucia Gurioli. Without those named above this project would not have been possible.

Completion of this thesis would not have been possible without the loving support of my friends and family. l'd like to thank my wife for allowing me to pursue this. To my parents, I wouldn't be here today without your encouragement, guidance, love and support. 


\section{TABLE OF CONTENTS}

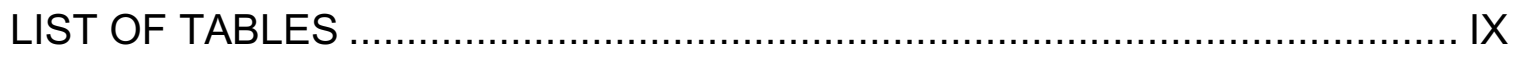

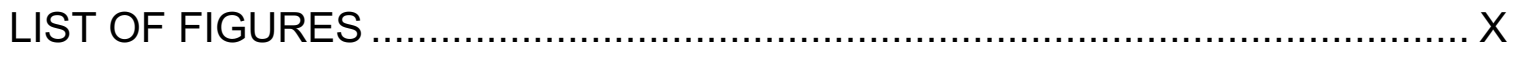

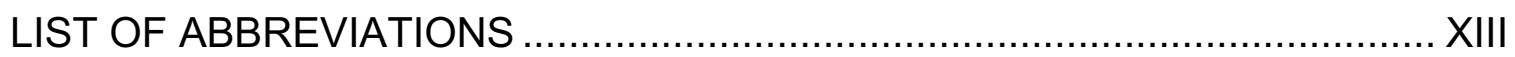

INTRODUCTION

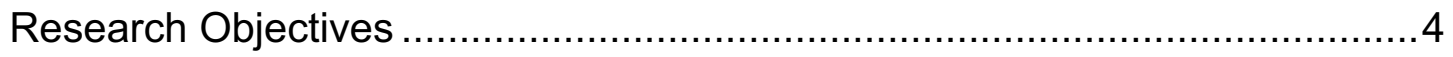

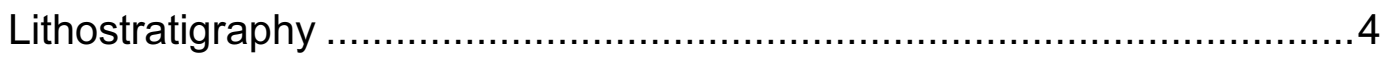

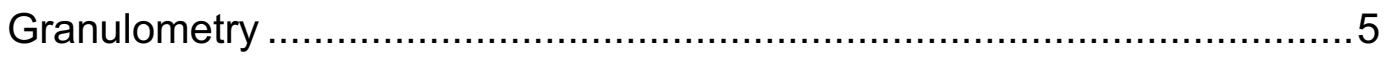

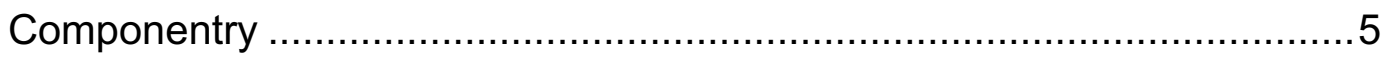

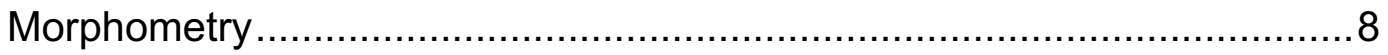

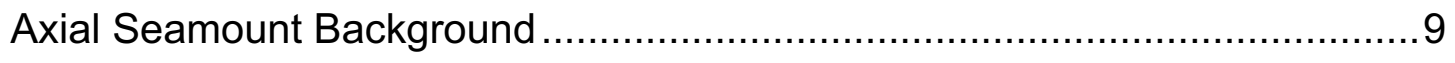

METHODS

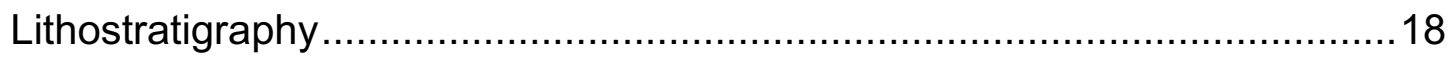

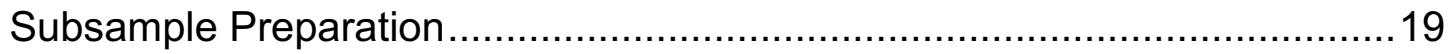

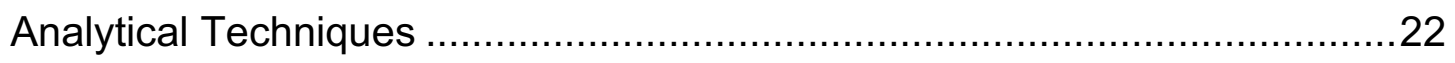

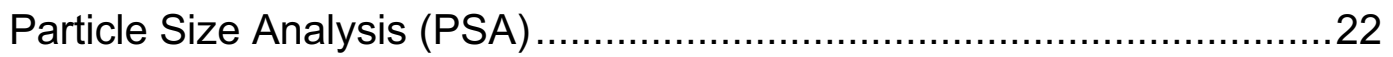

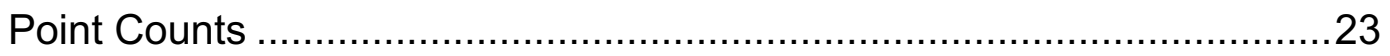

SEM/EDX

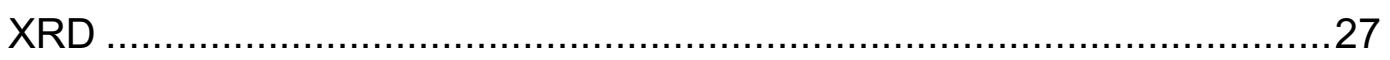

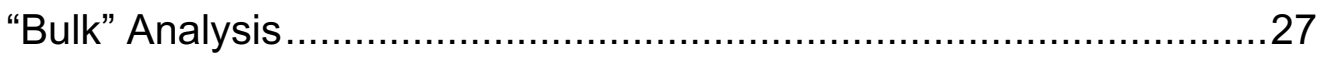

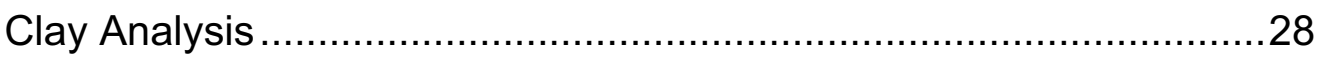

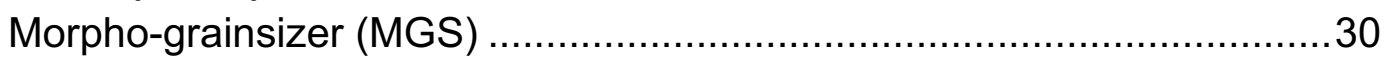

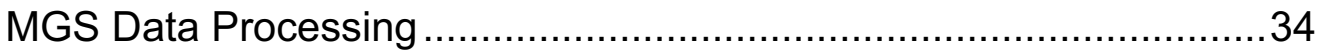

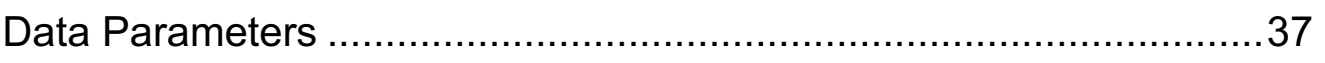

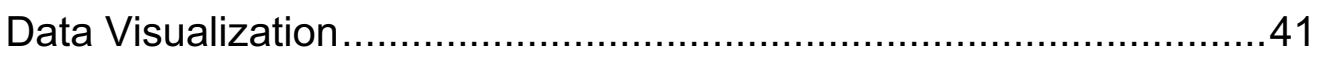

Point Density Plots Using ArcGIS....................................................43

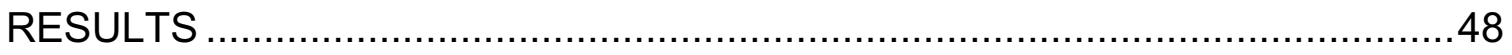

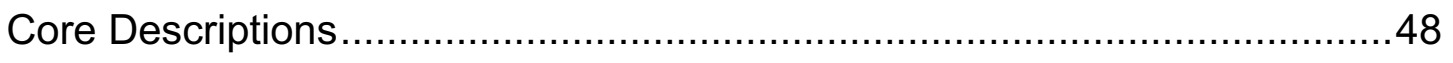

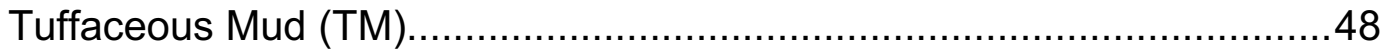

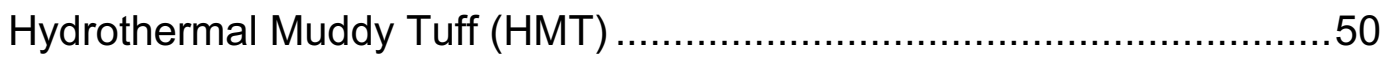

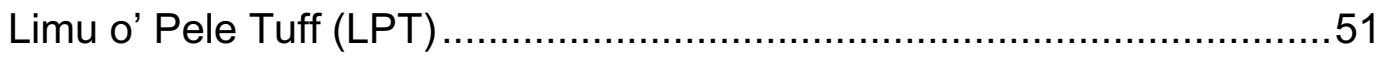

Tuffaceous Ooze (TO) …….........................................................

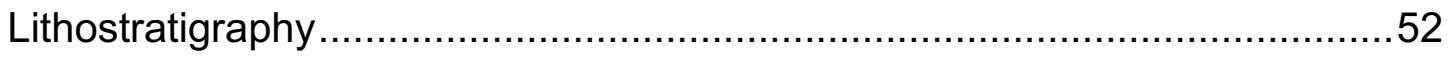




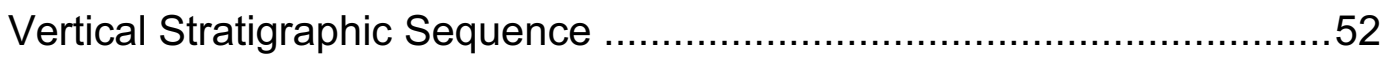

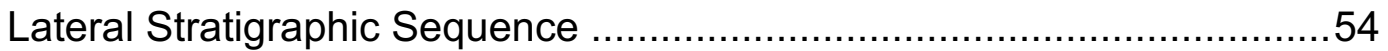

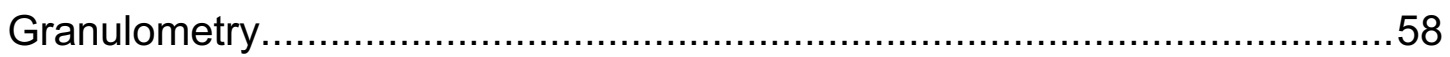

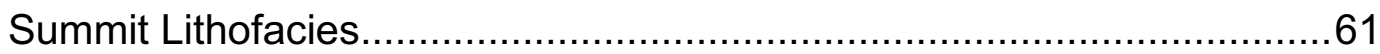

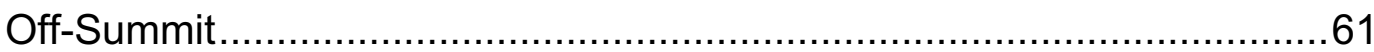

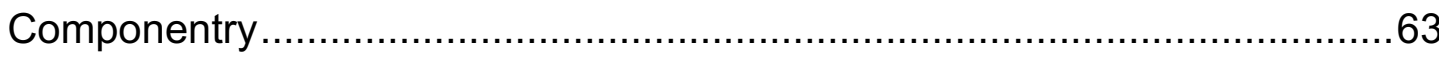

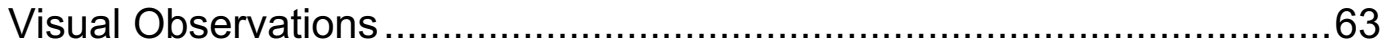

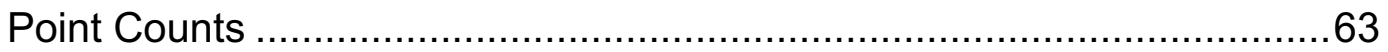

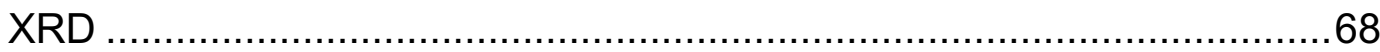

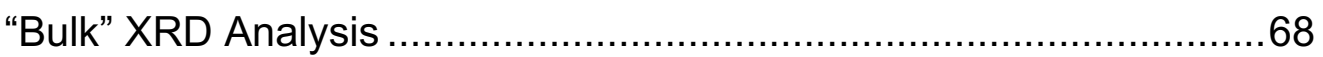

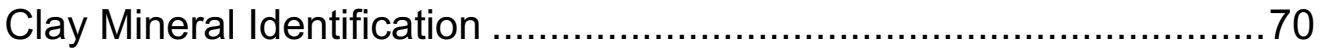

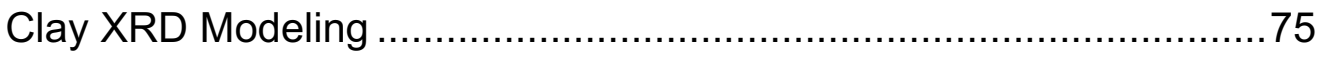

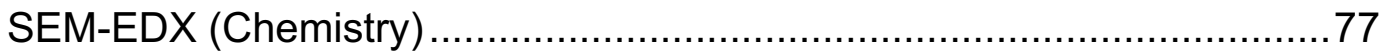

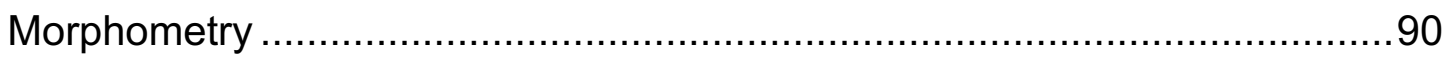

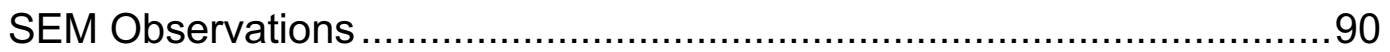

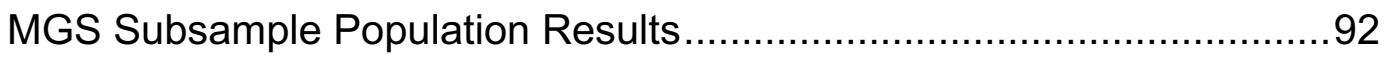

Subsample Comparison Descriptions ..........................................92

Point Density Plot Analysis..............................................................93

Convexity Distribution Frequency Curves .......................................97

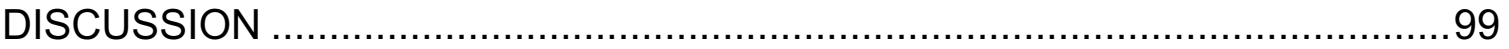

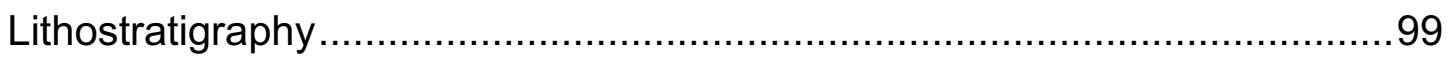

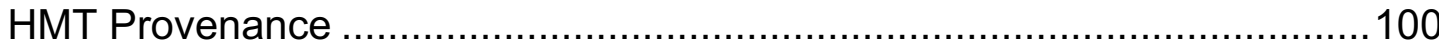

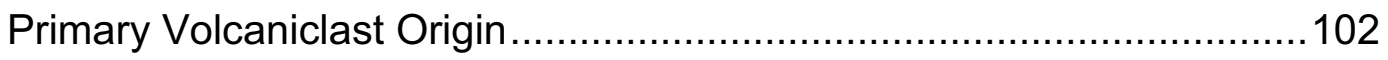

Non-Primary Volcaniclast Origin - Conduit Wall-Rock ..........................103

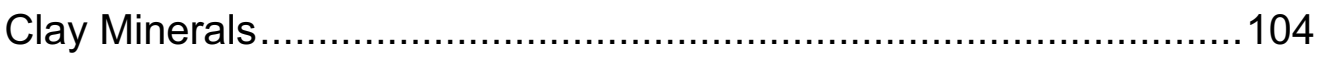

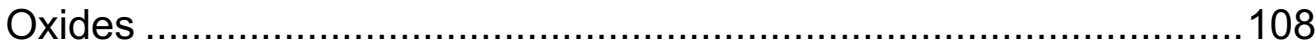

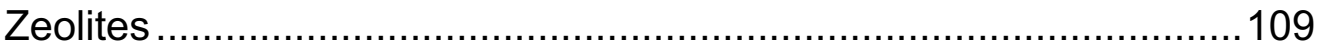

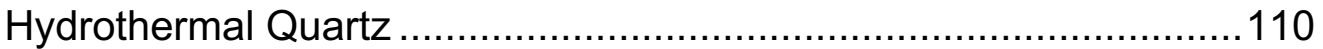

Greenschist-Grade Minerals.......................................................110

Non-Primary Volcaniclast (Accessory Lithic) Provenance ................111

Authigenic Volcaniclast Origin - Eruption Plume ...................................112

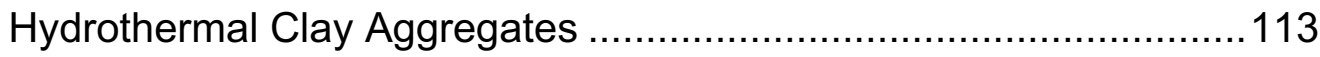

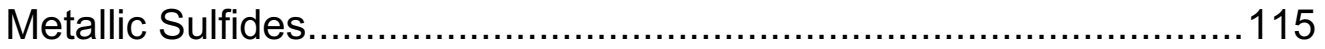

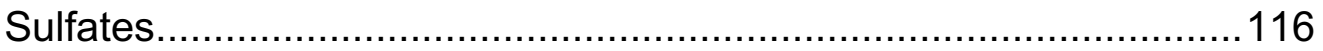

Authigenic Volcaniclast (Accidental Lithic) Provenance ...................117

Fragmentation and Eruption Style ....................................................118

Fragmentation Style Background …............................................118 


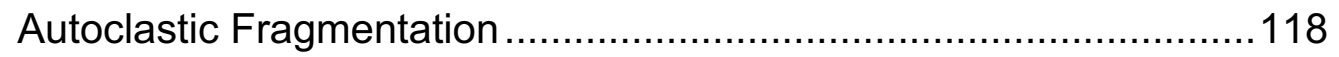

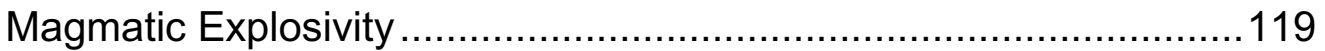

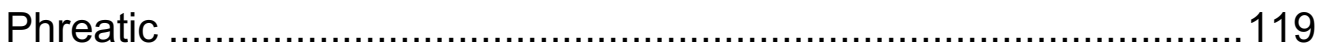

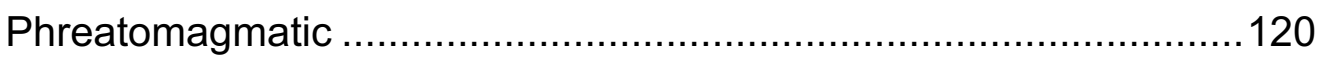

HMT Eruption Style and Fragmentation Mechanism ...........................121

Subsample Population Morphology ..............................................121

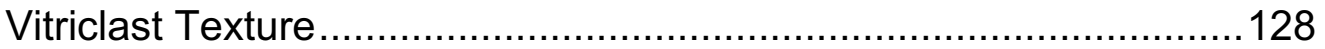

Fragmentation and Eruption Style Conclusions ...................................130

Deep Marine Dispersal........................................................................131

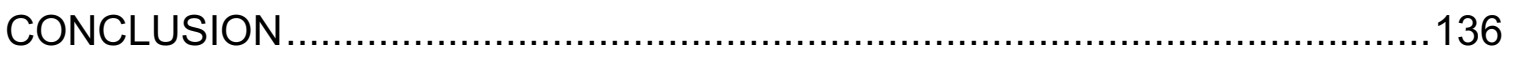

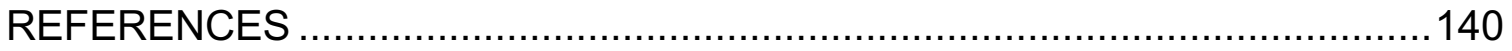

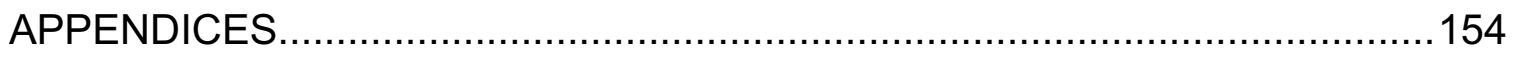

Appendix A: Core Descriptions ……......................................................154

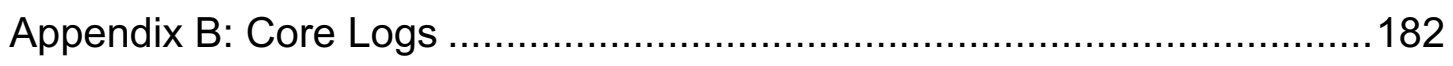




\section{LIST OF TABLES}

Table 1. Lithofacies described on Axial Seamount......................................12

Table 2. Methods and their application used in this study for lithofacies characterization.

Table 3. Summary of analyses used for each core and subsample.................16

Table 4. Summary of point count categories and description of particles counted

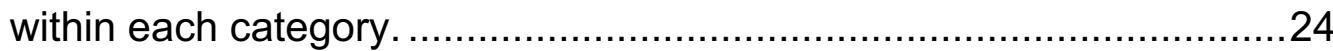

Table 5. Shape parameters used in ash morphology studies. .........................38

Table 6. Particle morphometry results comparison using MGS method and traditional point count.................................................................. 43

Table 7. Results of PSA and analysis based on identified lithofacies. ..............60

Table 8. Results of HMT PSA analysis based on proximity to the caldera.........60

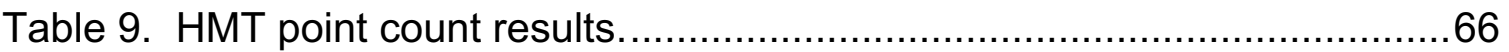

Table 10. Minerals identified in "bulk" XRD diffractograms. .............................70

Table 11. Results of clay XRD treatment scans. .........................................

Table 12. Summary of minerals identified on grains of interest using EDX.......79

Table 13. Results of solidity vs. convexity plots $2 \sigma$ field range values..............95

Table 14. Summary of lithics (accessory and accidental) identified on Axial Seamount and implications........................................................ 101

Table 15. Samples used for ash morphology comparison. ...........................124 


\section{LIST OF FIGURES}

Figure 1. Regional map showing location of Axial Seamount ............................3

Figure 2. Typical componentry observed within HMT ….................................

Figure 3. Map showing location of cores and scoop bags collected on Axial Seamount used in this study

Figure 4. Map showing location of cores used in offset transect 20

Figure 5. Map showing location of off-summit core used for "background" grainsize comparison. 21

Figure 6. Basalt (N-MORB) EDX spectra standard from the northern East pacific Rise 26

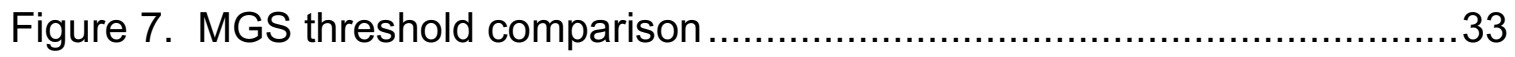

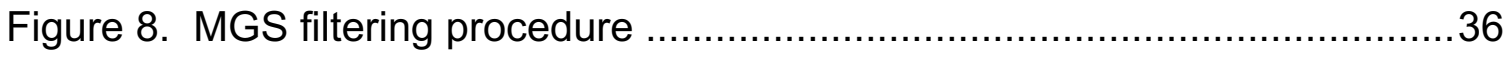

Figure 9. Example of particles with varying convexity and solidity values..........39

Figure 10. Example of particles with varying intensity standard deviation and intensity mean values

Figure 11. Intensity standard deviation vs. intensity mean component fields.....42

Figure 12. MGS density plot radii comparison.............................................45

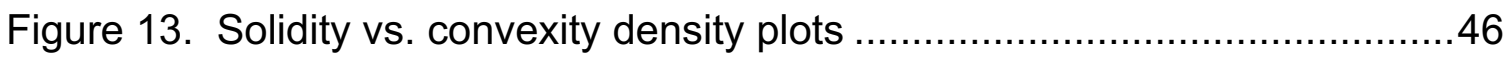

Figure 14 . Intensity standard deviation vs. intensity mean density plots ...........47

Figure 15. Representative proximal, medial, and distal cores showing described lithofacies, structures, magnetic susceptibility, particle size analysis, and point count results............................................................. 49

Figure 16. Regional stratigraphy found on Axial Seamount ...........................53

Figure 17. Observations of lithofacies thickness across offset transect .............55

Figure 18. HMT thickness profile along offset transect .................................56 


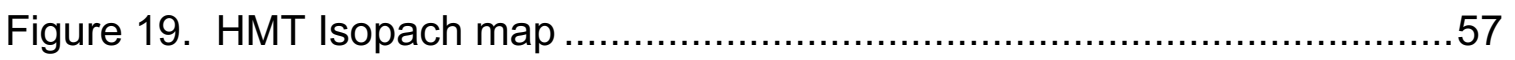

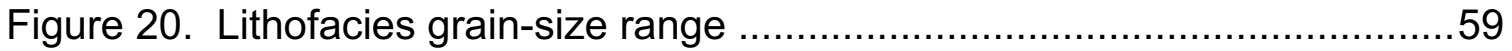

Figure 21. Grain-size frequency distribution curves ..................................62

Figure 22. Point count results based on subsample grain-size ......................65

Figure 23. Point count results of all twenty-seven subsamples .......................67

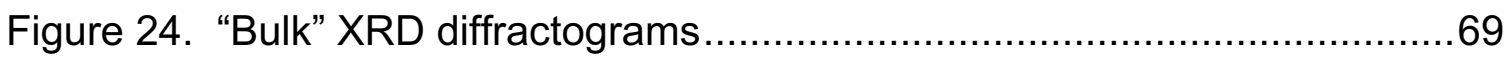

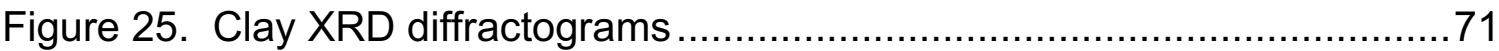

Figure 26. Randomly oriented $<2 \mu \mathrm{m}$ XRD diffractogram for 060 clay peak .......74

Figure 27. Modeled clay XRD diffractograms …….......................................

Figure 28. SEM images of partially altered vitriclasts ....................................78

Figure 29. Partially altered vitriclast EDX spectra ..................................... 80

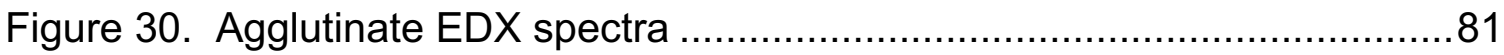

Figure 31. Hydrothermal clay aggregate EDX spectra ..................................82

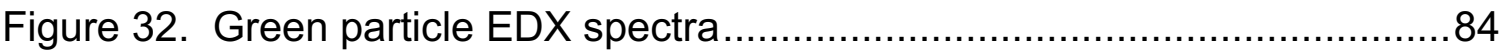

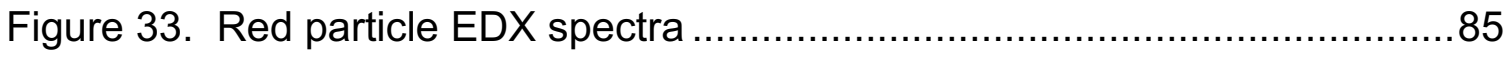

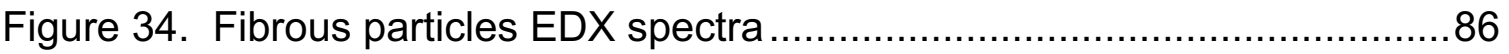

Figure 35. EDX spectra of white particle showing various accessory minerals..87

Figure 36. EDX spectra of white particle showing zeolites .............................88

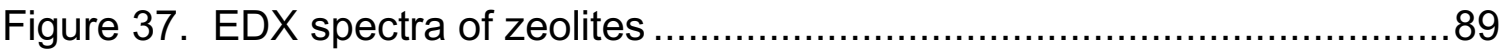

Figure 38. SEM images of vitriclast morphologies (fluidal and angular/blocky) .91

Figure 39. Comparison of solidity vs. convexity subsample plots ....................94

Figure 40. Comparison of Intensity standard deviation vs. intensity mean subsample plots 
Figure 41. Convexity distribution frequency curves .....................................98

Figure 42. Oceanic crust minerals present within HMT ...............................105

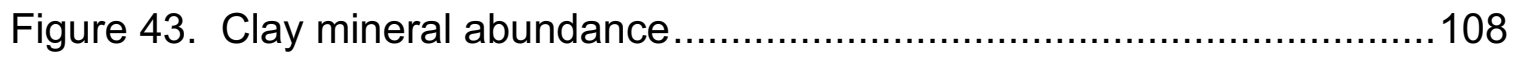

Figure 44. Authigenic hydrothermal minerals and temperature conditions ......114

Figure 45. Solidity vs. convexity plot compared to other eruptions .................123

Figure 46. Convexity frequency distribution curves compared to sub-aerial

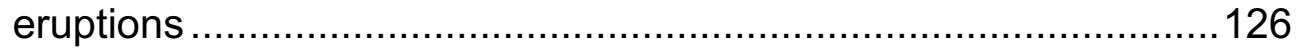

Figure 47. Conceptual model of HMT formation processes ..........................132 


\section{LIST OF ABBREVIATIONS}

C/S - Interstratified Chlorite/Smectite - (Corrensite)

CVX - Convexity

EDX - Electro-dispersive Spectroscopy

HMT - Hydrothermal Muddy Tuff

Int. $M$ - Intensity mean

Int. SD - Intensity standard deviation

JdFR - Juan de Fuca Ridge

LPA - Lower Pillow Alteration Zone

LPT - Limu o' Pele Tuff

LZD - Lithologic Transition Zone

mbsf - meters below the sea floor

mbsl - meters below sea level

MFCl - Molten fuel-coolant interaction

MGS - Morpho-grainsizer

MLML - Moss Landing Marine Laboratory

MOR - Mid-Ocean Ridge

$\mathrm{MPa}$ - Megapascal

PC - Push Core

PSA - Particle Size Analysis

SB - Scoop Bag

SEM - Scanning Electron Microscope 


\author{
SLD - Solidity \\ TM - Tuffaceous Mud \\ TO - Tuffaceous Ooze \\ UPA - Upper Pillow Alteration Zone \\ XRD - X-ray Diffraction \\ ZZ - Zeolite Alteration Zone
}




\section{INTRODUCTION}

Deep-sea caldera systems provide the necessary structural elements (e.g. ring faults) to permit interaction between the lithosphere and hydrosphere (Mueller et al., 2009). These structures increase the porosity of the seafloor up to 33\% (Gilbert et al., 2007), allowing for circulation of warm seawater (Cole et al., 2005) that precipitates authigenic minerals (Inoue, 1995). Deeply eroded submarine calderas show that dikes extend between their parent magma chambers to ring faults at the surface (Browning and Gudmundsson, 2015). This plumbing system provides access for seawater to seep deep into the crust where it can interact with the magmatic system (Mueller et al., 2009; Portner et al., 2015).

The potential for magma-seawater interaction results in phreatomagmatic style eruptions (Geshi et al., 2002; Zimanowski et al., 2015; Liu et al., 2017). This study restricts the term phreatomagmatic to only include subsurface magmaseawater interaction and does not include interaction between magma and seawater above the seafloor. Phreatomagmatic eruptions are driven by the expansion of boiling seawater to steam and are therefore limited to relatively shallow crustal depths where pressures are $<30 \mathrm{MPa}$. At depths greater than this, seawater behaves as a supercritical fluid that lacks the expansion force required to drive phreatomagmatic eruptions (Bischoff and Rosenbauer, 1985). Phreatomagmatic eruption deposits often result in a heterogeneous mixture of primary volcaniclasts, broadly including fresh glassy shards (vitriclasts) from the 
erupting magma, and non-primary volcanic fragments (lithics) that are stripped from conduit walls during the eruption (Barberi et al., 1989).

Although many studies on phreatomagmatic eruptions have been conducted in subaerial volcanic settings, very little is understood about them in deep-marine settings. Moreover, few studies have investigated the potential for magmaseawater interaction along submarine caldera systems despite its potential importance in producing ancient volcanogenic massive sulfide deposits where fault patterns mimic caldera ring structures and dikes (Large et al., 1992; Galley et al., 2007; Mueller et al., 2009). Due to the potential source of mineral resources (e.g. copper, gold, zinc), modern seafloor massive sulfide (SMS) deposits in active hydrothermal systems are of growing interest for natural resource extraction (Murray, 2019).

This study addresses magma-seawater interaction in submarine caldera systems and how it can influence deep-sea volcanic processes by characterizing a volcaniclastic succession on Axial Seamount (Fig. 1). An active submarine volcano, Axial Seamount lies on the Juan de Fuca Ridge (JdFR) approximately 1,500 meters below sea level $(\mathrm{mbsl})$. Axial Seamount is one of the most wellmapped and abundantly sampled deep-marine volcanoes in the world, which when coupled with the presence of a large caldera and up to 65 centimeter-thick volcaniclastic unit extending several kilometers away from caldera margins, provides an excellent opportunity to study how deep-sea calderas influence volcanic, hydrothermal, and volcaniclastic processes. 


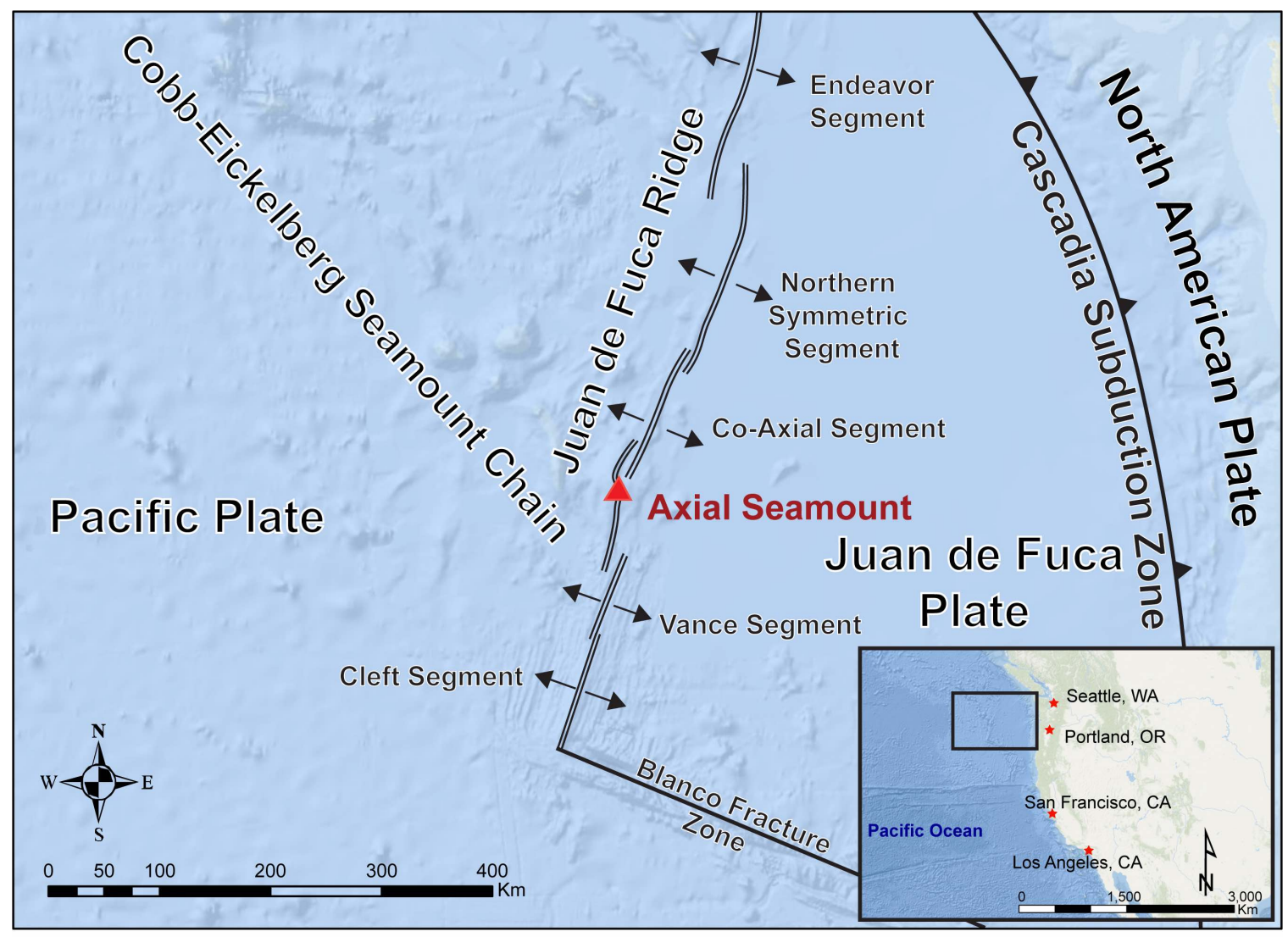

Figure 1. Regional map showing location of Axial Seamount and other segments on the Juan de Fuca Ridge (JdFR), Cobb Eickelberg Seamount chain, and other structural features. Locations of structural segments based on Van Ark et al. (2007). Inset shows regional map relative to major cities on the west coast of North America. 
This study focuses on a unique hydrothermal muddy tuff (HMT) lithofacies found near the caldera margins on Axial Seamount. The lithology of HMT was chosen due to its importance in potentially recording caldera formation (Portner et al. 2015). In contrast to typical 'black smoker' hydrothermal vent sediments that are generally sulfide-rich and lack vitriclasts, the HMT lithofacies found on Axial Seamount is composed of mostly non-sulfide bearing ash-rich hydrothermal sediment. By using lithostratigraphy, granulometry, componentry, and morphometry, this study tests the hypothesis that HMT formed during phreatomagmatic eruptions as a result of caldera collapse on Axial Seamount.

\section{Research Objectives}

This study has two primary research objectives:

1. Determine the physical association between Axial Seamount's caldera and HMT lithofacies through stratigraphic analysis of the volcaniclastic succession.

2. Identify the provenance of HMT and understand its volcaniclastic origin by characterizing deposit granulometry, componentry, and morphometry.

The methodological approach used to address these objectives and some terminological clarification are explained below.

\section{Lithostratigraphy}

Lithostratigraphic trends of the volcaniclastic succession on Axial Seamount were evaluated to determine the source of HMT. Associations of lithofacies to caldera ring faults were evaluated using deposit thickness trends. Relationships 
of lithofacies thicknesses to each other provide insight into modes of origin and deposition, and ultimately, their association or non-association to the seamount caldera system. Lithostratigraphic analysis is therefore used to provide insight into lithofacies source(s), transport, and deposition on the seafloor.

\section{Granulometry}

Granulometry refers to grain-size distribution, which is important in understanding eruptive processes as grain-size is directly related to total kinetic energy when fragmentation occurs in the presence of water (Wohletz et al., 1986; White, 1996). Granulometry also helps reveal sedimentary structures (e.g. grading and laminations), which can be used to understand dispersal. For example, graded bedding in the submarine environment forms by turbulent fluid flows where larger and less buoyant particles settle first, while smaller, more buoyant particles settle at a slower rate (Barreyre et al., 2011). These differences in hydrodynamic properties influence settling velocity and are also linked to particle morphology. Granulometry analysis was conducted to evaluate grain-size distributions with regards to fragmentation energy and sedimentary structures to explore transport mechanisms.

\section{Componentry}

Componentry refers to the material and components of bulk sediment subsamples (including mineralogy) and the chemical makeup of individual particles. Components within HMT may be divided into three main categories that include: primary volcaniclasts, non-primary volcaniclasts, and authigenic 
hydrothermal minerals (Fig. 2). In this study, the term "primary volcaniclast" is used to refer to a particle that is magmatically associated with erupting magma and includes vitriclasts (Fig. 2A and B), monocrystalline volcanic minerals (e.g. plagioclase, olivine), and phyric fragments.

Conversely, the term "non-primary volcaniclast" refers to a fragment that is not associated with erupting magma, but instead, incorporated from the external environment during eruptions (e.g. conduit walls, volcano flanks; Fig. 2-C1 - C5; C8 - C11). The term "authigenic hydrothermal mineral" refers to minerals that precipitate from hydrothermal fluids (e.g. clays, sulfates, sulfides; Fig. 2-C6 and C7) associated with the eruption plume and are also non-primary to the erupting magma, but also not volcanic. Both non-primary volcaniclasts and authigenic hydrothermal minerals are therefore considered secondary particles (e.g. lithics).

Secondary components within HMT are of particular interest as chemical alteration of volcanic material results in clay minerals, which are abundant in hydrothermal environments (Utada, 1980; Inoue, 1995). Alteration mineral identification provides insight into the temperature controls and source-depth of potential phreatomagmatic eruptions (Alt et al., 1986). Additionally, authigenic hydrothermal mineralogy is indicative of temperature and chemical controls of hydrothermal fluids (Blount et al., 1977; Ellis and Mahon, 1977; Murnane and Clague, 1983; Inoue, 1995). Componentry analysis was therefore conducted to understand the provenance of non-vitric (e.g. secondary) HMT sediment. 


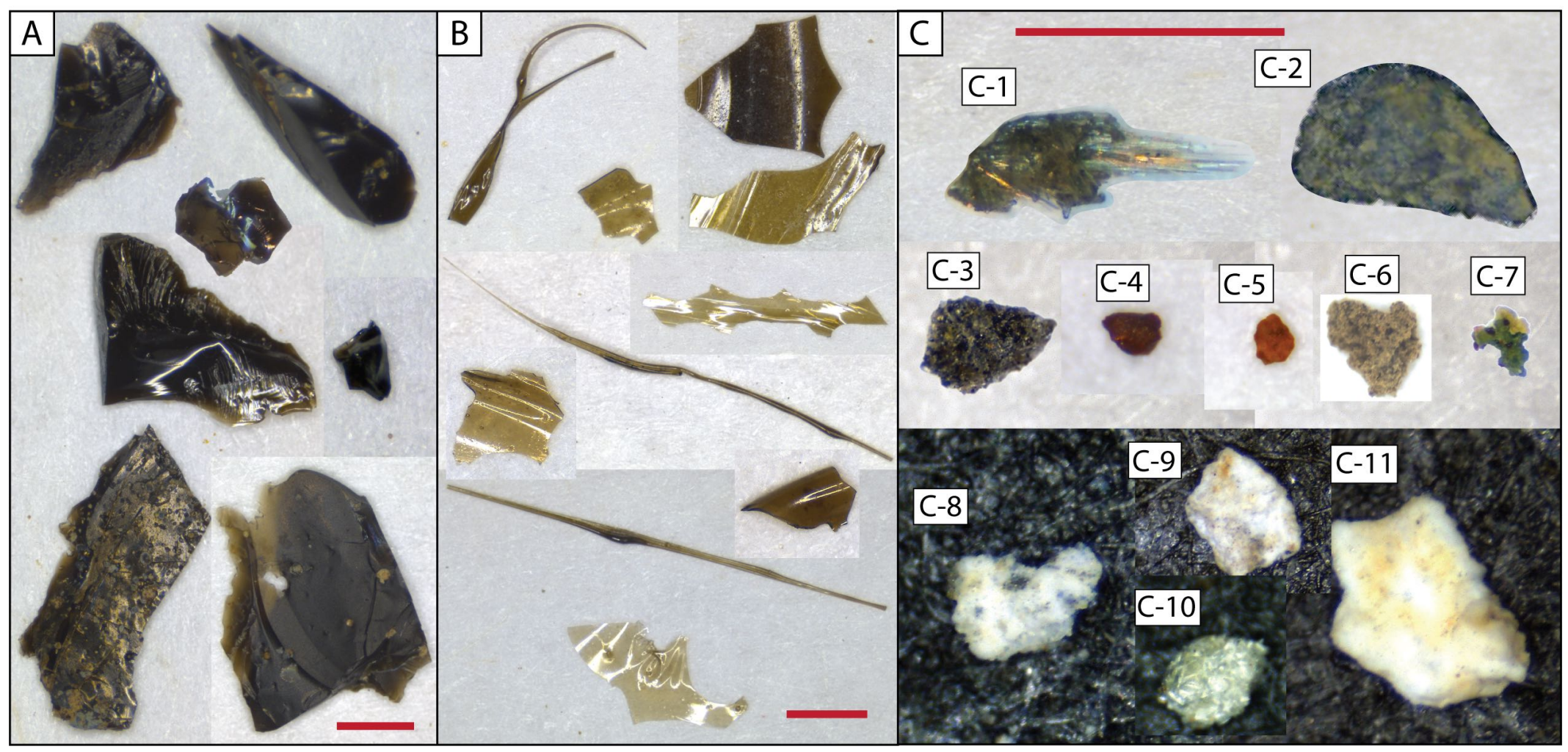

Figure 2. Componentry typical of HMT lithofacies. Red scale bars are $500 \mu \mathrm{m}$. (A) Primary vitriclasts with angular/blocky morphologies. (B) Primary vitriclasts with a variety of fluidal morphologies including limu o' Pele and Pele's hairs. (C) Non-primary volcaniclasts (lithics). (C-1) Green fibrous mineral. (C2) Green other. (C3) Crystalline basalt. (C4 and 5) Red particles. White other. (C6 \& C7) Green authigenic hydrothermal aggregate. (C8 - C11) White particles. Images enhanced for better color contrast. 


\section{Morphometry}

Morphometry refers to the texture (e.g. size, shape, vesicularity, surface features) of individual particles, and for the purpose of this thesis is restricted to vitriclasts only. Vitriclast morphometry is highly dependent on the rheologic state of the material being expelled and the environment in which it forms (Büttner et al., 2002; Zimanowski et al., 1997). Vitriclasts may be broadly characterized as either angular / blocky or fluidal. Angular / blocky shards (Fig. 2A) form when magma fragments while in a brittle state (Porreca et al., 2014) and may be described as dense or blocky with sharp, angular edges and generally rigid surfaces. Fluidal shards (Fig. 2B) have smooth surfaces that form when magma solidifies while in a ductile state. Fluidal vitriclasts include limu o' Pele which are considered bubble-wall shards, but their mode of formation is highly debated (Clague et al., 2009b; Schipper and White, 2010). Nevertheless, vitriclast texture is influenced by the magma fragmentation process and external environmental conditions (Büttner et al., 2002; Liu et al., 2017; Wohletz, 1986; Zimanowski et al., 1997). In a submarine environment, magma-seawater interaction is of particular importance because it can form unique particles with entirely different morphologies based on state of the magma (brittle or ductile) during fragmentation. Morphological analysis was conducted in an effort to determine fragmentation mechanisms and thus, eruption style. 


\section{Axial Seamount Background}

Axial Seamount lies on the active Juan de Fuca mid-oceanic ridge off the coast of Oregon and Washington States (Fig. 1). It is the youngest volcanic structure of the Cobb-Eickelberg seamount chain, a range of seamounts formed by the Cobb hotspot, which extends $1,800 \mathrm{~km}$ northwest to Alaska. Mid-ocean ridge (MOR) rift zones extend to the north and south of Axial Seamount as part of the Juan de Fuca Ridge (JdFR). The seamount has a well-expressed summit caldera that is approximately $8 \times 3 \mathrm{~km}$ trending generally north-south.

Geophysical data suggest that outward dipping ring faults, that extend down to the magma chamber $\sim 2 \mathrm{~km}$ beneath the seafloor, accommodate caldera inflation and deflation between eruption episodes (Wilcock et al., 2018).

Geophysical monitoring of Axial Seamount began in 1987 (Fox, 1990). In 1996, the National Oceanic and Atmospheric Administration (NOAA) implemented the New Millennium Observatory (NeMO) to record interactions between hydrothermal venting and volcanic activity using time-series data (Hamond et al., 2015). In 2014, the Ocean Observatories Initiative (OOI) completed the Axial Seamount cabled array, a network of numerous scientific instruments allowing for real-time observation (Kelley et al., 2014; Delaney et al., 2016). The extensive network of scientific monitoring recorded data during three eruptions in 1998,2011 , and most recently in 2015 . Ocean bathymetry and geophysical data reveal that an increase in seismicity, bottom pressure, and caldera inflation coincide with eruptions (Wilcock et al., 2018). Implementation of 
this extensive scientific monitoring network has resulted in Axial Seamount becoming one of the most well-studied deep-sea volcanoes in the world.

In addition to scientific monitoring, volcanic rocks and seafloor sediment retrieved from Axial Seamount has been analyzed in numerous studies. Seafloor mapping near the caldera indicates that the majority of volcanic activity is effusive (non-explosive) as evident by extensive lava flows (Clague et al., 2013); however, vitriclast deposits around the caldera margin indicate that some eruptions were explosive (Helo et al., 2011; Portner et al., 2015). The summit lavas on Axial Seamount are chemically distinct from lavas erupted on the adjacent ridge axis. The presence of the Cobb hot spot along the axial segment of the ridge results in an increased supply of hot-spot derived magma that is slightly more primitive and enriched in incompatible elements (e.g. $\left.\mathrm{TiO}_{2}\right)$ compared to typical mid-ocean ridge basalt (MORB) lavas found along adjacent rift zones on the JdFR (Chadwick et al., 2005; Dreyer et al., 2013).

Magmatism throughout Axial Seamount's recent ( $<2$ kyr) eruptive history exhibits at least three chemically distinct periods. Variations in $\mathrm{MgO}, \mathrm{K}_{2} \mathrm{O}$ and $\mathrm{TiO}_{2}$, which are good proxies for distinguishing primitive magma (high $\mathrm{MgO}$ wt. \%) from slightly more evolved (low MgO wt. \%) magma compositions (Sun, 1982; Arevalo and McDonough, 2010) support this. A shift from a compositionally diverse transitional (T)-MORB with low (<8.0 wt. \%) MgO to normal (N)-MORB containing higher (>8.0 wt. \%) MgO occurred approximately 900 years ago followed by another transition back to T-MORB with low MgO about 600 years 
ago (Dreyer et al., 2013). This chemical stratigraphy observed in lavas is also observed in vitriclasts within the volcaniclastic succession around the caldera (Beth Johnson pers. comm.).

A 45 thousand-year (Kyr) record of volcanism and sedimentation on Axial Seamount is preserved in a $<1$-meter-thick volcaniclastic sequence around the summit (Clague et al., 2013; Dreyer et al., 2013). This sequence of sediment has been categorized into four different lithologic facies based on the composition, grain-size, chemical heterogeneity and stratification style (Portner et al., 2015). Lithofacies include a tuffaceous mud (TM), hydrothermal muddy tuff (HMT), limu o' Pele tuff (LPT), and tuffaceous ooze (TO), all of which formed in the same environment (mid-ocean ridge) but are inferred to indicate different eruption styles and dispersal processes. Table 1 summarizes lithofacies characteristics described by Portner et al. (2015) and incorporates visual observations of 25 cores described in this study. Detailed descriptions based on visual observations in this study are presented in results. 
Table 1. Lithofacies described on Axial Seamount (modified from Portner et al., 2015).

\begin{tabular}{|c|c|c|c|c|c|c|c|}
\hline Lithofacies & $\begin{array}{c}\text { Described } \\
\text { Composition }\end{array}$ & $\begin{array}{l}\text { Components } \\
\text { (approx. bulk \%) }\end{array}$ & $\begin{array}{l}\text { Modal Ash } \\
\text { Range (\%) }\end{array}$ & Grain-Size & Fabric & $\begin{array}{l}\text { Interpreted Mode } \\
\text { of Origin }\end{array}$ & $\begin{array}{l}\text { Described Matrix } \\
\text { Color }\end{array}$ \\
\hline $\begin{array}{l}\text { Tuffaceous } \\
\text { Mud (TM) }\end{array}$ & Ashy mud & $\begin{array}{l}60-30 \text { Mud (clay) } \\
40-20 \text { Angular vitriclasts } \\
30-10 \text { Fluidal vitriclasts } \\
10-2 \text { Lithics } \\
<2 \text { Biogenic }\end{array}$ & $10-45$ & $\begin{array}{l}\text { Fine to } \\
\text { coarse } \\
\text { grained; very } \\
\text { poorly sorted }\end{array}$ & $\begin{array}{l}\text { Diffuse to defined } \\
\text { lamination; bioturbation }\end{array}$ & $\begin{array}{l}\text { Pelagic fall-out } \\
\text { and distal gravity } \\
\text { flow }\end{array}$ & \begin{tabular}{l} 
Moderate brown \\
(5YR 5/6) \\
\multicolumn{1}{c}{ Or } \\
Moderate yellowish \\
brown (10YR 5/6)
\end{tabular} \\
\hline $\begin{array}{l}\text { Hydrothermal } \\
\text { Muddy Tuff } \\
\text { (HMT) }\end{array}$ & $\begin{array}{l}\text { Sandy mud to } \\
\text { Muddy sand } \\
\text { (with ash) }\end{array}$ & $\begin{array}{l}40-30 \text { Angular vitriclasts } \\
30-20 \text { Fluidal vitriclasts } \\
30-20 \text { Mud (clay) } \\
20-10 \text { Hydrothermal } \\
\text { Lithics } \\
<2 \text { Volcanic mineral } \\
\text { fragments \& Lithics }\end{array}$ & $10-60$ & $\begin{array}{l}\text { Fine to very } \\
\text { fine grained; } \\
\text { well sorted }\end{array}$ & $\begin{array}{l}\text { Normal grading with } \\
\text { "normal-to-reverse } \\
\text { graded" section; well- } \\
\text { defined laminations } \\
\text { resulting in "reverse-to- } \\
\text { normal graded" sections. }\end{array}$ & $\begin{array}{l}\text { Phreatomagmatic } \\
\text { plume fall }\end{array}$ & $\begin{array}{l}\text { Light Olive Grey (5Y } \\
5 / 2)\end{array}$ \\
\hline $\begin{array}{l}\text { Limu o Pele } \\
\text { (LPT) }\end{array}$ & Ash & $\begin{array}{l}60-20 \text { Fluidal Vitriclasts } \\
40-70 \text { Angular vitriclasts } \\
6-2 \text { Volcanic mineral } \\
\text { fragments } \\
5-1 \text { Volcanic Lithics }\end{array}$ & $>90$ & $\begin{array}{l}\text { Medium - } \\
\text { very coarse } \\
\text { grained; } \\
\text { moderately to } \\
\text { well sorted }\end{array}$ & $\begin{array}{l}\text { Normal grading; planar } \\
\text { grain fabric; rip-up clasts } \\
\text { of TO }\end{array}$ & $\begin{array}{l}\text { Proximal gravity } \\
\text { flow }\end{array}$ & None (Black) \\
\hline $\begin{array}{l}\text { Tuffaceous } \\
\text { Ooze (TO) }\end{array}$ & Ashy mud & $\begin{array}{l}>90 \% \text { Foraminifera } \\
<10 \% \text { Angular vitriclasts }\end{array}$ & $5-10$ & $\begin{array}{l}\text { Fine grained; } \\
\text { Very well } \\
\text { sorted }\end{array}$ & Structureless & Pelagic fall-out & \begin{tabular}{l} 
Greyish orange \\
(10YR 7/4) $\quad$ Or \\
\multicolumn{1}{c}{$\begin{array}{c}\quad \\
\text { Yellowish grey }(5 Y \\
7 / 2)\end{array}$}
\end{tabular} \\
\hline
\end{tabular}




\section{METHODS}

Nearly 370 sediment push cores and scoop bags have been retrieved by remotely operated vehicle (ROV) from Axial Seamount during five expeditions between 2006 and 2016. This study primarily focuses on subsamples retrieved from push cores, but scoop bag subsamples are used for dataset comparison. Cores are stored at San Jose State University (SJSU), Monterey Bay Aquarium Research Institute (MBARI), and the United States Geological Survey (USGS) in Santa Cruz. A subset of longer $(>20 \mathrm{~cm})$ push cores were split at the USGS in Santa Cruz. Core and scoop bag sample locations on Axial Seamount used in this study are shown in Figure 3. A summary of methods and their application(s) used in this study are provided in Table 2. A log of methods used for each core and subsample are presented in Table 3. 


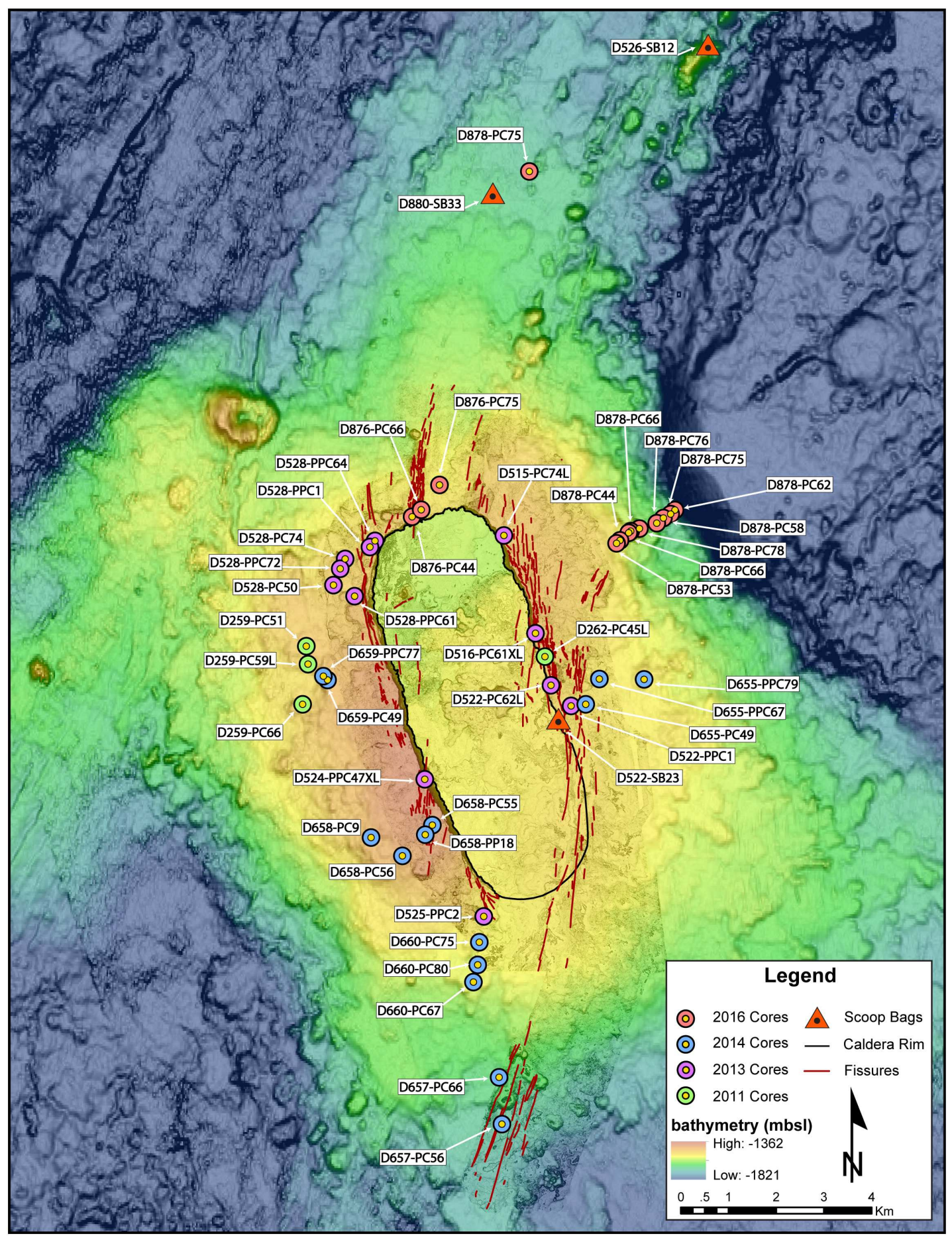

Figure 3. Bathymetric map of Axial Seamount showing location of caldera (black line), fissures (red lines), and location of push cores and scoop bag samples analyzed in this study. Bathymetric data are from AUV and ship-based seabeam EM300 data acquired by MBARI. Caldera rim and fissures were drawn in by colleagues at MBARI pers. Comm. 
Table 2. Methods and their application used in this study for lithofacies characterization.

\begin{tabular}{|c|c|c|c|}
\hline Characteristic & Method & Application & \# analyzed \\
\hline Lithostratigraphy & $\begin{array}{l}\text { Core } \\
\text { Descriptions }\end{array}$ & Litho-stratigraphic associations to the caldera & $25^{a}$ \\
\hline $\begin{array}{l}\text { Granulometry } \\
\text { (Grain-size) }\end{array}$ & $\begin{array}{l}\text { Laser } \\
\text { diffraction }\end{array}$ & Primary method for grain-size analysis & $66^{\mathrm{b}}$ \\
\hline \multirow{3}{*}{$\begin{array}{l}\text { Componentry } \\
\text { (mineralogy \& } \\
\text { chemistry) }\end{array}$} & Point counts & Bulk HMT component proportions & $27^{\mathrm{b}}$ \\
\hline & $\mathrm{XRD}$ & Analysis of bulk \& clay mineralogy & $10 / 4^{c}$ \\
\hline & EDX & Chemical analysis of hydrothermal particle & $28^{d}$ \\
\hline \multirow{3}{*}{$\begin{array}{l}\text { Morphometry } \\
\text { (particle shape) }\end{array}$} & Point counts & $\begin{array}{l}\text { Proportions of vitriclast morphology } \\
\text { (qualitative) }\end{array}$ & $5^{b}$ \\
\hline & SEM & $\begin{array}{l}\text { Visually analysis of high-resolution images of } \\
\text { individual glass particles }\end{array}$ & $77^{d}$ \\
\hline & MGS & Vitriclast morphology analysis (quantitative) & $41^{b}$ \\
\hline
\end{tabular}

a25 cores described.

bSubsamples

"10 subsamples used for "bulk" XRD; 4 subsamples used for clay XRD analysis.

dIndividual particles analyzed 
Table 3. Log of core and subsamples and the methods used in this study.

\begin{tabular}{|c|c|c|c|c|c|c|c|c|c|c|}
\hline Core & $\begin{array}{l}\text { Sample depth } \\
\text { (from top of core) }\end{array}$ & $\begin{array}{l}\text { Subsample } \\
\text { Name }\end{array}$ & $\begin{array}{c}\text { Core } \\
\text { described }\end{array}$ & PSA & $\begin{array}{l}\text { Point } \\
\text { count }\end{array}$ & $\begin{array}{l}\text { XRD } \\
\text { "bulk" }\end{array}$ & $\begin{array}{l}\text { CXRD } \\
\text { (clay) }\end{array}$ & $\begin{array}{l}\text { SEM } \\
\text { mount }\end{array}$ & MGS & $\begin{array}{c}\text { MGS } \\
\text { (point count) }\end{array}$ \\
\hline D515-PC74L & & & $\mathrm{x}$ & & & & & & & \\
\hline D516-PC61XL & & & $\mathrm{x}$ & & & & & & & \\
\hline \multirow[t]{2}{*}{ D522-PPC1 } & & & $\mathrm{x}$ & & & & & & & \\
\hline & 9.0 & D522-PPC1_9.0 & & & & $\mathrm{x}$ & $\mathrm{x}$ & & & \\
\hline \multirow[t]{28}{*}{ D522-PC62L } & & & $\mathrm{x}$ & & & & & & & \\
\hline & 3.0 & D522-PC62L_3.0 & & & & & & & $\mathrm{x}$ & \\
\hline & 10.0 & D522-PC62L_10.0 & & $\mathrm{x}$ & & & & & & \\
\hline & 11.5 & D522-PC62L_11.5 & & & & $\mathrm{x}$ & & & & \\
\hline & 13.0 & D522-PC62L_13.0 & & $\mathrm{x}$ & $x$ & & & & & \\
\hline & 15.0 & D522-PC62L_15.0 & & & $\mathrm{x}$ & & & & $\mathrm{x}$ & $\mathrm{x}$ \\
\hline & 16.0 & D522-PC62L_16.0 & & $\mathrm{x}$ & & & & & & \\
\hline & 19.0 & D522-PC62L_19.0 & & $x$ & & & & & & \\
\hline & 21.5 & D522-PC62L_21.5 & & & & $\mathrm{x}$ & $\mathrm{x}$ & & & \\
\hline & 23.0 & D522-PC62L_23.0 & & $\mathrm{x}$ & $x$ & & & & & \\
\hline & 26.0 & D522-PC62L_26.0 & & $\mathrm{x}$ & & & & & & \\
\hline & 27.0 & D522-PC62L_27.0 & & & & & & & $\mathrm{x}$ & $\mathrm{x}$ \\
\hline & 28.0 & D522-PC62L_28.0 & & $\mathrm{x}$ & $x$ & & & $x$ & & \\
\hline & 29.0 & D522-PC62L_29.9 & & & & $\mathrm{x}$ & & & & \\
\hline & 31.0 & D522-PC62L_31.0 & & $\mathrm{x}$ & & & & & & \\
\hline & 32.0 & D522-PC62L_32.0 & & & & & & & $\mathrm{x}$ & \\
\hline & 34.5 & D522-PC62L_34.5 & & $\mathrm{x}$ & & & & & & \\
\hline & 35.5 & D522-PC62L_35.5 & & $x$ & & & & & & \\
\hline & 36.0 & D522-PC62L_36.0 & & $x$ & & & & & & \\
\hline & 37.5 & D522-PC62L_37.5 & & $\mathrm{x}$ & $x$ & & & & & \\
\hline & 38.5 & D522-PC62L_38.5 & & $\mathrm{x}$ & & & & & & \\
\hline & 39.0 & D522-PC62L_39.0 & & $\mathrm{x}$ & & & & & & \\
\hline & 40.0 & D522-PC62L_40.0 & & $x$ & & & & & & \\
\hline & 41.0 & D522-PC62L_41.0 & & $x$ & $\mathrm{x}$ & & & & & \\
\hline & 42.5 & D522-PC62L_42.5 & & $\mathrm{x}$ & & & & & & \\
\hline & 44.5 & D522-PC62L_44.5 & & $\mathrm{x}$ & & & & & & \\
\hline & 46.5 & D522-PC62L_46.5 & & $x$ & $x$ & & & & & \\
\hline & 48.5 & D522-PC62L_48.5 & & $\mathrm{x}$ & & & & & & \\
\hline \multirow[t]{11}{*}{ D522-PC66 } & & & $x$ & & & & & & & \\
\hline & 6.5 & D522 PC-66_6.5 & & $\mathrm{x}$ & & & & & & \\
\hline & 8.0 & D522-PC66_8.0 & & $x$ & $x$ & & & & & \\
\hline & 10.0 & D522-PC66_10.0 & & $x$ & & & & & & \\
\hline & 11.0 & D522-PC66_11.0 & & $x$ & & & & & & \\
\hline & 12.0 & D522-PC66_12.0 & & $\mathrm{x}$ & $x$ & & & & & \\
\hline & 14.0 & D522-PC66_14.0 & & $\mathrm{x}$ & & & & & & \\
\hline & 15.5 & D522-PC66_15.5 & & $x$ & & & & & & \\
\hline & 17.0 & D522-PC66_17.0 & & $x$ & $\mathrm{x}$ & & & & & \\
\hline & 19.0 & D522-PC66_19.0 & & $x$ & $x$ & & & & & \\
\hline & 19.0 & D522-PC66_19.0 & & $\mathrm{x}$ & & & & & & \\
\hline \multirow[t]{10}{*}{ D524-PC47XL } & & & $x$ & & & & & & & \\
\hline & 10.0 & D524-PC47XL_10.0 & & & & & & & $x$ & \\
\hline & 22.5 & D524-PC47XL_22.5 & & $\mathrm{x}$ & & & & & & \\
\hline & 24.5 & D524-PC47XL_24.0 & & $x$ & & & & & & \\
\hline & 27.0 & D524-PC47XL_27.0 & & $x$ & $x$ & & & & & \\
\hline & 27.0 & D524-PC47XL_27.0 & & & & & & & $x$ & $\mathrm{x}$ \\
\hline & 29.5 & D524-PC47XL_29.5 & & $\mathrm{x}$ & & & & & & \\
\hline & 32.0 & D524-PC47XL_32.0 & & & & & & & $\mathrm{x}$ & \\
\hline & 41.0 & D524-PC47XL_41.0 & & & & & & & $x$ & \\
\hline & 48.0 & D524-PC47XL_48.0 & & & & & & & $\mathrm{x}$ & \\
\hline \multirow[t]{11}{*}{ D525-PPC2 } & & & $x$ & & & & & & & \\
\hline & 17.0 & D525-PPC2_17.0 & & $x$ & & & & & & \\
\hline & 19.0 & D525-PPC2_19.0 & & $\mathrm{x}$ & & & & & & \\
\hline & 21.0 & D525-PPC2_21.0 & & $x$ & & & & & & \\
\hline & 23.0 & D525-PPC2_23.0 & & & $x$ & & & & $x$ & \\
\hline & 24.0 & D525-PPC2_24.0 & & $\mathrm{x}$ & & & & & & \\
\hline & 26.5 & D525-PPC2_26.5 & & $x$ & & & & & & \\
\hline & 28.5 & D525-PPC2_28.5 & & & & & & & $\mathrm{x}$ & \\
\hline & 29.5 & D525-PPC2_29.5 & & $x$ & $x$ & & & & & \\
\hline & 29.5 & D525-PPC2_29.5 & & & & & & & $x$ & \\
\hline & 32.0 & D525-PPC2_32.0 & & & & & & & $\mathrm{x}$ & \\
\hline D528-PPC72 & & & $x$ & & & & & & & \\
\hline D655-PPC43 & & & $\mathrm{x}$ & & & & & & & \\
\hline
\end{tabular}


Table 3. Continued.

\begin{tabular}{|c|c|c|c|c|c|c|c|c|c|c|}
\hline Core & $\begin{array}{l}\text { Sample depth } \\
\text { (from top of core) }\end{array}$ & $\begin{array}{l}\text { Subsample } \\
\text { Name }\end{array}$ & $\begin{array}{c}\text { Core } \\
\text { described }\end{array}$ & PSA & $\begin{array}{l}\text { Point } \\
\text { count }\end{array}$ & $\begin{array}{l}\text { XRD } \\
\text { "bulk" }\end{array}$ & $\begin{array}{l}\text { CXRD } \\
\text { (clay) }\end{array}$ & $\begin{array}{l}\text { SEM } \\
\text { mount }\end{array}$ & MGS & $\begin{array}{c}\text { MGS } \\
\text { (point count) }\end{array}$ \\
\hline D655-PPC49 & & & $x$ & & & & & & & \\
\hline \multirow[t]{2}{*}{ D655-PC67 } & & & $x$ & & & & & & & \\
\hline & 13.5 & D655-PC67_13.5 & & & $\mathrm{x}$ & & & & $\mathrm{x}$ & $\mathrm{x}$ \\
\hline \multirow[t]{9}{*}{ D655-PPC79 } & & & $x$ & & & & & & & \\
\hline & 7.0 & D655-PPC79_7.0 & & & & $\mathrm{x}$ & & & & \\
\hline & 15.5 & D655-PPC79_15.5 & & $\mathrm{x}$ & & & & & & \\
\hline & 17.5 & D655-PPC79_17.5 & & $\mathrm{x}$ & $\mathrm{x}$ & & & & & \\
\hline & 19.5 & D655-PPC79_19.5 & & $x$ & & & & & & \\
\hline & 20.0 & D655-PPC79_20.0 & & & & $\mathrm{x}$ & $\mathrm{x}$ & & & \\
\hline & 22.0 & D655-PPC79_22.0 & & & & & & & $\mathrm{x}$ & \\
\hline & 23.0 & D655-PPC79_23.0 & & $\mathrm{x}$ & $\mathrm{x}$ & & & & & \\
\hline & 26.0 & D655-PPC79_26.0 & & $\mathrm{x}$ & $\mathrm{x}$ & & & & & \\
\hline \multirow[t]{2}{*}{ D875-PC75 } & & & $x$ & & & & & & & \\
\hline & 3.0 & D875-PC75_3.0 & & $\mathrm{x}$ & & & & & & \\
\hline \multirow[t]{6}{*}{ D876-PC66 } & & & $\mathrm{x}$ & & & & & & & \\
\hline & 13.0 & D876-PC66_13.0 & & $\mathrm{x}$ & & & & & & \\
\hline & 15.0 & D876-PC66_15.0 & & $\mathrm{x}$ & & & & & & \\
\hline & 16.0 & D876-PC66_16.0 & & $x$ & & & & & & \\
\hline & 17.0 & D876-PC66_17.0 & & $x$ & & & & & & \\
\hline & 19.5 & D876-PC66_19.5 & & $\mathrm{x}$ & & & & & & \\
\hline \multirow[t]{3}{*}{ D876-PC75 } & & & $\mathrm{x}$ & & & & & & & \\
\hline & 18.0 & D878-PC75_18.0 & & & $\mathrm{x}$ & & & & $x$ & \\
\hline & 21.0 & D878-PC75_21.0 & & & & & & & $x$ & $\mathrm{x}$ \\
\hline \multicolumn{3}{|l|}{ D878-PC44 } & $\mathrm{x}$ & & & & & & & \\
\hline \multirow[t]{11}{*}{ D878-PC53 } & & & $\mathrm{x}$ & & & & & & & \\
\hline & 5.0 & D878-PC53_5.0 & & $x$ & & & & & & \\
\hline & 5.5 & D878-PC53_5.5 & & & & $x$ & & & & \\
\hline & 8.0 & D878-PC53_8.0 & & $\mathrm{x}$ & & & & & & \\
\hline & 10.0 & D878-PC53_10.0 & & $x$ & & & & & & \\
\hline & 12.0 & D878-PC53_12.0 & & & & $\mathrm{x}$ & $\mathrm{x}$ & & & \\
\hline & 12.0 & D878-PC53_12.0 & & $\mathrm{x}$ & & & & & & \\
\hline & 14.0 & D878-PC53_14.0 & & $\mathrm{x}$ & $\mathrm{x}$ & & & & & \\
\hline & 14.0 & D878-PC53_14.0 & & & & & & & $\mathrm{x}$ & \\
\hline & 16.0 & D878-PC53_16.0 & & $\mathrm{x}$ & $\mathrm{x}$ & & & & & \\
\hline & 18.0 & D878-PC53_18.0 & & $x$ & $\mathrm{x}$ & & & & & \\
\hline \multicolumn{3}{|l|}{ D878-PC58 } & $\mathrm{x}$ & & & & & & & \\
\hline \multicolumn{3}{|l|}{ D878-PC62 } & $\mathrm{x}$ & & & & & & & \\
\hline \multicolumn{3}{|l|}{ D878-PC63 } & $\mathrm{x}$ & & & & & & & \\
\hline \multicolumn{3}{|l|}{ D878-PC66 } & $\mathrm{x}$ & & & & & & & \\
\hline \multirow[t]{10}{*}{ D878-PC75 } & & & $\mathrm{x}$ & & & & & & & \\
\hline & 4.0 & D878-PC75_4.0 & & & & & & & $\mathrm{x}$ & \\
\hline & 9.0 & D878-PC75_9.0 & & $\mathrm{x}$ & & & & & & \\
\hline & 11.0 & D878-PC75_11.0 & & $\mathrm{x}$ & & & & & & \\
\hline & 11.0 & D878-PC75_11.0 & & & & $\mathrm{x}$ & & & & \\
\hline & 13.0 & D878-PC75_13.0 & & $\mathrm{x}$ & & & & & & \\
\hline & 15.0 & D878-PC75_15.0 & & $\mathrm{x}$ & $\mathrm{x}$ & & & & $\mathrm{x}$ & $\mathrm{x}$ \\
\hline & 17.0 & D878-PC75_17.0 & & $\mathrm{x}$ & $\mathrm{x}$ & & & & & \\
\hline & 17.0 & D878-PC75_17.0 & & & & $x$ & & & & \\
\hline & 18.5 & D878-PC75_18.5 & & & & & & & $\mathrm{x}$ & \\
\hline \multirow[t]{3}{*}{ D878-PC76 } & & & $\mathrm{x}$ & & & & & & & \\
\hline & 10.0 & D878-PC76_10.0 & & $\mathrm{x}$ & & & & & & \\
\hline & 12.0 & D878-PC76_12.0 & & $\mathrm{x}$ & & & & & & \\
\hline \multicolumn{3}{|l|}{ D878-PC78 } & $\mathrm{x}$ & & & & & & & \\
\hline \multirow{2}{*}{ D881-PC72L } & & & $x$ & & & & & & & \\
\hline & 1.5 & D881-PC72L_1.5 & & $x$ & & & & & & \\
\hline
\end{tabular}




\section{Lithostratigraphy}

Characteristics of 25 representative push cores were visually described. The selection preference of cores used for descriptions was based on their ability to be described (core accessibility and preservation), lithology, volcaniclastic features, location around the caldera (carinal direction), and proximity to caldera margins. Distinct lithofacies were identified, separated based on criteria outlined by Portner et al. (2015), and measured for thickness.

Core descriptions include: lithofacies designation, grain-size, ash content, ash morphology, sorting, components (primary / non-primary volcaniclasts, authigenic hydrothermal minerals), structures (laminations, grading, etc.), unit contacts, color (using the Munsell color system), and geophysical logs (when available). Components and modal ash percent within each lithofacies were visually estimated. Geophysical characteristics of push cores, including seismic velocity, bulk density, and magnetic susceptibility, were measured at the USGS in Santa Cruz. Magnetic susceptibility, which measures the magnetic field strength of a material, aided in defining HMT contacts due to the high magnetic susceptibility of some hydrothermal minerals (Luyendyk and Melson, 1967; Airo, 2002).

Thickness of HMT measured in core descriptions was used to create thickness profiles and an isopach map. Although thickness measurements were based on core descriptions, observations of ROV video reveal that in situ volcaniclastic lithofacies are thicker. During the coring process, de-watering and 
compression causes the lithofacies to compress approximately $25 \%$. References to lithofacies thickness henceforth refers to thickness measured in the split core.

\section{Subsample Preparation}

Subsamples were extracted from representative cores approximately every other centimeter throughout the HMT lithofacies to be analyzed for granulometry, componentry, and morphometry. Altogether, 97 subsamples were extracted from 13 of the 25 described cores. Subsamples were consistently named using a location-based scheme. For example, subsample D522-PC62L_27.0 refers to Doc Ricketts ROV dive (D) number "522", push core (PC) number "62" (the "L" denotes a long core $>20 \mathrm{~cm}$ ), and "27.0" for the subsample depth of extraction (measured from the top of the core). Some cores have a PPC for piston push core, others just have PC for a short $(<20 \mathrm{~cm})$ core barrel. The selection of cores used for subsampling was based on their proximity to the caldera: proximal $(<100$ $m$ from caldera rim), medial $(100 m-1000 m)$, and distal $(>1,000 m)$.

Cores were subsampled from all margins surrounding the caldera, and along an outward transect orthogonal to the eastern caldera margin. This transect combined two smaller sub-transects that are offset by $\sim 2.5 \mathrm{~km}$ (Fig. 4), thus allowing for detailed observations of volcaniclastic and lithostratigraphic changes with increasing distance from the caldera rim. Additionally, one core (D881PC72L), which sits on a high pillow cone located approximately $42 \mathrm{~km}$ south of the summit of Axial Seamount (Fig. 5), was analyzed for grain-size distribution as 
a baseline for "ambient" background sedimentation. The base of D881-PC72L was dated to be $>40 \mathrm{kyr}$ (Chen and Clague, 2015).

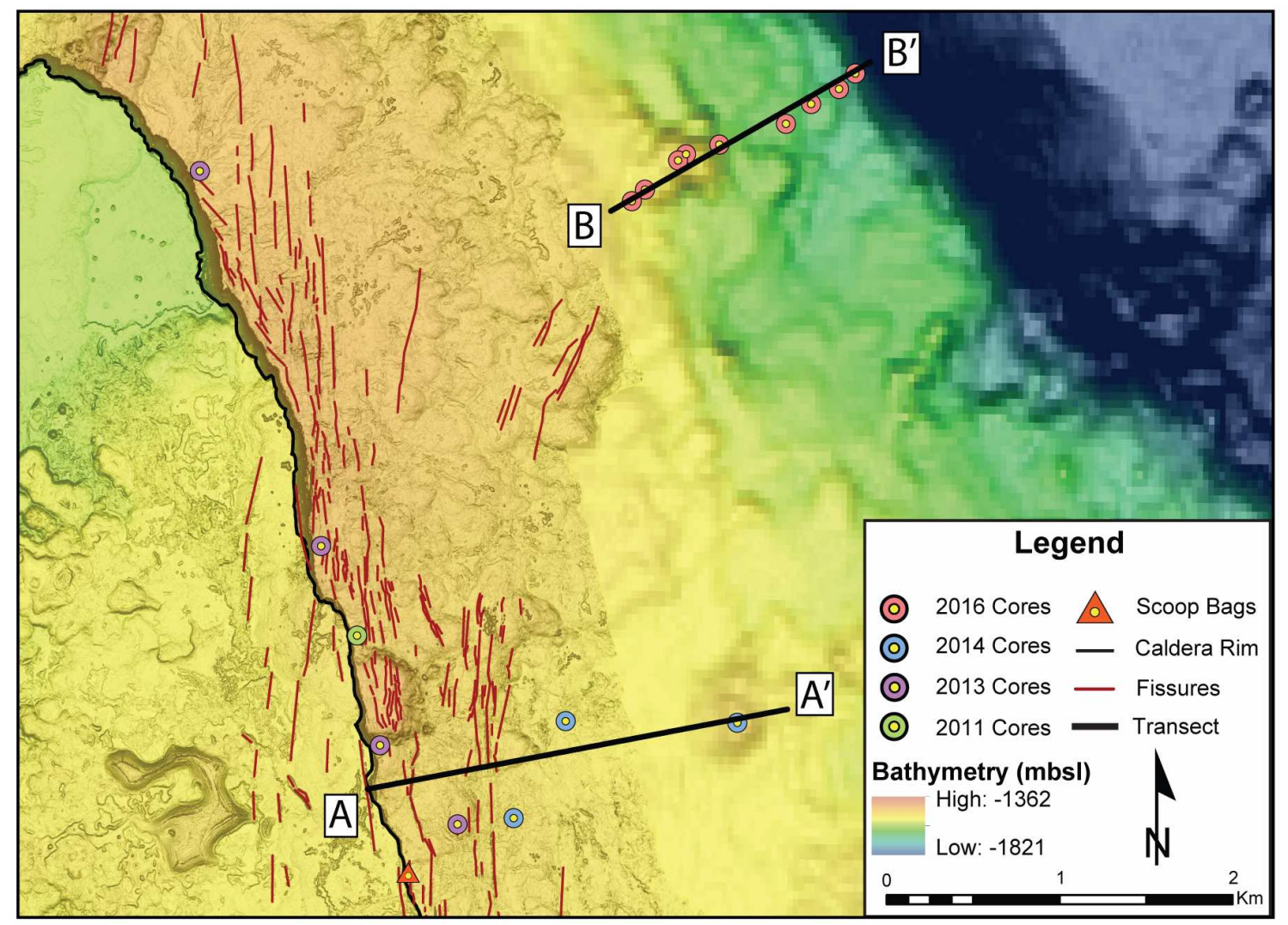

Figure 4. Map showing east side of the caldera where two transects $\left(A-A^{\prime} ; B-\right.$ $B^{\prime}$ ), offset by about $2.5 \mathrm{~km}$, are combined to create a full transect. Bathymetric data is from AUV and ship-based seabeam EM300 data acquired by MBARI. Caldera rim and fissures were drawn in by colleagues at MBARI pers. Comm. 


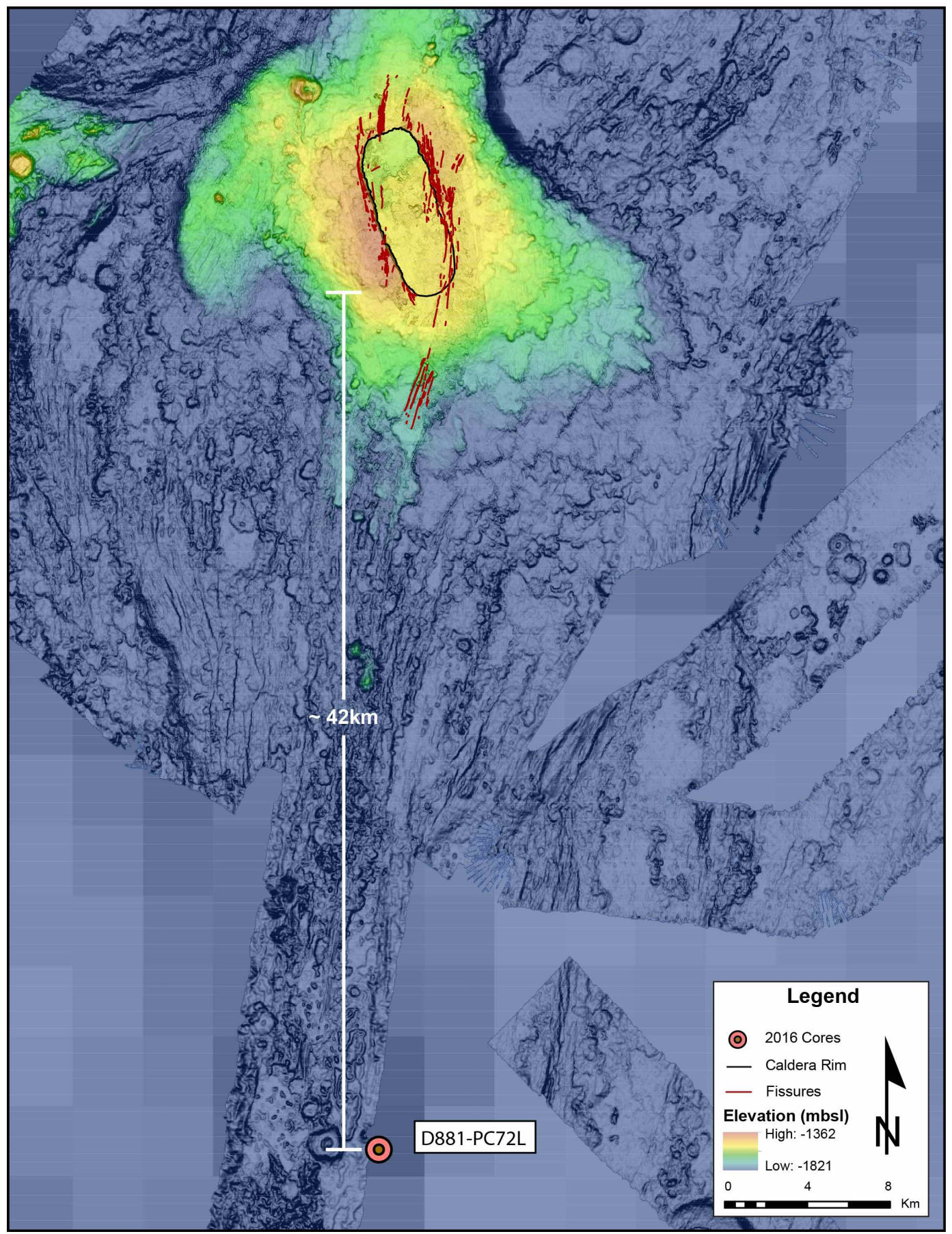

Figure 5. Bathymetric map showing location of Axial Seamount in relation to core $D 881-P C 72 L$ used for "background" sedimentation granulometry analysis. Bathymetric data is from AUV and ship-based seabeam EM300 data acquired by MBARI. Caldera rim and fissures were drawn in by colleagues at MBARI pers. Comm. 
All subsamples, regardless of the method to be used, were extracted from the core and weighed (wet). The mass required for subsamples varied depending on the method to be used for analysis, but a typical subsample contained $\sim 6 \mathrm{~g}$ of wet material that was dried overnight at $60-70^{\circ} \mathrm{C}$. Dried samples were then weighed and soaked in $80 \mathrm{ml}$ of a solution of $500 \mathrm{ml} \mathrm{DI}$ water and $70 \mathrm{mg}$ of sodium hexametaphosphate (deflocculant). The sediment / deflocculant mixture was left overnight in the solution and then sonicated for 30 minutes to fully disaggregate clay flocs. Once the initial sample preparation procedure was complete, subsamples were selected for granulometry, componentry and morphometry.

\section{Analytical Techniques}

\section{Particle Size Analysis (PSA)}

Bulk subsamples were analyzed for grain-size distribution using laser diffraction particle size analysis (PSA) at the USGS in Santa Cruz, CA. Bulk subsample mass needed for the laser diffraction method was $>3 \mathrm{~g}$ wet. Subsamples for the laser diffraction method were sieved to $<1000 \mu \mathrm{m}$ to prevent large particles from clogging the instrument. The mass of particles $>1000 \mu \mathrm{m}$ was recorded, normalized based on mass percent, and eventually re-combined with $<1000 \mu \mathrm{m}$ PSA results. Prepared $<1000 \mu \mathrm{m}$ subsamples in de-flocculent solution were taken to USGS in Santa Cruz to be analyzed using a Beckman Coulter LS 13320 laser diffraction particle size analyzer. The subsample was diluted in $400-500 \mathrm{ml}$ of DI water and mixed using an agitator for $3-5$ minutes. 
The solution containing the subsample was transferred to the instrument using a pipet (extracted from a consistent depth for each subsample) until laser obscuration reached $8-12 \%$. The instrument sonicated the solution while measuring grain-size to reduce particle aggregates. This method measures vol. $\%$ of particles by the diffraction of light (McCave et al., 1986).

A total of 66 subsamples from 11 cores were measured for grain-size using the laser diffraction method. Pre-existing grain-size analysis results (using wetsieving techniques) of TM and LPT from Portner et al. (2015) were used for comparison. Grain-size data using the laser particle diffraction method was plotted using the two grain-size plots: vol. \% plotted against grain-size $(\mu \mathrm{m})$ and cumulative vol. \% plotted against grain-size. Combined laser diffraction $(<1000$ $\mu \mathrm{m})$ and sieving PSA data $(>1000 \mu \mathrm{m})$ was input into Gradistat (Blott and Pye, 2001) to calculate a variety of grain-size statistics including mean grain-size, peak mode, sorting, and skewness (Folk and Ward, 1957).

\section{Point Counts}

All subsamples used for point counting grains were sprinkled onto a $1 \times 1 \mathrm{~cm}$ grid-paper and particles were only counted if they fell on the grid line to eliminate selective particle bias. For all samples, 500 grains / subsample $(n=500)$ were counted and tallied manually. To determine the appropriate grain-size for point counts, an initial point count was conducted using representative subsample D522-PC66_19.0 (retrieved from HMT) in three different size-fractions including $63-125 \mu \mathrm{m}, 125-250 \mu \mathrm{m}$, and $250-500 \mu \mathrm{m}$. The $125-250 \mu \mathrm{m}$ size-fraction 
was chosen because it includes representative mixture of the three primary components (primary volcaniclasts, non-primary volcaniclasts, and authigenic hydrothermal minerals), and is coarse enough for easy visual identification. Twenty-six additional subsamples, extracted from cores with a variety of proximities to the caldera and depths within HMT, were point counted in the 125 $-250 \mu \mathrm{m}$ size fraction.

A summary of particle descriptions used during point counts are presented in Table 4. Agglutinate particles are presumed to be authigenic hydrothermal clay aggregates coated in sideromelane. Therefore, these may be considered hybrid particles in that they consist of both authigenic hydrothermal minerals primary vitric material. For the purposes of point counts, they were counted in the authigenic hydrothermal minerals category.

Table 4. Summary of point count categories and description of particles counted within each category.

\begin{tabular}{|l|l|l|}
\multicolumn{1}{l}{ Primary Volcaniclasts } & \multicolumn{1}{l}{$\begin{array}{l}\text { Non-primary } \\
\text { volcaniclasts }\end{array}$} & $\begin{array}{l}\text { Authigenic } \\
\text { Hydrothermal Minerals }\end{array}$ \\
\hline Angular vitriclast & Altered glass (angular) & Green aggregates \\
fluidal vitriclast & Altered glass (fluidal) & Yellow aggregates \\
Vesicular (angular) vitriclast & Crystalline basalt/diabase & Pure sulfide \\
Vesicular (fluidal) vitriclast & Spherulitic & Agglutinate ${ }^{\text {a }}$ \\
Plagioclase & Red/orange particles & \\
Olivine & Green fibrous & \\
Phyric & Green other & \\
& White fibrous & \\
& White other & \\
\hline
\end{tabular}

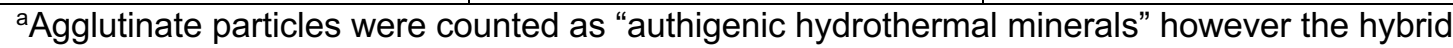
nature of these particles means that they could also be considered "primary volcaniclasts". 


\section{SEM/EDX}

Scanning electron microscope (SEM) / energy dispersive X-ray spectroscopy (EDX) was used to examine vitriclast morphologies and the chemical composition of non-vitric grains. Representative particles ranging from $125-250$ $\mu \mathrm{m}$ were selected by hand during point counts and mounted on standard $15 \mathrm{~mm}$ SEM stubs. These grains include the full range of components observed within HMT. Two mounts were created and gold-coated (to reduce electron charging) using a Polaron E5400 sputter coating system.

SEM mounts were analyzed using a Hitachi S-3400N scanning electron microscope equipped with an Oxford Instruments X-Max X-ray probe located at Moss Landing Marine laboratory (MLML). The SEM was operated using the variable pressure vacuum setting set to $6.0 \mathrm{~Pa}$. Accelerating voltage was set to $30.0 \mathrm{kV}$ for all acquired images, probe current was set between $60.0-70.0$ mAmps based on the required strength of acquiring EDX spectra and so that measured deadtime was greater than $12 \%$. Working distance was set between $10.0-10.2 \mathrm{~mm}$ for all EDX spectra. Prior to spectra collection, the EDX probe was calibrated using a copper standard and verified by collecting spectra on known basaltic grains which were compared to San Jose State University basalt standard spectra (Fig. 6). 


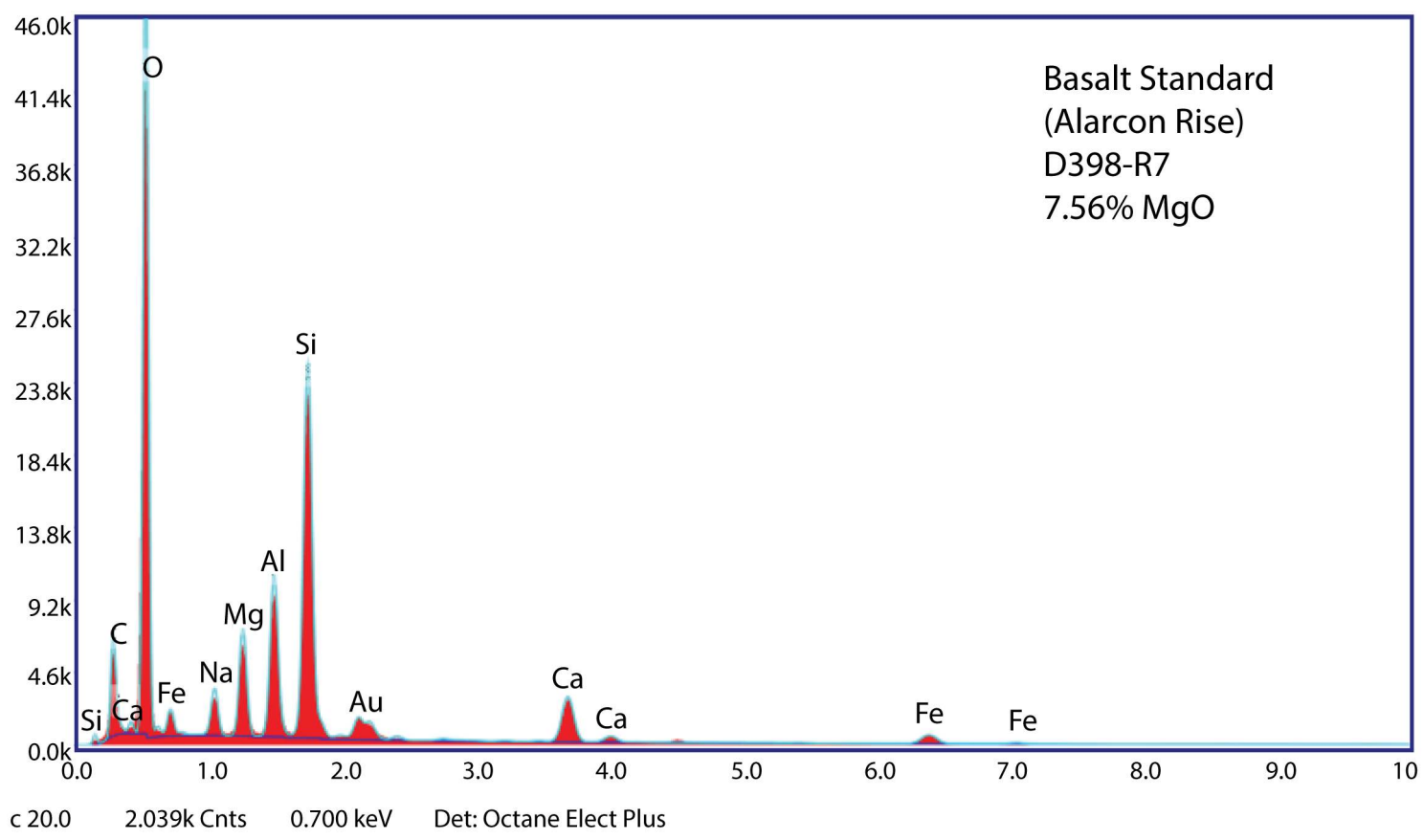

Figure 6. Basalt (N-MORB) EDX spectra standard from the northern East pacific Rise. $\mathrm{MgO}$ in standard is $~ 7.56 \mathrm{wt} . \%$, which is comparable to HMT vitriclast geochemistry on Axial Seamount.

Grains selected for EDX point chemistry were selected based primarily on mineral morphology. Multiple "regions of interest" were selected for EDX analysis and spectra were taken from $3-7$ points within each region of interest.

Chemistry results were analyzed using INCA "Point \& ID" software and filtered by hand to remove elements shown with overlapping peaks (not likely to be in the subsample). Mineral identification of points of interest were aided by SEM images (particle morphology), and measured spectra compared to known spectra of minerals using "SEM Petrology Atlas" (Welton, 2003). 


\section{$X R D$}

Nine subsamples were analyzed for "bulk" subsample (non-glass) mineralogy using powdered X-ray Diffraction (XRD). Clay mineralogy was determined using two subsample preparations: (i) a $<2 \mu \mathrm{m}$ random powder diffraction mount and (ii) a thin film peel mount of $<2 \mu \mathrm{m}$ clays from representative subsamples. The latter was modelled using computer software. Full subsample preparation and methods are outlined below.

\section{"Bulk" Analysis}

Subsamples selected for "bulk" XRD were first run through a Frantz magnetic separator to filter out glass particles to reduce the effect of broad baseline humps (obscuring mineral peaks) that result from the non-crystalline nature of glassy material. For "bulk" XRD analysis, non-magnetic minerals (e.g. plagioclase) needed to be separated from glass (low magnetic susceptibility) and grouped with minerals with a high magnetic susceptibility (e.g. pyroxene) to produce a subsample that excluded volcanic glass.

The Frantz magnetic separator was set to a $15^{\circ}$ tilt and each subsample was run through the instrument three times with increasing magnetic susceptibility. The first run was set to $0.25 \mathrm{amps}$, the second run was set to $0.50 \mathrm{amps}$, and the third run was set to 1.00 amps. After runs one and two, the magnetic constituents were separated, and the non-magnetic material was re-run at the higher magnetic susceptibility setting ( $1.00 \mathrm{amps})$ to filter glass from non-magnetic minerals (e.g. plagioclase). After this run, the glass was separated out while the 
non-magnetic constituents (e.g. plagioclase) were recombined with previously separated magnetic material to be analyzed for XRD. The remaining material (magnetic susceptibility-filtered bulk) was gently crushed to a powder in a mortar and pestle for XRD analysis.

Magnetic susceptibility-filtered bulk subsamples were taken to USGS (Santa Cruz) for XRD analysis. Powder mounts were prepared using a back-fill disk method. All subsamples were run using a copper anode with $\mathrm{k} \alpha \lambda=1.540598$. Divergence slits were fixed at $19 \mathrm{~mm}$. A continuous scan was performed at $2 \theta$ angles between $3-70^{\circ}$. Diffraction results were analyzed by hand using several in-print powder diffraction manuals including: Selected Powder Diffraction Data for Minerals (Berry, 1974), Mineral Powder Diffraction File Search manual (Bayliss et al., 1986) and on-line resources (Lufuente et al., 2015). Rigaku PPXL$2 \mathrm{XRD}$ mineral-search software (V. 2.8.4) was used to confirm mineralogy using the auto-search / match functions at SJSU and MLML.

\section{Clay Analysis}

Four representative subsamples were selected for clay mineralogy analysis using XRD. Subsample preparation followed the millipore transfer method outlined by Moore \& Reynolds (1989). Selected powders from bulk XRD were measured to $2.00 \mathrm{~g}$ (dry) and added to $100 \mathrm{~mL}$ of deflocculant solution. The subsample-solution mixture was sonicated for 15 minutes to disaggregate clay particles. To separate the $<2 \mu \mathrm{m}$ size fraction, the solution was centrifuged using an international clinical safeguard centrifuge (model CL) on setting \#1 
(approximately $1475 \mathrm{rpm}$ ). The subsample was centrifuged for 30 seconds once the centrifuge reached full speed (about 1 minute in total). Once the centrifuge slowed to a complete stop, the $<2 \mu \mathrm{m}$ fraction was decanted into a beaker and sonicated for another 5 minutes. Clay particles were separated from solution onto filter paper using a vacuum filtration device. The clay particles on the filter paper were gently rolled onto a petrographic slide, allowed to air dry, and stored in an ethylene glycol chamber. The resulting clay peel film ensures that all clay minerals are oriented with their crystallographic $\mathrm{C}$-axis perpendicular to the surface of the petrographic slide.

Once clay peel films were prepared, they were scanned following the recommended clay XRD analysis (Poppe et al., 2001) from $2^{\circ}-50^{\circ} 2 \theta$ at a step of 0.03 , using a Rigaku XRD instrument with a copper anode $(k \alpha \lambda=1.540598)$ located at MLML. A series of XRD treatments were performed on each subsample including untreated, treated with ethylene glycol, $400{ }^{\circ} \mathrm{C}$ heat treatment, and $550{ }^{\circ} \mathrm{C}$ heat treatment. Changes to peaks characteristics (e.g. expansions, collapses, destroyed) were used to identify specific clay minerals based on the Clay Mineral Identification Flow Diagram (Poppe et al., 2001). Although specific peak locations $(\AA)$ are important in identifying clay minerals, slight variations are common and may occur due to ambient measurement conditions (e.g. laboratory humidity), treatment process (e.g. flooding subsample with glycol, temperature variations during heat treatments), or chemical coordination of clays. Therefore, clay peak locations discussed in results are 
referred to as the general peak location identifiable for clay minerals (e.g. a 16.7 $\AA$ will be generalized and inferred to be a $17 \AA$ peak).

The modeling software NEWMOD, developed in 1985 by R. C. Reynolds Jr., has been the standard method for quantifying clay mineral mixtures using XRD diffractograms (Yuan and Bish, 2010). NEWMOD modeling software was used in this study to replicate results of unknown XRD spectra by defining specific stoichiometric clay compositions. XRD spectra of glycolated $<2 \mu \mathrm{m}$ subsamples, prepared with the clay peel film technique, were imported into NEWMOD to be modeled. Clay components were modeled by matching d-spacing and peak intensity in unknown subsamples to model output in NEWMOD. Once interstratified clays and reichweite ordering were defined and associated peaks identified, clay component mixtures were modeled iteratively until all clay peak positions and relative heights were present. Cation abundances for individual clay species and clay mixture abundance percentages were manually manipulated to help match peak intensities.

\section{Morpho-grainsizer (MGS)}

A Morphologi G3S (MGS) was used to quantitatively measure particle shapes. The instrument is designed to quantify the shape of individual particles based on high-resolution two-dimensional images and provides statistical analysis without operator bias. Analysis of 41 subsamples from 8 cores using the MGS was conducted at the Laboratoire Magmas et Volcans, Université Clermont 
Auvergne in Clermont-Ferrand, France following the method outlined by Leibrandt and Le Pennec (2015).

To focus on primary volcaniclast (e.g. vitriclasts, free crystals) morphologies, subsamples from the $250-500 \mu \mathrm{m}$ and $500-1000 \mu \mathrm{m}$ size fractions were run through a Frantz magnetic separator to filter particles that were not volcanic glass. The process of separation is different than that used for XRD separation as this method aimed to exclusively separate out primary volcaniclasts. The Frantz was set to a $15^{\circ}$ tilt and the first run was set to 0.35 amps. The magnetic material was set aside, and the non-magnetic material was re-run at a setting of $0.5 \mathrm{amps}$. After this run, the magnetic material were mostly non-volcanic glass particles, and was therefore separated. This process was repeated twice further to ensure exclusion of all magnetic material. Once Each size fraction had been filtered, they were ready to be analyzed by the MGS for particle shape.

Two methods of dispersal were available to spread subsamples onto the glass slide: automatic and manual. The automatic dispersion unit (ADU) was used for most subsamples and used an air compressor to inject air into the contained subsample. The air pressure was set to 1.2 bars, the injection time $\left(T_{i}\right)$ was set to $40 \mathrm{~ms}$, and the settling time $\left(T_{\mathrm{s}}\right)$ was set to 20 seconds. These settings worked for particle sizes $>125 \mu \mathrm{m}$. If particles to be measured were $<125$ $\mu \mathrm{m}$, the air pressure was reduced to 1.0 bars, $T_{i}$ was reduced to $80 \mathrm{~ms}$, and $T_{s}$ was increased to 40 seconds. After automatic dispersion, the particles were visually checked to verify a good dispersion (e.g. few particles touching). For 
particles $>500 \mu \mathrm{m}$, particles were manually dispersed by sprinkling them onto the glass slide and manually separating any particles that were touching. The manual dispersal method was preferred for the $500-1000 \mu \mathrm{m}$ size-fraction because particles were large enough to visibly move into position (minimizing the chances of touching particles), allowing the operator to scan a larger area resulting in more particles scanned. $2.5 \mathrm{x}$ and $5.0 \mathrm{x}$ optics were tested to compare image quality, but always yielded similar results for the $250-500 \mu \mathrm{m}$ size fraction. Therefore, after testing numerous runs, it was determined that using the $2.5 x$ objective with the $250-500 \mu \mathrm{m}$ size-fraction was the preferred combination as the $2.5 \mathrm{x}$ optics scanned the desired area considerably faster without compromising image quality and results.

Diascopic lighting (bottom light) was used to give better contrast of particles. The scans did not overlap and particles on the edges were automatically stitched together allowing the MGS to count all grains within the scanned boundaries. The focus was manually set on a representative particle of intermediate thickness prior to scanning. Differential z-stacking was enabled with one additional focus level above and below (196 $\mu \mathrm{m}$ above; $-196 \mu \mathrm{m}$ below for $2.5 \mathrm{x}$ optics) to obtain best image resolution and focal depth for particles of different thicknesses.

Lighting was manually configured by setting the lamp power (LP) and exposure. The LP ranged from 51 to 82 and the exposure ranged from 0.31 to 1.74. Gamma lighting correction was fixed at 1.0. The LP was configured to provide maximum contrast between the background and particles. The threshold 
determines the separation of particles from the background and ranges from 0 to 255 (black to white). Various subsamples were scanned in order to determine the optimal threshold range to be between $120-160$. The lower the threshold the better the results for particle shape parameters; however, if abundant fluidal particles are present, the thin particles will not be separated well from the background (Fig. 7). For this reason, most subsamples were scanned using a threshold between $140-150$.

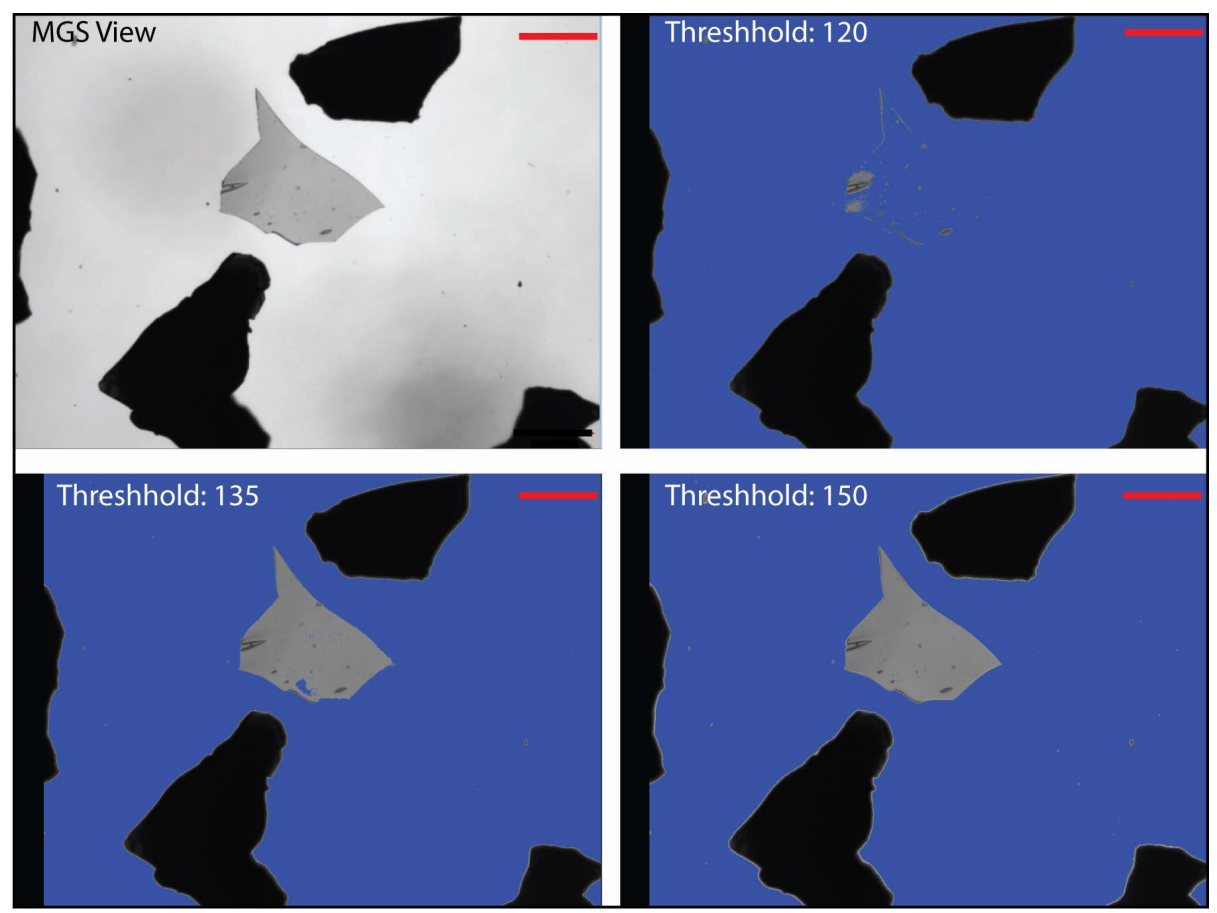

Figure 7. Differing MGS threshold values and their effect on particle scans. (MGS View) showing a thin particle in the middle and several thicker vitriclasts surrounding in plane light view. (Threshold 120) shows the thin particle cannot be separated from the background. (Threshold 135) the outline of thin particle is separated from the background, but a hole is present. With the hole filling option set to "on", this particle will be scanned. Thicker vitriclasts have a slight grey shadow on their boarder. (Threshold 150) completely separates the thin particle yet the thick vitriclasts have a noticeable grey "halo" which may skew shape parameter results. 
For automatically dispersed subsamples, the default scan area was used $\left(5541.769 \mathrm{~mm}^{2}\right)$. For manually dispersed subsamples, the scan area was manually set to cover the area of manually placed particles. Hole filling, which allows a particle to be properly scanned as long as the perimeter is completely separated from the background (even if the middle of the particle is not separated), was enabled to properly scan fluidal particles at lower thresholds (Fig. 7: threshold 135). Automatic filters were set to exclude particles with CE diameter $<100 \mu \mathrm{m}$ for all scans of subsamples $>250 \mathrm{um}$.

\section{MGS Data Processing}

Once scans were complete, additional manual filtering was required to exclude touching particles, improperly stitched particles, or dust (Fig. 8). The manual filtering process excludes approximately $6-25 \%$ of the total scanned particle population (excluding the $<100 \mu \mathrm{m}$ automatic filter). Subsamples dispersed using the ADU method required a larger proportion of scanned particles to be excluded whereas subsamples that were dispersed manually required considerably less particles to be excluded. Five steps were taken to ensure unusable particles were filtered out:

1. Plotting particle area $\left(\mu \mathrm{m}^{2}\right)$ on the $\mathrm{x}$-axis and the solidity parameter on the y-axis (Fig. 8a), particles were excluded based on the particle area parameter. For the $250-500 \mu \mathrm{m}$ size fraction, particles with an area $>500,000 \mu \mathrm{m}^{2}$ were filtered out, thereby removing large particle aggregates. Conversely, particles with an area $<50,000 \mu \mathrm{m}^{2}$ were 
excluded, thereby filtering small, improperly stitched / scanned particles and dust.

2. Using this same plot, outlier particles with low solidity $(<0.7)$ were visually inspected and manually discarded if they were determined to be unusable. Some of this group were pele's hairs and thus were not discarded; however, most images in this exclusion category included grains that were touching.

3. Plotting circularity on the x-axis and solidity on the $y$-axis, outlier particles with low circularity $(<0.6)$ were visually inspected and manually excluded if determined to be unusable (Fig. 8b). Elongate particles including pele's hairs fall into this category and were not filtered.

4. Using convexity on the $\mathrm{x}$-axis and CE diameter on the Y-axis, particles with low convexity $(<0.8)$ were visually inspected and manually discarded if they were determined to be unusable (Fig. 8c).

5. Particles remaining after the above filtering steps were individually examined. Any particles deemed unusable requiring exclusion (e.g. touching particles, improperly stitched) were manually discarded. 

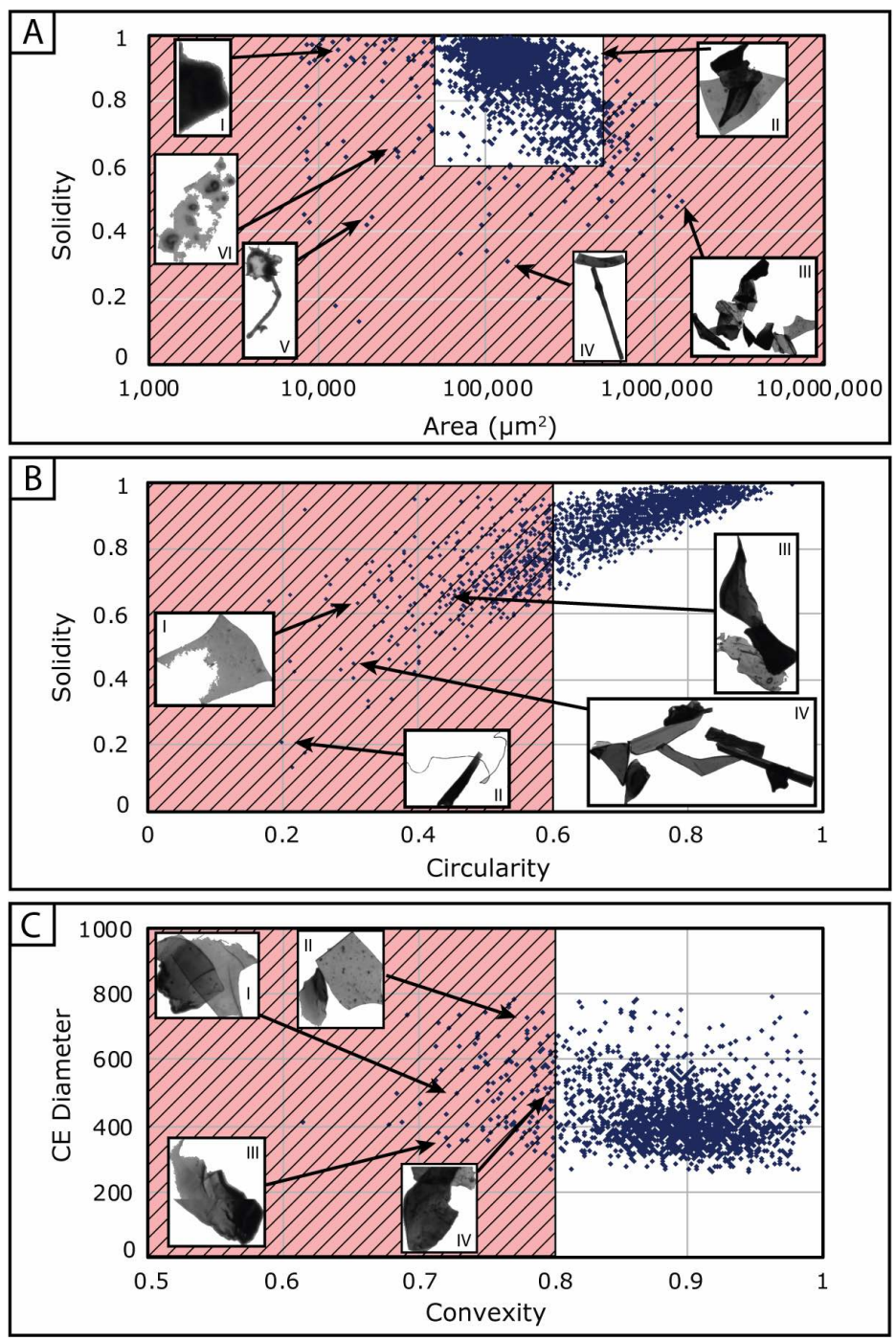

$$
\begin{array}{|l}
\mathrm{n} \text { (pre-filtering) }=2,427 \\
\mathrm{n} \text { (post-filtering) }=1,862 \\
\quad \text { Data Point } \\
1 / / \text { Region of Exclusion } \\
\text { (after positive identification) }
\end{array}
$$

Figure 8. MGS particle filtering procedure. Particles falling within red hatched area were filtered out for all subsample scans. (A) Particles are separated by size with smaller particles being improperly stitched (I) and larger particles being aggregates of multiple particles (e.g. II, III, IV). Other filtered particles include those scanned debris on the stage $(V)$ or improperly separated from background (VI). Particle aggregates also had a low solidity (e.g. III \& IV) and were therefore also excluded. (B) Particles with low circularity values were improperly scanned particles (e.g. I) and particle aggregates (e.g. II, III, IV) were filtered out. (C) Particles with low convexity values were found to be touching/overlapping particles (e.g. I, II, IV) or improperly stitched (III) and were subsequently filtered out. 


\section{Data Parameters}

MGS datasets were examined using a variety of calculated shape parameters and instrument measurements. Many methods of calculating shape parameters exist. This study uses shape parameters that were automatically calculated by Malvern's "Morphologi" software. A summary of shape parameters used in our study and a comparison of other methods are presented in Table 5. After testing various combinations of plotting data using shape parameters, four primary measurements were found to be most useful: convexity (CVX), solidity (SLD), intensity mean (Int. M), and intensity standard deviation (Int. SD).

Convexity is a measure of particle "edge roughness" while solidity is a measure of "morphological roughness" (Fig. 9; Liu et al., 2015). Shape parameters CVX and SLD were chosen because these shape parameters have been used extensively in previous ash morphology studies (e.g. Buckland et al., 2017; Leibrandt and Le Pennec, 2015; Liu et al., 2015; Nurfiani and Bouvet de Maisonneuve, 2018). Intensity mean and intensity standard deviation are not measurements of particle shape, but instead measurements of light transmission through a particle. Intensity Mean measures the intensity of light passing through a particle whereas Intensity standard deviation measures the range of light intensity that passes through a particular particle (Fig. 10). 
Table 5. Various shape parameters used in ash morphology studies along with the mathematical formula, sensitivity, and alternative names (table modified from Leibrandt and Le Pennec, 2015 and Liu et al., 2015).

\begin{tabular}{|c|c|c|c|c|c|}
\hline $\begin{array}{l}\text { Shape } \\
\text { Parameter }\end{array}$ & Abbreviation & Formula & Symbols & Sensitivity & Alternative Names \\
\hline Aspect Ratio & AR & $\frac{W_{b}}{L_{b}}$ & $\begin{array}{l}\text { Wb: Width }(\mu \mathrm{m}) \\
\text { Lb: Length }(\mu \mathrm{m})\end{array}$ & Form & $\begin{array}{l}\text { Aspect ratio } \\
\text { Ellipse aspect ratio } \\
\text { Ellipticity }\end{array}$ \\
\hline Elongation & $E$ & $1-A R$ & AR: Aspect ratio & Form & $\mathrm{N} / \mathrm{A}$ \\
\hline Convexity a & $C V X$ & $\frac{P_{c h}}{P}$ & $\begin{array}{l}\text { Pch: Circle equivalent } \\
\text { perimeter }(\mu \mathrm{m}) \\
\text { P: Perimeter }(\mu \mathrm{m})\end{array}$ & $\begin{array}{l}\text { Textural } \\
\text { roughness }\end{array}$ & Roughness \\
\hline Circularity & $\mathrm{Cc}$ & $\frac{2 \sqrt{\pi A}}{P}$ & $\begin{array}{l}\text { A: Area }\left(\mu \mathrm{m}^{2}\right) \\
\text { P: Perimeter }(\mu \mathrm{m}) \\
\text { Pce: Circle equivalent } \\
\text { perimeter }\end{array}$ & $\begin{array}{l}\text { Form \& } \\
\text { roughness }\end{array}$ & $\begin{array}{l}\text { Shape factor } \\
\text { Particle irregularity }\end{array}$ \\
\hline HS Circularity & $\mathrm{HCc}$ & $\frac{4 \pi A}{P^{2}}$ & $\begin{array}{l}\text { A: Area }\left(\mu \mathrm{m}^{2}\right) \\
\text { P: Perimeter }(\mu \mathrm{m})\end{array}$ & $\begin{array}{l}\text { Form \& } \\
\text { roughness }\end{array}$ & $\begin{array}{l}\text { Form factor } \\
\text { Sphericity } \\
\text { Roundness }\end{array}$ \\
\hline Solidity a & SLD & $\frac{A}{A_{c h}}$ & $\begin{array}{l}\text { A: Area }(\mu \mathrm{m} 2) \\
\text { Ach: Circle equivalent } \\
\text { area }\left(\mu \mathrm{m}^{2}\right)\end{array}$ & $\begin{array}{l}\text { Morphological } \\
\text { roughness }\end{array}$ & $\mathrm{N} / \mathrm{A}$ \\
\hline
\end{tabular}

aDenotes shape parameter used in this study 


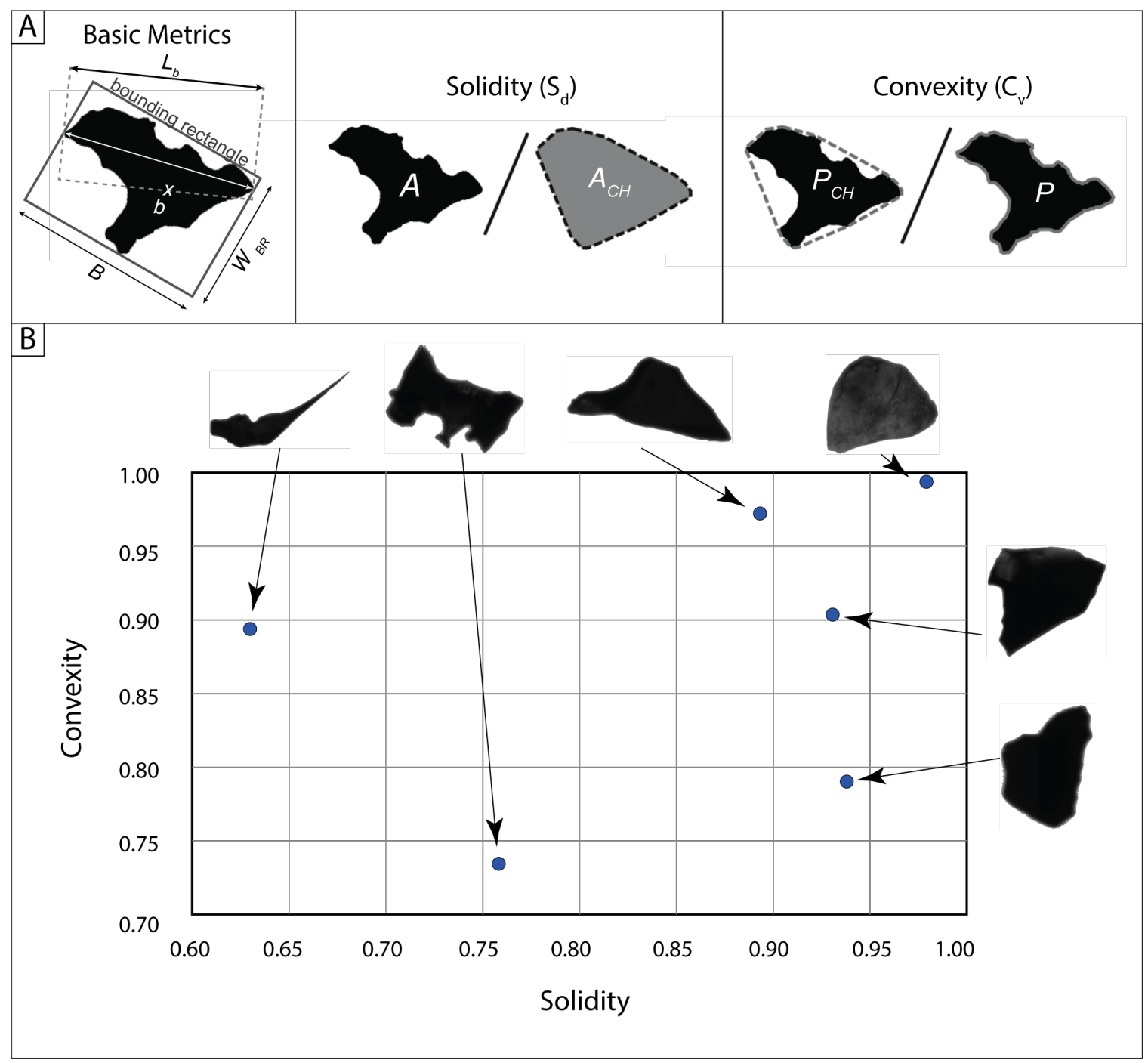

Figure 9. Plot showing examples of convexity and solidity for several primary volcaniclasts from subsample D522-PC62L_27.0 (HMT). (A) Basic metrics and calculations of convexity and solidity. See Table. 9 for definitions and abbreviations. Modified from Leibrandt and Le Pennec (2015) (B) Plot showing examples of particles with differing values of solidity ( $\mathrm{x}$-axis) and convexity ( $\mathrm{y}$ axis). Refer to Table 5 for mathematical definitions of solidity and convexity. 


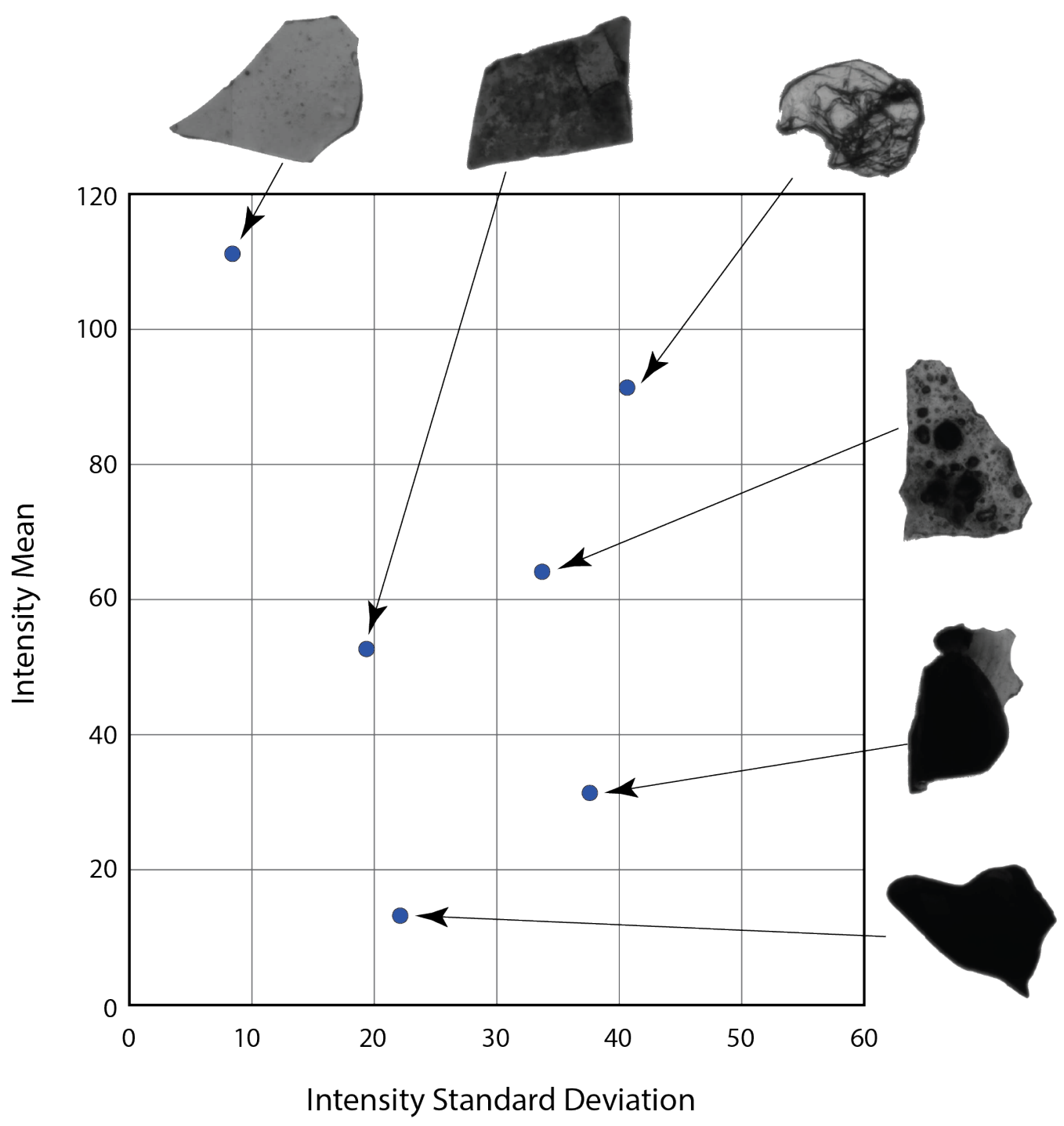

Figure 10. Plot showing examples of particles with differing values of intensity standard deviation (x-axis) and intensity mean (y-axis). Particles are primary volcaniclasts from subsample D522-PC62L_27.0 (HMT). 


\section{Data Visualization}

Convexity frequency distribution curves were used to show variations in convexity between different subsamples. Additionally, plots of individual particles using traditional plots of solidity vs. convexity (SLD vs. CVX), argued to be useful for comparing ash morphologies (Liu et al., 2015), were implemented into this study to compare Axial Seamount subsamples with other known eruptions. Plots of intensity standard deviation value on the x-axis and intensity mean on the $y$ axis, a new method that has not been used in ash morphology studies, were used to evaluate proportions of fluidal and non-fluidal vitriclasts. We henceforth use the term "Int. STD vs. Int. M" to describe these plots.

Int. STD vs. Int. M plots were created to estimate and compare the relative abundance of free crystals (e.g. plagioclase), fluidal vitriclasts (limu o' Pele), and angular / blocky vitriclasts, to other subsamples. To create known fields of particle morphologies (fluidal, angular / blocky, and crystals), 100 representative particles of each field from four different subsamples were selected by hand to ensure correct identification. Fields were manually drawn around the spread of representative points (Fig. 11). While there is some over in vitriclasts and crystals fields, this method works well for differentiating limu o' Pele, which is the dominant style of fluidal vitriclasts in subsamples from Axial Seamount.

To test the reliability of using Int. STD vs. Int. M fields to determine abundance of fluidal particles, five subsamples used in the MGS method were also point counted using 300 grains / subsample. During these point counts, 
three categories were counted: angular / blocky vitriclasts, fluidal vitriclasts, and other. Particles that were not vitriclasts (e.g. plagioclase, crystalline basalt) were counted in the "other" category. Fluidal particles were calculated as a percent.

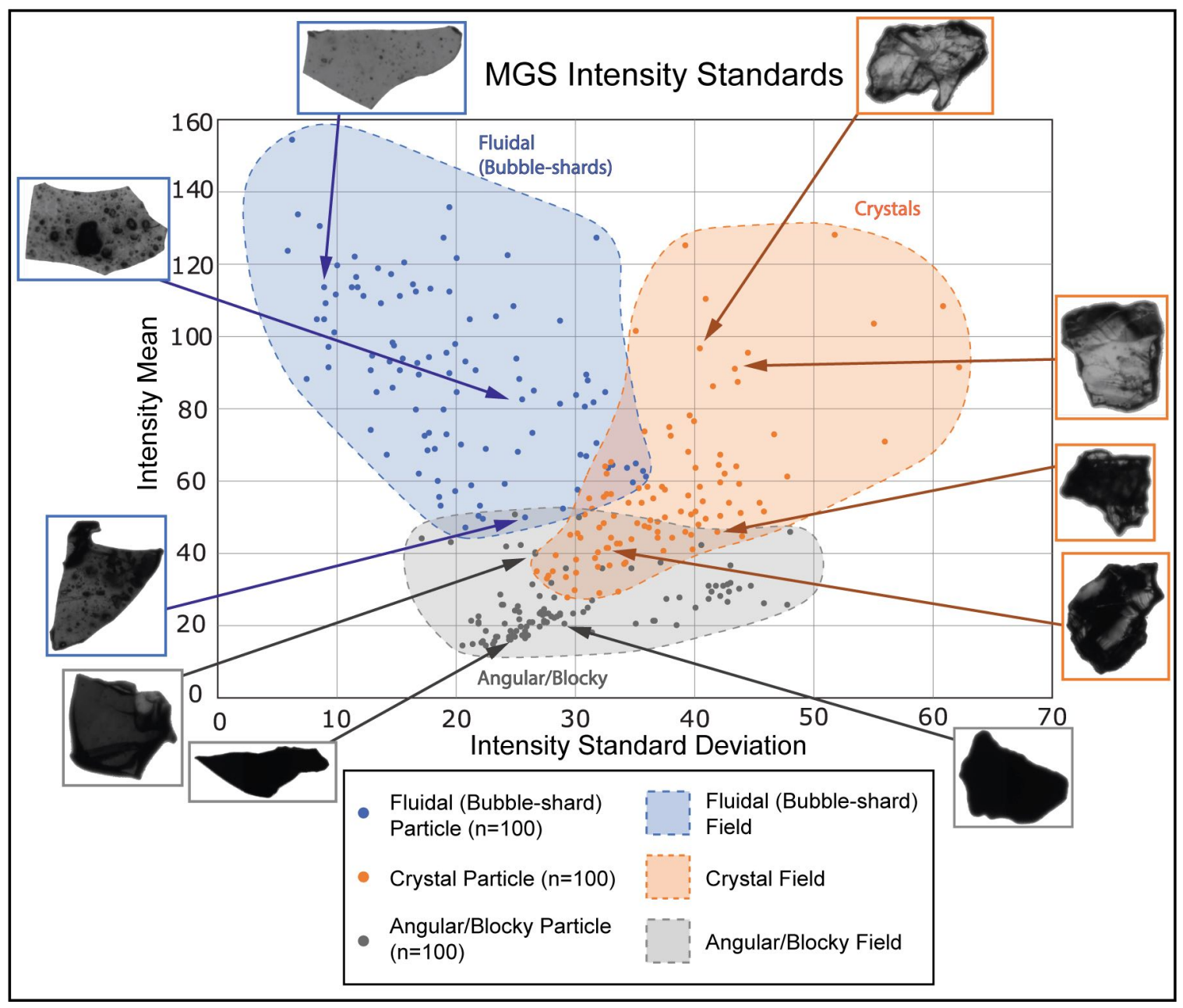

Figure 11. Plot of Intensity standard deviation vs. intensity mean. One-hundred known particles of fluidal vitriclasts (blue), angular/blocky vitriclasts (grey), and crystals (orange) were plotted. Representative particles, with corresponding colored outlines, and their locations on the plot are shown. Fields were drawn around particles to create particle population fields (shaded regions). 
To calculate the percentage of fluidal particles using the MGS method, points falling in the "fluidal" field were manually counted and divided by the total number of particles scanned. Fluidal particles from both methods were consistent with the largest variation between the MGS and point counting method being less than $3 \%$ of the total particles (Table. 6). Although there is some overlap in particle morphology fields, particularly between angular / blocky vitriclasts and crystals, the MGS method works well for differentiating limu o' Pele, which is the dominant style of fluidal vitriclasts in subsamples from Axial Seamount.

Table 6. Particle morphometry results comparison using MGS method and traditional point count.

\begin{tabular}{|l|l|l|l|l|l|}
\hline Sub-sample & $\begin{array}{c}\text { Fluidal } \\
\text { Particles } \\
\text { (MGS) }\end{array}$ & $\begin{array}{c}\text { Total } \\
\text { Particles } \\
\text { (MGS) }\end{array}$ & $\begin{array}{c}\text { Percent } \\
\text { Fluidal } \\
\text { (MGS) }\end{array}$ & $\begin{array}{c}\text { Percent } \\
\text { Fluidal (Point } \\
\text { Counts) }\end{array}$ & $\begin{array}{c}\text { Percent } \\
\text { Difference }\end{array}$ \\
\hline D522-PC62L_15.0 & 80 & 1385 & $5.78 \%$ & $4.00 \%$ & $1.78 \%$ \\
\hline D522-PC62L_27.0 & 228 & 2077 & $10.98 \%$ & $11.30 \%$ & $0.32 \%$ \\
\hline D524-PC47XL_27.0 & 211 & 2118 & $9.96 \%$ & $11.00 \%$ & $1.04 \%$ \\
\hline D876-PC75_21.0 & 115 & 1772 & $6.49 \%$ & $4.30 \%$ & 2.19 \\
\hline D878-PC75_15.0 & 526 & 1862 & $28.25 \%$ & $28.00 \%$ & $0.25 \%$ \\
\hline
\end{tabular}

\section{Point Density Plots Using ArcGIS}

Particle parameter data from MGS scans was exported from "Morphologi" software. To express the high number of data points (single grain analyses) for any individual subsample scan, point density plots were created using both SLD vs. CVX and Int. STD vs. Int. M plots to express the $68.2 \%(1 \sigma)$ and $95.4 \%(2 \sigma)$ 
confidence field of all data points. Depending on the type of plot, specific parameters (e.g. CVX, SLD) were selected, and imported into ArcGIS, and plotted as a spatial point dataset (vector data). Spatial analyst toolbox, in ArcGIS, was used to create a point density raster of each dataset. The "neighborhood" setting was set with a radius that covered the most continuous and representative field of input data points. The radius of the "neighborhood" setting depends on the standard deviation of the input data. After testing various radii (Fig. 12), a radius of 18 (cell units) was selected for SLD vs. CVX plots, and a radius of 20 was used for Int. STD vs. Int. M plots. These settings were chosen because they were found to most accurately represent the data compared to higher and lower settings.

Once the point density fields were created, they were re-classified to display 3 regions $(1 \sigma, 2 \sigma$, and $>2 \sigma)$ using break percentages of points. These segments were set to $100,31.8$, and 4.6 , thus creating 3 fields containing $68.2 \%(1 \sigma)$; $95.4 \%(2 \sigma)$; and $100 \%$ of data points. The classifications were colored to display the $1 \sigma$ field as a dark color, the $2 \sigma$ field as a light color, and $>2 \sigma$ was displayed as no data. Therefore, the shaded boundary contains $95.4 \%(2 \sigma)$ of data points. Using these steps, point density plots of MGS data were displayed as fields of $1 \sigma$, and $2 \sigma$. Density plots were created for both SLD vs. CVX plots (Fig. 13) and Int. SD vs. Int. M plots (Fig. 14). 

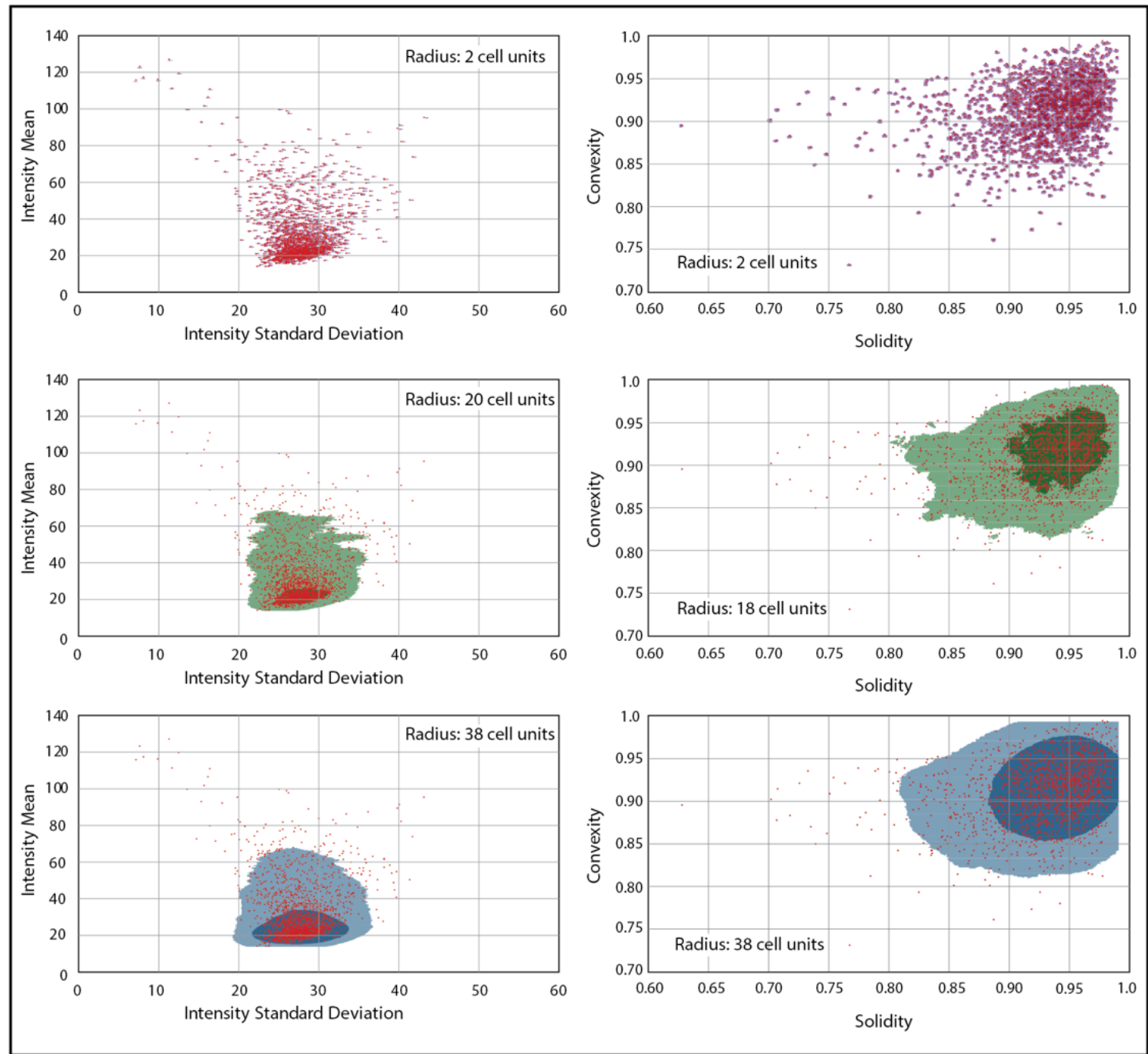

Figure 12. Plots comparing point density radii settings. Plots of intensity standard deviation vs. intensity mean (left) and solidity vs. convexity for subsample D522-PC62L_27.0 (HMT). Red points are individual particles whereas colored fields represent point density plots. Darker field represents $68.2 \%(1 \sigma)$ of points while lighter colored field represents $95.4 \%(2 \sigma)$ of data points. Points falling outside of shaded regions are $>2 \sigma$ and are considered outliers. Top plots show point density plots with a radius $=2$. Middle plots show point density plot with radii $=20$ and 18 for intensity standard deviation vs. intensity mean and solidity vs. convexity plots, respectively. Bottom plots show a radius $=38$. 


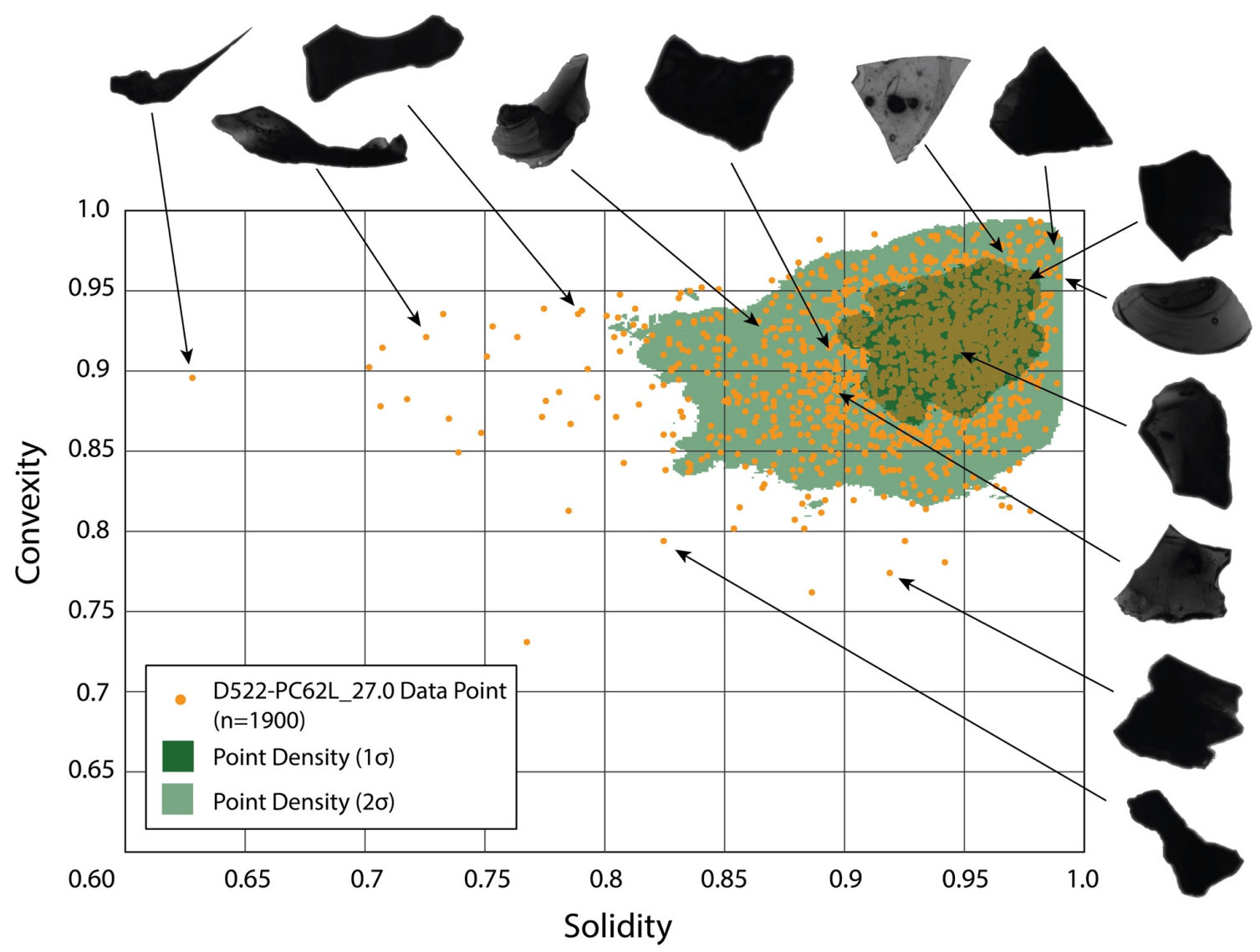

Figure 13. Solidity vs. convexity point density plot of subsample D522PC62L_27.0 (HMT) showing data points (orange). Data density fields are shown in green where the dark green field represents $1 \sigma(68.2 \%$ of all data points) and the light green field represents $2 \sigma(95.4 \%$ of all data points). Representative particle images and plot locations are shown. 


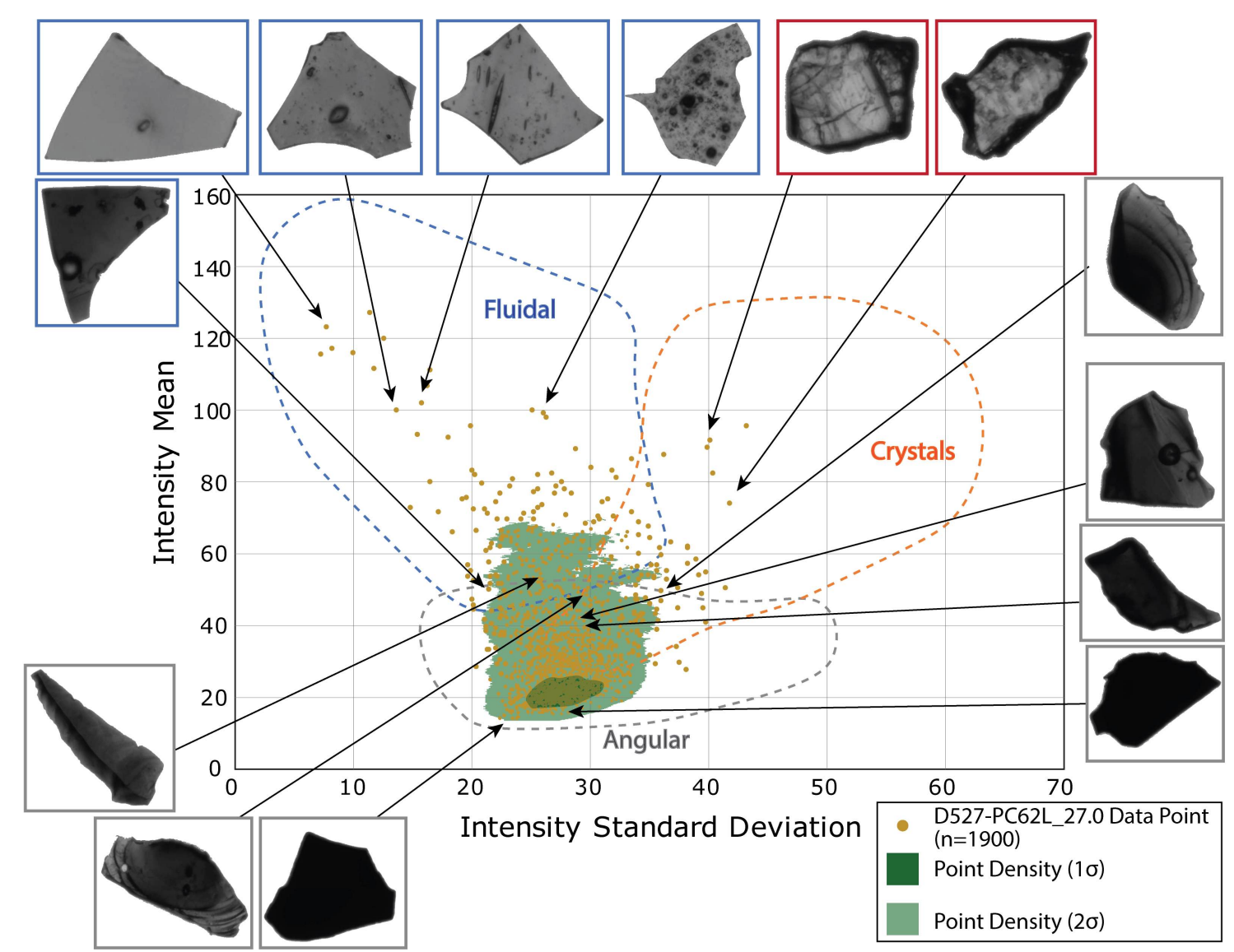

Figure 14. Intensity standard deviation vs. intensity mean point density plot of subsample D522-PC62L_27.0 (HMT) showing data points (orange) and data density fields are shown in green where the dark green field represents $1 \sigma$ (68.2\% of all data points) and the light green field represents $2 \sigma(95.4 \%$ of all data points). Morphology fields (fluidal, crystals, and angular) are represented by colored dashed fields (blue $=$ fluidal; orange $=$ crystals; grey $=$ angular). Representative particle images are bordered with their respective morphology color and their location on the plot is shown. 


\section{RESULTS}

\section{Core Descriptions}

Visual observations of 25 cores were described and build on those reported by Portner et al. (2015). Modified lithofacies descriptions based on cores observed in this study are summarized in Table 1. General observations reveal that the individual beds of LPT and HMT are normal graded (coarser material near the bottom fining upwards) whereas TM is structureless. This is true regardless of whether other lithofacies are present, or proximity of the core to caldera margins. Foraminifera are found in TO, LPT (in rip-up clasts of TO), and TM, but are notably absent in HMT. Bioturbation is common within all lithofacies except LPT, which sometimes distorts boundaries and / or structures. Although characteristics are variable from core to core, general descriptions and overall trends of each lithofacies are outlined below, with an emphasis placed on HMT. Figure 15 shows representative cores and associated characteristics from proximal, medial, and distal locations. Individual core descriptions are presented in Appendix A. Core logs were created using sedimentologic descriptions and geophysical properties measured from the cores (Appendix B).

\section{Tuffaceous Mud (TM)}

Tuffaceous mud (TM) is composed of orange / brown mud with fine ash medium lapilli-sized vitriclasts and is poorly sorted. Visually estimated modal percentage of ash ranges from $10-45 \%$, making this unit mud-matrix supported. Vitriclasts consist of a mixture of both fluidal and angular / blocky shards, with 

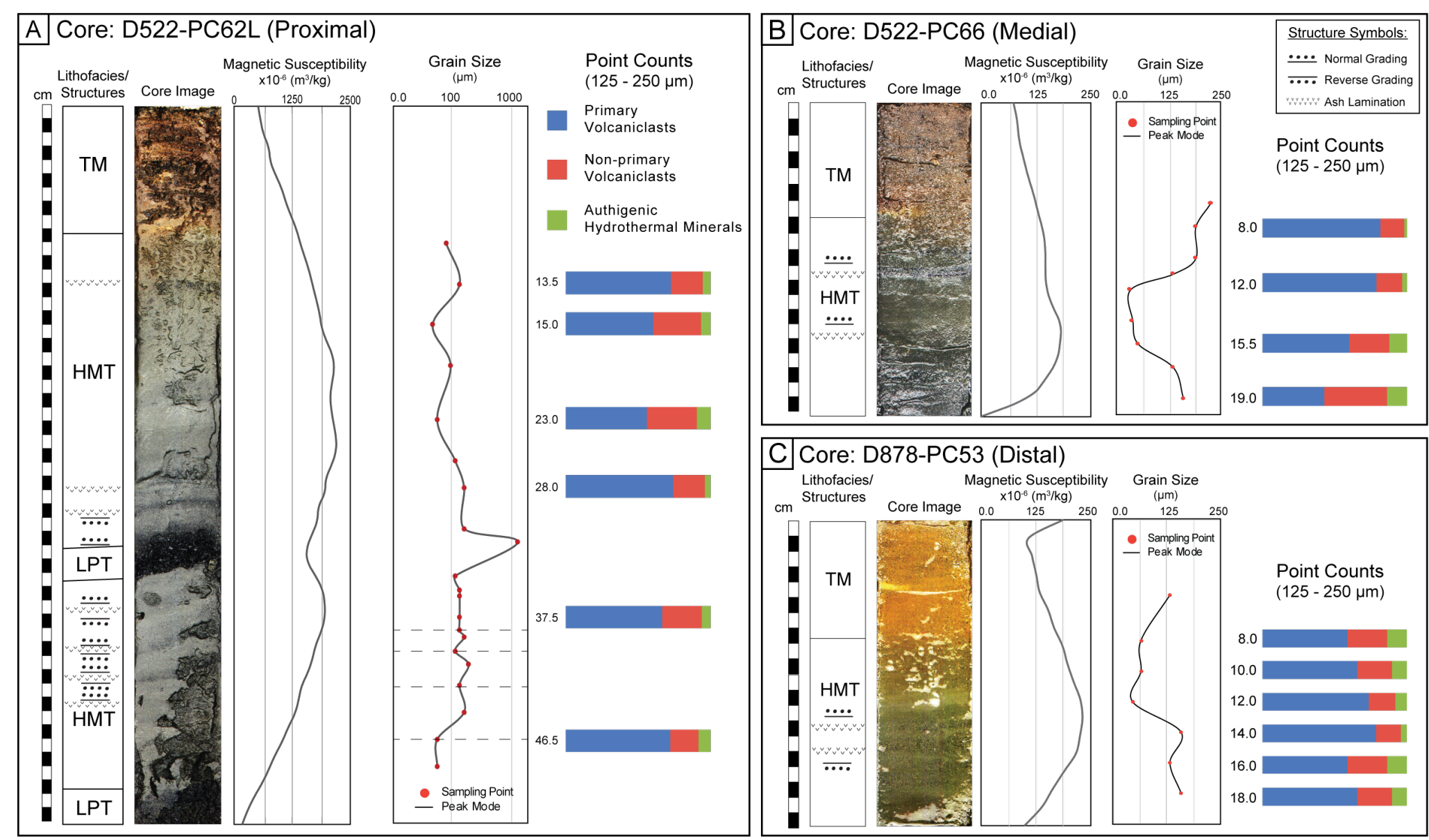

Figure 15. Figure showing representative proximal, medial, and distal cores accompanied by identified lithofacies, sedimentary structures, magnetic susceptibility, grain-size, and point count results. For grain-size, red circles represent sampling points while black line show trends. Point counts are shown at sampling depths to show relative abundance of components (blue $=$ primary volcaniclasts; red $=$ non-primary volcaniclasts; green $=$ authigenic hydrothermal minerals). (A) Proximal core D522-PC62L. (B) Medial core D522-PC66. (B) Distal core D878-PC53. Core images enhanced for better contrast. 
fluidal vitriclasts being more common in laminations. Beds are generally structureless, but variably contain diffuse laminations of concentrated vitriclasts and / or laminated mud where ash is absent. Vitriclasts are predominantly fresh / clean, but some altered Fe-oxide coated shards are present. Other components present in low abundance include biogenics, free crystals (e.g. plagioclase), and red / orange Fe-oxide particles. Overall color was described as either moderate brown (5YR 5/6) or moderate yellowish brown (10YR 5/4).

\section{Hydrothermal Muddy Tuff (HMT)}

Hydrothermal muddy tuff (HMT) is composed of intermixed fluidal to angular / blocky vitriclasts, free crystals (plagioclase, olivine, phyric fragments), crystalline basalt / diabase, altered oceanic crust fragments (e.g. actinolite / tremolite), the sulfide mineral pyrite, and clay aggregates. Beds are generally are generally fine to very fine grained. Clay aggregates comprise most of the fine-grained mud within the unit along with sulfides, namely pyrite. Visually estimated modal ash percent ranges from $\sim 10-60 \%$. Several proximal ( $<100 \mathrm{~m}$ from caldera margins) and medial $(100-1,000 \mathrm{~m})$ cores containing HMT tend to have a higher visually estimated modal ash abundance near the bottom and top of lithofacies.

Laminations (both well-developed and diffuse) are common, range in thickness from $\sim 1 \mathrm{~mm}-10 \mathrm{~mm}$ and generally consist of medium- to coarsegrained fluidal ash. Well-developed laminations are common in proximal and some medial cores. Distinct laminations within distal cores $(>1,000 \mathrm{~m})$ are less prevalent. Diffuse ash laminations are present in medial (Fig. 15B) and some 
distal cores (Fig. 15C). Many laminae exhibit "reverse-to-normal graded" grainsize distributions (Fig. 15A). A distinct "pale green" lamination observed near the top of HMT exists in 10 of the described cores, all of which are either proximal or medial, and often marks the boundary of HMT and overlying TM. Overall color of the HMT is light olive grey (5Y 5/2). Geophysical characteristics show that HMT has high magnetic susceptibility compared to other lithofacies due to abundance of magnetic material (Fig. 15).

\section{Limu o' Pele Tuff (LPT)}

Limu o' Pele tuff (LPT) is primarily composed of fresh glass shards (>90\%) with the remaining constituents consisting of plagioclase, olivine, phyric glass, and crystalline basalt / diabase. Vitriclast morphology is a mix of angular / blocky and fluidal. Angular / blocky grains tend to occur near the base of the lithofacies while fluidal shards are more common near the top. Grain-size ranges from coarse ash to medium lapilli and the beds are normal graded. LPT is normal graded and also generally grades from abundant angular / blocky vitriclasts near the bottom of the lithofacies to fluidal vitriclasts in the top of the lithofacies. Ripup clasts from underlying muddy units are sometimes present. Geophysical characteristics of LPT show it has generally higher density compared to other lithofacies due to the predominance of glass particles and lack of silt / clay.

\section{Tuffaceous Ooze (TO)}

Tuffaceous ooze (TO) is comprised of $>90 \%$ foraminifera mixed with small abundances of orange / brown mud and fine - medium ash that is predominantly 
angular / blocky. Larger fluidal vitriclasts (medium - coarse ash) are sometimes present. This lithofacies is structureless and highly bioturbated.

\section{Lithostratigraphy}

\section{Vertical Stratigraphic Sequence}

A lithostratigraphic sequence is consistently observed throughout cores on Axial Seamount (Fig. 16). Age constraints have been placed on the current lithostratigraphy using ${ }^{14} \mathrm{C}$ chrono-stratigraphy from foraminifera (Clague et al., 2013; Portner et al. 2015; and unpublished data). Lithostratigraphy on Axial Seamount is complimented by vitriclast $\mathrm{MgO}$ variability from subsamples where 15 vitriclasts per a $2 \mathrm{~cm}$ thick slice of core were analyzed (Clague et al., 2013; B. Johnson pers. Comm.).

The top (youngest) of the stratigraphic sequence begins with TM (<800 ka), which overlies HMT, and is present at the top of all described cores. HMT (900 1,200 ka) overlies LPT lithofacies and was present in all summit cores except the furthest core from the caldera ( $D 878-P C 62 ;>3.5 \mathrm{~km}$ from caldera margin). LPT $(1,200-1,500 \mathrm{ka}$ ) sits beneath, or within the lower portion of HMT (or TM if HMT is absent) and was absent in 8 summit cores that contained HMT (e.g. HMT was the basal unit). TO (> 1,500 ka) lies beneath the LPT lithofacies. The upper portion of this facies invariably shows increasing modal percentage of ash grading into the overlying LPT. Presence of TO is atypical near the caldera and was only observed in 5 of the 23 described cores (primarily distal cores). 


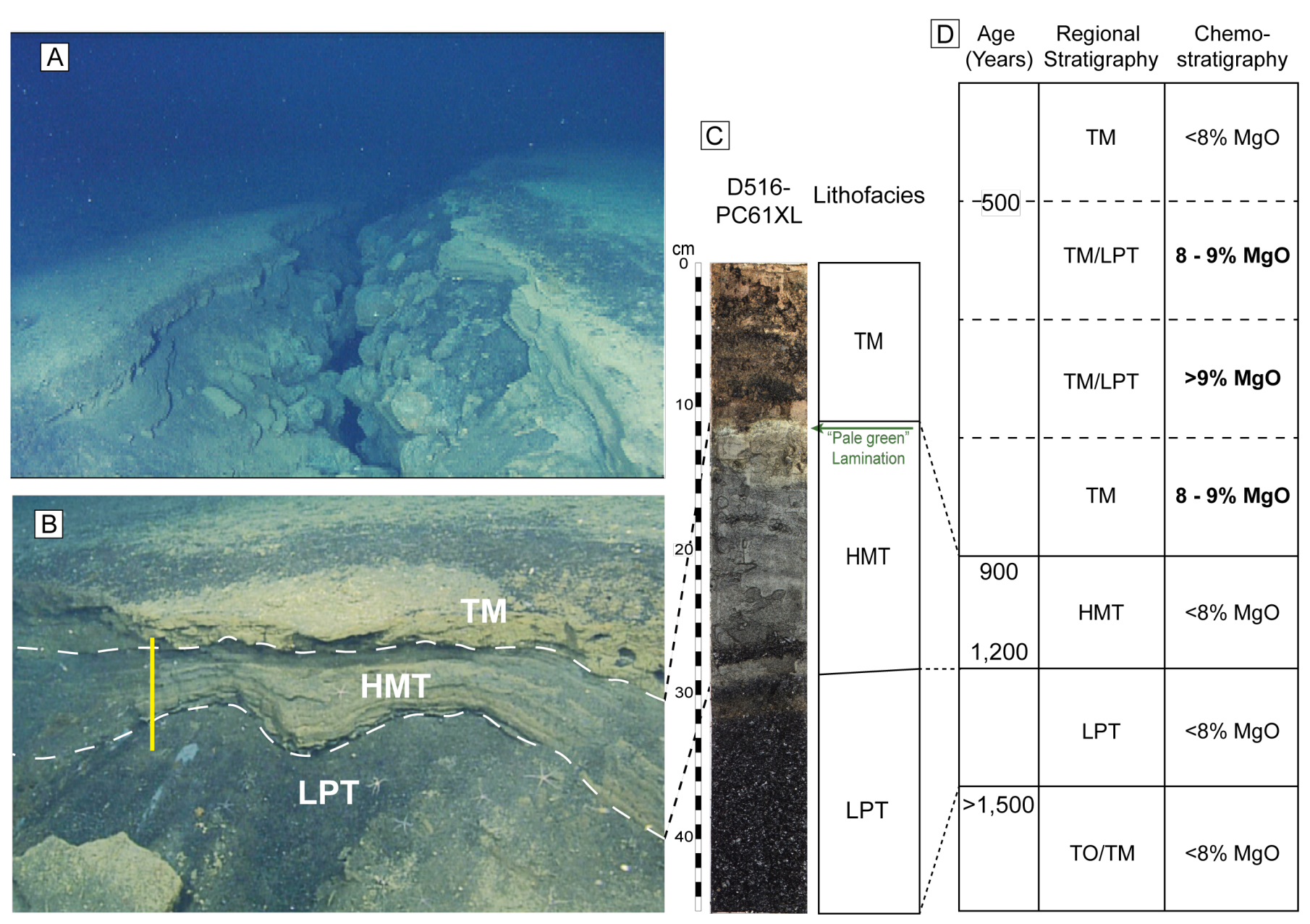

Figure 16. Regional stratigraphy found on Axial Seamount. (A) Image taken from ROV looking towards a fissure (B) Image taken by ROV's showing the wall of fissure in (A) showing TM, HMT, and LPT lithofacies. Vertical yellow line is $30 \mathrm{~cm}$. (C) Image of core D516-PC61XL, which was retrieved in the vicinity of image B, accompanied by visually described lithofacies. (D) table showing general regional stratigraphy correlated with ${ }^{14} \mathrm{C}$ chronostratigraphy and $\mathrm{MgO}$ chemo-stratigraphy. Bold $\mathrm{MgO}$ indicates a period of more primitive lava chemistry. 


\section{Lateral Stratigraphic Sequence}

A clear lithostratigraphic association between the caldera margin and HMT lithofacies exists. Thickness observations of all lithofacies (Fig. 17) along the offset transect reveal variations in thickness associated with caldera margins. Results show greater HMT thickness near caldera margins (Fig. 18), which thins away as distance increases and overall thickness of HMT is asymmetric with regards to the caldera. The southeast side of the caldera rim, also the location of active fissures (Clague et al., 2013; Dryer et al., 2013), contains thicker sections of HMT while the northwest side is considerably less thick (Fig. 19). HMT laterally extends further on the southeast $(>3.4 \mathrm{~km})$ compared to the northwest $(1.5 \mathrm{~km})$ side of the caldera rim and tends to follow contours of seafloor bathymetry.

Results of LPT are similar to that of HMT where the lithofacies is thicker near caldera margins in proximal cores and thin as distance away from the caldera increases. Conversely, TO is notably absent near caldera margins and only appears in distal cores more than $3.1 \mathrm{~km}$ away from the caldera. TM thickness remains consistent, or only slightly increases, with increasing distance away from the caldera. TM is the only facies observed on the caldera floor where sediment is entirely all younger than $800 \mathrm{kyr}$ and $<25 \mathrm{~cm}$ thick (Clague et al. 2013). 


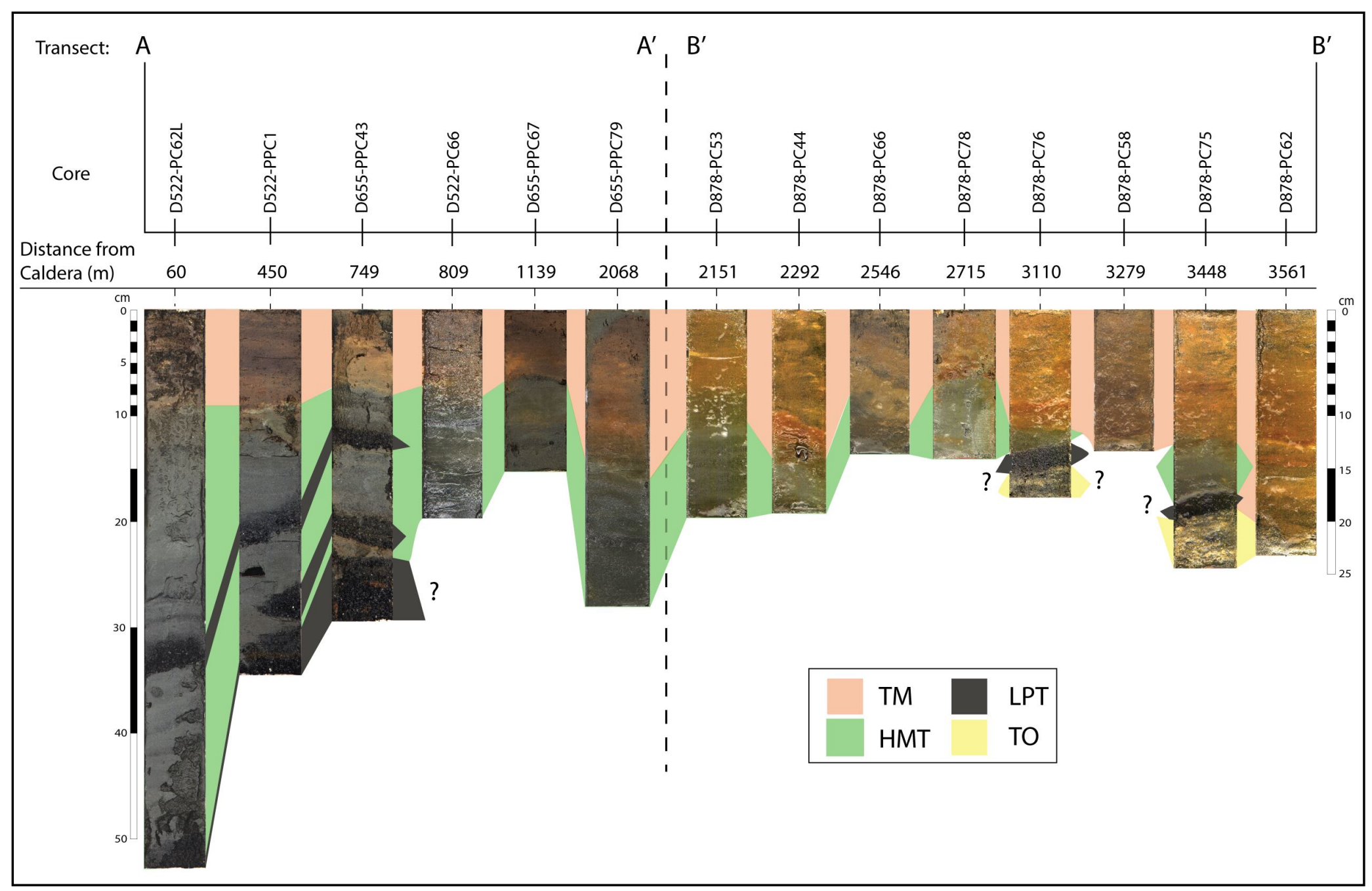

Figure 17. Select cores along offset-transect (including distance from caldera) and thicknesses of TM (orange field), HMT (green field), LPT (grey field), and TO (yellow field). HMT and LPT noticably thins with increasing distance from caldera margin. 


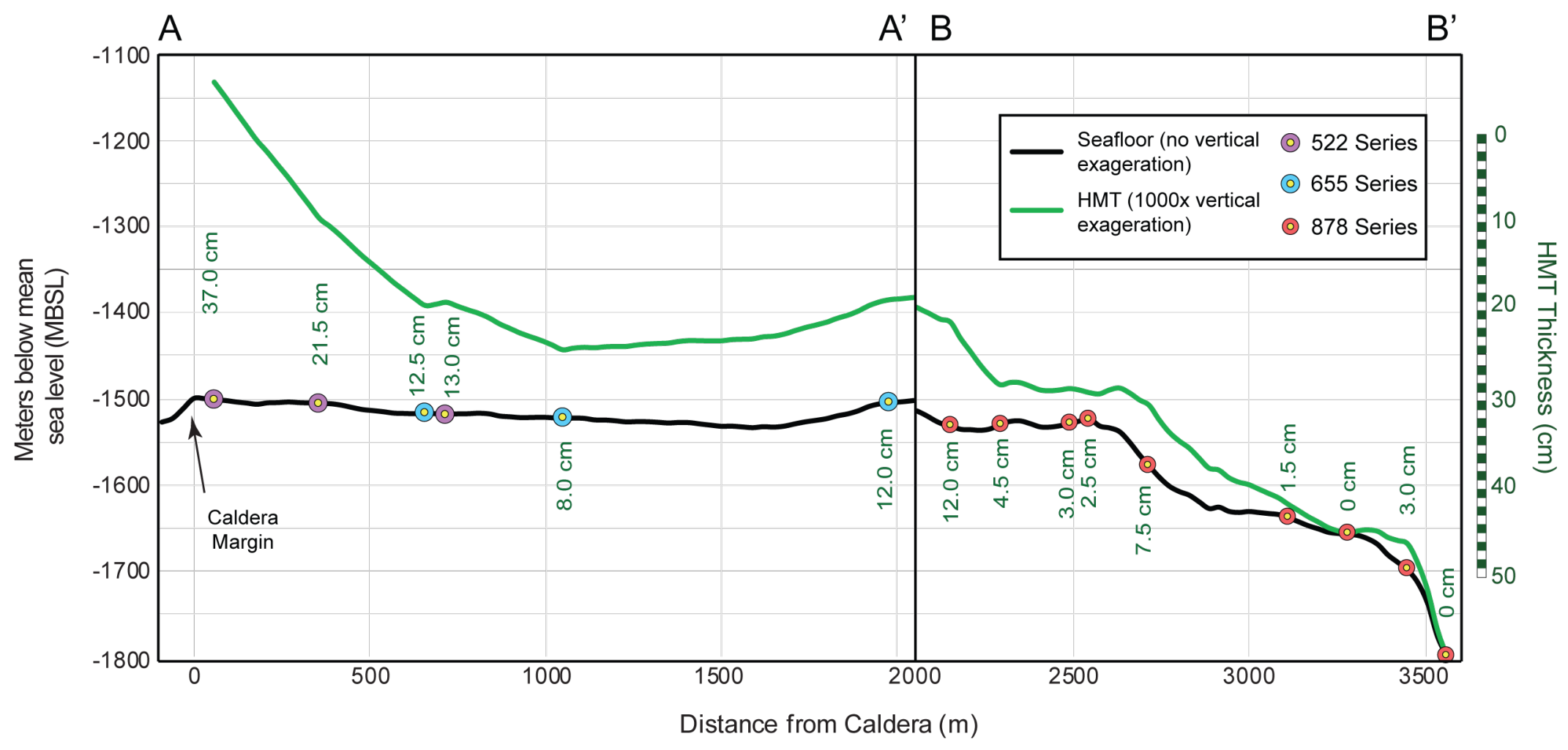

Figure 18. HMT thickness profile along offset transect. Thick black line shows profile of seafloor in meters below seafloor (no vertical exaggeration). Thick green line shows HMT thickness along the seafloor (vertically exaggerated 1000 times for clarity). Locations of cores are represented by circles with color corresponding to the dive number. 


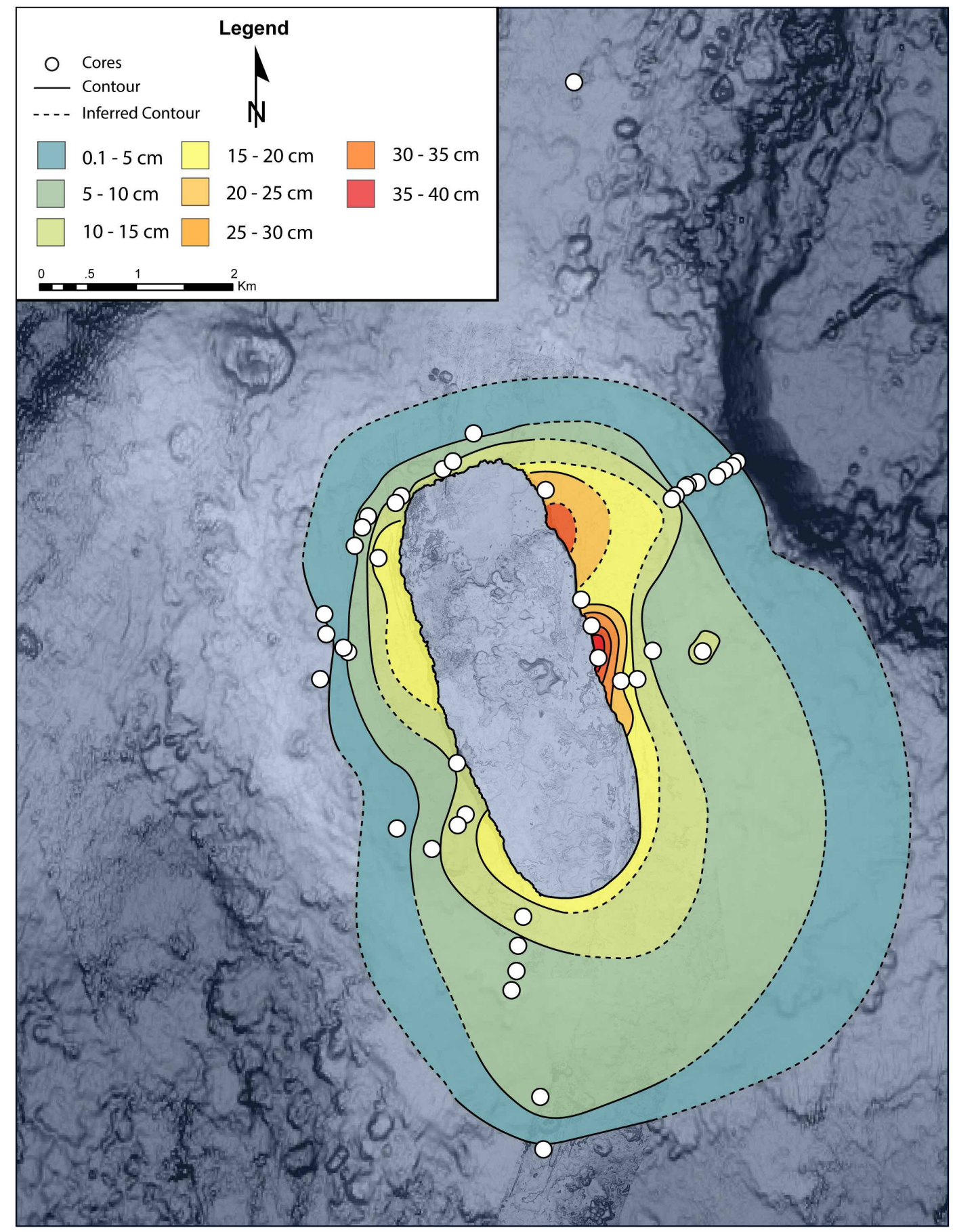

Figure 19. Isopach map showing thickness of HMT present around Axial Seamount. Thickness is based on described cores (white circles) with inferred isopach bounding lines. Thick black line outlines the caldera. Note that HMT is considerably thicker on the east side of the caldera and extends further away from the caldera towards the southeast. Caldera rim and fissures were drawn in by colleagues at MBARI pers. Comm. 


\section{Granulometry}

Grain-size analysis focused on HMT lithofacies, but several subsamples within TM and LPT, and an off-summit subsample (TO) were also analyzed for comparison. Results are consistent with the overall grain-size trends observed qualitatively in the core descriptions (above). All three lithofacies are notably coarser than the off-summit (TO) subsample analyzed for "background sedimentation". HMT contains the finest mean grain-size and peak mode compared to TM and LPT, while LPT is significantly coarser than TM and HMT (Fig. 20A). Further grain-size analysis within HMT reveals some variability based on proximity of a core to the caldera, and depth within a core (Fig. 20B). Distal cores generally consist of finer grain-sizes in the top of the lithofacies whereas proximal cores have greater variability. Average peak modes in the bottom and middle of subsamples from distal HMT cores are slightly coarser than proximal and medial cores. This is consistent with core observations where proximal and medial cores have distinct laminations (which presumably constrains coarse material) whereas distal cores lack distinct laminations resulting in a dispersal of coarse material throughout the entire lithofacies.

No notable distinction in sorting, skewness (peak symmetry) or kurtosis (peak sharpness) could be discerned between HMT and TM. All subsamples were poorly sorted or very poorly sorted and either symmetrical, fine skewed or very fine skewed. Kurtosis was variable and included leptokurtic, mesokurtic, and platykurtic. Results are presented in Tables 7 and 8 and summarized below. 

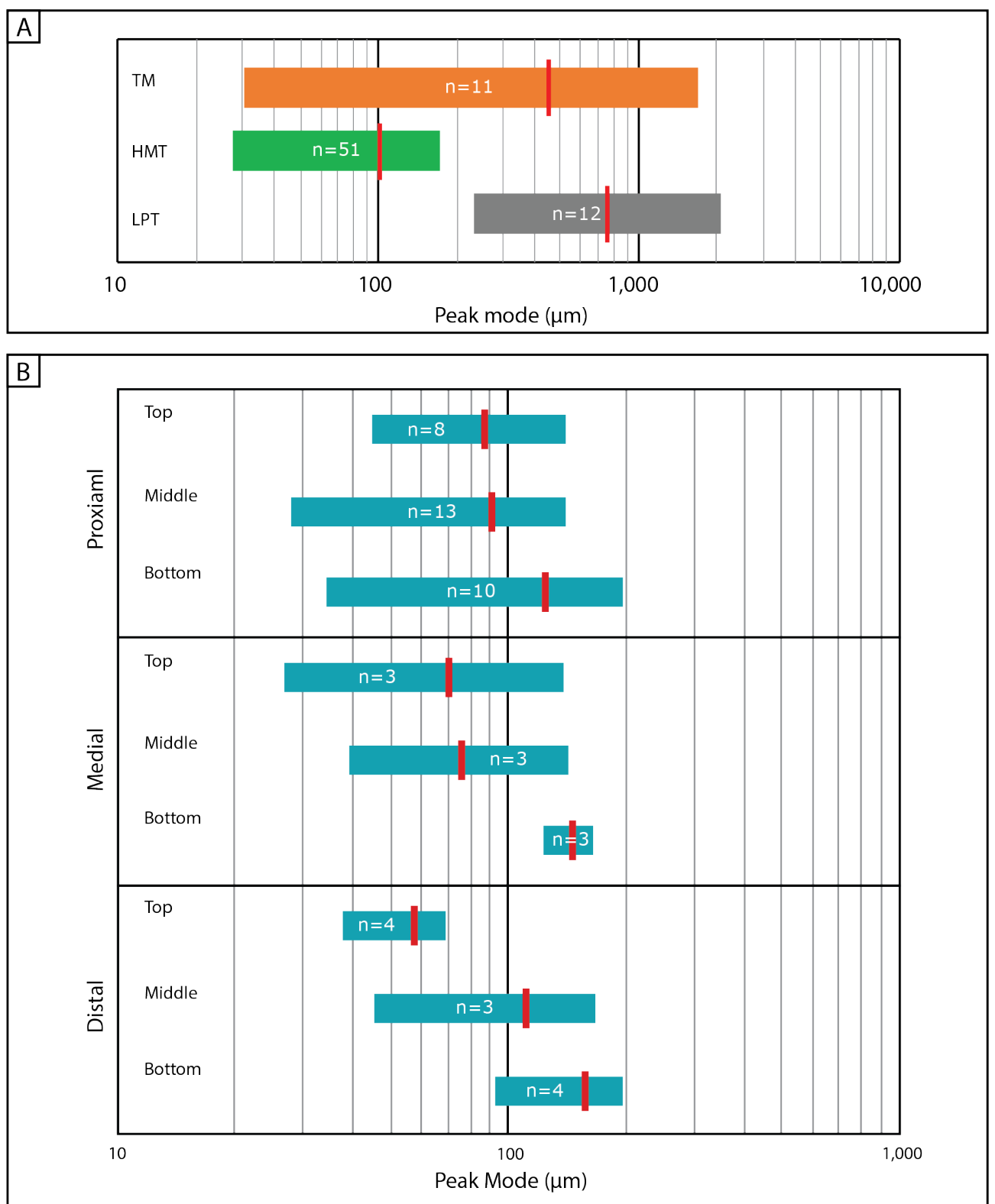

Figure 20. Graph showing variation in the range and mean grain-size. (A) Range of grain-size for subsamples analyzed from different lithofacies (Orange = TM; Green = HMT; Grey = LPT). Vertical red line represents mean grain-size of all subsamples. (B) Range and mean of grain-size for all subsamples analyzed from HMT. Subsamples are separated by proximity to the caldera, and whether the subsample was retrieved from the top, middle, or bottom of HMT. 
Table 7. Results of PSA and analysis based on identified lithofacies.

\begin{tabular}{|c|c|c|c|c|c|c|c|c|c|c|c|c|c|c|c|c|c|}
\hline \multirow{2}{*}{$\begin{array}{l}\text { Litho- } \\
\text { facies }\end{array}$} & \multirow{2}{*}{$\begin{array}{c}\text { \# Sub- } \\
\text { samples }\end{array}$} & \multirow{2}{*}{$\begin{array}{c}\text { Average } \\
\text { Peak } \\
\text { Mode } \\
(\mu \mathrm{m})\end{array}$} & \multicolumn{3}{|c|}{ Modal Distribution } & \multicolumn{4}{|c|}{ Skewness } & \multicolumn{3}{|c|}{ Kurtosis } & \multicolumn{5}{|c|}{ Sorting } \\
\hline & & & 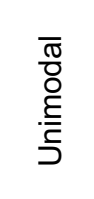 & 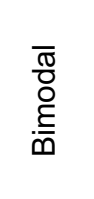 & $\begin{array}{l}\bar{\pi} \\
\frac{0}{0} \\
\text { E } \\
i=\end{array}$ & 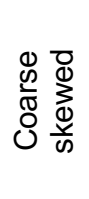 & 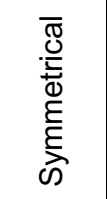 & 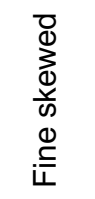 & 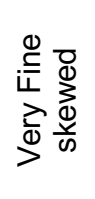 & 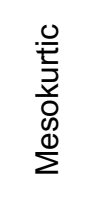 & 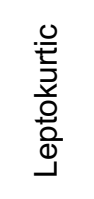 & 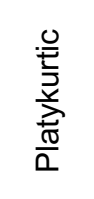 & 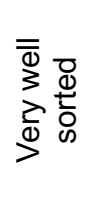 & 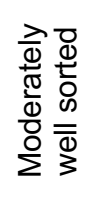 & 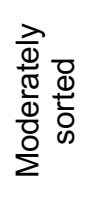 & 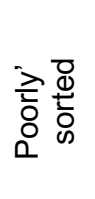 & 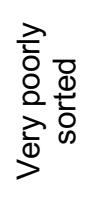 \\
\hline TM & 11 & 335 & $\begin{array}{c}3 \\
(27 \%)\end{array}$ & $\begin{array}{c}5 \\
(46 \%) \\
\end{array}$ & $\begin{array}{c}3 \\
(27 \%) \\
\end{array}$ & $\begin{array}{c}0 \\
(0 \%)\end{array}$ & $\begin{array}{c}2 \\
(18 \%)\end{array}$ & $\begin{array}{c}5 \\
(46 \%) \\
\end{array}$ & $\begin{array}{c}4 \\
(36 \%) \\
\end{array}$ & $\begin{array}{c}2 \\
(18 \%) \\
\end{array}$ & $\begin{array}{c}7 \\
(64 \%) \\
\end{array}$ & $\begin{array}{c}2 \\
(18 \%) \\
\end{array}$ & $\begin{array}{c}0 \\
(0 \%) \\
\end{array}$ & $\begin{array}{c}0 \\
(0 \%)\end{array}$ & $\begin{array}{c}1 \\
(8 \%) \\
\end{array}$ & $\begin{array}{c}5 \\
(46 \%) \\
\end{array}$ & $\begin{array}{c}5 \\
(46 \%) \\
\end{array}$ \\
\hline HMT & 54 & 100 & $\begin{array}{c}46 \\
(83 \%)\end{array}$ & $\begin{array}{c}8 \\
(15 \%)\end{array}$ & $\begin{array}{c}1 \\
(2 \%)\end{array}$ & $\begin{array}{c}0 \\
(0 \%)\end{array}$ & $\begin{array}{c}2 \\
(4 \%)\end{array}$ & $\begin{array}{c}39 \\
(71 \%)\end{array}$ & $\begin{array}{c}14 \\
(25 \%)\end{array}$ & $\begin{array}{c}16 \\
(29 \%)\end{array}$ & $\begin{array}{c}36 \\
(66 \%)\end{array}$ & $\begin{array}{c}3 \\
(5 \%)\end{array}$ & $\begin{array}{c}0 \\
(0 \%)\end{array}$ & $\begin{array}{c}0 \\
(0 \%)\end{array}$ & $\begin{array}{c}0 \\
(0 \%)\end{array}$ & $\begin{array}{c}34 \\
(63 \%)\end{array}$ & $\begin{array}{c}20 \\
(37 \%)\end{array}$ \\
\hline LPT & 12 & 831 & $\begin{array}{c}11 \\
(92 \%)\end{array}$ & $\begin{array}{c}1 \\
(8 \%)\end{array}$ & $\begin{array}{c}0 \\
(0 \%)\end{array}$ & $\begin{array}{c}0 \\
(0 \%)\end{array}$ & $\begin{array}{c}4 \\
(33 \%)\end{array}$ & $\begin{array}{c}3 \\
(25 \%)\end{array}$ & $\begin{array}{c}5 \\
(42 \%)\end{array}$ & $\begin{array}{c}1 \\
(8 \%)\end{array}$ & $\begin{array}{c}5 \\
(42 \%)\end{array}$ & $\begin{array}{c}6 \\
(50 \%)\end{array}$ & $\begin{array}{c}2 \\
(17 \%)\end{array}$ & $\begin{array}{c}1 \\
(8 \%)\end{array}$ & $\begin{array}{c}4 \\
(33 \%)\end{array}$ & $\begin{array}{c}5 \\
(42 \%)\end{array}$ & $\begin{array}{c}0 \\
(0 \%)\end{array}$ \\
\hline
\end{tabular}

Table 8. Results of HMT PSA analysis based on proximity to the caldera.

\begin{tabular}{|c|c|c|c|c|c|c|c|c|c|c|c|c|c|c|}
\hline \multirow{2}{*}{$\begin{array}{c}\text { HMT } \\
\text { Proximity }\end{array}$} & \multirow{2}{*}{$\begin{array}{c}\text { \# Sub- } \\
\text { samples }\end{array}$} & \multirow{2}{*}{$\begin{array}{c}\text { Average } \\
\text { Peak } \\
\text { Mode } \\
(\mu \mathrm{m})\end{array}$} & \multicolumn{3}{|c|}{ Modal Distribution } & \multicolumn{4}{|c|}{ Skewness } & \multicolumn{3}{|c|}{ Kurtosis } & \multicolumn{2}{|c|}{ Sorting } \\
\hline & & & $\begin{array}{l}\frac{\pi}{0} \\
\frac{0}{0} \\
\frac{5}{5} \\
\end{array}$ & $\begin{array}{l}\bar{\pi} \\
\frac{0}{0} \\
\frac{\varrho}{0} \\
\overline{0}\end{array}$ & 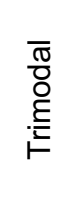 & 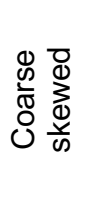 & 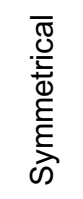 & 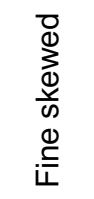 & 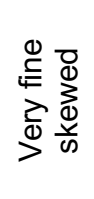 & 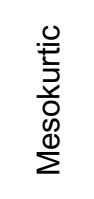 & $\begin{array}{l}\frac{0}{ \pm} \\
\frac{1}{0} \\
0 \\
\frac{0}{0}\end{array}$ & 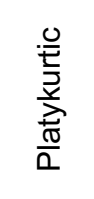 & 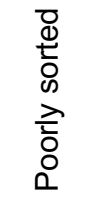 & 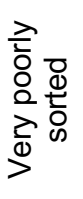 \\
\hline Proximal & 34 & 98 & $\begin{array}{c}30 \\
(88 \%)\end{array}$ & $\begin{array}{c}3 \\
(9 \%)\end{array}$ & $\begin{array}{c}1 \\
(3 \%)\end{array}$ & $\begin{array}{c}0 \\
(0 \%)\end{array}$ & $\begin{array}{c}2 \\
(5 \%)\end{array}$ & $\begin{array}{c}19 \\
(56 \%)\end{array}$ & $\begin{array}{c}13 \\
(39 \%)\end{array}$ & $\begin{array}{c}24 \\
(71 \%)\end{array}$ & $\begin{array}{c}8 \\
(24 \%)\end{array}$ & $\begin{array}{c}2 \\
(5 \%)\end{array}$ & $\begin{array}{c}21 \\
(62 \%)\end{array}$ & $\begin{array}{c}13 \\
(38 \%)\end{array}$ \\
\hline Medial & 9 & 97 & $\begin{array}{c}6 \\
(66 \%)\end{array}$ & $\begin{array}{c}3 \\
(33 \%)\end{array}$ & $\begin{array}{c}0 \\
(0 \%)\end{array}$ & $\begin{array}{c}0 \\
(0 \%)\end{array}$ & $\begin{array}{c}0 \\
(0 \%)\end{array}$ & $\begin{array}{c}5 \\
(56 \%)\end{array}$ & $\begin{array}{c}4 \\
(44 \%)\end{array}$ & $\begin{array}{c}3 \\
(33 \%)\end{array}$ & $\begin{array}{c}5 \\
(56 \%)\end{array}$ & $\begin{array}{c}1 \\
(11 \%)\end{array}$ & $\begin{array}{c}5 \\
(56 \%)\end{array}$ & $\begin{array}{c}4 \\
(44 \%)\end{array}$ \\
\hline Distal & 11 & 107 & $\begin{array}{c}9 \\
(82 \%)\end{array}$ & $\begin{array}{c}2 \\
(18 \%)\end{array}$ & $\begin{array}{c}0 \\
(0 \%)\end{array}$ & $\begin{array}{c}0 \\
(0 \%)\end{array}$ & $\begin{array}{c}0 \\
(0 \%)\end{array}$ & $\begin{array}{c}9 \\
(82 \%)\end{array}$ & $\begin{array}{c}2 \\
(18 \%)\end{array}$ & $\begin{array}{c}4 \\
(36 \%)\end{array}$ & $\begin{array}{c}7 \\
(64 \%)\end{array}$ & $\begin{array}{c}0 \\
(0 \%)\end{array}$ & $\begin{array}{c}8 \\
(73 \%)\end{array}$ & $\begin{array}{c}3 \\
(27 \%)\end{array}$ \\
\hline
\end{tabular}




\section{Summit Lithofacies}

Grain-size analysis reveals distinct differences in grain-size metrics between each lithofacies. TM is highly variable with peak mode ranging from $30 \mu \mathrm{m}-$ $1,500 \mu \mathrm{m}(5.1 \varnothing--1.5 \varnothing)$ with the average falling near $446 \mu \mathrm{m}(1.1 \varnothing ;$ Fig. $21 \mathrm{~A})$. TM grain-size generally decreases with increasing distance away from the caldera which is consistent with core description observations where higher modal percent of coarse ash is more abundant in proximal cores. HMT is generally fine grained with peak modes ranging from about $30-170 \mu \mathrm{m}(5.1-$ $2.56 \varnothing)$ and the average falling near $100 \mu \mathrm{m}$ (3.3 ø; Fig. 21B). HMT grain-size tends to be more variable in proximal cores due to the presence of more welldefined ash laminations, and more homogenous in distal cores. LPT is much coarser grained than TM and HMT with peak modes ranging from approximately $300 \mu \mathrm{m}$ to $>2000 \mu \mathrm{m}(1.75 \varnothing--1.0 \varnothing ;$ coarse ash $)$ and the average falling near $875 \mu \mathrm{m}(0.19 \varnothing ;$ Fig. 21C). Greater range of LPT grain-size is present in proximal cores and is well to moderately-well sorted for any individual subsample.

\section{Off-Summit}

In addition to grain-size analysis of each lithofacies, the off-ridge core D881$P C 72 L$ (approximately $42 \mathrm{~km} \mathrm{~S}$. of the caldera) was subsampled and analyzed for "ambient sedimentation" and is considered to be from TO lithofacies. Grainsize analysis results reveal ambient sedimentation is significantly finer-grained than that of average TM, HMT, and LPT subsamples. 

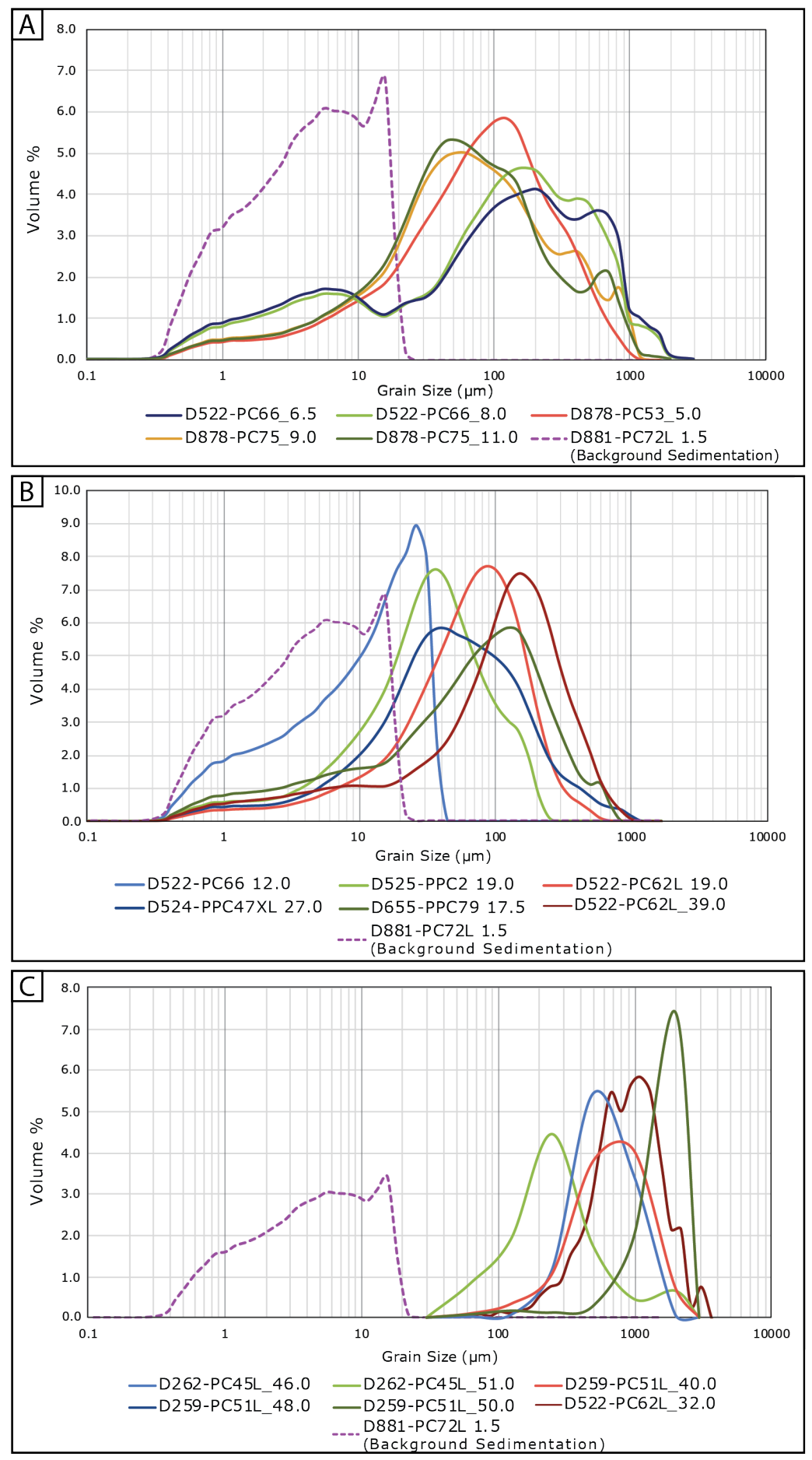

Figure 21. Grain-size distributions analyzed from different lithofacies. Dashed purple line represents "background sedimentation" from off-summit core D881PC72L (TO) approximately $42 \mathrm{~km} \mathrm{~S}$. of the caldera. (A) Grain-size distributions from TM lithofacies. (B) Grain-size distributions from HMT lithofacies. (C) Grainsize distributions from LPT lithofacies. 


\section{Componentry}

\section{Visual Observations}

Three major components were visually identified within HMT including primary volcaniclasts, non-primary volcaniclasts, and authigenic hydrothermal minerals (Table 4). Primary volcaniclasts include vitriclasts, ranging from unaltered (fresh basalt glass) to slightly altered $(<20 \%$ altered by visual estimation). Vitriclasts are predominantly angular / blocky (Fig. 2A), but fluidal vitriclasts are also present (Fig. 2B). For further information regarding vitriclasts, see morphology below. Primary volcaniclasts also include free crystals (plagioclase and olivine) and phyric glass shards. Non-primary volcaniclasts (Fig. $2 \mathrm{C}-1-11$ ) include oceanic crust (unaltered or altered) fragments: crystalline basalt / diabase, green blocky? (pyroxene?), green fibrous (actinolite?), white fibrous (tremolite?), white zeolites (?), red particles (iddingsite?), and moderately to completely altered vitriclasts, which are identified by a coating of various colors. Authigenic hydrothermal minerals (Fig. 2C-6 and C7) are made up of green / yellow clay aggregates and yellow hydrothermal sulfides (e.g. pyrite). Vitric "agglutinate" particles are unique in that sideromelane (basalt glass) has presumably stretched and coated hydrothermal clay aggregates and may be considered both primary and authigenic in origin.

\section{Point Counts}

Representative HMT subsample D522-PC62L 46.5 shows that finer size fractions have considerably less primary volcaniclasts than the coarser size 
fraction ( $42 \%$ vs. $79 \%$, respectively), which considerably less non-primary volcaniclasts and authigenic hydrothermal minerals. Abundance of non-primary volcaniclasts increase from $16 \%$ in the coarser size-fraction to $30 \%$ in the finer size-fraction while authigenic hydrothermal minerals increase from $5 \%$ to $21 \%$. Results of the $125-250 \mu \mathrm{m}$ size-fraction are similar to the coarse size-fraction $(250-500 \mu \mathrm{m})$. In addition to differences in the three major components, vitriclast morphology also varies with grain-size (Fig. 22B). Fluidal shards make up more than $12 \%$ of all vitriclasts in the $250-500 \mu \mathrm{m}$ size fraction whereas the $63-125 \mu \mathrm{m}$ size fraction contains only $4.25 \%$.

Results of 27 representative subsamples in the $125-250 \mu \mathrm{m}$ size fraction from HMT are presented in Table 9 and plotted on a ternary diagram (Fig. 23A). An average of all 27 subsamples reveal that primary volcaniclasts are the most abundant $(70 \%)$, non-primary volcaniclasts make up $24 \%$, and authigenic hydrothermal minerals are the least abundant (6\%). Abundance of authigenic hydrothermal minerals shows little variation ( $2 \%$ to $13 \%)$. Conversely, primary and non-primary volcaniclasts are more variable (56\% to $81 \%$ vs. $15 \%$ to $34 \%$, respectively).

To further investigate primary vs. non-primary volcaniclast variability, subsamples were separated and re-plotted based on subsample characteristics including depth within HMT lithofacies, proximity of core in relation to the caldera, and subsample mean grain-size (Fig. 23B - D). No relation exists between componentry and proximity to caldera, depth within HMT, or subsample mean 
grain-size, implying that HMT componentry of the $125-250 \mu \mathrm{m}$ size fraction is relatively homogenous.
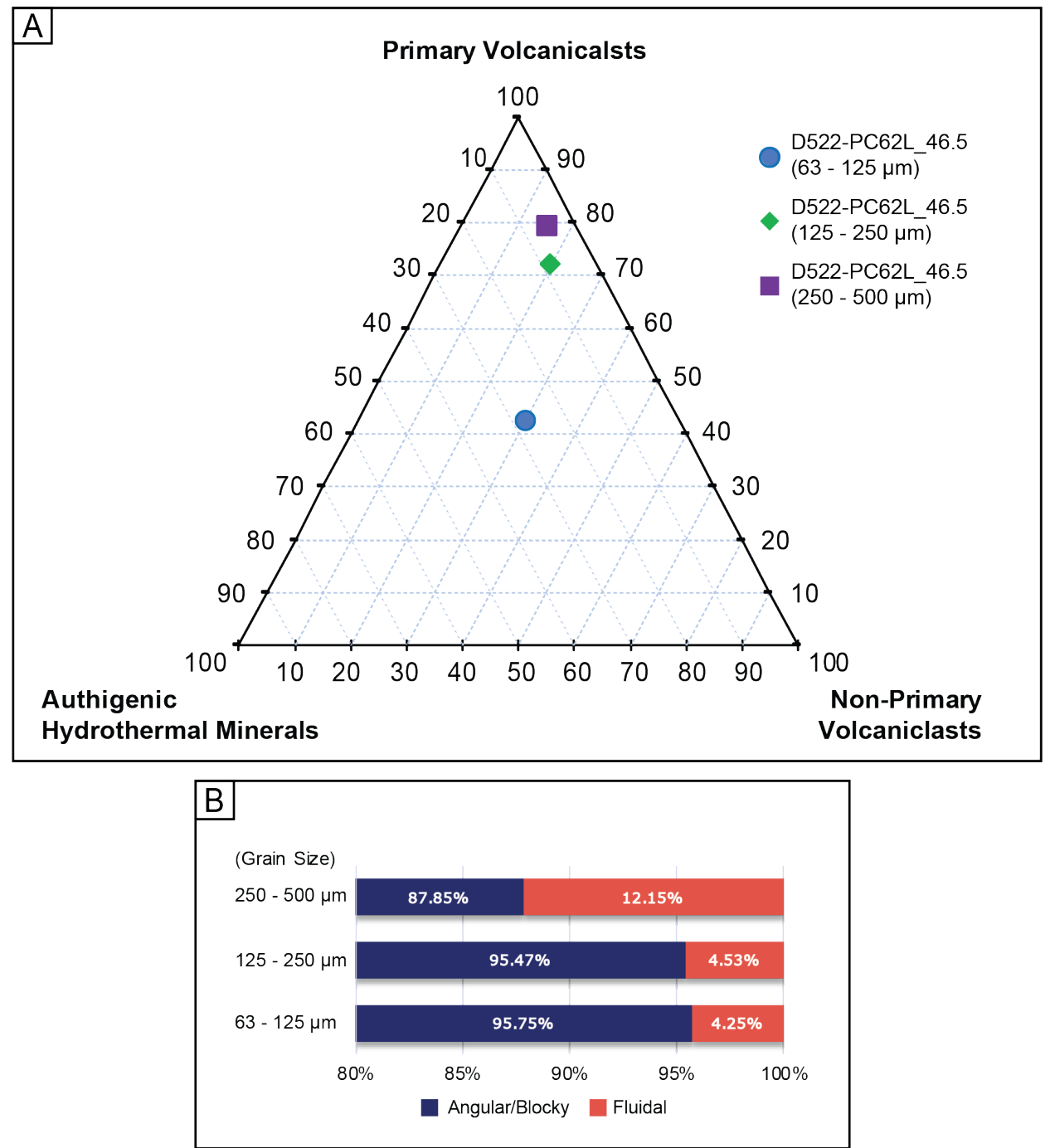

Figure 22. Point count ternary plots of HMT. (A) Results of various grain-size fractions $(n=500)$ from subsample D522-PC62L 46.5 (Fig. 15). Decrease in grainsize results in a decrease in primary volcaniclast abundance. However, primary volcaniclasts are still prevalent (>40\%) in fine grain-size fractions. (B) Bar charts show percent of fluidal vs. angular/blocky vitriclasts. Coarser size-fractions are more abundant in fluidal shards whereas the fine size-fraction contain more angular/blocky vitriclasts. 
Table 9. Results of point counts $(n=500)$ in the $125-250 \mu \mathrm{m}$ size fraction of HMT.

\begin{tabular}{|c|c|c|c|c|c|c|c|c|c|c|c|c|c|c|c|c|c|c|c|c|c|c|c|}
\hline \multirow[b]{2}{*}{ Subsample } & \multicolumn{8}{|c|}{ Primary Volcaniclasts } & \multicolumn{8}{|c|}{ Non-Primary Volcaniclasts } & \multicolumn{5}{|c|}{ Hydrothermal Minerals } & \multicolumn{2}{|c|}{ Total $(\%)$} \\
\hline & $\begin{array}{l}\frac{10}{5} \\
\frac{\pi}{5} \\
\frac{5}{<}\end{array}$ & 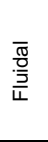 & 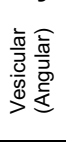 & 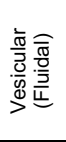 & $\begin{array}{l}\frac{\pi}{\mathscr{m}} \\
\frac{\pi}{0} \\
\frac{0}{9} \\
\frac{\pi}{0}\end{array}$ & 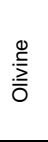 & 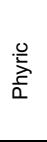 & 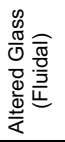 & 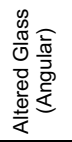 & 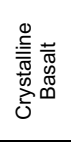 & 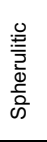 & 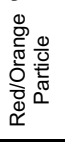 & 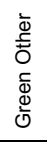 & 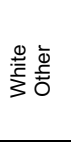 & 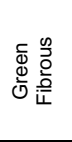 & 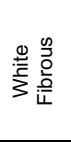 & 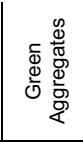 & 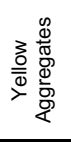 & 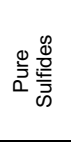 & 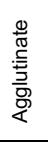 & 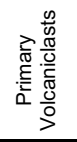 & 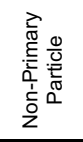 & 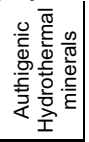 \\
\hline 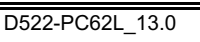 & 286 & 77 & 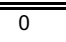 & 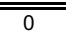 & $\overline{59}$ & $\overline{22}$ & 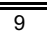 & $\overline{0}$ & 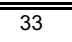 & 38 & 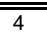 & $\overline{10}$ & 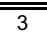 & $\overline{222}$ & $\overline{00}$ & 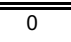 & $\overline{11}$ & $\overline{24}$ & $\overline{22}$ & 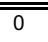 & 72.60 & 22.00 & $\overline{5.40}$ \\
\hline D522-PC62L_15.0 & 238 & 12 & 0 & 0 & 41 & 3 & 13 & 1 & 85 & 43 & 0 & 8 & 9 & 21 & 0 & 0 & 6 & 26 & 0 & 2 & 60.43 & 32.87 & 6.69 \\
\hline D522-PC62L_23.0 & 191 & 4 & 0 & 0 & 68 & 3 & 15 & 0 & 94 & 35 & 1 & 8 & 16 & 16 & 0 & 2 & 7 & 38 & 1 & 1 & 56.20 & 34.40 & 9.40 \\
\hline D522-PC62L_28.0 & 307 & 11 & 1 & 0 & 48 & 0 & 4 & 0 & 58 & 23 & 5 & 5 & 2 & 16 & 0 & 0 & 1 & 17 & 2 & 0 & 74.20 & 21.80 & 4.00 \\
\hline D522-PC62L_37.5 & 263 & 12 & 1 & 0 & 40 & 5 & 12 & 67 & 0 & 33 & 4 & 6 & 5 & 20 & 0 & 1 & 3 & 25 & 3 & 0 & 66.60 & 27.20 & 6.20 \\
\hline D522-PC62L_41.0 & 281 & 10 & 0 & 0 & 51 & 4 & 21 & 0 & 55 & 44 & 5 & 9 & 0 & 8 & 0 & 0 & 0 & 11 & 1 & 0 & 73.40 & 24.20 & 2.40 \\
\hline D522-PC62L_46.5 & 316 & 15 & 0 & 0 & 21 & 0 & 9 & 1 & 45 & 20 & 0 & 11 & 1 & 19 & 0 & 0 & 0 & 41 & 1 & 0 & 72.20 & 19.40 & 8.40 \\
\hline D522-PC66_8.0 & 313 & 39 & 0 & 1 & 36 & 0 & 5 & 2 & 39 & 28 & 1 & 5 & 4 & 8 & 0 & 2 & 3 & 14 & 0 & 0 & 78.80 & 17.80 & 3.40 \\
\hline D522-PC66_12.0 & 242 & 3 & 1 & 0 & 48 & 2 & 4 & 0 & 77 & 29 & 0 & 14 & 3 & 16 & 0 & 0 & 5 & 53 & 0 & 3 & 60.00 & 27.80 & 12.20 \\
\hline D522-PC66_15.5 & 179 & 15 & 0 & 0 & 18 & 0 & 2 & 7 & 159 & 20 & 4 & 9 & 1 & 17 & 0 & 0 & 3 & 65 & 0 & 1 & 42.80 & 43.40 & 13.80 \\
\hline D522-PC66_19.0 & 267 & 31 & 1 & 0 & 63 & 4 & 4 & 1 & 52 & 35 & 0 & 4 & 4 & 15 & 0 & 1 & 4 & 11 & 0 & 3 & 74.00 & 22.40 & 3.60 \\
\hline D524-PC47XL_27.0 & 248 & 30 & 0 & 0 & 32 & 3 & 9 & 2 & 76 & 39 & 1 & 6 & 7 & 18 & 0 & 0 & 8 & 17 & 0 & 4 & 64.40 & 29.80 & 5.80 \\
\hline D525-PPC2_23.0 & 275 & 23 & 0 & 0 & 28 & 2 & 7 & 0 & 68 & 39 & 0 & 8 & 9 & 12 & 0 & 2 & 5 & 20 & 1 & 1 & 67.00 & 27.60 & 5.40 \\
\hline D525-PPC2_29.5 & 282 & 24 & 0 & 0 & 21 & 6 & 8 & 0 & 89 & 25 & 1 & 3 & 7 & 11 & 0 & 0 & 4 & 18 & 1 & 0 & 68.20 & 27.20 & 4.60 \\
\hline D655-PPC67_13.5 & 270 & 14 & 2 & 0 & 37 & 4 & 7 & 0 & 61 & 25 & 3 & 10 & 8 & 22 & 0 & 0 & 2 & 34 & 0 & 1 & 66.80 & 25.80 & 7.40 \\
\hline D655-PPC79_17.5 & 254 & 50 & 0 & 0 & 49 & 4 & 14 & 0 & 42 & 27 & 4 & 8 & 7 & 16 & 0 & 1 & 2 & 18 & 2 & 2 & 74.20 & 21.00 & 4.80 \\
\hline D655-PPC79_23.0 & 294 & 45 & 0 & 0 & 53 & 2 & 12 & 0 & 28 & 26 & 1 & 4 & 4 & 10 & 1 & 0 & 3 & 12 & 1 & 4 & 81.20 & 14.80 & 4.00 \\
\hline D655-PPC79_26.0 & 332 & 40 & 0 & 0 & 16 & 1 & 9 & 0 & 28 & 28 & 0 & 5 & 1 & 20 & 0 & 0 & 2 & 17 & 0 & 1 & 79.60 & 16.40 & 4.00 \\
\hline D876-PC75_18.0 & 282 & 41 & 0 & 0 & 52 & 13 & 6 & 1 & 46 & 27 & 4 & 2 & 3 & 2 & 0 & 0 & 7 & 14 & 0 & 0 & 78.80 & 17.00 & 4.20 \\
\hline D878-PC53_8.0 & 235 & 20 & 0 & 0 & 27 & 1 & 12 & 1 & 83 & 18 & 0 & 11 & 11 & 14 & 0 & 0 & 3 & 61 & 0 & 3 & 59.00 & 27.60 & 13.40 \\
\hline D878-PC53_10.0 & 251 & 20 & 0 & 0 & 45 & 1 & 12 & 0 & 63 & 12 & 0 & 12 & 6 & 26 & 0 & 1 & 4 & 44 & 0 & 3 & 65.80 & 24.00 & 10.20 \\
\hline D878-PC53_12.0 & 269 & 16 & 0 & 0 & 64 & 5 & 15 & 0 & 45 & 22 & 0 & 9 & 6 & 10 & 0 & 0 & 7 & 28 & 0 & 4 & 73.80 & 18.40 & 7.80 \\
\hline D878-PC53_14.0 & 264 & 18 & 0 & 1 & 33 & 2 & 1 & 3 & 80 & 35 & 0 & 5 & 7 & 21 & 0 & 1 & 5 & 24 & 0 & 0 & 63.80 & 30.40 & 5.80 \\
\hline D878-PC53_16.0 & 263 & 12 & 0 & 3 & 20 & 0 & 1 & 2 & 114 & 12 & 3 & 8 & 4 & 16 & 0 & 1 & 1 & 39 & 0 & 1 & 59.80 & 32.00 & 8.20 \\
\hline D878-PC53_18.0 & 289 & 26 & 0 & 2 & 41 & 3 & 3 & 4 & 60 & 29 & 1 & 5 & 2 & 13 & 0 & 0 & 4 & 15 & 0 & 3 & 72.80 & 22.80 & 4.40 \\
\hline D878-PC75_15.0 & 257 & 59 & 0 & 0 & 31 & 5 & 5 & 1 & 63 & 40 & 0 & 2 & 8 & 16 & 0 & 1 & 1 & 11 & 0 & 0 & 71.40 & 26.20 & 2.40 \\
\hline D878-PC75_17.0 & 281 & 42 & 0 & 0 & 33 & 1 & 4 & 0 & 54 & 35 & 0 & 13 & 2 & 12 & 0 & 1 & 0 & 21 & 0 & 1 & 72.20 & 23.40 & 4.40 \\
\hline Average & 268 & 24 & 0 & 0 & 40 & 3 & 8 & 3 & 63 & 29 & 2 & 7 & 5 & 15 & 0 & 1 & 3 & 27 & 1 & 1 & 68.52 & 25.10 & 6.38 \\
\hline
\end{tabular}



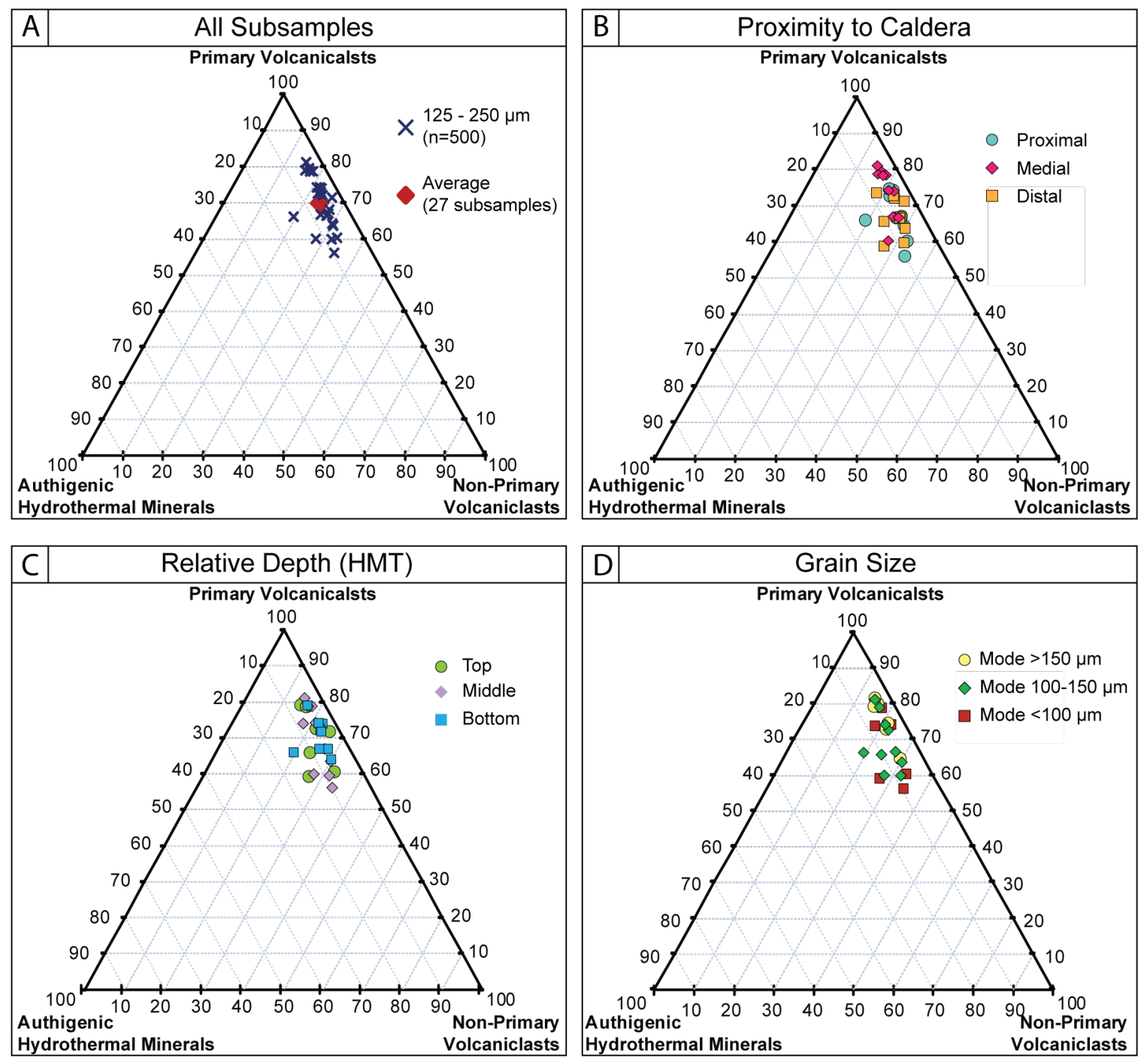

Figure 23. (A) Results of point counts from 27 subsamples $(n=500)$ in the 125 $250 \mu \mathrm{m}$ size-fraction of HMT. Individual subsamples are shown by a blue " $X$ " and an average of all subsamples is denoted by a red diamond. (B) Plot of subsamples based on proximity of core to the caldera (proximal $=<100 \mathrm{~m}$; medial $=100-1,000 \mathrm{~m}$; distal $=>1,000 \mathrm{~m}$ ). (C) Plot of subsamples segregated by relative depth within HMT (top, middle or bottom of lithofacies). (D) Plot of subsamples based on subsample mean grain-size. 


\section{$X R D$}

\section{"Bulk" XRD Analysis}

X-ray diffraction of 10 "bulk" subsamples from HMT and TM lithofacies were analyzed. Major peaks and intensities of each subsample were similar regardless of lithofacies (Fig. 24). Some minor differences are observed specifically in the "pale green" lamination observed near the top of HMT (subsample D522-PPC1 9.0) which shows a distinct peak near $9.48 \AA$ that is absent in other subsamples, and a single peak near 2.517 whereas other subsamples have a "doublet" peak near 2.567 / $2.517 \AA$.

Identified unaltered volcanic minerals include amphibole (hornblende), Mgrich pyroxene (augite, enstatite, diopside), plagioclase (anorthite), and olivine. Minerals identified that are typical of altered oceanic crust include amphibole (actinolite, tremolite), chlorite, epidote, and plagioclase (albite), zeolites (heulandite and laumontite) and clay minerals (see clay mineral identification). Additional minerals typical of deep-sea hydrothermal systems include quartz and pyrite. Table 10 summarizes major peaks and associated minerals. Minor mineral components are difficult to resolve due to overwhelmingly large abundances of aforementioned minerals. 


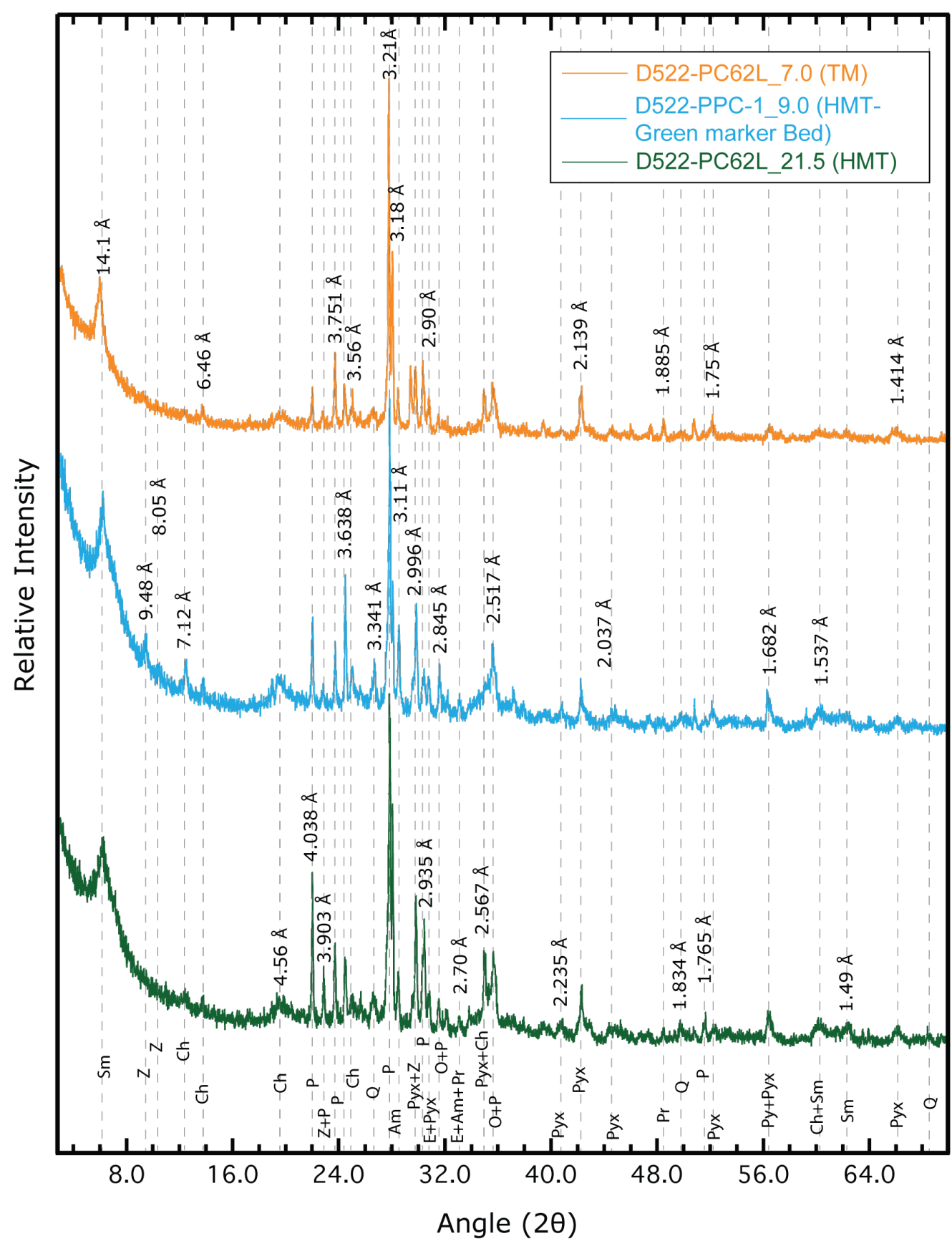

Figure 24. X-ray diffractogram of representative glass-separated "bulk" subsamples D522-PC62L_7.0 (TM), D522-PPC1_9.0 (HMT pale green lamination), and D522-PC62L_21.5 (HMT). Major peaks are labeled with dspacing $(\AA)$ and with identified primary mineral(s). Mineral identification is summarized in Table. 10. Minerals are indicated by the following abbreviations: Am: Amphibole (actinolite, tremolite, hornblende); Ch: Chlorite; E: Epidote; O: Olivine; P: Plagioclase (anorthite, albite); Pr: Pyrite; Pyx: Pyroxene (diopside, augite); Q: Quartz; Sm: Smectite; Z: Zeolite (heulandite, laumontite). 
Table 10. Summary of major identified XRD peaks and associated mineral(s).

\begin{tabular}{cl|cl}
$\begin{array}{c}\text { d-spacing } \\
(\boldsymbol{A})\end{array}$ & Minerals & $\begin{array}{c}\text { d-spacing } \\
(\boldsymbol{A})\end{array}$ & Minerals \\
\hline 14.100 & Smectite & 2.900 & Pyroxene + Epidote \\
9.480 & Zeolite & 2.845 & Olivine + Plagioclase \\
7.120 & Zeolite & 2.700 & Pyrite + Epidote \\
6.460 & Chlorite & 2.567 & Olivine + Pyroxene \\
4.560 & Chlorite & 2.517 & Olivine \\
4.038 & Plagioclase & 2.235 & Pyroxene \\
3.903 & Plagioclase +Zeolite & 2.139 & Pyroxene \\
3.751 & Plagioclase & 2.037 & Pyroxene + Chlorite \\
3.638 & Plagioclase & 1.885 & Pyrite \\
3.560 & Chlorite & 1.834 & Quartz \\
3.341 & Quartz & 1.765 & Plagioclase \\
3.210 & Pyroxene + Plagioclase & 1.682 & Pyroxene + Pyrite \\
3.180 & Plagioclase & 1.537 & Smectite + Chlorite \\
3.110 & Amphibole + Plagioclase & 1.490 & Smectite \\
2.996 & Pyroxene + Plagioclase & 1.414 & Pyroxene \\
2.935 & Pyroxene + Plagioclase + Zeolite & 1.372 & Quartz \\
\hline
\end{tabular}

\section{Clay Mineral Identification}

Four "bulk" XRD subsamples were analyzed for clay mineralogy: D522$P C 62 L 21.5$ is a proximal HMT subsample, D522-PPC1 9.0 is a proximal subsample retrieved from the "pale green" lamination near the top of the HMT lithofacies, D655-PPC79 20.0 is a medial HMT subsample, D878-PC53 12.0 is a distal HMT subsample (Fig. 25). Refer to Figure 3 for core locations and Appendix B for subsample depth. Results of clay peaks observed in each subsample throughout the clay XRD treatment process are summarized in Table 11. The primary clay components include smectite, chlorite and interlayered smectite / chlorite. 


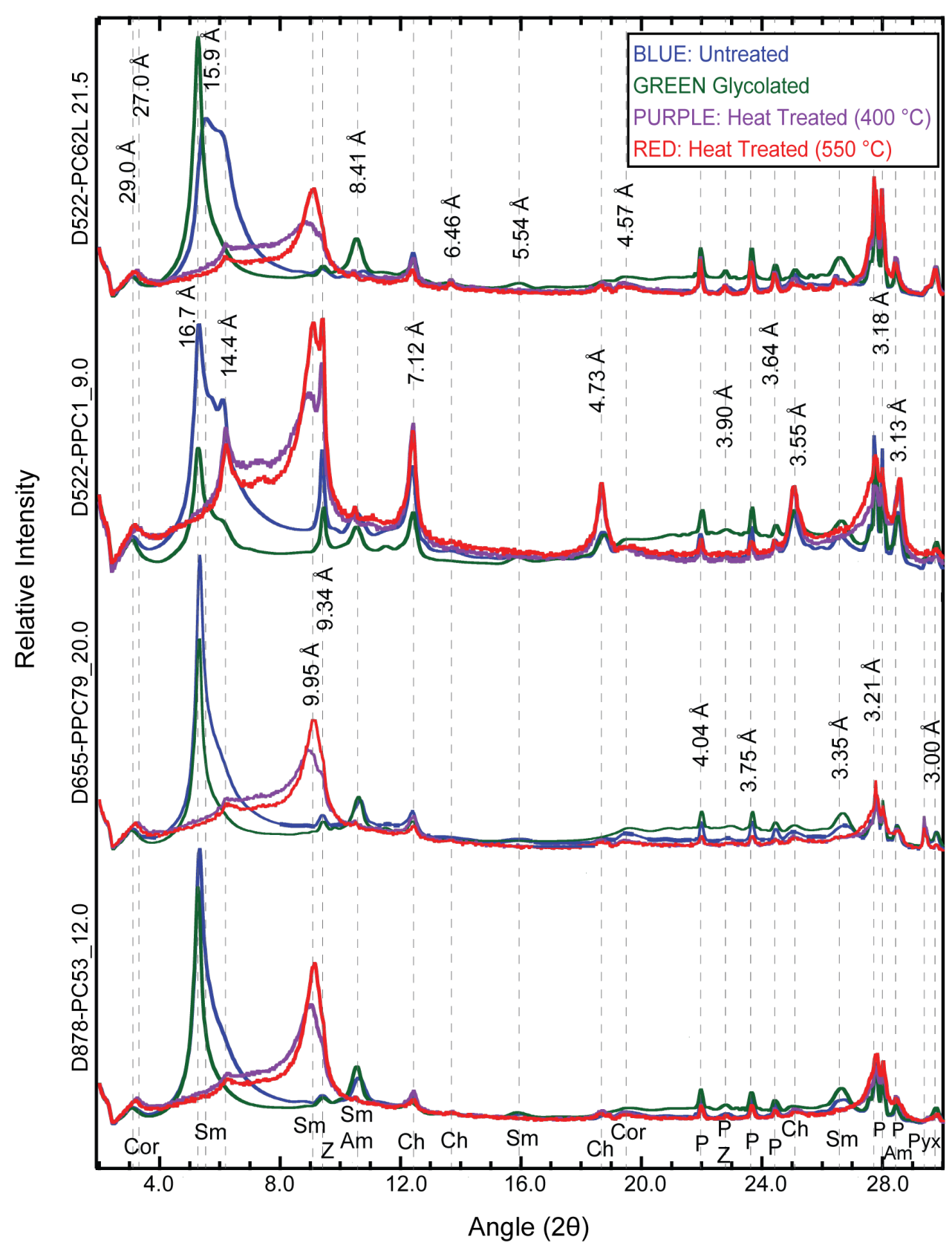

Figure 25. XRD diffractograms of four $<2$ um subsamples of HMT analyzed for clay mineralogy. Various treatments of subsamples are shown (Blue: untreated; Green: glycolated; Purple: heat treated to $400{ }^{\circ} \mathrm{C}$; Red: heat treated to $550^{\circ} \mathrm{C}$. Changes in XRD diffractograms are used to infer clay species and summarized in Table 11. Subsamples D522-PC62L_21.5, D655PPC79_20.0, and D878$P C 53 \_12.0$ all have nearly identical patterns while D522-PPC1_9.0 (pale green lamination) is notably different. Identified clay minerals are indicated by the following abbreviations: Am: Amphibole; Ch: Chlorite; Cor: Corrensite; P: Plagioclase; Pyx: Pyroxene; Sm: Smectite; Z: Zeolite. 
Table 11. Flow table showing results of clay XRD treatment scans of $<2 \mu \mathrm{m}$ oriented clay subsamples. Numerical value represents major peak $(\AA)$. Arrows show peak changes after treatment. Peak expansion or collapse is represented by crossing arrows. Clay proportions modeled using NEWMOD are shown.

\begin{tabular}{|c|c|c|c|c|c|c|}
\hline Subsample & Untreated & Glycolated & $\begin{array}{l}\text { Heat } \\
\text { Treatment } \\
(400 \mathrm{C})\end{array}$ & $\begin{array}{l}\text { Heat } \\
\text { Treatment } \\
(550 \mathrm{C})\end{array}$ & $\begin{array}{l}\text { Identified } \\
\text { Clays }\end{array}$ & $\begin{array}{l}\text { NEWMOD } \\
\text { Proportions } \\
(\%)\end{array}$ \\
\hline $\begin{array}{l}\text { D522- } \\
\text { PC62L_21.5 }\end{array}$ & $\begin{array}{l}29 \longrightarrow \\
16 \longrightarrow \\
14 \longrightarrow \\
7 \longrightarrow\end{array}$ & $\begin{array}{l}30 \longrightarrow \\
\end{array}$ & $\begin{array}{l}27 \longrightarrow \\
14.4 \longrightarrow \\
10 \longrightarrow \\
7 \longrightarrow\end{array}$ & $\begin{array}{l}29 \longrightarrow \\
14.4 \longrightarrow \\
10 \longrightarrow \\
7 \longrightarrow\end{array}$ & $\begin{array}{l}\text { Corrensite } \\
\text { Chlorite } \\
\text { Saponite/ } \\
\text { Nontronite } \\
\text { Chlorite }\end{array}$ & $\begin{array}{l}\text { Corrensite: } \\
21 \\
\text { Chlorite: } 33 \\
\text { Smectite: } \\
31 / 15 \text { (Tri/Di) }\end{array}$ \\
\hline $\begin{array}{l}\text { D525- } \\
\text { PPC1_9.0 }\end{array}$ & $\begin{array}{l}29 \longrightarrow \\
17 \longrightarrow \\
14 \longrightarrow \\
7 \longrightarrow\end{array}$ & $\begin{array}{l}29 \longrightarrow \\
17 \longrightarrow \\
14.4 \longrightarrow \\
7 \longrightarrow\end{array}$ & $\begin{array}{l}27 \longrightarrow \\
14.4 \longrightarrow \\
10 \longrightarrow \\
7 \longrightarrow\end{array}$ & $\begin{array}{l}29 \longrightarrow \\
14.4 \longrightarrow \\
10 \longrightarrow \\
7 \longrightarrow\end{array}$ & $\begin{array}{l}\text { Corrensite } \\
\text { Chlorite } \\
\text { Saponite/ } \\
\text { Nontronite } \\
\text { Chlorite }\end{array}$ & $\begin{array}{l}\text { Corrensite: } \\
23 \\
\text { Chlorite: } 57 \\
\text { Smectite: } \\
20 / 0 \text { (Tri/Di) }\end{array}$ \\
\hline $\begin{array}{l}\text { D655- } \\
\text { PPC79_20.0 }\end{array}$ & $\begin{array}{l}29 \longrightarrow \\
17 \longrightarrow \\
7 \longrightarrow\end{array}$ & $\begin{array}{l}30 \longrightarrow \\
17 \longrightarrow \\
7 \longrightarrow\end{array}$ & $\begin{array}{l}27 \longrightarrow \\
14.4 \longrightarrow \\
10 \longrightarrow \\
7 \longrightarrow\end{array}$ & $\begin{array}{l}29 \longrightarrow \\
14.4 \longrightarrow \\
10 \longrightarrow \\
7 \longrightarrow\end{array}$ & $\begin{array}{l}\text { Corrensite } \\
\text { Chlorite } \\
\text { Saponite/ } \\
\text { Nontronite } \\
\text { Chlorite }\end{array}$ & \\
\hline $\begin{array}{l}\text { D878- } \\
\text { PC53_12.0 }\end{array}$ & $\begin{array}{l}29 \longrightarrow \\
17 \longrightarrow \\
7 \longrightarrow\end{array}$ & $\begin{array}{l}29- \\
17 \\
7\end{array}$ & $\begin{array}{l}27 \longrightarrow \\
14.4 \longrightarrow \\
10 \longrightarrow \\
7 \longrightarrow\end{array}$ & $\begin{array}{l}27 \longrightarrow \\
14.4 \longrightarrow \\
10 \longrightarrow \\
7 \longrightarrow\end{array}$ & $\begin{array}{l}\text { Corrensite } \\
\text { Chlorite } \\
\text { Saponite/ } \\
\text { Nontronite } \\
\text { Chlorite }\end{array}$ & \\
\hline
\end{tabular}


Discrete smectites are identifiable by the $14 \AA$ untreated peak expanding to $17 \AA$ after glycolation. Heat treatment results in a collapse to about $9.5 \AA$, which is consistent with nontronite. Additionally, the untreated $17 \AA$ peak which is unchanged after glycolation, and collapses to about $9.5 \AA$. Although untreated subsamples containing smectites generally have a 001 peak at $14 \AA$, low-charge $\mathrm{Fe}^{2+}$ coordinated saponite has been described to have a $17 \AA$ peak (Yeniol, 2007). This $17 \AA$ peak is inferred to collapse to $10 \AA$ after heat treatments. Identified smectite clays include nontronite and saponite.

Corrensite, a perfect 50 / 50 interlayering of smectite and chlorite, is identified by a peak located at about $29 \AA$ for untreated scans. After glycolation, this peak remains unchanged, or expands only slightly to about $30 \AA$. Heat treatments at $400{ }^{\circ} \mathrm{C}$ and $550^{\circ} \mathrm{C}$ result in a slight collapse to about $27 \AA$. Although the pattern of expansion to $30 \AA$ and collapse to $27 \AA$ is not a common pattern, it is consistent with corrensite as observed by Beaufort and Meunier, 1994. Additional peaks are attributed to other minerals (e.g. plagioclase, quartz, zeolites, pyroxene, amphibole). The peak near $9.34 \AA$ is dominant in subsample $D 522-$ PPC1 9.0, but much smaller in the other subsamples, and is consistent with the zeolite laumontite. Other differences in peak locations and intensities between subsamples may be explained by different clay mixture proportions.

Identification of discrete chlorite is based on two peak evaluations. Untreated scans show peaks near $14 \AA$ and $7 \AA$, which remain unchanged throughout the treatment process. Peak intensity does vary during heat treatments, which is 
consistent with $\mathrm{Fe}^{2+}$-bearing chlorite which tends to give a weaker $14 \AA$ peak (Brindley, 1952).

XRD scans of $<2 \mu \mathrm{m}$ powdered size fraction to evaluate the 060 reflection indicates dominance of tri-octahedral clays as evident by the peak near $1.536 \AA$ (Fig. 26). The minor peak near $1.490 \AA$ may indicate small proportions of dioctahedral clays. Based on the 060 results and the series of chemical and heat treatments, major identified clays include trioctahedral smectite $\left(\mathrm{Mg}\right.$ and $\mathrm{Fe}^{2+}-$ coordinated saponite), corrensite (interlayered 50 / 50 mix of chlorite / smectite), and chlorite with minor proportions of dioctahedral smectite $\left(\mathrm{Fe}^{3+}\right.$-coordinated nontronite).

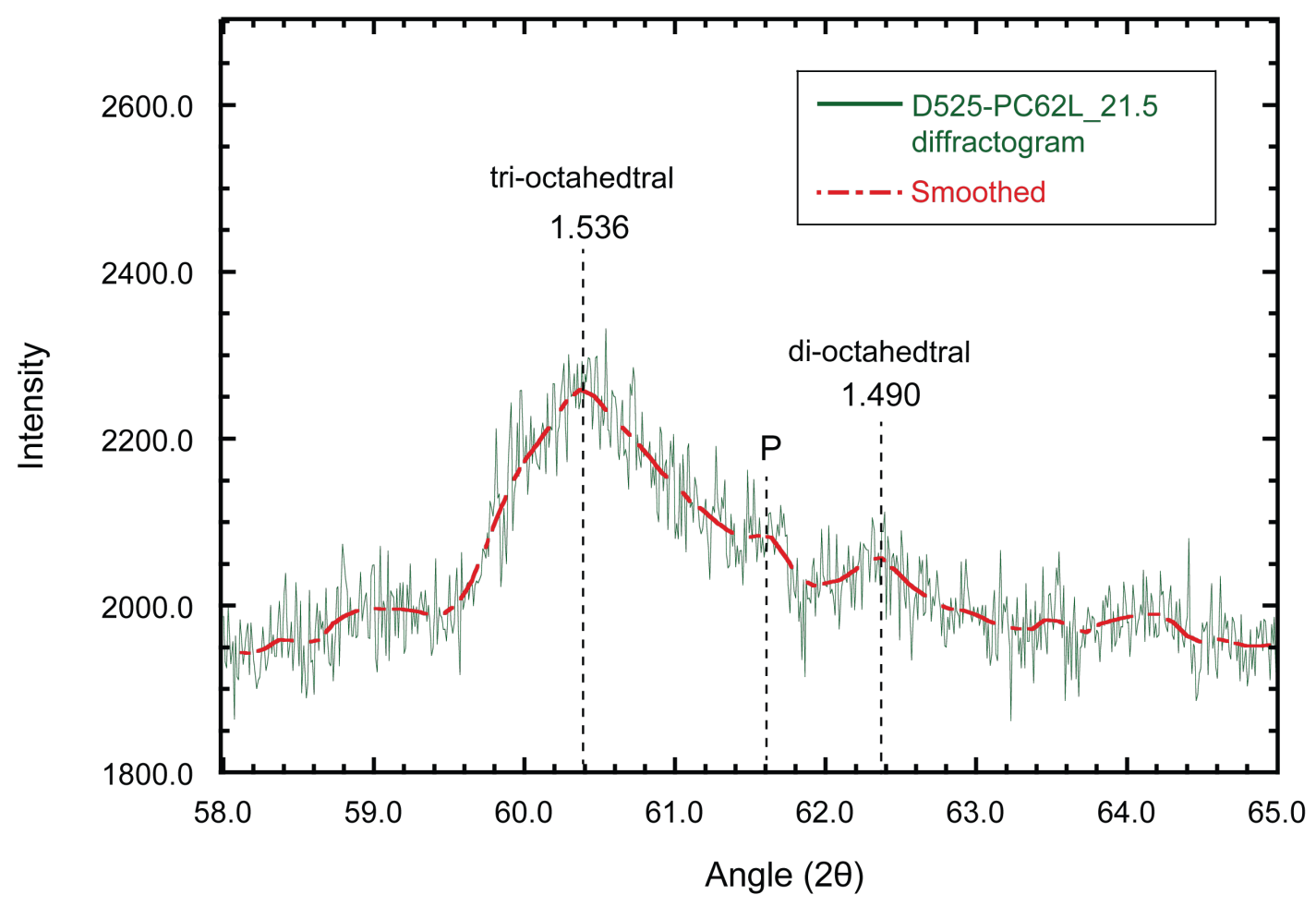

Figure 26. XRD diffractogram for randomly oriented $<2 \mu \mathrm{m}$ size fraction clay to determine the 060 peak location. Dominant peak at $1.536 \AA$ indicates trioctahedral clay species whereas slight peak at $1.490 \AA$ suggests the presence of some di-octahedral clays. Minor peak indicated by " $\mathrm{P}$ " is plagioclase. 


\section{Clay XRD Modeling}

Clay modeling software, NEWMOD, was used to model mixture percentages of the three major clay components (smectite, corrensite, and chlorite) based on glycolated XRD scans. Subsamples D522-PC62L 21.5, D655-PC79 21.0, and D878-PC53 12.0 were nearly identical, therefore only subsamples $D 522-P C 62 L$ 21.5 and D522-PPC1 9.0 were modeled. Results are summarized in Table 11.

Models of glycolated XRD scans (Fig. 27) reveal that chlorite is the major component in both subsamples making up 33\% in subsample D522-PC62L 21.0 and $57 \%$ in subsample D522-PPC1 9.0. Tri-octahedral smectite makes up roughly $31 \%$ of subsample D522-PC62L 21.0 , and about $20 \%$ in D522-PPC1 9.0. Subsample D522-PC62L 21.0 also contains $15 \%$ of di-octahedral smectite. Proportions of corrensite are $21 \%$ and $23 \%$ in subsamples D522-PC62L 21.0 and D522-PPC1 9.0, respectively.

Subsample D522-PC62L_21.5 has relatively larger proportions of smectite and chlorite, and lesser amounts of corrensite. Conversely, chlorite is the major clay mineral component in D522-PPC1_9.0 and contains less smectite and corrensite proportions. These subsamples differ in that $D 522-P C 62 L 21.0$ has overall higher proportions of smectite with both di- and tri-octahedral components present whereas D522-PPC1 9.0 has overall smaller proportions of smectite and the di-octahedral component is absent. 

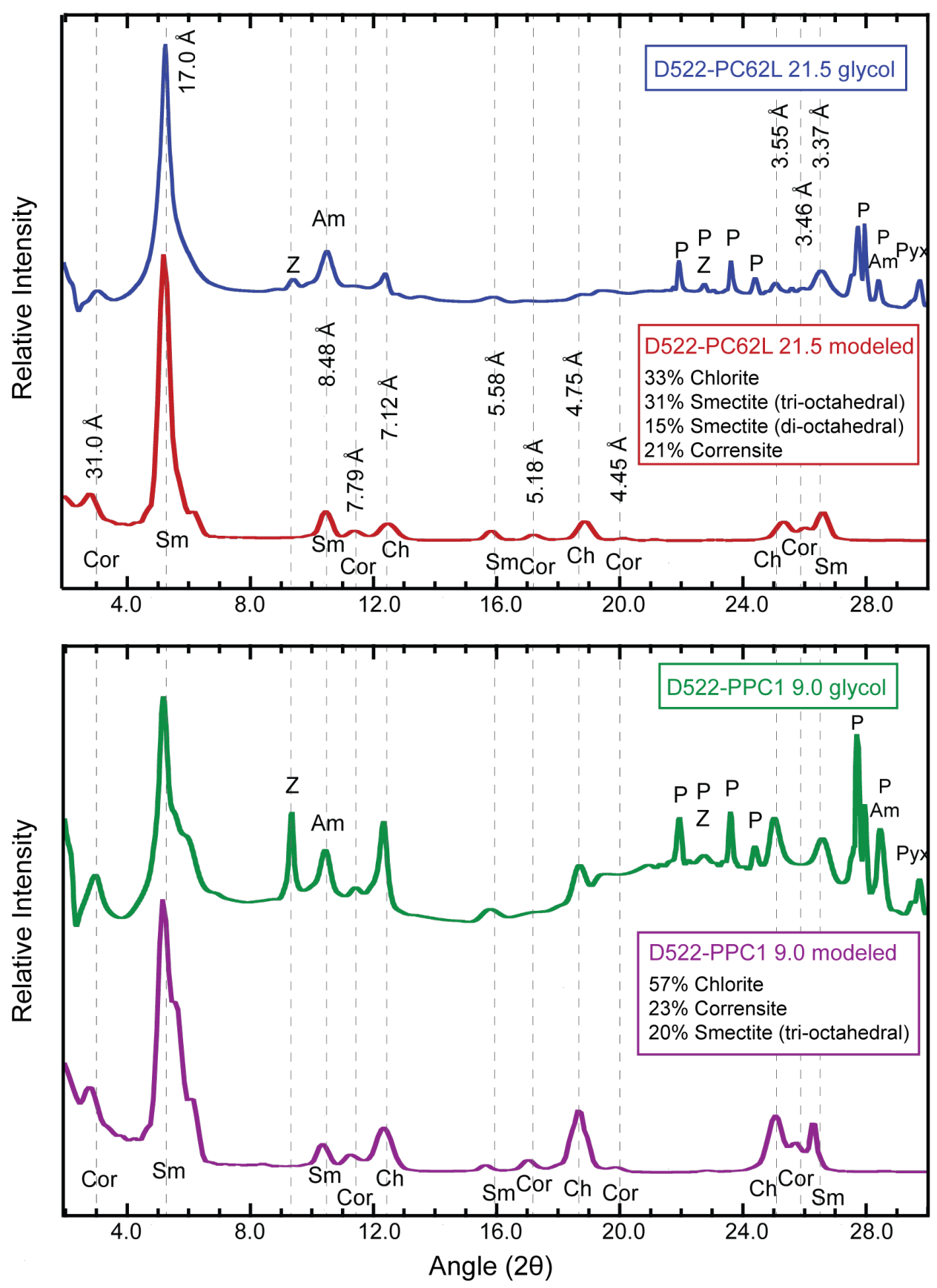

Figure 27. Glycolated clay $<2 \mu \mathrm{m}$ oriented subsample XRD diffractograms accompanied with the modeled diffractogram using NEWMOD for subsample D522-PC62L_21.5 (Top) and D522-PPC1_9.0 (Bottom). Peaks missing from the model are due to non-clay minerals (e.g. zeolites). Model mixture percentages are presented with the respective modeled subsample. Identified minerals are indicated by the following abbreviations: Ch: Chlorite; Cor: Corrensite; Sm: Smectite; Am: Amphibole; P: Plagioclase; Pyx: Pyroxene; Z: Zeolite. Bold indicates clay species. 


\section{SEM-EDX (Chemistry)}

Major element geochemistry was evaluated using SEM-EDX from: partially altered vitriclasts (Fig. 28A-1 - 3), vitric agglutinates (Fig. 28B-1), green hydrothermal aggregates (Fig. 28B-2), yellow hydrothermal aggregates (Fig. 28B-3), green particles (Fig. R28C-1), red particles (Fig. 28C-2), fibrous particles (Fig. 28C-3), and white particles (Fig. 28D-1 - 3). Results are described below and summarized in Table 12.

Partially altered vitriclasts tend to contain areas of progressive alteration (Fig. 29). Smooth surfaces are consistent with basaltic glass. Areas of glass that have incipient alteration contain a pitted appearance under SEM, whereas areas of the grain that are encrusted with a white alteration product appear spongy. The alteration substance encrusting fresh basalt glass is consistent with palagonite or smectite based on SEM morphology, EDX spectra, and XRD diffractograms. Vitric agglutinate EDX chemistry are consistent with basalt glass standards indicating that these particle surfaces are sideromelane (Fig. 30). Chemistry is consistent regardless of whether EDX is retrieved from "sub-spherical" or smooth glass areas.

Green hydrothermal aggregates are dominated by clay $\left(\mathrm{Fe}^{2+}\right.$-bearing chlorite or saponite) and often contain small $(<20 \mu \mathrm{m})$ crystals of pyrite (Fig. 31A). Yellow hydrothermal aggregates also include small pyrite crystals but are dominated by nontronite clay and also tend to contain ilmenite $\left(\mathrm{FeTiO}_{3}\right)$, and iron-oxide (goethite?; $\mathrm{FeO}(\mathrm{OH})$ ) crystals (Fig. 31B). Green particles have a mixture of 

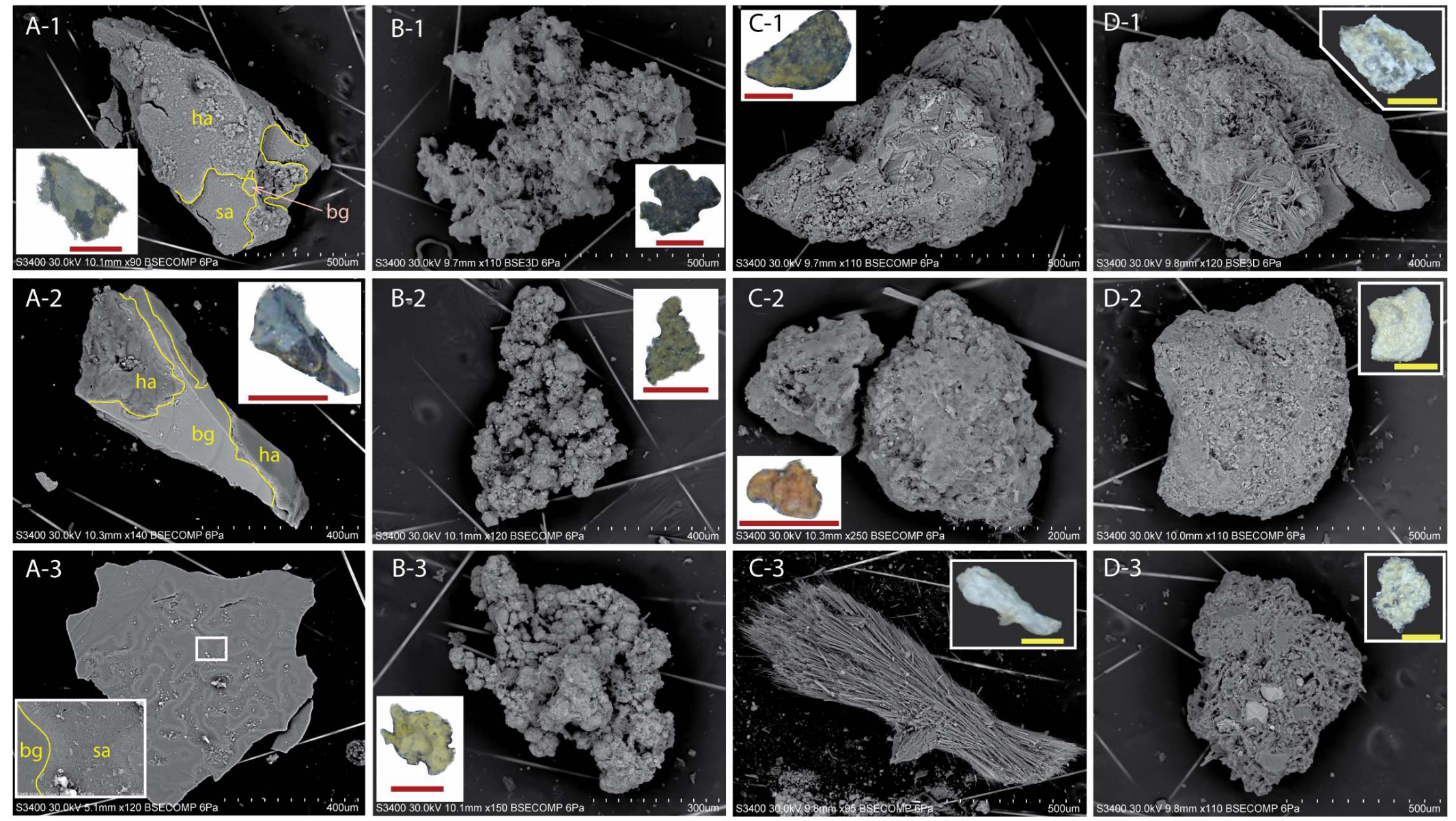

Figure 28. SEM images of representative non-primary $(A ; C ; D)$ and authigenic hydrothermal mineral components (B) in HMT. Insets show plane light image of the grain using a binocular microscope. Scale lines are $500 \mu \mathrm{m})$. (A-1 - A-3) selected altered vitriclasts. Yellow lines show contact between various stages of alteration [fresh basalt glass (bg), slightly altered (sa), and highly altered vitriclast encrusted with clays (ha)]. (B-1) vitric-agglutinate particle. (B-2) Green hydrothermal clay aggregate. (B-3) Yellow hydrothermal clay aggregate. (C-1) Green particle. (C-2) Red particle. (C-3) White fibrous particle. (D-1 - D-3) Various "white particles". 
Table 12. Summary of minerals identified on grains of interest using EDX.

\begin{tabular}{|c|c|c|c|c|c|}
\hline $\begin{array}{l}\text { Particle } \\
\text { Type }\end{array}$ & $\begin{array}{l}\text { EDX Spectra } \\
\text { Reference }\end{array}$ & Overall Color & Morphology & Primary Constituent & Accessory Minerals \\
\hline Agglutinate & Fig. 30 & Black/dark color & Sub-spherical aggregates & sideromelane & None \\
\hline $\begin{array}{l}\text { Altered } \\
\text { Vitriclasts }\end{array}$ & Fig. 29 & $\begin{array}{l}\text { Variable (white, } \\
\text { orange, brown) }\end{array}$ & $\begin{array}{l}\text { Variable (smoothed, pitted, } \\
\text { spongey, vermicular/ } \\
\text { grooved) }\end{array}$ & $\begin{array}{l}\text { Basaltic glass, palagonite, } \\
\text { smectite }\end{array}$ & None \\
\hline $\begin{array}{l}\text { Green } \\
\text { Aggregates }\end{array}$ & Fig. 31A & Pale/bright green & Sub-spherical aggregates & $\begin{array}{l}\text { Smectite: } \\
\text { saponite }\left(\mathrm{Fe}^{2+}\right)\end{array}$ & Pyrite \\
\hline $\begin{array}{l}\text { Yellow } \\
\text { Aggregates }\end{array}$ & Fig. 31B & Pale yellow & Sub-spherical aggregates & $\begin{array}{l}\text { Smectite: } \\
\text { nontronite/saponite }\left(\mathrm{Fe}^{3+}\right)\end{array}$ & $\begin{array}{l}\text { Fe-Oxides (goethite?); TiO } \\
\text { (ilmenite) }\end{array}$ \\
\hline Red particles & Fig. 33 & Red & Variable & Iddingsite & $\begin{array}{l}\text { Smectitic Clays (nontronite); } \\
\text { Fe-oxides } \\
\text { (goethite/hematite); } \\
\text { ilmenite/titanomagnetite }\end{array}$ \\
\hline $\begin{array}{l}\text { Green } \\
\text { Particles }\end{array}$ & Fig. 32 & Dark green/black & $\begin{array}{l}\text { Variable (euhedral faces, sub- } \\
\text { spherical aggregates, and } \\
\text { encrusting coatings) }\end{array}$ & Pyroxene & Smectitic clays (saponite) \\
\hline $\begin{array}{l}\text { Fibrous } \\
\text { Particles }\end{array}$ & Fig. 34 & $\begin{array}{l}\text { White or pale } \\
\text { yellow/green }\end{array}$ & Fibrous (prismatic) & Actinolite/tremolite & None \\
\hline $\begin{array}{l}\text { White } \\
\text { Particles }\end{array}$ & $\begin{array}{l}\text { Figs. } 35,36 \\
\text { and } 37\end{array}$ & $\begin{array}{l}\text { Pure white or off- } \\
\text { white/beige }\end{array}$ & $\begin{array}{l}\text { Variable (euhedral crystals, } \\
\text { prismatic fibers, curvaceous } \\
\text { fibers, platy, smooth, blocky) }\end{array}$ & Phyric/plagioclase & $\begin{array}{l}\text { Fe-Oxides } \\
\text { (goethite/hematite); } \\
\text { zeolites (heulandite, } \\
\text { laumontite); pyrite; barite; } \\
\text { ilmenite/ titanomagnetite }\end{array}$ \\
\hline
\end{tabular}



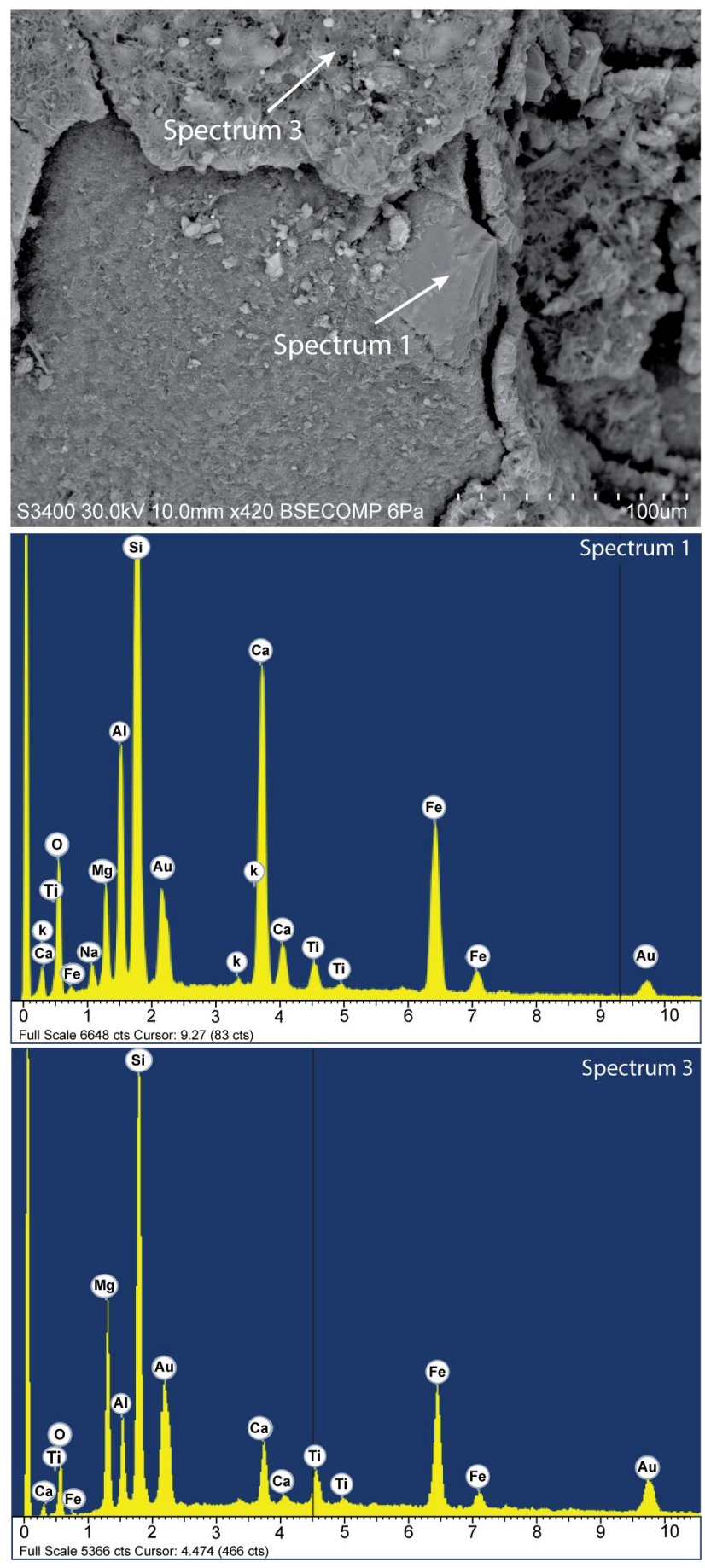

Figure 29. EDX spectra of altered glass. Spectrum 1 shows high Si, Al, Ca and moderate $\mathrm{Fe}, \mathrm{Mg}$, consistent with basalt glass standards. Spectrum 3 has lower abundances of $\mathrm{Ca}, \mathrm{Al}$ with increased $\mathrm{Mg}$ which, in conjunction with the "spongey" texture, is consistent with clay. Presence of Ti likely indicates presence of titanium oxide minerals (bright white spots) near spectrum 3. Presence of $A u$ is from gold coating used under the SEM to reduce electron charging. 


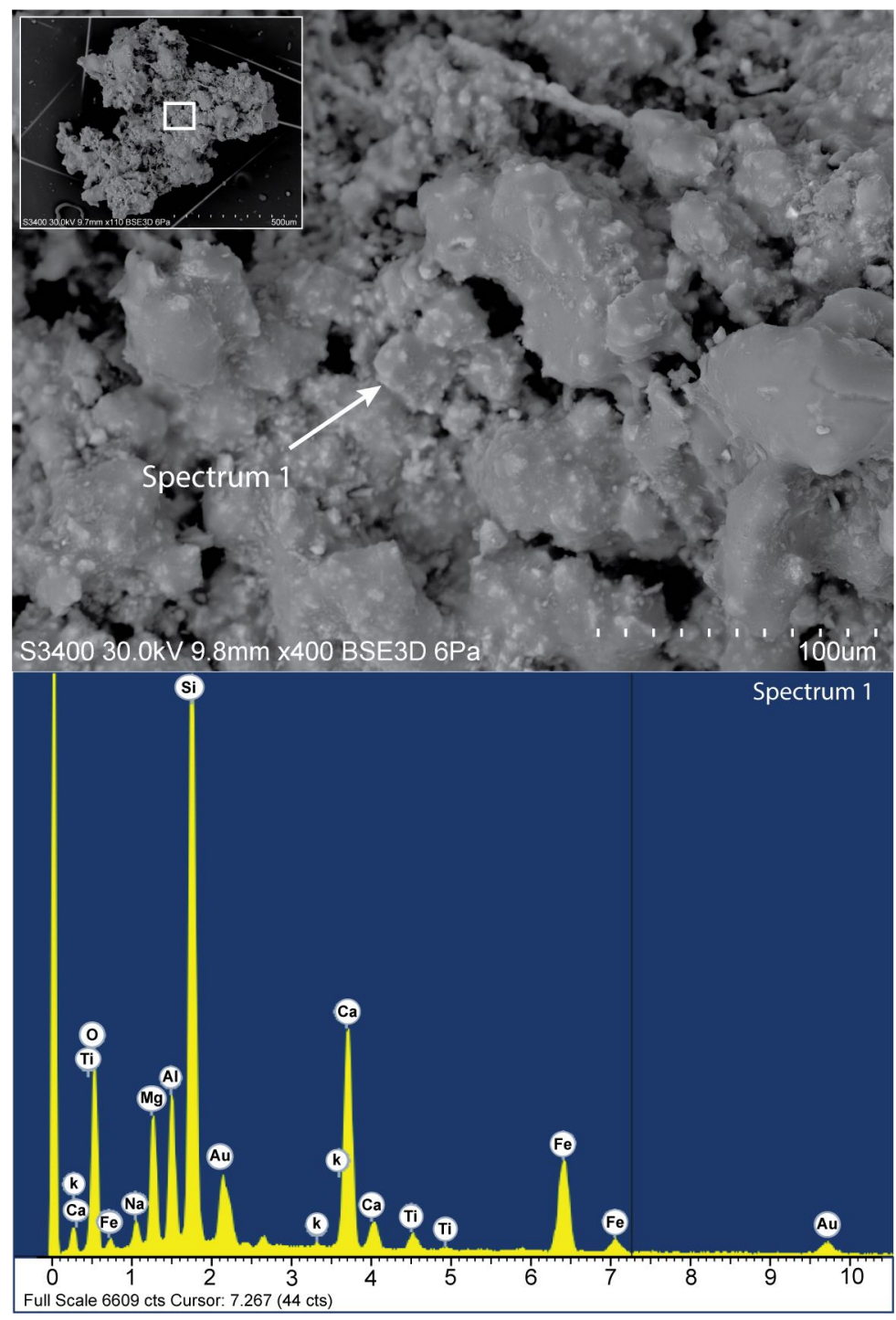

Figure 30. EDX spectra of agglutinate particle. Spectrum 1 shows high Si with moderate proportions of $\mathrm{Ca}, \mathrm{O}, \mathrm{Al}, \mathrm{Mg}$ and $\mathrm{Fe}$, all of which are consistent with basalt glass (see Fig. 6). Presence of Au is from gold coating used under the SEM to reduce electron charging. 

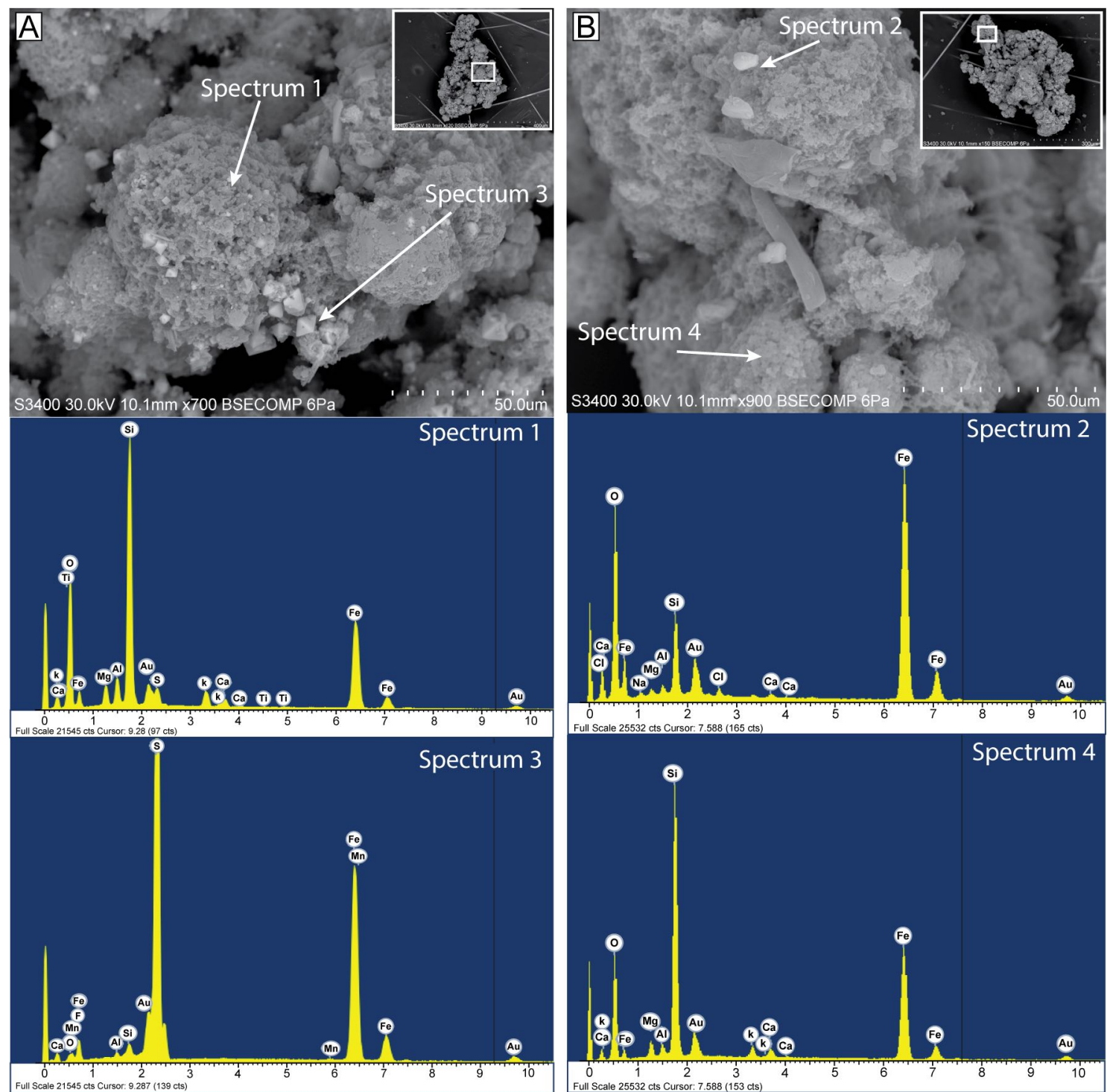

Figure 31. EDX spectra of hydrothermal clay aggregates. (A) green clay aggregate. Spectrum 1 shows dominant peaks of $S$ and $\mathrm{Fe}$ and relatively low abundances of other elements. High $S$ and $F e$ and the euhedral mineral faces are consistent with pyrite $\left(\mathrm{FeS}_{2}\right)$. Spectrum $\mathbf{3}$ shows spectra of the "sponge" textured material and shows high abundance of $\mathrm{Si}, \mathrm{O}$, and Fe consistent with clay. (B) Yellow clay aggregate. Spectrum 2 (bright white spots) is consistent with $\mathrm{Fe}$-oxide minerals (goethite?). Spectrum $\mathbf{4}$ is rich in $\mathrm{Si}$ and Fe has a claylike appearance, consistent with nontronite. Presence of $A u$ is from gold coating used under the SEM to reduce electron charging. 
euhedral crystal faces and clay textures and have chemistry consistent with pyroxenes (augite) at various stages of chemical alteration to clays (chlorite?; Fig. 32). Red particles are likely iddingsite, an alteration product of olivine at various stages of alteration (Smith et al., 1987), and may be coated in $\mathrm{Fe}^{3+}$ clays (nontronite) and include small crystals of iron oxide (hematite?; $\mathrm{Fe}_{2} \mathrm{O}_{3}$ ) and ilmenite and / or titanomagnetite $\left[\mathrm{Fe}^{2+}\left(\mathrm{Fe}^{3+}, \mathrm{Ti}_{2} \mathrm{O}_{4}\right.\right.$; Fig. 33].

Fibrous particles are split into two categories by color; white and pale-yellow / light green fibrous particles have similar EDX spectra showing roughly equal proportions of $\mathrm{Ca}, \mathrm{Mg}$, and Fe (Fig. 34; 06_41). Both types of fibrous minerals have continuous prismatic fibers as evident in SEM images. Based on chemistry, color and prismatic fibrous morphology indicate that these white and green minerals are tremolite and actinolite, respectfully (Fig. 34; 06_29 and 06_11-L4).

White particles are often polymineralic (Fig. 35 and 36) and are generally pure-white or pale white / beige in color, sometimes with areas of pale yellow / green, and often contain very small $(<20 \mu \mathrm{m})$ darker crystals within them. Based on EDX spectra and morphologies observed in SEM images, these components are euhedral plagioclase (albite) crystals and chlorite, respectively. Regions on white particles that contain areas of small $(<5 \mu \mathrm{m})$ white monomineralic crystals with a blocky morphology are consistent with the zeolite laumontite $\left[\mathrm{Ca}\left(\mathrm{AlSi}_{2} \mathrm{O}_{6}\right)_{2}{ }^{\bullet}\right.$ $4 \mathrm{H}_{2} \mathrm{O}$; Fig. 36]. Other white monomineralic $\sim 10 \mu \mathrm{m}$ crystals with a tabular / "coffin shaped" habit are consistent with heulandite $\left[(\mathrm{Ca}, \mathrm{Na})_{2-3} \mathrm{Al}{ }_{3}(\mathrm{Al}, \mathrm{Si})_{2} \mathrm{Si}_{13} \mathrm{O}_{36} \cdot 12 \mathrm{H}_{2} \mathrm{O}\right.$;

Fig. 37]. One grain also has a spectra consistent with barite [(BaSO 4$)$; Fig. 35]. 


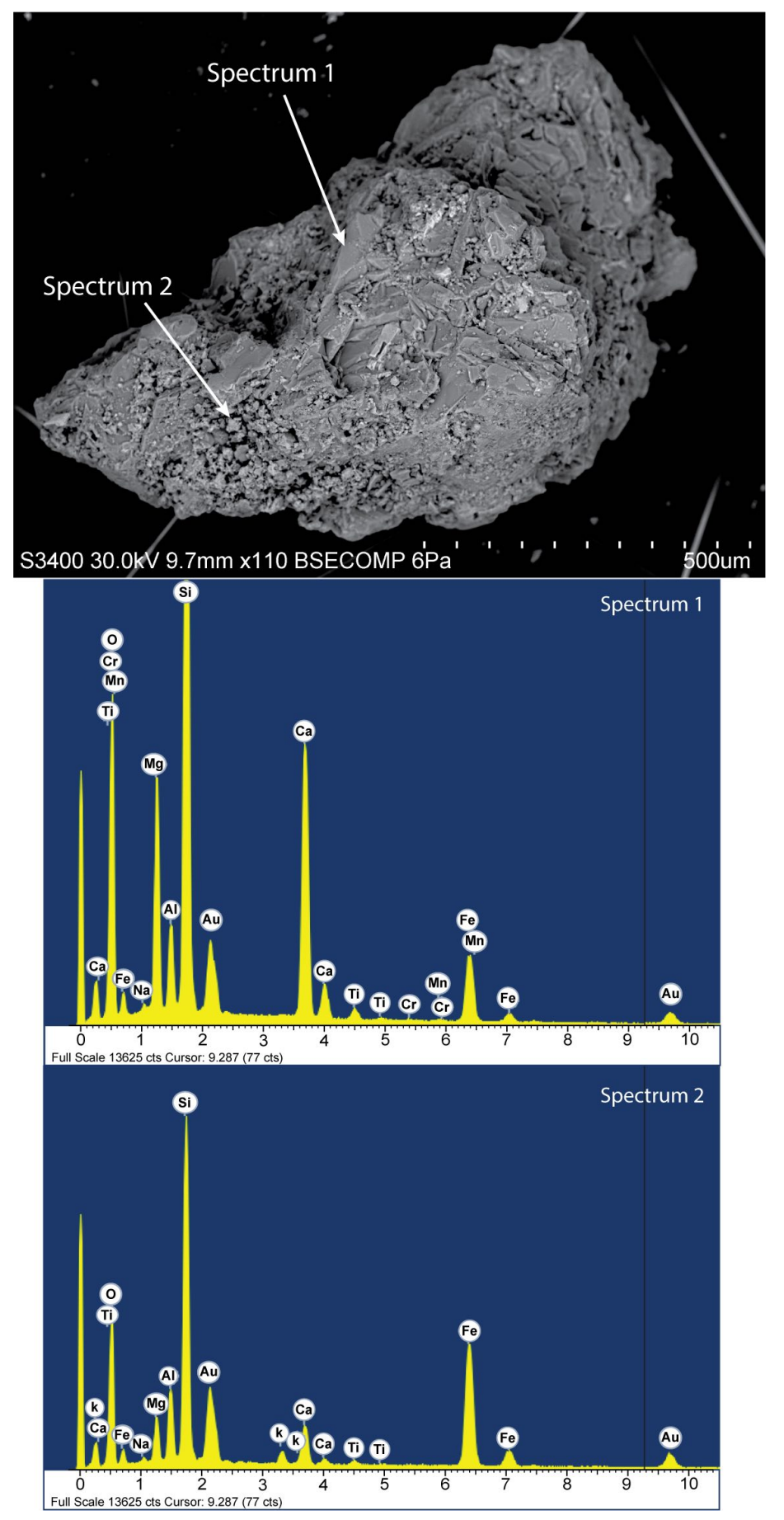

Figure 32. EDX spectra of a green particle. Spectrum 1 was measured on a euhedral crystal face and has spectra consistent with pyroxene, showing high $\mathrm{Si}$, $\mathrm{Ca}$, and $\mathrm{Mg}$. Spectrum 2 was measured from an area on the particle with a green encrusting clay, and aggregate-like texture, and has spectra consistent with clay (high $\mathrm{Si}$, moderate $\mathrm{Fe}, \mathrm{Al}$, and $\mathrm{Mg}$. Presence of $\mathrm{Au}$ is from gold coating used under the SEM to reduce electron charging. 


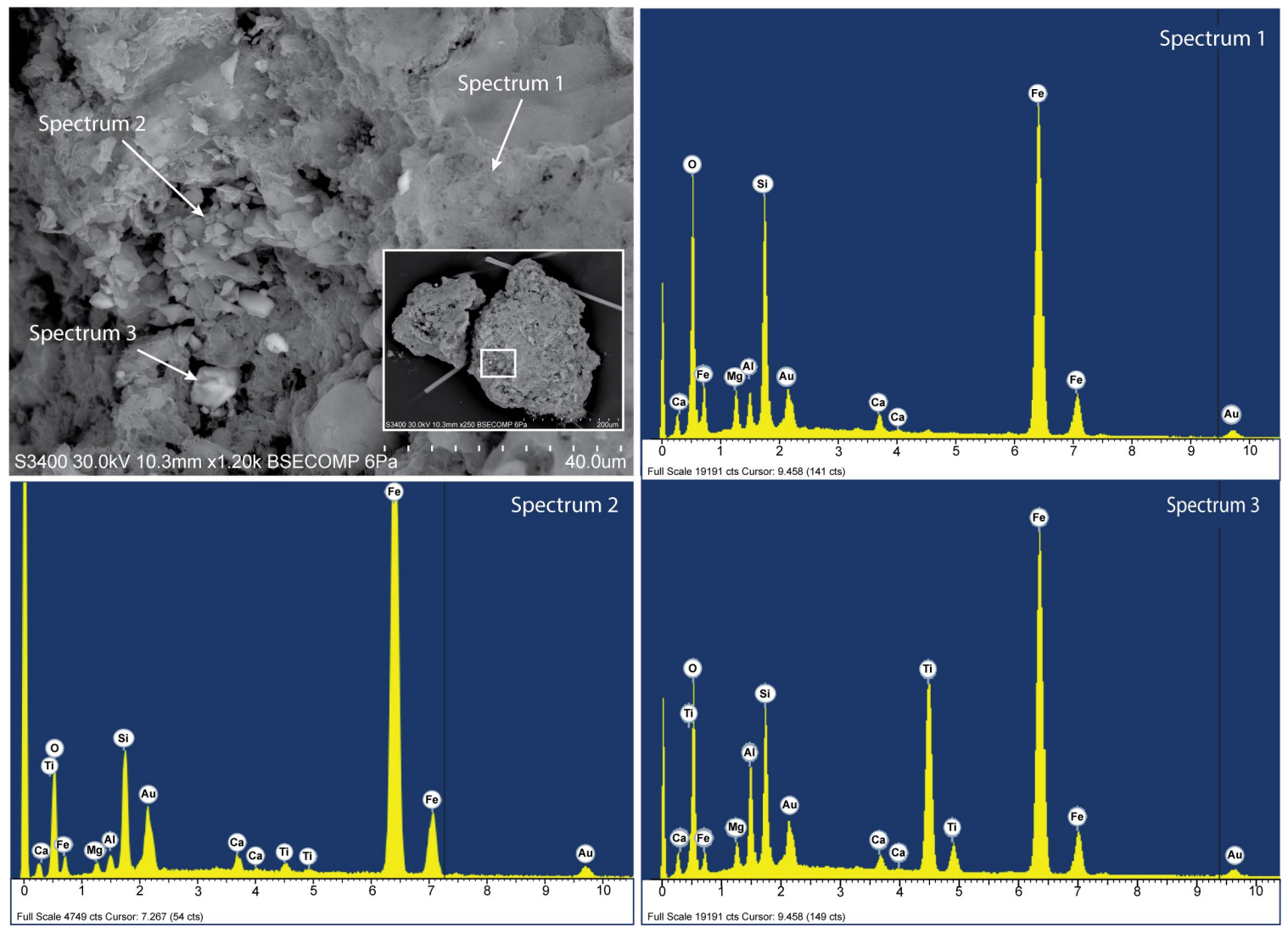

Figure 33. EDX spectra of a red particle. Spectrum 1 was measured on a location with a "spongey" like texture and has dominant $\mathrm{Fe}$, and $\mathrm{Si}$, peaks which are consistent with consistent with dioctahedral (Fe ${ }^{3+}$-rich) nontronite. Spectrum 2. Was measured on a sub-euhedral grain and has a very strong Fe signature and roughly equal parts $\mathrm{Si}$ and $\mathrm{O}$. The strong Fe may be indicative of a Fe-O (hematite?) with Si coming from surrounding clay. Spectrum 3 was measured on a bright white grain with sub-euhedral crystal faces and has a strong $\mathrm{Fe}$ and moderate $\mathrm{Ti}$, and $\mathrm{Si}$ peaks. The presence of $\mathrm{Fe}$, and $\mathrm{Ti}$ is consistent with titanomagnetite. Presence of $\mathrm{Au}$ is from gold coating used under the SEM to reduce electron charging. 

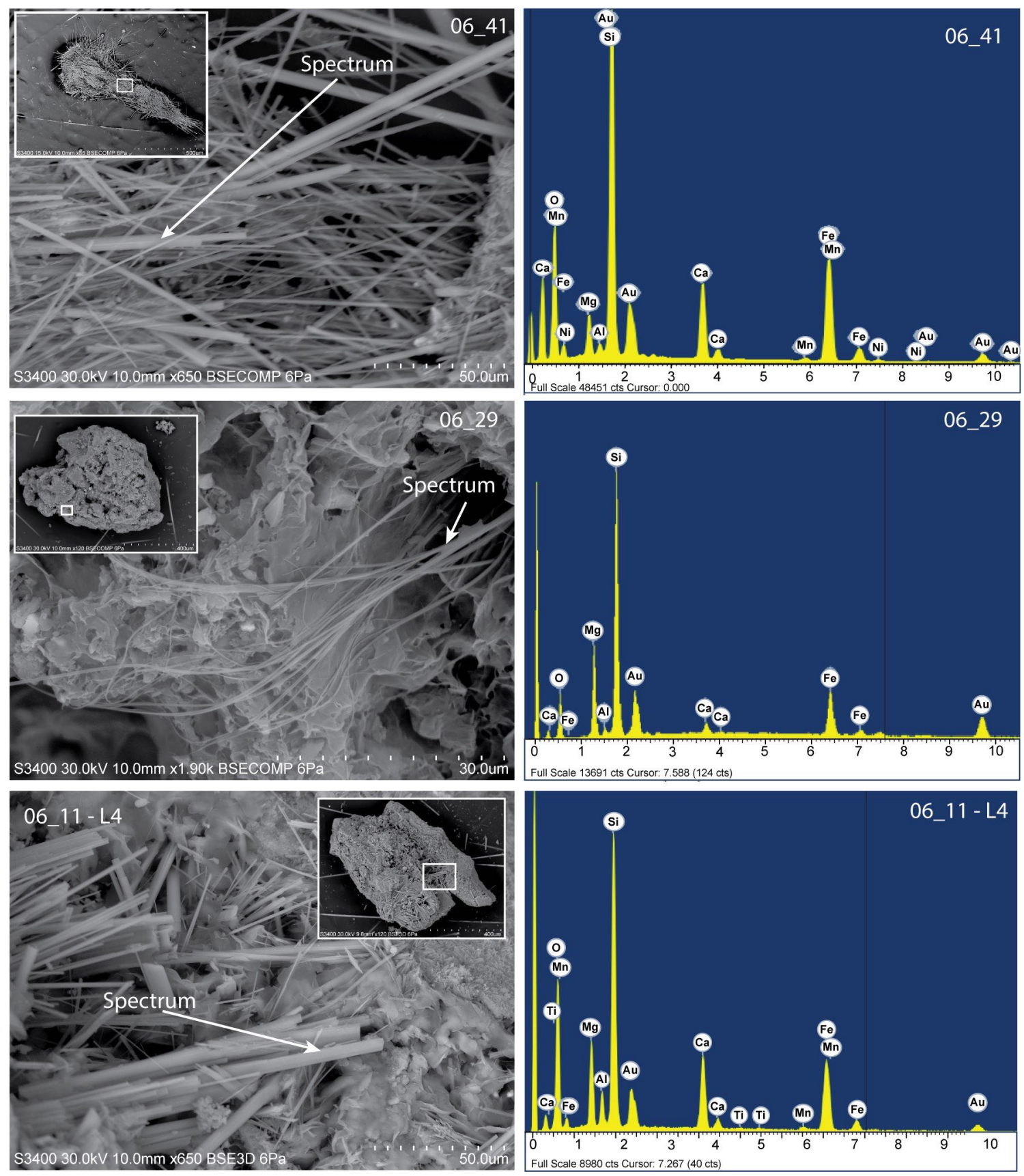

Figure 34. EDX spectra of fibrous morphologies which consist of white prismatic fibrous minerals (06_41), slightly curved "fiber bundles" (06_29), and off white/green prismatic fibers (06_11_L4). Spectra consist of high Si with moderate $\mathrm{Fe}, \mathrm{Ca}$, and $\mathrm{Mg}$. Fiber diameter is $>5 \mu \mathrm{m}$. Spectra and fibrous morphologies are consistent with amphibole (actinolite/tremolite). Presence of $\mathrm{Au}$ is from gold coating used under the SEM to reduce electron charging. 

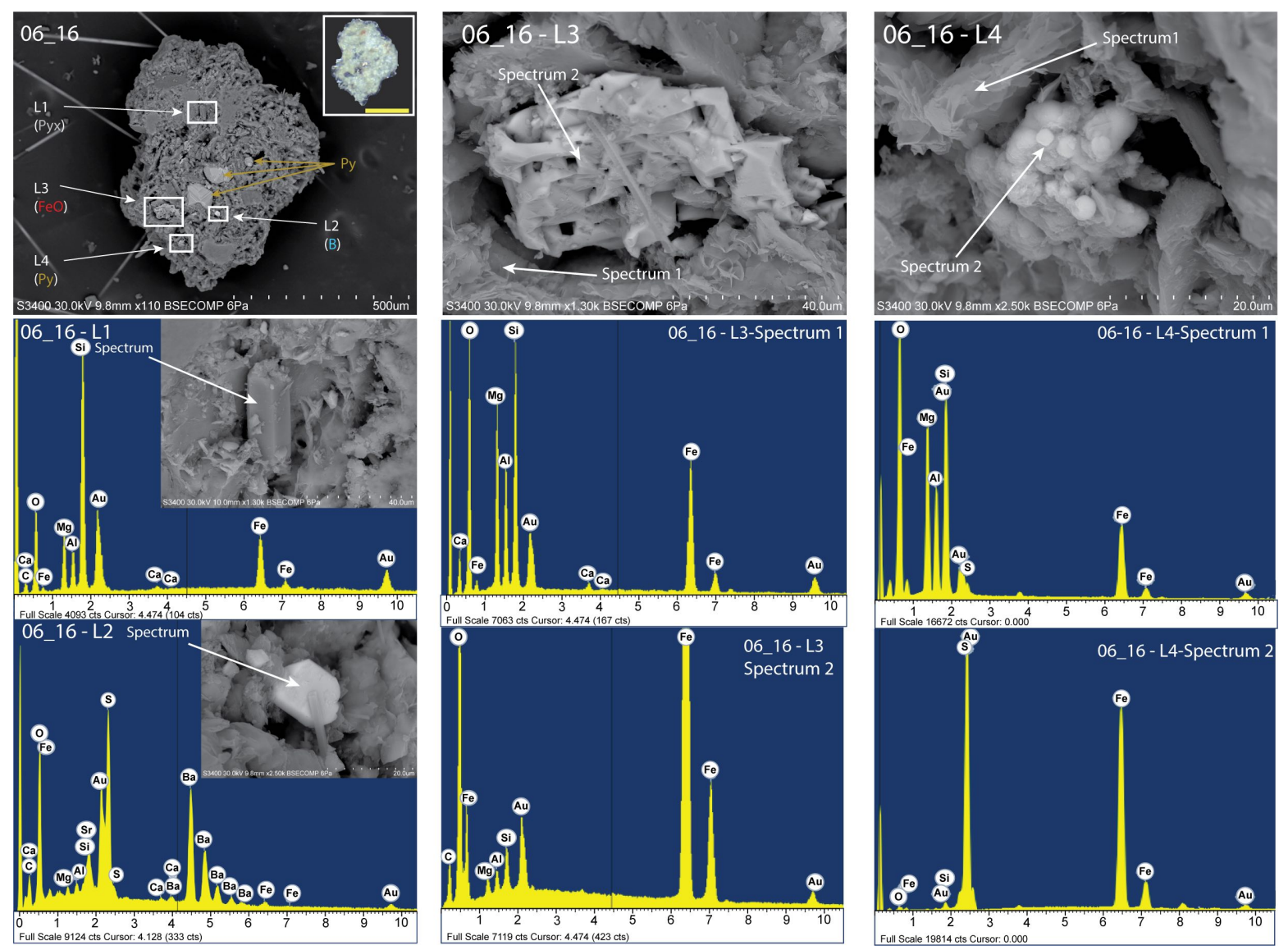

Figure 35. White particle 06_16 with 4 different locations of interest (L1-L4) with identified minerals at each location (Pyx: Pyroxene; B: Barite; FeO: Fe-oxide; Py: Pyrite). (L1) has spectra and morphology consistent with pyroxene. (L2) has strong $\mathrm{S}, \mathrm{O}$ and $\mathrm{Ba}$ signatures consistent with barite $\left(\mathrm{BaSO}_{4}\right)$. (L3) spectrum 1 has high $\mathrm{Si}$, $\mathrm{Mg}$, and $\mathrm{Fe}$ consistent with clay. Spectrum 2 has high $\mathrm{Fe}$ and $\mathrm{O}$ signatures consistent with $\mathrm{Fe}$-oxide mineral goethite? (L4) spectrum 1 has spectra consistent with clay (high $\mathrm{Mg}, \mathrm{Si}, \mathrm{O}$ and $\mathrm{Fe}$ ) while spectrum 2 has abundant $\mathrm{Fe}$ and $\mathrm{S}$ consistent with pyrite. Botryoidal crystal shape consistent with framboidal pyrite. Presence of $\mathrm{Au}$ is from gold coating used under the SEM to reduce electron charging. 


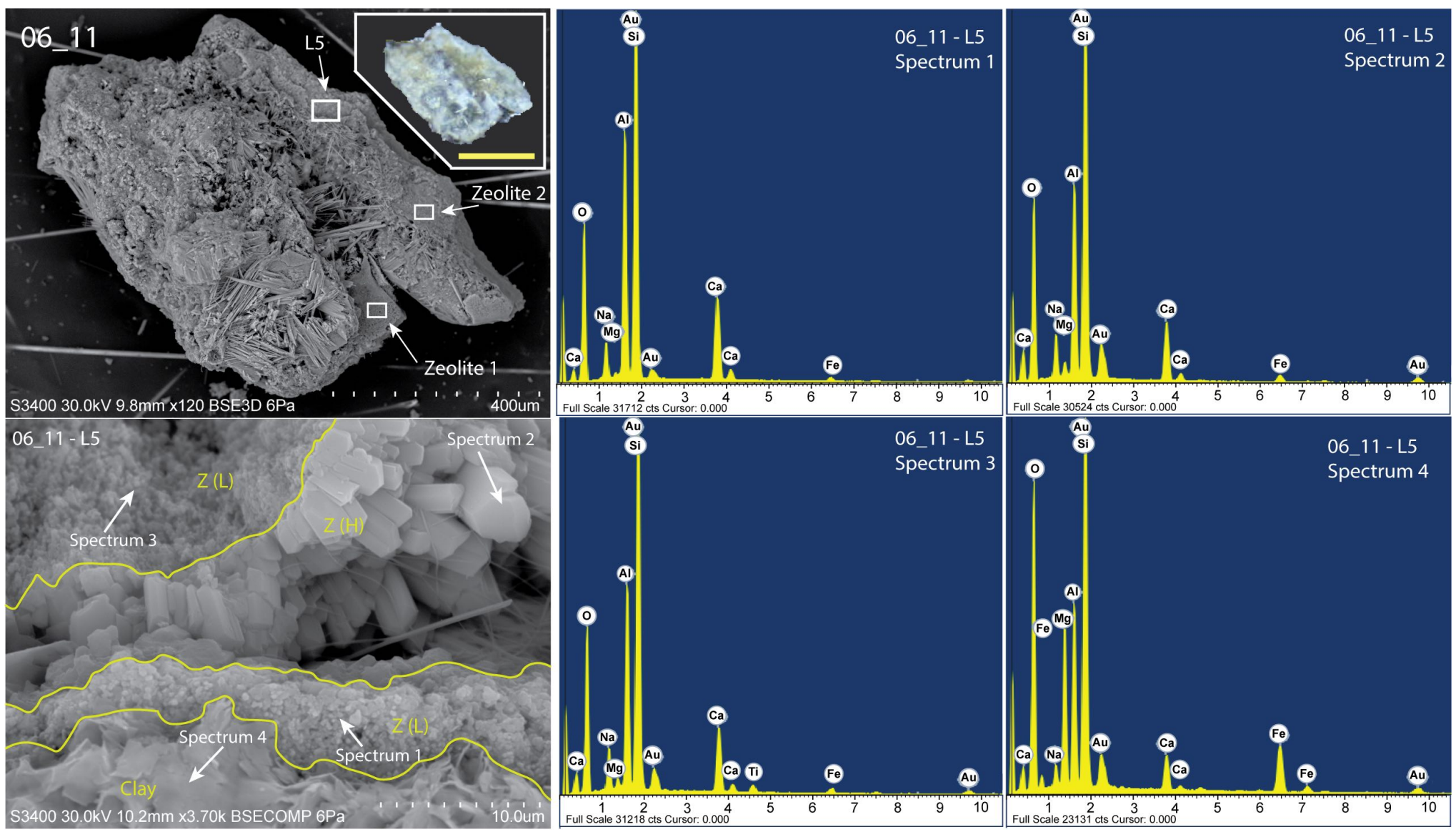

Figure 36. EDX of white particle 06_11-L5. Spectrum 1 and spectrum 3 show high Si and Al and moderate Ca and the morphology is consistent with the zeolite laumontite $[Z(L)]$. Spectrum 2 was measured on tabular/"coffinshaped" crystals of $\sim 10 \mu \mathrm{m}$ and have spectra showing high Si and Al and moderate $\mathrm{Ca}$, consistent with the zeolite heulandite $[\mathrm{Z}(\mathrm{H})]$. Spectrum 4 was measured in a platy material which is high in $\mathrm{Si}, \mathrm{Al}$, Mg. The morphology and high levels of $\mathrm{Mg}$ are consistent with clay. Zeolites 1 and 2 are shown in Figure 37. Presence of Au is from gold coating used under the SEM to reduce electron charging. 


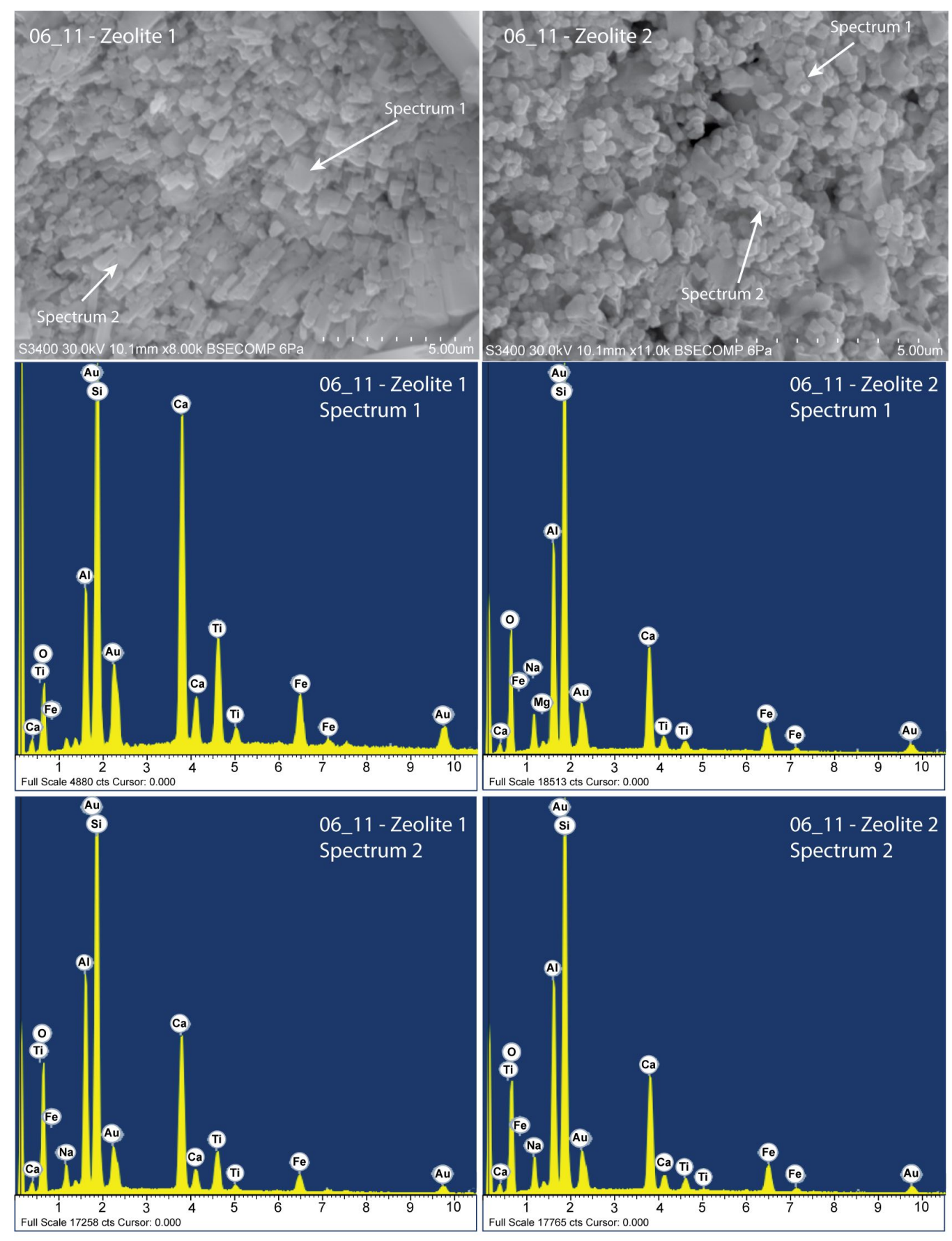

Figure 37. EDX spectra of small $(<10 \mu \mathrm{m})$ euhedral zeolite crystals on particle $06 \_11$ Locations of zeolite 1 and zeolite 2 are shown in Fig. 36. Zeolite 1 shows strong Si, Al and $\mathrm{Ca}$ with moderate amounts of $\mathrm{Fe}$ and Ti. Zeolite 2 also contains strong $\mathrm{Si}, \mathrm{O}$, and $\mathrm{Ca}$ but contains some $\mathrm{Na}$. Blocky morphologies and spectra of both zeolite $1 \& 2$ are consistent with the zeolite laumontite [ $\mathrm{Ca}\left(\mathrm{AlSi}_{2} \mathrm{O}_{6}\right)_{2} \bullet 4 \mathrm{H}_{2} \mathrm{O}$ ]. Presence of $\mathrm{Au}$ is from gold coating used under the SEM to reduce electron charging. 
Dark crystals with a yellow metallic luster have chemistry consistent with pyrite $\left(\mathrm{FeS}_{2}\right)$ whereas dark crystals with a black / dark brown metallic luster are consistent with ilmenite and / or titanomagnetite. Dark brown crystals with an earthy luster have spectra and crystal morphology consistent with goethite $(\mathrm{FeO}(\mathrm{OH}))$ and hematite.

\section{Morphometry}

\section{SEM Observations}

A SEM was used to observe surface features of fluidal and angular / blocky vitriclasts within HMT (Fig. 38). Fluidal shards have smooth faces and may be further subdivided based on morphology to include limu o' Pele (Fig. 38A-1 - 3), tubular (Fig. 38A-4), taffy (Fig. 38A-5), and Pele's hairs (Fig. 38A-6). Lim o' Pele dominate the fluidal shard population and characteristically have a thin, platy morphology, often flat but sometimes folded over. Faces of limu o' Pele sometimes contain microlites or enclosed bubbles protruding from the surface. Tubular vesicular vitriclasts have smooth surfaces but are vesicular on end margins resembling a tube. "Taffy-like" vitriclasts have a stretched-like "taffy" appearance. Pele's hairs are thin $(<100 \mu \mathrm{m}$-diameter $)$ and elongate, with smooth cylindrical margins resembling a hair. "Agglutinate" particles morphologically resemble clay aggregates typical of the hydrothermal environment, but are entirely coated in a thin, smooth basaltic glass as evident by EDX spectra. 

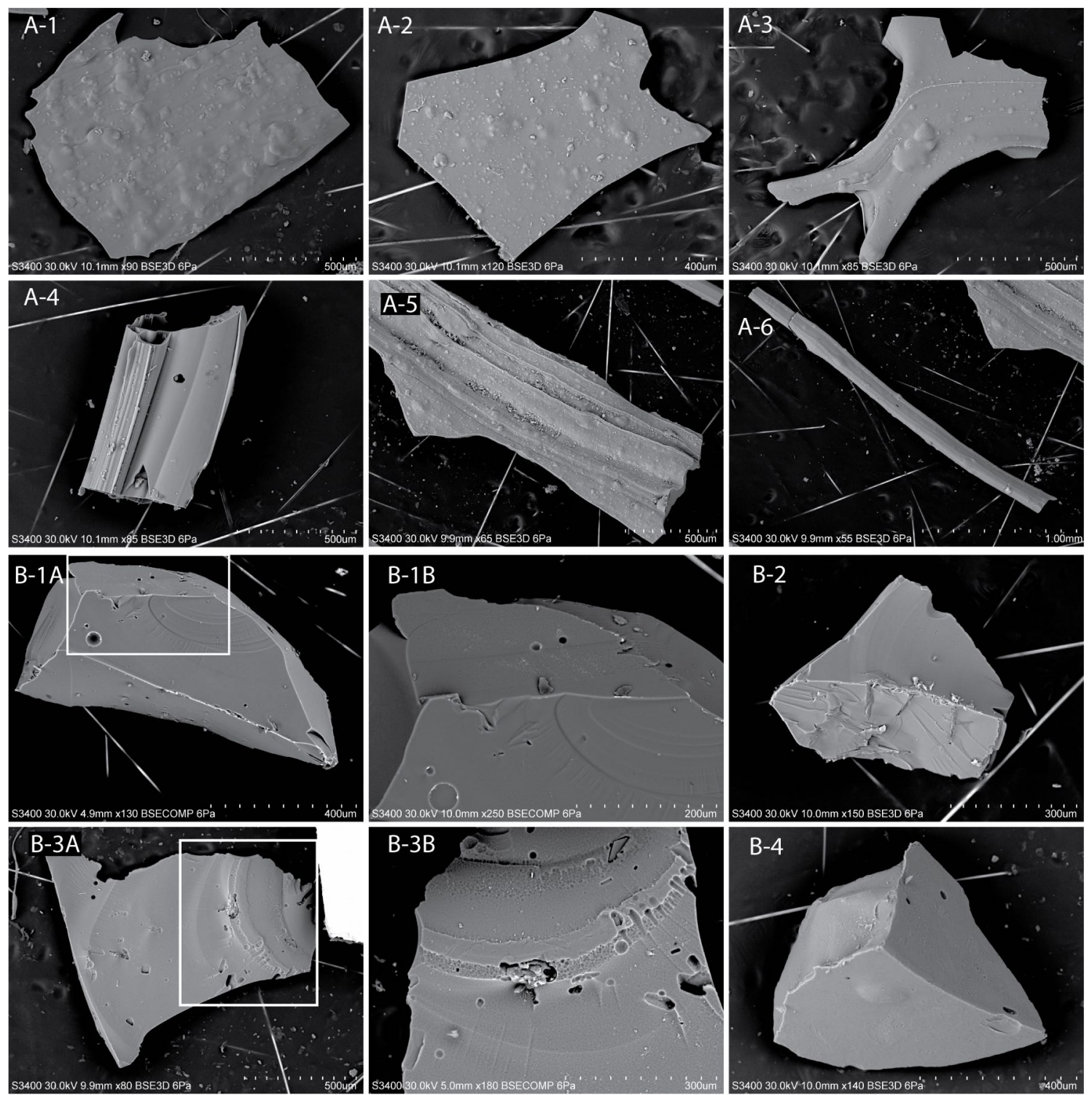

Figure 38. SEM images of vitriclast morphologies. (A) Examples of fluidal vitriclasts. A-1 - A-3 show examples of limu o' Pele bubble wall shards. Bubbletexture on face may be microlite crystals enveloped in glass? A-4 shows a vitriclast with tubular vesicles. A-5 shows limu o' Pele with a taffy texture. A-6 shows a Pele's hair. (B) Examples of angular/blocky glass particles. B-1A shows an angular vitriclast with sharp edges and smooth glassy faces with conchoidal fracture patterns and radiating perpendicular step-fractures (B-1B). B-2 shows angular vitriclast with step-fracturing on bottom face. B-3A shows an angular vitriclast showing conchoidal fracture smooth face with pitting (B-3B) in fracture rings. B-4Blocky vitriclast displaying sharp margins with smooth glass faces and minimal vesicles. 
Angular / blocky particles have sharp, well defined corner margins with semismooth surfaces that show brittle fragmentation features (e.g. conchoidal fracture fractures, step fracturing; Fig. 38B-1 - 4). Larger angular / blocky particles often contain small ( $20-50 \mu$ m diameter) vesicles that make up no more than $10 \%$ of the surface. Highly vesicular particles (containing $\sim 40 \%$ vesicles) were only observed in $<1 \%$ of vitriclasts according to point counts and were not observed under SEM.

\section{MGS Subsample Population Results}

\section{Subsample Comparison Descriptions}

Subsample MGS populations from volcaniclastic lithofacies on Axial Seamount (TM, HMT, LPT) were compared talus scoop bag subsamples collected from the summit of Axial Seamount (See Fig. 3 for locations). Subsample D522-SB23 was retrieved from a talus pile from a 2011 lava flow that cascaded over the caldera wall. Subsample D526-SB12 was collected from an andesite pillow cone talus pile. Subsample D880 -SB33 was collected from a sheet flow talus pile near a fissure. All scoop bag subsamples are inferred to have fragmented by autoclastic (non-explosive) fragmentation (D. Kapule pers. Comm.).

In addition to scoop bag subsamples, two subsamples from West Mata were also analyzed and compared to subsamples on Axial Seamount. Subsample J2_r17_r28 is a proximal scoop bag and J2-418_Sed7 is a distal scoop bag subsample, both of which contain boninite ash from the 2009 eruption in which 
explosive style activity was directly observed by ROV (Resing et al., 2011). This subsample is therefore representative of ash fragmented by magmatic explosivity. These autoclastic and pyroclastic scoop bag subsamples are used to compare against MGS ash populations and discussed further in the fragmentation and eruption style section.

\section{Point Density Plot Analysis}

To differentiate ash morphologies on Axial Seamount, point density plots of TM, HMT, and LPT core subsamples were compared to scoop bag subsamples. Data plotted on SLD vs. CVX plots (Fig. 39) shows variation between core and scoop bag subsamples. Field value results are summarized in Table 13. Scans from TM and LPT show broad $2 \sigma$ field ranges in both solidity $(>0.7)$ and convexity (>0.7). HMT is more constrained overall with the $2 \sigma$ field ranges for both solidity and convexity $>0.8$. Slopes for TM, HMT, and LPT subsamples are all moderately-steep $(1.54-1.88)$.

Talus scoop bag subsamples (D526-SB12; D880-SB33) have more constrained convexity $2 \sigma$ field values $(>0.85)$ while the solidity field range is variable and similar to that of TM, HMT, and LPT $(>0.7)$. Trend lines based on $1 \sigma$ slopes have much more gentle slopes $(0.55-0.67)$. Subsample J2-417_r28 (West Mata) shows a constrained solidity $2 \sigma$ field $(>0.8)$ and wider convexity value (>0.7) than Axial Seamount push core subsamples and has the steepest slope of all measured subsamples (2.22). 


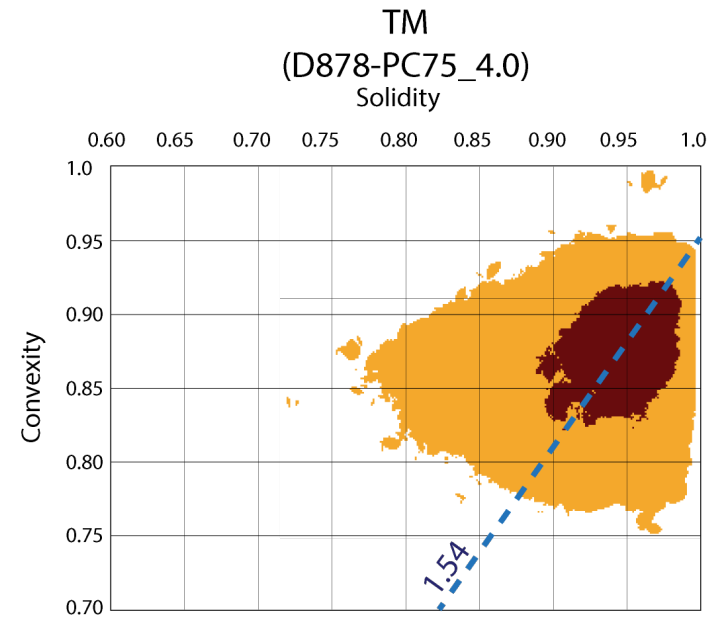

Pillow Cone Talus Pile

(D526-SB12)

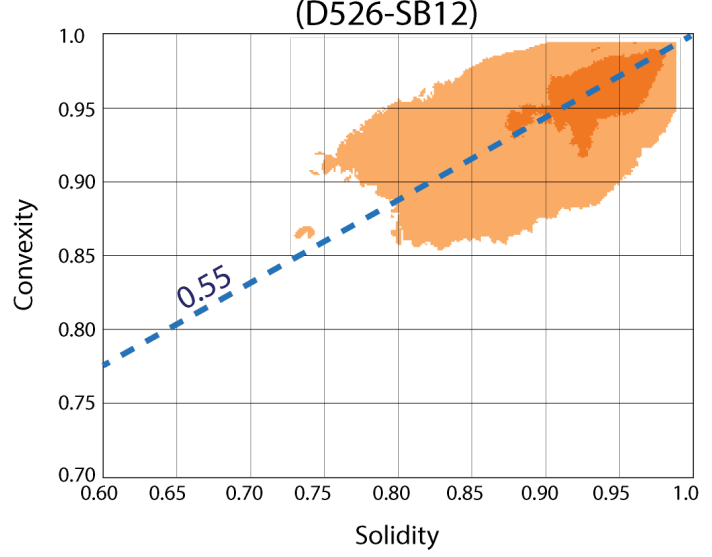

HMT

(D522-PC62L_27.0)
Solidity
LPT

$\underset{\text { Solidity }}{\text { (D524-PC47XL41.0) }}$

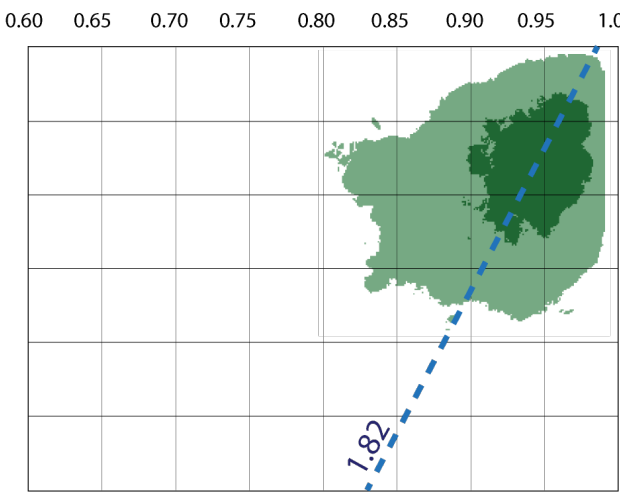

Sheet Flow Talus Pile (D880-SB33)

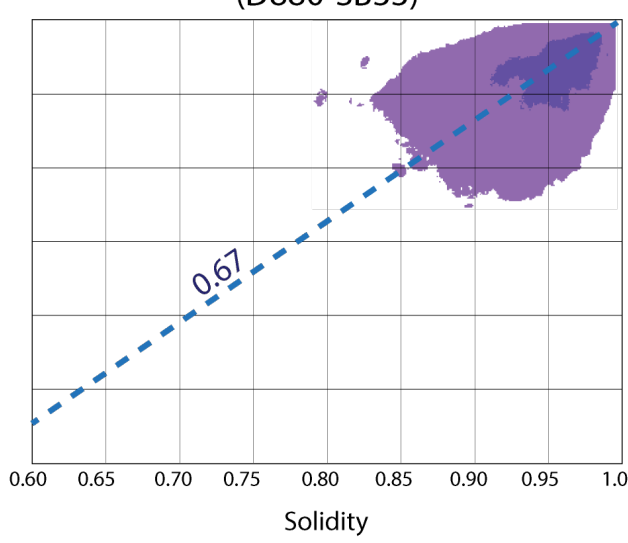

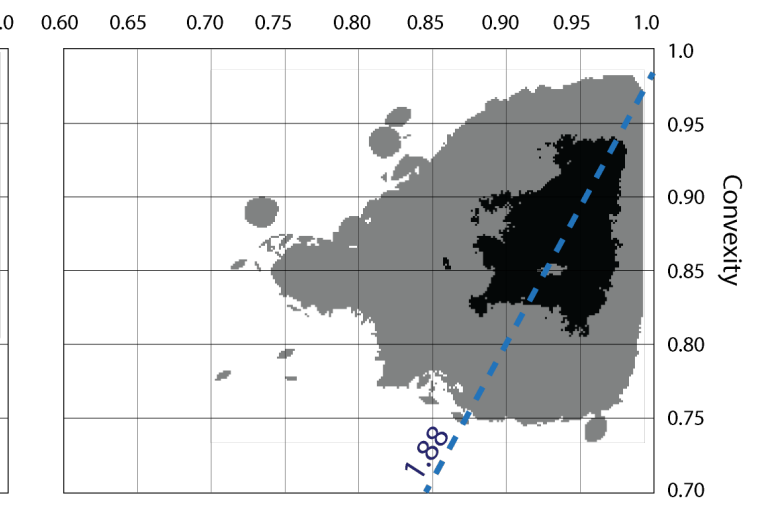

Explosive - Strombolian (J2-417_r28; West Mata)

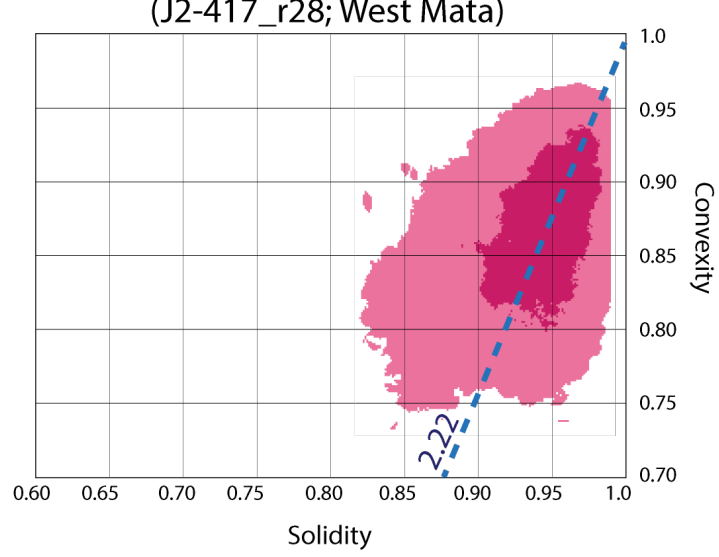

Figure 39. Solidity vs. Convexity point density plots. (Top) Results of representative subsamples from each lithofacies (TM, HMT, and LPT). (Bottom) Results of scoop bag subsamples D526-SB12 and D880-SB33, and sample from West Mata, J2-417_r28. Dashed blue line through plots are the slope of $2 \sigma$ data points. Results are summarized in Table. 13. 
Table 13. Results of solidity vs. convexity plots $2 \sigma$ field range values.

\begin{tabular}{|c|c|c|c|}
\hline & SLD $^{a}$ & $\operatorname{cVX}^{a}$ & Slope ${ }^{b}$ \\
\hline $\begin{array}{l}\text { Talus } 1 \\
\text { (D526-SB12) }\end{array}$ & $>0.85$ & $>0.73$ & 0.55 \\
\hline $\begin{array}{l}\text { Talus 2 } \\
\text { (D880-SB33) }\end{array}$ & $>0.87$ & $>0.79$ & 0.67 \\
\hline $\begin{array}{l}\text { TM } \\
\text { (D878-PC75_4.0) }\end{array}$ & $>0.75$ & $>0.73$ & 1.54 \\
\hline $\begin{array}{l}\text { HMT } \\
\text { (D522-PC62L_27.0) }\end{array}$ & $0.81-0.99$ & $>0.80$ & 1.82 \\
\hline $\begin{array}{l}\text { LPT } \\
\text { (D524-PC47XL_41.0) }\end{array}$ & $0.73-0.98$ & $>0.70$ & 1.88 \\
\hline $\begin{array}{l}\text { W. Mata } \\
\left(J 2-417 \_r 28\right)\end{array}$ & $0.73-0.96$ & $>0.82$ & 2.22 \\
\hline
\end{tabular}

Plots of Int. SD vs. Int. M show differences in ash populations based on lithofacies and proximity to the caldera (Fig. 40A). The presence of $2 \sigma$ density shading falling in a particular field (e.g. fluidal) implies a statistically significant amount of that particular particle style. For example, subsample D878-PC75_4.0 (TM distal) has more $2 \sigma$ shading occupying the "fluidal field compared to subsample D522-PC62L_32.0. (LPT proximal). Therefore, D878-PC75_4.0 contains significantly more fluidal particles relative to $D 522-P C 62 L \_32.0$, which is consistent with core descriptions where distal TM tends to contain more fluidal vitriclasts than proximal LPT. 

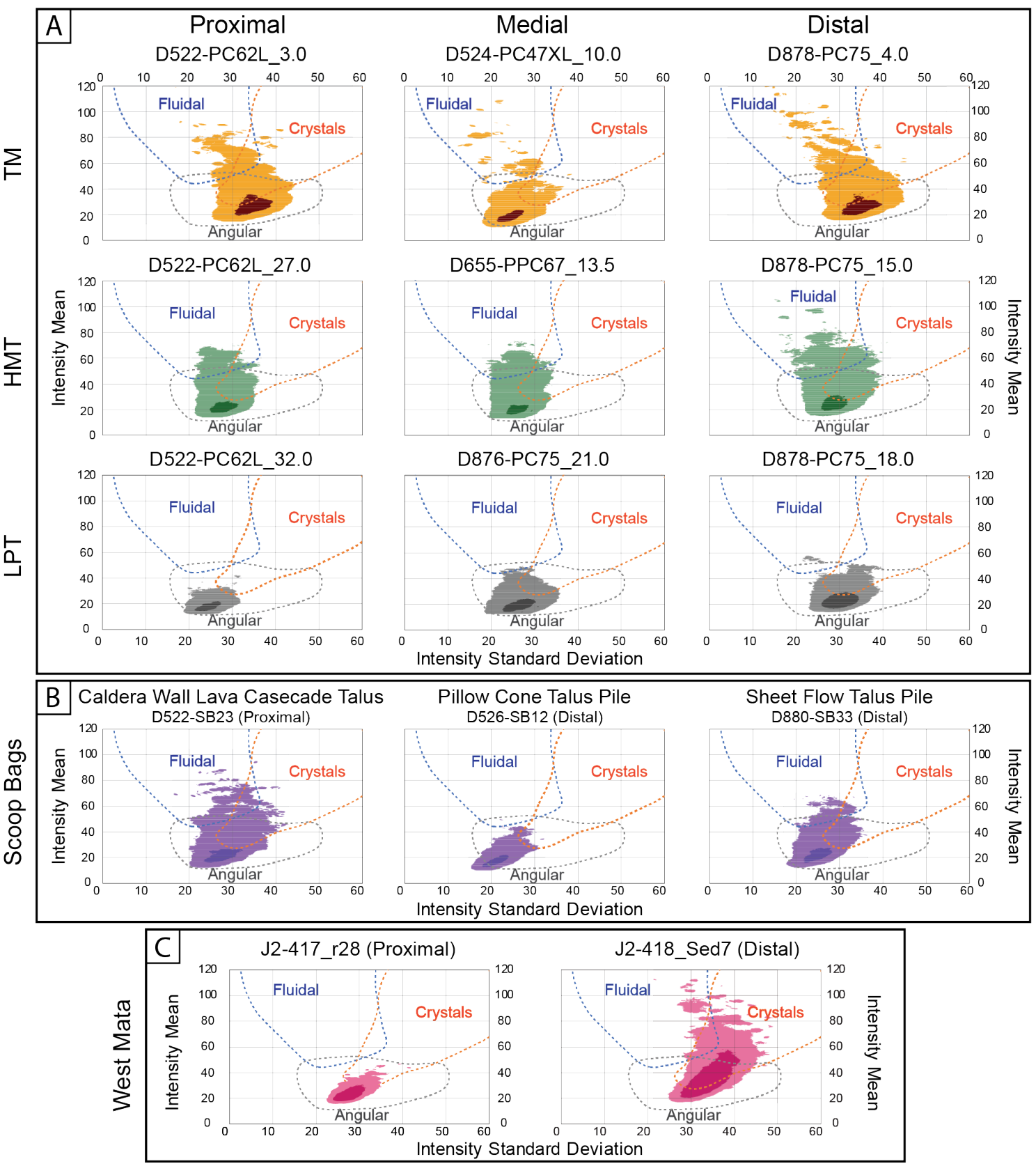

Figure 40. Intensity Standard Deviation vs. Intensity Mean point density plots. (A) Representative subsamples from each lithofacies (Orange $=\mathrm{TM}$; Green $=$ HMT; Grey = LPT) and from varying proximities to the caldera. (B)

Representative scoop bag subsamples from varying proximities to the caldera. (C) subsamples from West Mata for comparison 
All three lithofacies show that distal subsamples contain a higher proportion of fluidal particles and crystals compared to the proximal and medial subsamples. TM contains the highest proportion of fluidal particles followed by HMT, whereas LPT contains only a small percent of fluidal particles. TM and LPT tend to contain more crystals than HMT. In addition to scans from each lithofacies, three scoop bag subsamples (Fig. 40B) and two subsamples from West Mata (Fig. 40C) were also plotted for comparison. Scoop bag subsamples are highly variable with subsamples D522-SB23 and D880-SB33 containing both fluidal shards and crystals $(2 \sigma$ field "intensity mean" values $>90)$ whereas the $2 \sigma$ field for subsample D526-SB12 is mostly constrained to the "angular / blocky vitriclast" field. Meanwhile, the proximal (J2-417_r28) and distal (J2-418_Sed7) subsamples from West Mata are vastly different. The proximal subsample spread is constrained primarily to the "angular" field whereas the distal subsample spread extends into the "fluidal" and "crystals" fields.

\section{Convexity Distribution Frequency Curves}

Distribution frequency curves of convexity (Fig. 41) show distinct differences between scoop bag subsamples (D526-SB12 and D880-SB 33), representative HMT subsample (D522-PC62L_27.0), and other subsamples from TM (D8789PC75_4.0), LPT (D524-PC47XL_41.0). Scoop bag subsamples have narrow asymmetric peaks $<0.95$ whereas the HMT curve is symmetrical with the peak falling between $0.92-0.95$. Subsamples from TM and LPT also have symmetrical peaks, but the distribution frequency is broader with peaks generally 
falling $<0.9$ convexity values. Subsample types with inferred fragmentation mechanisms are similar (e.g. scoop bag subsamples; TM, LPT, West Mata), while HMT stands out as being notably different.

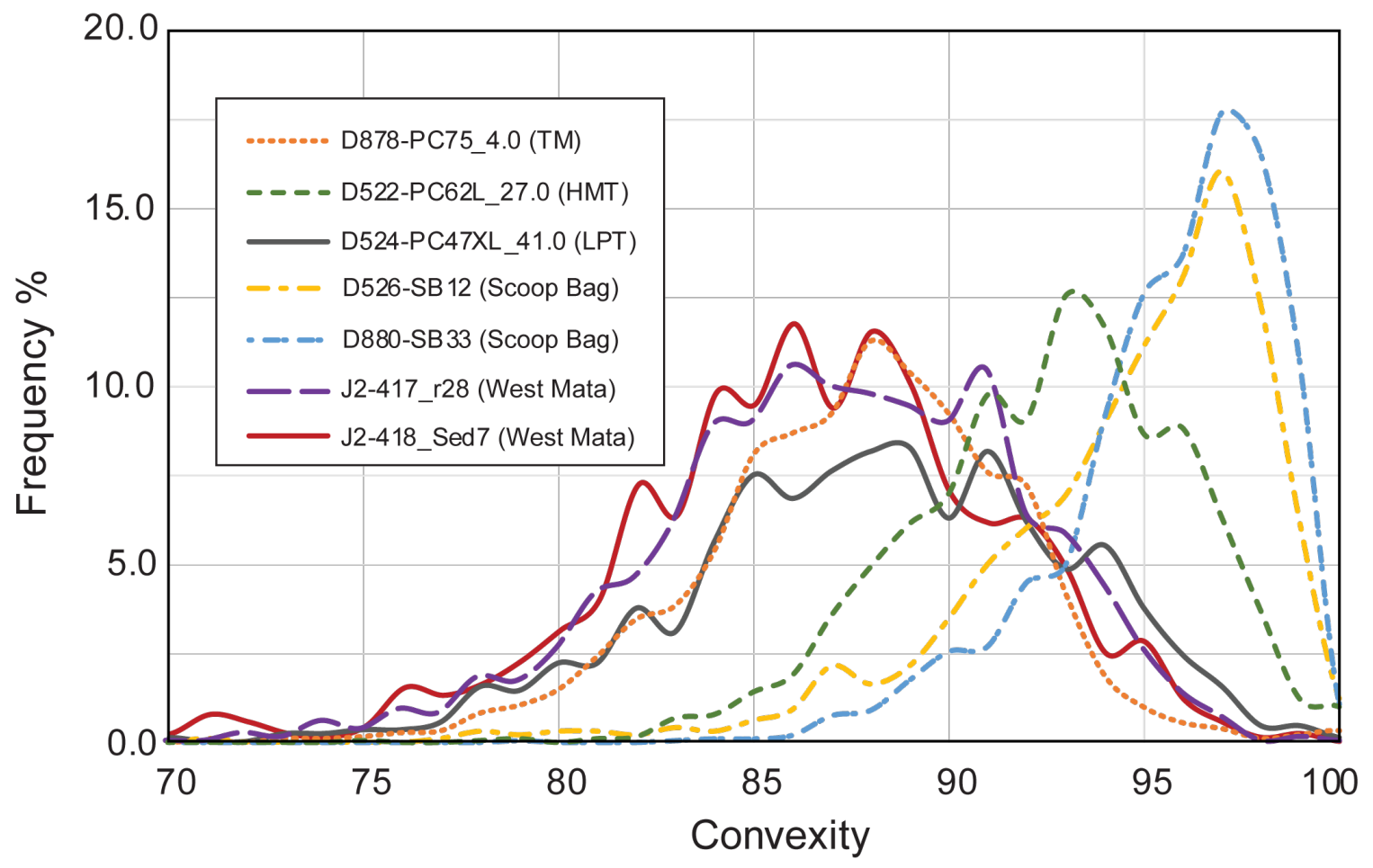

Figure 41. Convexity frequency distribution curves comparing representative subsamples from each lithofacies and scoop bags on Axial Seamount, and subsamples from West Mata. 


\section{DISCUSSION}

\section{Lithostratigraphy}

Grain-size results comparing off-summit subsamples vs. other lithofacies suggest that products of volcanic eruptions are mostly constrained to Axial Seamount's summit, supporting the idea that the volcaniclastic lithofacies (LPT, HMT, and TM) source is on Axial Seamount's summit. General stratigraphy observed around the caldera indicates chronological control on the deposition of each lithofacies. Lithostratigraphy is discussed below based in chronological order from oldest (TO) to youngest (TM).

Absence of TO in proximal and medial cores may be caused by nondeposition, erosion by bottom currents and / or burial by lava flows. TO is interpreted to be background sedimentation (Portner et al., 2015), thus eliminating the idea of non-deposition. High bottom current circulation velocities constrained to the summit on Axial Seamount (Xu and Lavelle, 2017) may provide a mechanism to eradicate TO near the caldera. Additionally, TO only occurs in cores $>1500$ years old which coincides with volcanism and effusive volcanism (Clague et al., 2013), suggesting that older sedimentary deposits (e.g. TO) were buried by younger lava flows.

Observations of LPT and HMT show both lithofacies thin with increasing distance from the caldera (Fig. 18). This indicates that their eruptive source was near the current location of the caldera and primary eruptive vents (Caress et al., 2012; Chadwick et al., 2013). Caldera formation is important in that it effectively 
increases the porosity of oceanic crust up to $33 \%$ (Gilbert et al., 2007) by way of ring faults around its margins. These structures allow for substantial seawater infiltration and ultimately magma-seawater interaction in the subsurface, which explains the thickening of HMT toward the caldera.

Formation of TM is marked by a notable absence of hydrothermal lithics seen in underlying HMT (e.g. authigenic hydrothermal minerals, altered oceanic crust) and fine-grained vitriclasts signifying the end of caldera formation. TM is interpreted to have formed by pelagic fall-out in conjunction with periodic eruptions with the same eruption style that produced LPT. TM lithofacies thickness is relatively consistent across the offset transect (Fig. 17), further suggesting primarily a pelagic fall-out origin from vents near and far from the caldera.

\section{HMT Provenance}

HMT is composed of (1) primary volcaniclasts produced by eruption and fragmentation of (juvenile) magma, (2) non-primary particles of fragmented oceanic bedrock (accessory lithics), and (3) authigenic hydrothermal particles that precipitate from hydrothermal fluids (accidental lithics). Non-primary particles that are incorporated into a plume of primary volcaniclasts as a result of volcanic eruptions are referred to as accessory lithics. Meanwhile, accidental lithics refer to particles that are locally entrained into a plume (e.g. authigenic hydrothermal minerals). Table 14 summarizes accessory and accidental lithics identified as 
Table 14. Summary of lithics (accessory and accidental) identified on Axial Seamount and implications.

\begin{tabular}{|c|c|c|c|c|c|c|}
\hline $\begin{array}{l}\text { Lithic } \\
\text { Type }\end{array}$ & $\begin{array}{l}\text { Mineral } \\
\text { Category }\end{array}$ & Mineral & $\begin{array}{l}\text { Temperature } \\
\text { Conditions }^{\text {a }}\end{array}$ & $\begin{array}{c}\text { Primary } \\
\text { Alteration } \\
\text { Zone }\end{array}$ & $\begin{array}{l}\text { Oxidation } \\
\text { Conditions }\end{array}$ & $\begin{array}{c}\text { Cation } \\
\text { Exchange }\end{array}$ \\
\hline \multirow{4}{*}{$\begin{array}{c}\text { Authigenic } \\
\text { Altered }\end{array}$} & \multirow{4}{*}{ Clay } & Saponite & Low & UPA & Reducing $^{b}$ & $\mathrm{Fe}^{2+}, \mathrm{Mg}^{2+}$ \\
\hline & & Nontronite & Low & UPA & Oxidizing & $\mathrm{Fe}^{3+}$ \\
\hline & & Corrensite & Medium & LPA & Reducing ${ }^{b}$ & \\
\hline & & Chlorite & High & TZD & & \\
\hline \multirow{3}{*}{ Authigenic } & Sulfide & Pyrite & Varies & $\mathrm{N} / \mathrm{A}$ & Reducing & $\mathrm{Fe}^{2+}$ and $\mathrm{S}$ \\
\hline & Silicate & Quartz & Medium & $\mathrm{N} / \mathrm{A}$ & & $\mathrm{Si}$ \\
\hline & Sulfate & Barite & Medium & $\mathrm{N} / \mathrm{A}$ & & $\mathrm{Ba}$ \\
\hline \multirow{8}{*}{ Altered } & \multirow{2}{*}{ Oxide } & Goethite & Low & UPA & Oxidizing & $\mathrm{Fe}^{3+}$ \\
\hline & & Hematite & Low & UPA & Oxidizing & $\mathrm{Fe}^{3+}$ \\
\hline & \multirow{2}{*}{ Zeolite } & Heulandite & Low & $\mathrm{ZZ}$ & & $\mathrm{Al} \& \mathrm{Ca}$ \\
\hline & & Laumontite & Medium & TZD & & $\mathrm{Al} \& \mathrm{Ca}$ \\
\hline & \multirow{4}{*}{ Greenschist } & Actinolite & High & TZD & & $\mathrm{Fe}^{2+}, \mathrm{Mg}^{2+}$ \\
\hline & & Tremolite & High & TZD & & $\mathrm{Ca}, \mathrm{Fe}^{2+}, \mathrm{Mg}^{2+}$ \\
\hline & & Epidote & High & TZD & & $\mathrm{Ca}, \mathrm{Fe}^{3+}$ \\
\hline & & Albite & High & TZD & & $\mathrm{Na}, \mathrm{Ca}$ \\
\hline
\end{tabular}

Notes:

Temperature conditions generalized

${ }^{b}$ Assuming $\mathrm{Fe}^{2+}$ cation

Abbreviations:

UPA: Upper pillow alteration zone

ZZ: Zeolite alteration zone

LPA: Lower pillow alteration zone

TZD: Lithologic transition zone

N/A: Not applicable 
part of the hydrothermal system and their implications. Components are separated based on their inferred provenance sources and are described below.

\section{Primary Volcaniclast Origin}

Primary volcaniclasts are characterized by fresh (unaltered) glass particles to slightly altered. Although the majority of fresh vitriclasts are juvenile, and are therefore discussed in the context of volcanic processes (see fragmentation and eruption style), the presence of slightly altered vitriclasts suggests that not all vitriclasts are magmatically derived. Fresh volcanic glass (e.g. vitriclasts) alters to palagonite (Stroncik and Schmincke, 2001; Stroncik and Schmincke, 2002), the first stable phase of mafic glass alteration (Peacock, 1926; Hay and Jones, 1972). Partially altered vitriclasts to palagonite are likely from previous eruptions (e.g. not juvenile vitriclasts) and are therefore considered cognate lithics.

$\mathrm{MgO}$ geochemistry of vitriclasts is important to understanding the provenance of glass shards within the erupted material. Homogenous geochemical signatures reveal that all vitriclasts are magmatically derived whereas heterogenous geochemical signatures imply that existing vitriclasts from previous eruptions may have been stripped from conduit walls and incorporated into the erupted material (Portner et al., 2014). Therefore, an understanding of vitriclast chemistry is pertinent to separating out juvenile vitriclasts from cognate lithics. Portner et al. (2015) concluded that vitriclasts in HMT are chemically heterogeneous, implying that a population of unaltered vitriclasts are cognate and were entrained from glassy wall rock during eruption. Future geochemical 
analysis on HMT primary volcaniclasts is required to qualitatively make this distinction.

\section{Non-Primary Volcaniclast Origin - Conduit Wall-Rock}

Upwelling magma bodies and emplacement of new oceanic crust leads to significant heat-flow in mid-ocean ridge environments (Sclatter et., al 1981). High geothermal gradients near mid-ocean ridges results in thermal alteration of oceanic crust that includes clays, oxides, zeolites, and greenschist facies minerals (e.g. actinolite, epidote). Mineral assemblages provide insight into thermal alteration zones that occur at depth within a particular section of oceanic crust (Alt et al., 1986). These zones are characterized by the presence of specific minerals and include:

1. "Upper Pillow Alteration Zone" (UPA; 0-320 m) that generally consists of unaltered basaltic glass, crystalline basalts that contain unaltered pyroxenes and calcic plagioclase, with minor amounts of Fe-oxides (goethite), clays (saponite) and celadonite.

2. "Zeolite Alteration Zone" (ZZ; 254-290 m) that is a sub-zone of the upper pillow alteration zone and generally includes the first occurrence of zeolites (e.g. thomsonite; heulandite), in conjunction with clays (e.g. saponite) and celadonite.

3. "Lower Pillow Alteration Zone" (LPA; 320-624 m) consisting of slightly altered materials. Saponite often replaces olivine and plagioclase in this zone. Pyroxenes remain predominantly unaltered, with local alteration 
consisting of chlorite, talc, and actinolite. In this section, volcanic glass is completely replaced by clay minerals.

3. "Lithologic Transition Zone" (TZD; 624-1076 m) that is characterized by abundant of greenschist minerals including chlorite, actinolite, epidote, laumontite, prehnite. Plagioclase has undergone albitization and is partially replaced by high-temperature zeolites (e.g. laumontite).

These zones, described by Alt et al. (1986), are defined from drill cores retrieved from a different setting than that of Axial Seamount. Due to Axial Seamount's presence above a hotspot, it may have a higher temperature gradient, which would cause the depths associated with alteration zones to be shallower than described. Nonetheless, these alteration zones provide insight into relative depth and thermal conditions based on mineral assemblages in HMT. Alteration minerals observed in HMT are presented in Figure 42 and discussed below.

\section{Clay Minerals}

Clay minerals are a common alteration product resulting from warm hydrothermal fluids interacting with unaltered minerals in deep-sea hydrothermal Clay minerals produced in mafic volcanic settings are generally rich in $\mathrm{Fe}$ and $\mathrm{Mg}$, due to the leeching of $\mathrm{Fe}$ and $\mathrm{Mg}$ ions from mafic minerals, and often include saponite, nontronite, corrensite (C / S; interstratified chlorite / smectite), and chlorite, (Schiffman and Fridleifsson, 1991; Inoue, 1995). The formation of a clay mineral is sensitive to temperature. Therefore, the presence of a particular clay 


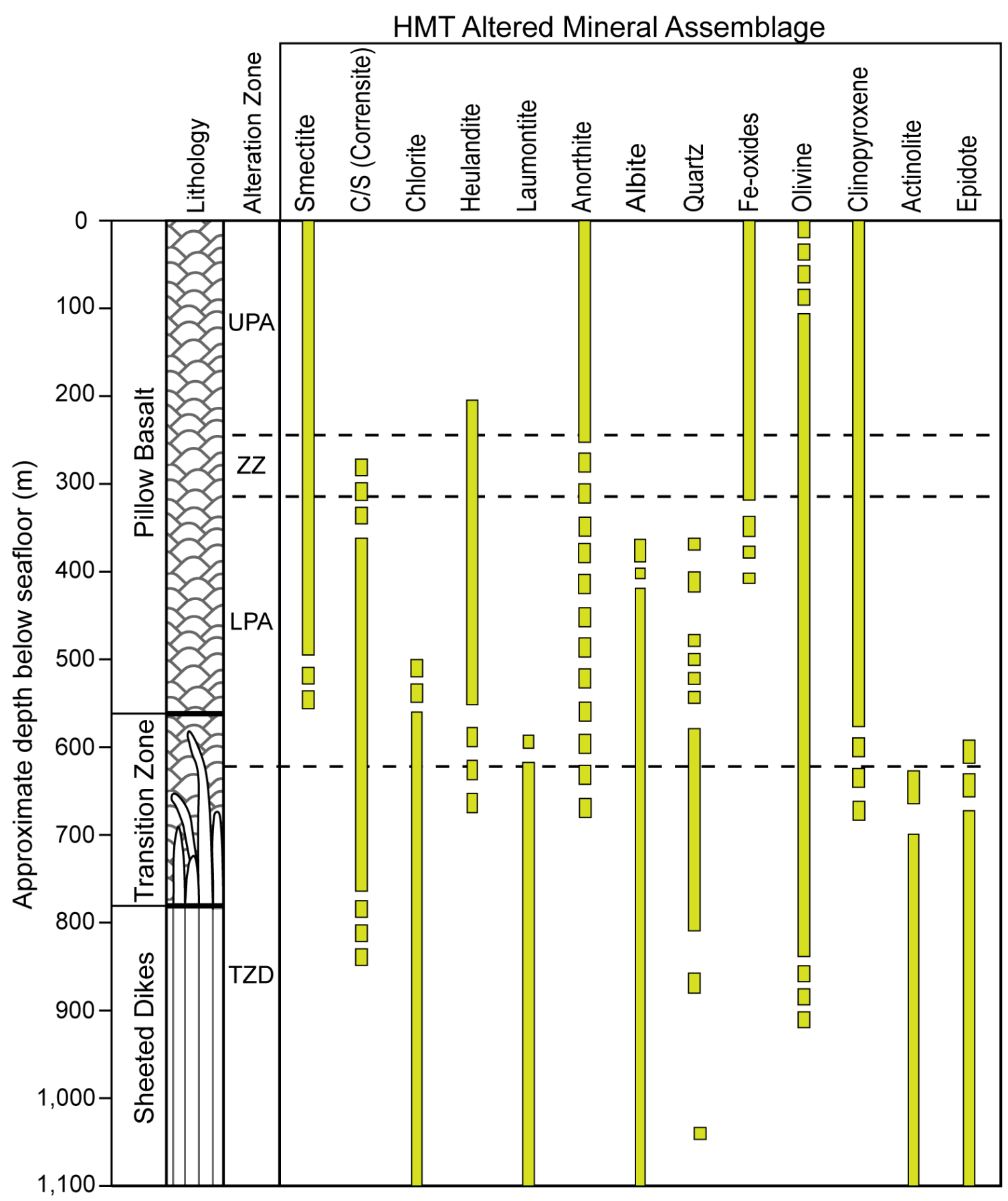

Figure 42. Accessory lithics identified in HMT on Axial Seamount showing crustal depths and alteration zones as described by Alt et al., 1986. Mineral depth ranges are from Alt et al., 1986 and references within. Temperature ranges on Axial Seamount are likely very different due to the high geothermal gradient and therefore is not included; however, depth ranges of minerals relative to each other are the same. 
species can provide reliable controls on depth of formation in oceanic crust where geothermal gradients are well-constrained (Utada, 1980; Schiffman and Fridleifsson, 1991; Inoue, 1995). Temperature, not pressure, is the primary control of the type of clay produced in deep-sea alteration, while oxidation state generally controls cation exchange (e.g. amount of $\mathrm{Mg}$ or Fe in saponite; Andrews, 1980; Yeniol, 2007).

Weathering of partly crystalline basalt at Low-temperatures $\left(<100^{\circ} \mathrm{C}\right)$ results in the alteration of glass selvages first to amorphous palagonite, which then crystallizes into smectite (nontronite or saponite). Intermediate temperature clay alteration begins above $100{ }^{\circ} \mathrm{C}$ and results in the recrystallization of smectite to interlayered chlorite / smectite until a 50 / 50 ratio is achieved in corrensite. As alteration evolves above temperatures of about $200{ }^{\circ} \mathrm{C}$ the chlorite / smectite interlayer ratio increases until corrensite entirely converts to discrete chlorite. Progression from low-temperature smectite, to intermediate temperature corrensite, and finally to high-temperature chlorite, occurs over a relatively narrow temperature range between 100 and $200{ }^{\circ} \mathrm{C}$ (Schiffman and Fridleifsson, 1991; Inoue, 1995).

SEM images of altered vitriclasts show a range of alteration including unaltered basaltic glass, slightly altered glass (palagonite), and smectite-altered glass (Fig. 28A-1 - 3). Results of clay XRD diffractograms (Fig. 25) reveal primary clay constituents within HMT include smectite, interstratified chlorite / smectite (corrensite), and chlorite. Smectite is predominantly tri-octahedral 
(saponite) and may have significant $\mathrm{Fe}^{2+}$ cation coordination implying reducing conditions; however, small proportions of di-octahedral smectite (nontronite) is present, particularly on red particles (Table 12). Peak locations at various stages of clay XRD treatments suggest that chlorite is $\mathrm{Mg}^{2+}$-rich, but that $\mathrm{Fe}^{2+}$-bearing chlorite is also present. Cation coordination implies different oxidation states with $\mathrm{Fe}^{2+}$ saponite and chlorite forming under reducing conditions while $\mathrm{Fe}^{3+}$ nontronite forming under oxidizing conditions.

Three of the four subsamples selected for clay XRD analysis (D522PC62L_21.5; D655-PPC79_20.0; D878-PC53_12.0) had nearly identical diffractograms throughout the clay treatment process suggesting that clays within HMT are mostly homogenous. The exception appears to be within the "pale green" lamination at the top of HMT (subsample D522-PPC1_9.0) where clay treatment diffractograms showed obvious differences. Most HMT subsamples consist of $33 \%$ chlorite, $\sim 46 \%$ smectite, the majority of which was modeled as trioctahedral (saponite), and $21 \%$ corrensite. This combination covers a broad range of temperature conditions. The bimodal distribution of low and high temperature clays (Fig. 43) distinctly segregates low-temperature smectite from high-temperature chlorite suggesting different provenances.

HMT subsample analyzed from the pale green lamination contains higher proportions of high-temperature clays including $57 \%$ chlorite, $23 \%$ corrensite, $20 \%$ trioctahedral smectite (saponite). These models indicate the presence of predominantly high-temperature clays in the "pale green" lamination (Fig. 43). 
High-temperature clays positioned stratigraphically at the top of HMT in proximal and medial cores suggests deeper parts of the hydrothermal system were ejected during volcanic eruptions.

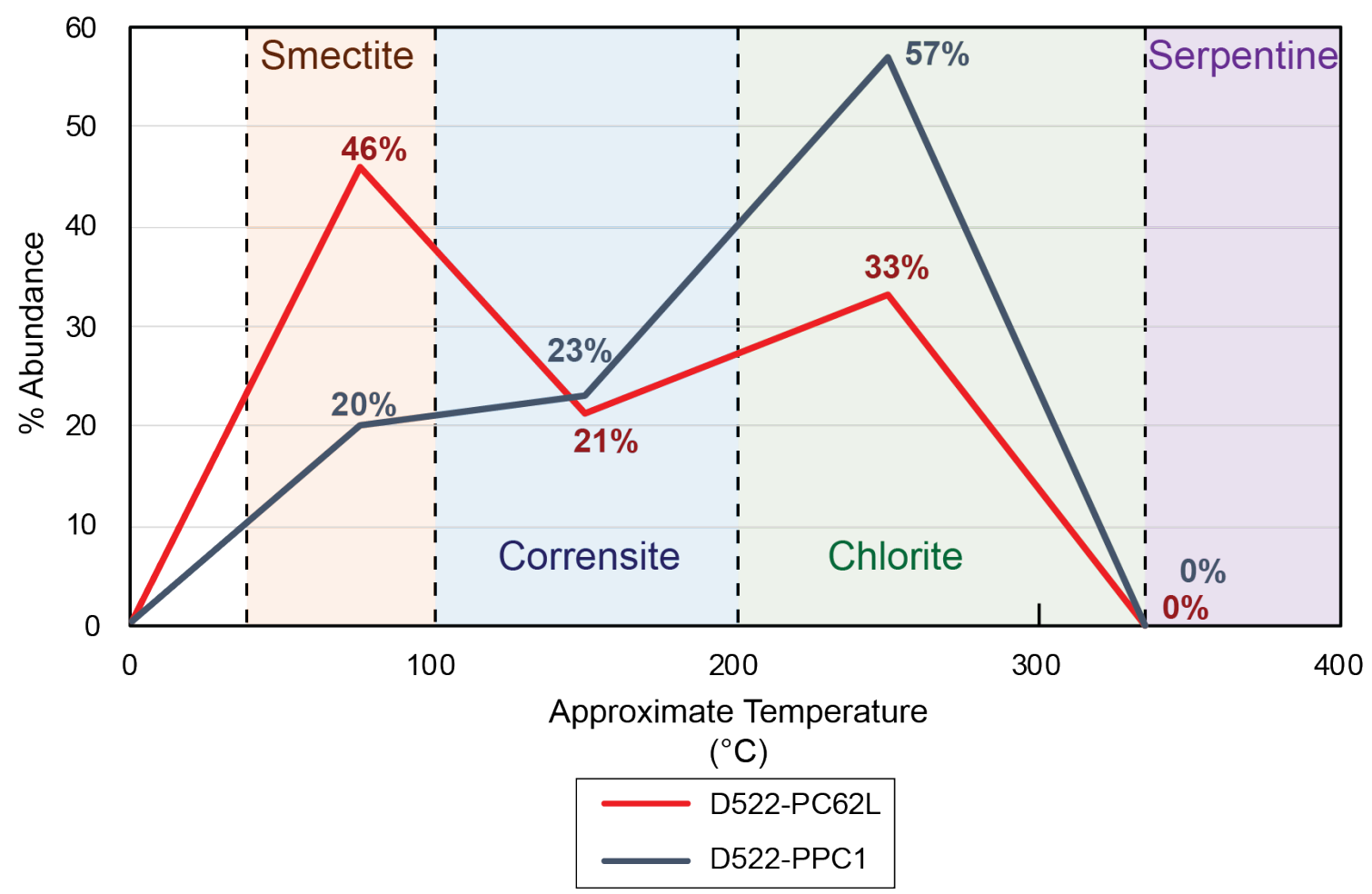

Figure 43. Figure showing relative proportions of clay species (smectite, corrensite, chlorite, and serpentine) based on NEWMOD clay models of two subsamples.

\section{Oxides}

The most common oxide minerals in volcanic and hydrothermal settings include Fe-oxide hematite $\left(\mathrm{Fe}_{2} \mathrm{O}_{3}\right)$, Fe-hydroxide goethite $(\mathrm{FeO}(\mathrm{OH}))$. Ti-oxides ilmenite $\left(\mathrm{FeTiO}_{3}\right)$ and titanomagnetite $\left(\mathrm{Fe}^{2+}\left(\mathrm{Fe}^{3+}, \mathrm{Ti}_{2} \mathrm{O}_{4}\right)\right.$ are observed under 
SEM in red particles (Fig. 33) but are not associated with thermal alteration. Hematite may be an accessory mineral in volcanic rocks or associated with alteration whereas goethite is exclusively associated with alteration. Oxide minerals are relatively low in abundance and therefore were not identified using XRD; however, SEM visual observations and EDX analysis show that Fe-oxides are present primarily on red lithics (Fig. 33) and yellow clays (Fig. 31B) but were also observed in a white particle (Fig. 35). Although it is difficult to differentiate hematite from goethite using SEM morphology (Welton, 2003), the presence of Fe-oxides implies alteration of shallow oceanic crust and oxidizing conditions in the UPA zone (Alt et al., 1986).

\section{Zeolites}

Zeolites are an important component of hydrothermal lithics because they are common in altered oceanic crust, are sensitive to temperature, and often replace volcanic glass and Ca-rich plagioclase (Coombs, 1954; Stewart, 1974; Boles, 1977). Common zeolite minerals found in deep-sea hydrothermal settings include: chabazite, clinoptilolite, heulandite, laumontite, mesolite, natrolite, scolecite, stilbite, thomsonite, and wairakite (Browne, 1978; Wirsching, U. 1981; Alt et al. 1986; Inoue, 1995; Neuhoff et al. 2006). Each zeolite tends to have a unique crystal morphology (e.g. fibrous, platy, blocky), which when coupled with

the high amounts of aluminum, allows for identification of specific zeolite minerals (Mumpton and Ormsby, 1976; Welton, 2003; Zhang et al. 2011). 
Results of individual grains using SEM / EDX and XRD diffractograms show that Ca-rich zeolites, laumontite and heulandite, are present on Axial Seamount, and are likely replacing calcic plagioclase and basaltic glass. These are some of the most common zeolites found in low-grade metamorphic settings (Mumpton, 2018). Heulandite occurs at low temperatures $\left(<150^{\circ} \mathrm{C}\right)$ and is often replaced by laumontite at higher temperatures (Coombs, 1954). Figure 37 shows laumontite appearing to replace heulandite suggesting lithics were present at overlapping zeolite formation temperatures $\left(100-200^{\circ} \mathrm{C}\right)$ which is consistent with the $\mathrm{C} / \mathrm{S}$ clay zone.

\section{Hydrothermal Quartz}

While quartz is not common in mafic volcanic settings, it is a common constituent in hydrothermal systems. In medium to high temperature hydrothermal systems $\left(230-380^{\circ} \mathrm{C}\right.$; Alt et al., 1986), Si enriched hydrothermal fluids seep into fractures and crystallize as quartz veins. Presence of quartz in HMT is likely a constituent of hydrothermal quartz veins stripped from conduit walls.

\section{Greenschist-Grade Minerals}

Greenschist-grade metamorphic minerals include chlorite, actinolite, tremolite, epidote, and albite. The presence of chlorite is discussed in detail above. Actinolite, tremolite, and epidote often replace amphiboles and pyroxenes whereas albite replaces Ca-rich anorthite (Alt et al., 1986). Although tremolite is generally associated with metamorphosed carbonate rocks and skarns, they are 
also present in metamorphic mafic and ultramafic rocks in Mg-rich systems (e.g. Nisbet et al., 1977; Franceschelli et al., 2002). Greenschist minerals have previously been reported as occurring predominantly within the lower pillow basalt and sheeted dike sections of oceanic crust (Alt et. al, 1986). Presence of these minerals suggests high-grade alteration $>600 \mathrm{~m}$ deep within the crust.

\section{Non-Primary Volcaniclast (Accessory Lithic) Provenance}

Non-primary volcaniclasts include crystalline wall-rock (e.g. basalt) and minerals associated with altered and unaltered oceanic crust including, plagioclase, pyroxene, amphibole, zeolites, chlorite, and epidote, all of which were confirmed by XRD and SEM-EDX analysis. Minerals indicative of shallow crust alteration, low temperatures include Fe-oxides, zeolites, and smectitic (nontronite \& saponite) clays, iddingsite. Fe-oxides and $\mathrm{Fe}^{3+}$ nontronite are indicative of oxidizing conditions, perhaps in the water column or shallow oceanic crust. Conversely, $\mathrm{Fe}^{2+}$ saponite is indicative of reducing conditions suggesting that oxidation conditions progress from oxidizing to reducing with increasing depth.

Presence of heulandite and laumontite, particularly found on the same particle, imply that altered lithics formed near transition temperatures between each of these minerals $\left(100-150^{\circ} \mathrm{C}\right)$. Interlayered chlorite / smectite (corrensite) with the addition of zeolites and are indicative of temperatures between $100-170{ }^{\circ} \mathrm{C}$. Presence of high-temperature altered minerals chlorite, epidote, actinolite and albite are representative of greenschist facies 
metamorphism deeper (>500 m) within the crust. Additionally, pyrite-laden chlorite suggests reducing conditions at high temperature (above $200^{\circ} \mathrm{C}$ ) and depths $>600 \mathrm{~m}$ within the crust.

Hydrothermal quartz is also indicative of moderate to high hydrothermal fluid temperatures, which when coupled with the absence of typical high-temperature hydrothermal minerals (e.g. cubanite, chalcopyrite), suggests that quartz formed as hydrothermal fluid-filled veins within the crust and not as a black smoker deposit. Fragments discussed above are inferred to have been incorporated into HMT after being stripped from surrounding bedrock and conduit walls and therefore may be referred to as accessory lithics. The presence of lowtemperature Fe-oxides to high temperature greenschist facies minerals indicate that accessory lithics were stripped as deep as the lithologic transition zone. Therefore, provenance of accessory lithics ranges from shallow unaltered crust to $600-800 \mathrm{~m}$ below the seafloor (mbsf).

\section{Authigenic Volcaniclast Origin - Eruption Plume}

Hydrothermal activity is commonly associated with deep-sea caldera systems (Cole et al., 2005). Increased oceanic crust permeability due to the presence of ring faults and fissures facilitates circulation of warm seawater resulting in authigenic minerals precipitated from expelled hydrothermal fluids. Minerals commonly associated with typical "black smoker" seafloor hydrothermal systems include pyrite, wurtzite, pyrrhotite, chalcopyrite, cubanite, and siderite, while clays are notably absent in these environments (Feely et al., 1987). Some metallic 
sulfides (e.g. pyrite, sphalerite) are less sensitive to temperature conditions. Instead, these are influenced by chemical controls (cation abundance and availability; Utada, 1980), and oxidation state (Andrews, 1980; Alt and Jiang, 1981). Less common hydrothermal minerals include hydrothermal sulfates (e.g. barite), the stabilities of which are dependent on temperature, chemical conditions, and solubility controls (Blount, 1977; Jamieson et al., 2015). Minerals associated with hydrothermal fluid precipitation are shown with associated hydrothermal fluid temperatures (Inoue et al., 1995; Feely et al., 1987 and references within) in Figure 44 and summarized below.

\section{Hydrothermal Clay Aggregates}

Hydrothermal clay aggregates include clays that are inferred to precipitate from hydrothermal fluids, and unique agglutinate particles. Although clays are described above (see Clay Minerals) clays described here have unique aggregate morphologies and are different from clays formed by replacement. Clays are not common in typical "black smoker" hydrothermal environments; however, point count results reveal that HMT contains both yellow and green clay aggregates. Secondary minerals in green clay aggregates include small pyrite crystals suggesting that the trioctahedral clays are $\mathrm{Mg}^{2+} / \mathrm{Fe}^{2+}$-rich saponite. Conversely, yellow clay aggregates contain Fe-oxide (goethite?) crystals suggesting the clay is dioctahedral nontronite $\left(\mathrm{Fe}^{3+}\right)$. 


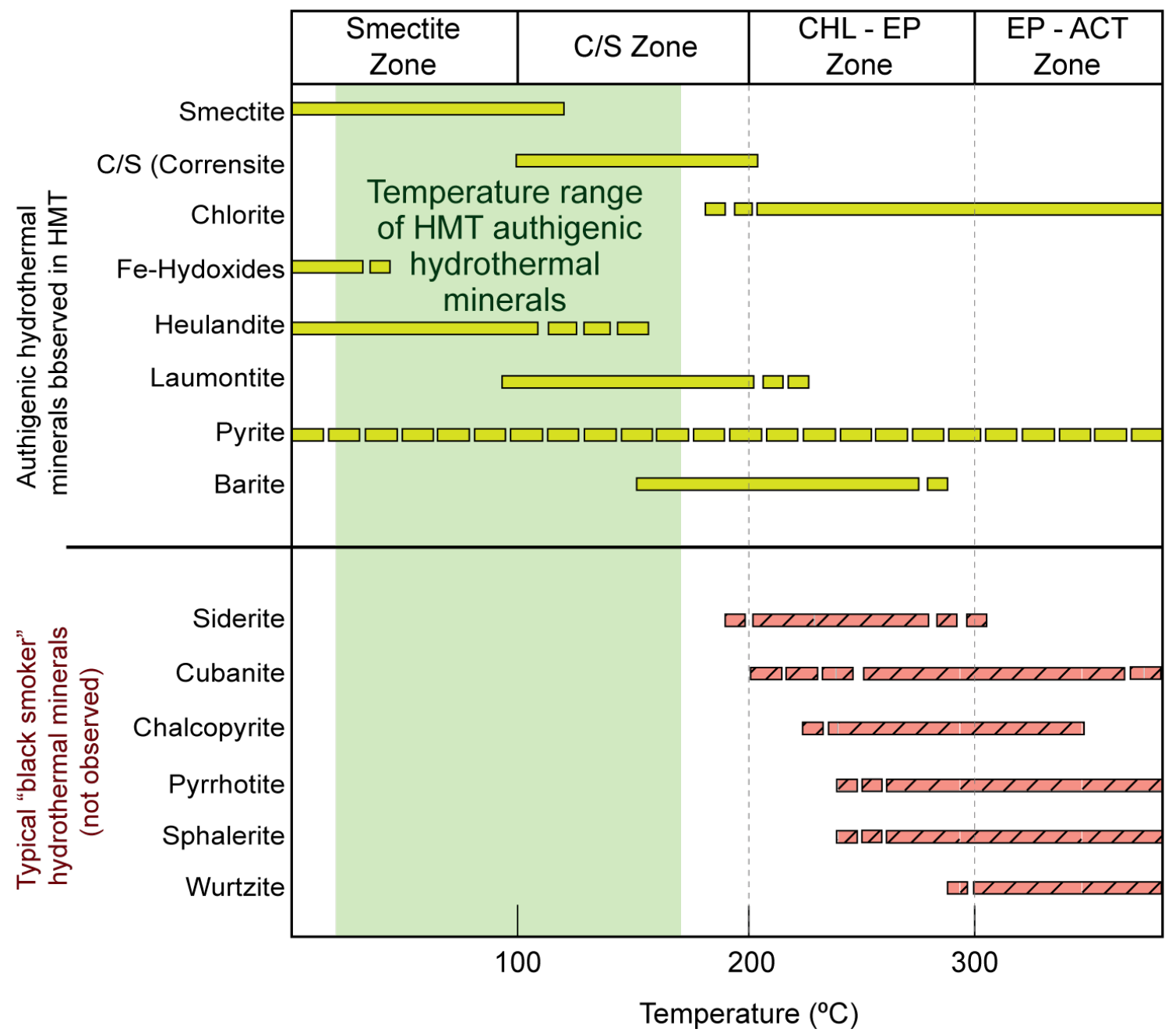

Figure 44. Authigenic hydrothermal minerals (precipitated from hydrothermal fluids) observed within HMT and their relative temperature ranges and context to clay zones, compared to temperature ranges of minerals commonly found in "typical" black smoker style hydrothermal systems. Absence of high-temperature minerals and abundance of low-temperature clays implies a relatively low hydrothermal fluid temperature on Axial Seamount. Note, high-temperature chlorite is present within HMT, yet is not inferred to precipitate from hydrothermal fluids. Temperature ranges from Inoue et al., 1995; Feely et al., 1987 and references within. 
Although both of these clays imply relatively low fluid temperatures (smectite zone; up to $100{ }^{\circ} \mathrm{C}$ ), they represent very different oxidation conditions. Green clay minerals likely precipitated in reducing conditions within the vent or conduit while yellow clays likely precipitated under oxidizing conditions in the water column or in the plume. Agglutinate particles (Fig. 28B-1) are unique in that their morphology is similar to that of a low-temperature hydrothermally precipitated clay aggregate yet are coated in basalt glass (Fig. 30). While less prevalent than other clay aggregates, their presence within HMT suggests that basalt magma was interacting with hydrothermal fluids while in a ductile state within the conduit or near the top of the vent.

\section{Metallic Sulfides}

Pyrite $\left(\mathrm{FeS}_{2}\right)$ was the only sulfide identified using EDX and was observed both independently and accompanying green $\mathrm{Fe}^{2+}$ saponitic clay aggregates (Fig. 31A), and chloritic alteration clays (Fig. 32). Hydrothermal systems are often associated with pyrite as sulfur breaks and ionizes from $\mathrm{H}_{2} \mathrm{~S}$ gas from the volcanic system and compounds with Fe. Due to the broad temperature range of pyrite formation (Alt et al., 1986), it is not indicative of temperature; however, the notable absence of other sulfides that are otherwise abundant in typical "black smoker" hydrothermal systems (e.g. cubanite, chalcopyrite, pyrrhotite, sphalerite, wurtzite; Feely et al., 1987) implies a relatively low hydrothermal fluid temperature $\left(<200{ }^{\circ} \mathrm{C}\right)$. The presence of pyrite is indicative of reducing conditions and presence of free $\mathrm{F}^{2+}$ and $\mathrm{S}^{2-}$ ions. Additionally, the presence of pyrite in 
green chlorite alteration clays and in saponite clay aggregates supports an oxygen reducing environment perhaps deeper in the hydrothermal system and shallow conduit. Lack of pyrite in other yellow clay aggregates (nontronite; Fig. 31B) implies oxidizing conditions, perhaps in the plume above the vent (see hydrothermal clay aggregates).

\section{Sulfates}

Results show that hydrothermal barite is present in low quantities within the hydrothermal system on Axial Seamount. Barite is one of the most common authigenic sulfates found in hydrothermal environments and forms from the leaching of $\mathrm{Ba}$ from the alteration of basalt resulting in barite precipitating from $\mathrm{Ba}^{2+}$-rich hydrothermal fluids mixing with $\mathrm{SO}_{4}{ }^{2-}$ in seawater (Blount, 1977; Kim

and McMurtry, 1991). Formation of barite in deep-sea hydrothermal settings has been identified take place between $150-300{ }^{\circ} \mathrm{C}$ (Hannington et al. 1995). Barite has an extremely low solubility constant, ranging from $10^{-6}$ to $10^{-3}$ molal (Blount, 1977), which preserves barite in normal oceanic conditions and is not prone to further alteration (Paytan et al. 1993, 1996a, 1996b). Therefore, the presence of barite in HMT supports the idea that $\mathrm{SO}_{4}{ }^{2-}$-rich seawater is interacting with altered basalt, thus leeching $\mathrm{Ba}^{2+}$ ions and precipitating as hydrothermal barite in moderate hydrothermal fluid temperatures on Axial Seamount. Barite was only observed on one grain in HMT. Paucity of barite in HMT suggests that hydrothermal fluid temperatures were near the minimum formation temperature for barite $\left(150^{\circ} \mathrm{C}\right)$. 


\section{Authigenic Volcaniclast (Accidental Lithic) Provenance}

Weathering of mafic oceanic crust and glass results in a diverse chemical system by leeching many elements including $\mathrm{Fe}, \mathrm{Mg}, \mathrm{Ca}, \mathrm{Al}, \mathrm{Ba}, \mathrm{S}$, (among others), which later alter or precipitate authigenic hydrothermal minerals including smectite (saponite / nontronite), barite, and pyrite. Presence of the aforementioned minerals and a lack of typical high-temperature hydrothermal minerals (e.g. cubanite, chalcopyrite, pyrrhotite, sphalerite, siderite, wurtzite) implies relatively low hydrothermal fluid temperatures ranging from $40^{\circ} \mathrm{C}$ up to about $170{ }^{\circ} \mathrm{C}$ (Fig. 44). Interestingly, smectite varieties include both trioctahedral $\left(\mathrm{Mg}^{2+} / \mathrm{Fe}^{2+}\right)$ saponite (containing small pyrite crystals; Fig. 31A), and $\mathrm{Fe}^{3+}$ nontronite (containing small FeO crystals; Fig. 31B) indicating variable oxidation conditions. Nontronite may be precipitating above the seafloor in the water column whereas saponite may precipitate within the shallow crust before being incorporated into the ascending plume. Saponite is more common than nontronite suggesting authigenic clays precipitated predominantly in reducing conditions. Formation temperatures of authigenic hydrothermal minerals are consistent with shallow upper crust conduit / vent margins, or seawater / plume columns, which is very different from deep TZD sources of accessory minerals. Incorporation of these authigenic minerals into HMT is presumed to have occurred by an eruption plume in the conduit or just above the vent. The former is supported by agglutinate particles which are presumed to be authigenic clay 
aggregates coated in basaltic glass. Authigenic hydrothermal minerals are therefore considered to be accidental lithics.

\section{Fragmentation and Eruption Style}

\section{Fragmentation Style Background}

Magma fragmentation may broadly be categorized as either effusive (nonexplosive), or explosive. Various magma fragmentation styles have been linked to different eruption styles. Non-explosive magma fragmentation includes autoclastic processes, while explosive fragmentation styles include (1) magmatic, (2) phreatic, and (3) phreatomagmatic explosivity (Büttner et al., 2002; Liu et al., 2017; Wohletz, 1986; Zimanowski et al., 1997). Fragmentation style may be inferred from vitriclast texture and unique morphologies (Büttner et al., 2002; Wohletz, 1983; Zimanowski et al., 1997) and are tested against results presented in this thesis below.

\section{Autoclastic Fragmentation}

Autoclastic (non-explosive) fragmentation, broadly including thermal quench granulation, occurs when magma / lava behaves as a brittle material and fractures under applied stress supplied by a moving lava flow or a lava flow flowing down a steep slope (Porreca et al., 2014; Skilling et al., 2001). Thermal quench granulation, sometimes described as autoclastic fragmentation, occurs when magma is cooled on contact with water and contracts rapidly, quenching under stress and fragmenting. 


\section{Magmatic Explosivity}

Magmatic explosivity is driven by volatile (namely $\mathrm{SO}_{2}, \mathrm{CO}_{2}$ and $\mathrm{H}_{2} \mathrm{O}$ )

degassing and rapid magma ascent (Sparks et al., 1977; Zimanowski et al., 1997 Clague et al. 2003). Coalescence of magmatic volatiles in low viscosity magmas (e.g. basalt) create large "slugs" that buoyantly rise through the conduit. Explosivity is constrained by numerous factors including gas expansion and overpressures, magma viscosity, conduit properties, and, particularly in submarine environments, overlying hydrostatic pressure (Papalle et al., 1999; Wilson et al., 1980; Clague et al., 2003). Although the juvenile products of magmatically explosive eruptions can be recognized in part by highly vesicular ash and lapilli in subaerial eruptions (Sparks et al., 1977; Heiken and Wohletz, 1991), the presence of such deposits in submarine environment are lacking and therefore explosive eruptions on the seafloor are somewhat debated (Maicher et al., 2000; White et al., 2003; Schipper et al., 2013; Cas et al., 2003). Nevertheless, active explosive eruptions on West Mata and NW-Rota-1 volcanoes in the Southwest Pacific conclusively show that explosive eruption can and do occur on the seafloor (Deardorff et al., 2011).

\section{Phreatic}

Phreatic eruptions are steam-driven explosive events that occur in the subsurface when water flashes to steam upon interaction with hot volcanic material (Barberi et al., 1992). Magmatic heat transfer to often circulating water sources (e.g. lakes, groundwater, shallow ocean) results in super-heated steam 
explosions driven by vapor expansion (Barberi et al., 1992; Germanovich and Lowell, 1995). The result is a violent eruption that fragments the host rock without direct interaction of magma (Ollier et al., 1974). Products of phreatic eruptions therefore only include country rock fragments while juvenile volcaniclasts are absent.

\section{Phreatomagmatic}

Phreatomagmatic eruptions differ from phreatic eruptions in that they involve direct interaction of water with magma, resulting in a rapid transition from liquid to vapor (steam) bubbles. The result is a highly explosive eruption (Büttner et al., 2002; Zimanowski et al., 1997) driven by molten fuel-coolant interaction (MFCl; White, 1996). MFCl refers to interaction between a fuel (magma) and a coolant (water) resulting in a highly explosive fragmentation process which occurs in four distinct stages over several milliseconds (White,1996). First, (i) contact between the fuel and coolant results in a stable vapor film. Next, (ii) the vapor film collapses resulting in transfer of thermal energy to mechanical energy driving fragmentation of fine, "primary" particles. Next, (iii) coolant expands explosively upon coolant "flashing" of bulk material mixing. During the last stage, (iv) "induced fragmentation" occurs when explosive expansion propels primary particles and melt into other particles resulting in "secondary" particles. These stages assume expansion of $\mathrm{H}_{2} \mathrm{O}$ from liquid to gas. Extreme pressures in subaqueous environments reduce the potential for phreatomagmatic explosivity by lowering the expansion capacity of the liquid-to-gas phase transition of water 
(Büttner et al., 2002; Zimanowski et al., 1997). MFCl is limited to the critical point of seawater (30 MPa; Bischoff and Rosenbauer, 1985; Portner et al., 2014), below which, heated seawater would behave as a supercritical fluid limiting any steam / vapor expansion.

In contrast to other eruption styles, which generally do not contain juvenile clasts and are highly vesicular (Heiken, 1972; Wohletz and Krinsley, 1982; McPhie et al., 1990), phreatomagmatic eruptions are generally characterized by fine-grained juvenile vitriclasts (Wohletz et al., 1986; White, 1996) that are "dense" or angular / blocky and often show brittle fragmentation features (e.g. step-fractures, pitting; Büttner et al., 1999; Büttner et al., 2002).

Phreatomagmatic explosivity and autoclastic fragmentation may occur together as seawater and magma interact resulting in an initial explosive fragmentation from steam-expansion and secondarily by thermal quench granulation (Van Otterloo et al., 2015).

\section{HMT Eruption Style and Fragmentation Mechanism}

\section{Subsample Population Morphology}

Ash particle shape analysis has been used extensively to infer fragmentation mechanism and / or eruption style (e.g. Dellino and La Volpe, 1996; Buttner et al., 2001; Riley et al., 2003; Maria and Carey, 2007; Leibrandt and Le Pennec, 2015; Liu et al., 2015; Buckland et al., 2017 Nurfiani et al., 2017). Representative datasets from Axial Seamount's HMT subsamples were plotted using SLD vs. CVX plots and compared to other known eruptions including Surtsey, Mount St. 
Helens, Tambora, and MOK seamount from the East Pacific Rise (Fig. 45). Table 15. summarizes sample comparisons to those analyzed from Axial Seamount and West Mata. Ash analyzed from phreatic (Surtsey) and magmatically explosive style eruptions (Mount St. Helens and Tambora) generally have lower solidity values and significantly lower convexity values indicating higher textural roughness correlating to higher vesicularities (Liu et al. 2015). Axial Seamount vitriclasts have similar solidity and convexity values to the MOK seamount data (>2000 m deep near the East Pacific Rise), analyzed by Maria and Carey (2007). High solidity and convexity values (>0.8 \& 0.8 respectively) are indicative of "dense" particles with low textural roughness, which are consistent the low volumes of volatile exsolution common in deep-marine eruptions.

SLD vs. CVX comparison plots of lithofacies in push cores, scoop bags, and a subsample from the 2009 West Mata eruption, shows some variability (Fig. 39; Table 13). While data suggest that there is a difference in fragmentation style between subsamples collected from lithofacies (TM, HMT, LPT), scoop bag subsamples, and other submarine volcanic samples, SLD vs. CVX plots do not appear to differentiate between subsamples collected from TM, HMT, and LPT. To further explore difference in fragmentation mechanisms between push core and scoop bag subsamples, convexity frequency distribution curves were analyzed. 


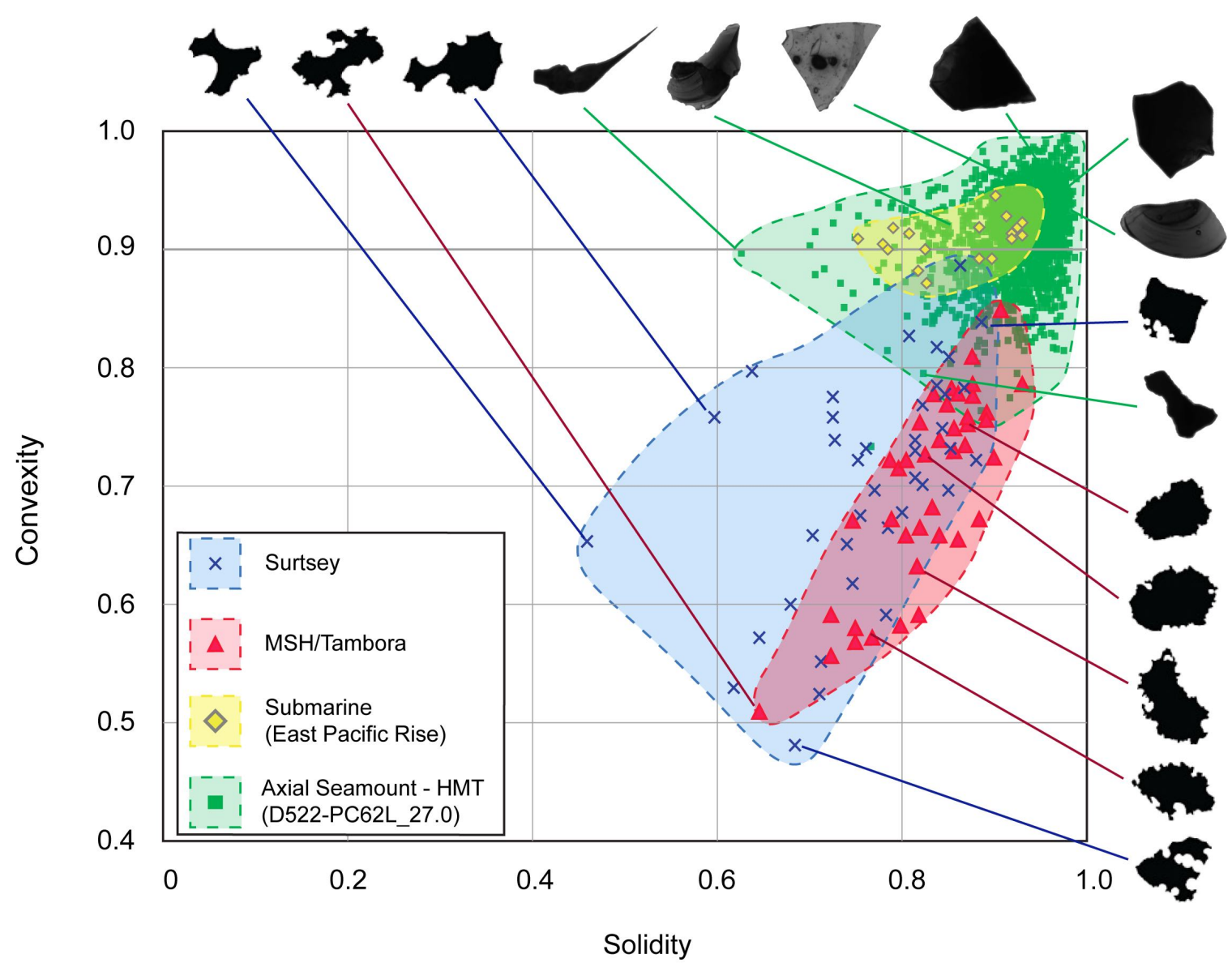

Figure 45. SLD vs. CVX plot of a representative HMT subsample (D522-

PC62L_27.0) compared to other ash samples. Lower convexity values shallowmarine (Surtsey) and subaerial eruptions (MSH and Tambora) correlate to higher vesicularity (Maria and Carey, 2007). HMT shows high convexity and solidity values similar to ash from MOK seamount (yellow) on the East pacific Rise, both of which have low vesicularity. Refer to Table 15 for sample comparisons. 
Table 15. Samples used for ash morphology comparison.

\begin{tabular}{|c|c|c|c|c|c|c|c|c|}
\hline $\begin{array}{r}\text { Location I } \\
\text { Samples }\end{array}$ & Occurance & $\begin{array}{c}\text { Eruption } \\
\text { year / age }\end{array}$ & Composition & $\begin{array}{c}\text { Magma } \\
\text { fragmentation } \\
\text { process }\end{array}$ & $\begin{array}{l}\text { Volcanic } \\
\text { explosivity } \\
\text { index (VEI) }\end{array}$ & $\begin{array}{c}\text { Grain size } \\
\text { analyzed } \\
(\mu \mathrm{m})\end{array}$ & $\begin{array}{l}\text { Vesicularity } \\
(\%)\end{array}$ & References \\
\hline $\begin{array}{c}\text { Axial Seamount } \\
T M \\
H M T \\
\text { LPT } \\
\text { Scoop Bags }\end{array}$ & Submarine (>1400 m) & $<1,500$ ya & Basalt & $\begin{array}{c}\text { Magmatic (TM) } \\
\text { Phretomagmatic (HMT) } \\
\text { Magmatic (LPT) } \\
\text { Autoclastic (Scoop Bags) }\end{array}$ & N/A & $250-500$ & $<10$ & $\begin{array}{l}\text { This study; Portner et al. (2015) } \\
\text { and references within }\end{array}$ \\
\hline $\begin{array}{l}\text { West Mata } \\
\qquad \begin{array}{l}\text { J2-417_r28 } \\
\text { J2-418_Sed7 }\end{array}\end{array}$ & Submarine (1200 m) & 2009 & Boninite & Magmatic? & N/A & $250-500$ & 31.4 & Resing et al. (2011) \\
\hline MOK Seamount & Submarine $(>2000 \mathrm{~m})$ & N/A & Basalt & Autoclastic & $\mathrm{N} / \mathrm{A}$ & $250-500$ & $<10$ & $\begin{array}{l}\text { Maria and Carey (2007) and references within; } \\
\text { Liu et al. (2015) and references within }\end{array}$ \\
\hline Mt. St. Helens & Subaerial & 1980 & N/A & Magmatic & 4 & $250-500$ & $\sim 79$ & $\begin{array}{l}\text { Newhall and Self (1982); King and Cashman (1994); } \\
\text { Liu et al. (2015) and references within }\end{array}$ \\
\hline Tambora & Subaerial & 1815 & Trachy-andesite & Magmatic & 7 & $350-500$ & $\sim 50$ & $\begin{array}{l}\text { Newhall and Self (1982); Gertisser et al. (2011); } \\
\text { Liu et al. (2015) and references within }\end{array}$ \\
\hline Surtsey & $\begin{array}{l}\text { Submarine }(<100 \mathrm{~m}) / \\
\text { subaerial }\end{array}$ & $1963-1964$ & Basalt & Phreatomagmatic $^{\mathrm{b}}$ & 2 & $250-500$ & $\sim 45$ & $\begin{array}{l}\text { Newhall and Self (1982); Moore (1985); } \\
\text { Liu et al. (2015) and references within }\end{array}$ \\
\hline $\begin{array}{l}\text { Tungurahua (2001) } \\
\text { TU2001-3 } \\
\text { TU2001-5 }\end{array}$ & Subaerial & 2001 & Andesite & Magmatic & 2 & $250-300$ & $N / A$ & $\begin{array}{l}\text { Leibrand and Le Pennec (2012; Leibrand and Le } \\
\text { Pennec (2015) and references within }\end{array}$ \\
\hline $\begin{array}{l}\text { Tungurahua (2006) } \\
\text { TU-2006-6 }\end{array}$ & Subaerial & 2006 & Andesite & Magmatic & 3 & $250-300$ & $N / A$ & $\begin{array}{l}\text { Fee et al. (2010); Leibrand and Le Pennec } \\
\text { (2015) and references within }\end{array}$ \\
\hline $\begin{array}{l}\text { Puy de Montchal } \\
\text { MC6ka-1 }\end{array}$ & Subaerial & $6.6 \mathrm{ka}$ & Basalt & Magmatic & N/A & $250-300$ & $N / A$ & $\begin{array}{l}\text { Leibrand and Le Pennec (2015) and references } \\
\text { within }\end{array}$ \\
\hline \multicolumn{9}{|c|}{$\begin{array}{l}\text { Notes: } \\
\text { a Arqued in this studv } \\
{ }^{\mathrm{b}} \text { Phreatomaamatic includes maama-water interaction above the vent }\end{array}$} \\
\hline $\begin{array}{l}\text { Abbreviations: } \\
\text { ka: thousand years } \\
\text { m: meters } \\
\text { N/A: Not described } \\
\text { VEl: Volcanic explo } \\
\text { ya: years ago }\end{array}$ & $\begin{array}{l}\text { ago } \\
\text { osivity index }\end{array}$ & & & & & & & \\
\hline
\end{tabular}


Convexity distribution curves were compared to subaerial volcanic ash samples of known eruption styles and inferred fragmentation mechanisms (Fig. 46A; Table. 15). Leibrandt and Le Pennec (2015) plotted convexity frequency distribution curves of four samples. Samples TU2001-5 and TU2001-3 are from the 2001 eruption of Tungurahua (andesitic stratovolcano in Ecuador), which is described as small-scale strombolian style eruption. The same volcano produced sample TU-2006-6, which was from a much more explosive plinian style eruption in 2006. The fourth sample, MC6ka-1, is from Puy de Montchal (basaltic scoria cone) in France, which formed from a strombolian style eruption. Axial Seamount vitriclast subsamples from TM, HMT, LPT, and subsamples from West Mata (J2417_r28 and J2-418_Sed7) were separated and plotted with similar distribution frequencies for comparison.

Subsamples from TM and LPT are similar to subsamples from West Mata (Fig. 46B), potentially suggesting a similar fragmentation style. Observations from West Mata show that the eruption was strombolian and produced vesicular and fluidal (limu o' Pele) vitriclasts (Resing et al., 2011; Clague et al., 2009a), suggesting that LPT and TM may also have formed by a similar eruption style. These subsamples are similar to ash sampled from Strombolian eruptions at Puy de Montchal.

The HMT subsample resembles ash analyzed from the 2006 eruption at Tungurahua (Fig. 46D), which is distinctly different from samples interpreted to have been fragmented by non-explosive (autoclastic) and explosive (pyroclastic) 

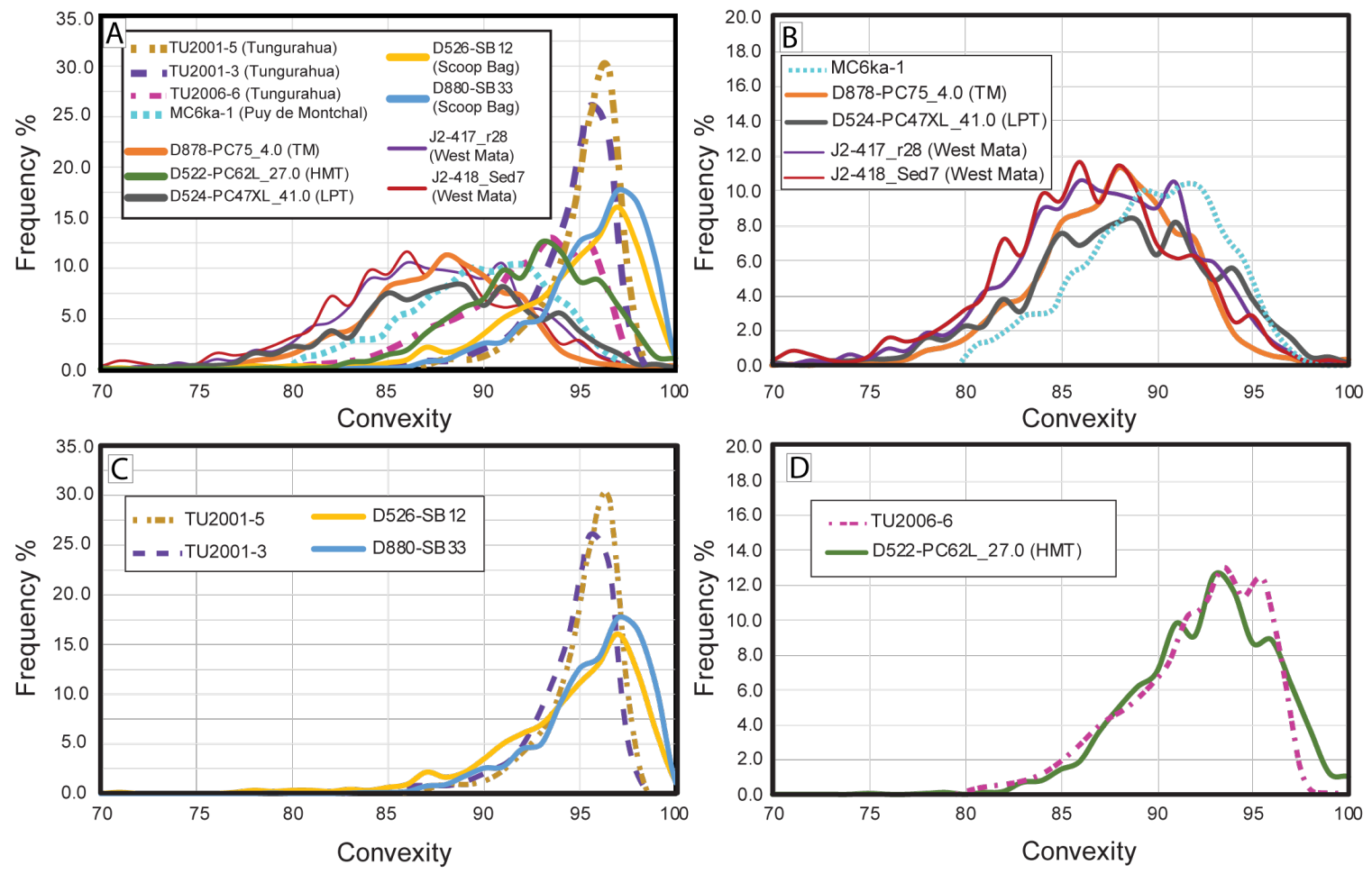

Figure 46. (A) Convexity distribution curves for all subsamples from Axial Seamount compared to the West Mata subsample, and subaerial eruptions analyzed by Leibrandt and Le Pennec (2015). TU-2001 is from the 2001 eruption of Tungurahua (Andesitic stratovolcano in Ecuador). TU-2006 is from the 2006 Tungurahua eruption. MC6ka is a sample from Puy de Montchal (basaltic scoria cone) in France. (B) Scoop bag subsamples from Axial Seamount (autoclastic fragmentation) are similar to the 2001 eruption of Tungurahua. (C) West Mata subsample (strombolian eruption style) is similar to TM and LPT lithofacies subsamples from Axial Seamount. These also show a similar peak location to ash from Puy de Montchal. (D) HMT subsample is notably different from scoop bag subsamples, West Mata, and other lithofacies (TM and LPT). It also shows a similar distribution to the 2006 Tungurahua eruption. Note different scales used in $B$ and $D$ to show distribution curves more clearly. Refer to Table 15 for sample comparisons. 
processes. The 2006 eruption at Tungurahua was more explosive (volcanic explosivity index: 3; Fee et al., 2010) compared to the 2001 eruption (volcanic explosivity index: 2; Le Pennec et al., 2012) resulting in a different ash morphology signature (Leibrandt and Le Pennec, 2015). Therefore, the unique curve of HMT compared to other submarine subsamples may imply a different fragmentation mechanism is responsible compared to scoop-bag subsamples, TM / LPT lithofacies, and West Mata.

Although there are similarities in subsample convexity distributions compared to those measured by Leibrandt and Le Pennec (2015), more work is required to better understand differences in ash morphology related to eruption style and fragmentation mechanisms in submarine vs. subaerial eruptions. Specifically, the practice of comparing submarine ash subsamples from Axial Seamount to subaerial eruptions may not be directly analogous due to entirely different magma compositions, volatile contents, vesicularities, conduit geometries, and ambient pressures at the vent surface. Nonetheless, similarities in convexity histograms of vitriclasts analyzed from Axial Seamount and West Mata (submarine) show distinct segregation, similar to differences in subaerial eruptions with different fragmentation mechanisms and eruption styles. The uniqueness of the HMT subsample compared to other lithofacies (TM and LPT), scoop bag subsamples, and strombolian style ash subsamples from West Mata supports the idea that ash within HMT was fragmented by a mechanism other 
than autoclastic fragmentation or magmatic explosivity during strombolian-style bubble bursts.

\section{Vitriclast Texture}

The texture of juvenile vitriclasts (size, shape, and vesicularity) provides insight into fragmentation energy and mechanism (Wohletz et al., 1995; White, 1996; Deardorff et al., 2011). Point count results show that vitriclasts are the primary component of HMT lithofacies ( $60 \%$; Fig. 23). While vitriclasts dominate coarser grain-size fractions, fine grain-sizes $(<125 \mu \mathrm{m})$ consist of $>40 \%$ vitriclasts implying that PSA analysis of bulk HMT represents the vitriclasts fraction. The mean grain-size of HMT is about $100 \mu \mathrm{m}$ (Fig. 20), which is consistent with high fragmentation energy and the likely involvement of external water (Wohletz et al., 1983; White, 1996). The fine-grained nature of HMT is therefore consistent with the highly energetic phreatomagmatic eruption style.

Texture is also strongly controlled by the physical state of the magma (liquid or solid) and fragmentation mechanisms. Vitriclasts may be divided into two distinct shapes, fluidal and angular / blocky. Fluidal vitriclasts occur when magma is fragmented while in a ductile state while angular / blocky vitriclasts occur once magma is in a brittle state after cooling below the glass-transition temperature (Tg; Allen et al., 2010). The Tg is defined as a kinetic transition of a magma from a liquid to solid-like behavior (Porreca et al., 2014).

Point count and MGS results of vitriclast morphology (Figs. 22B and 40) reveal that the vast majority ( $>90 \%$ ) of vitriclasts in the $125-250 \mu \mathrm{m}$ size 
fraction are angular / blocky while fluidal particles make up $<10 \%$. These results suggest that fragmentation styles predominantly occurred while magma was in a brittle-state. Moreover, the lack of fluidal vitriclasts in HMT argues against a magmatic explosivity fragmentation style (e.g. strombolian style), which has been the preferred submarine explosive eruption mechanism (Clague et al., 2009b; Resing et al. 2011) .

Morphologies of angular vitriclasts (Fig. 38) have surface features representative of brittle fragmentation including conchoidal fracturing and stepfractures. Both of these surface features form by MFCl processes during phreatomagmatic eruptions (White, 1996; Buttner et al., 1999; Buttner et al., 2002). Pitted features on fresh vitriclasts (Fig. 38B-3B) are particularly useful in identifying MFCl processes as they are thought to occur due to hydrothermal fluids etching of volcanic glass in the subsurface during ascent (Buttner et al., 2002). Rigid surface features observed in HMT vitriclasts supports brittle fragmentation.

Vesicularity is an important component of vitriclast texture and is controlled by volatile exsolution. High vesicularity is ubiquitous in explosive magmatic eruptions on land where volatile degassing and gas expansion drives explosivity (Sparks et al., 1977). Vesicular vitriclasts are uncommon $(<0.2 \%$ of total HMT subsamples on average), which is also evident by the "dense" particle populations in SLD vs. CVX plots. MGS results of SLD vs. CVX plots reveal that all subsamples have high solidity and convexity values therefore corresponding 
to low textural and morphological roughness (Liu et al., 2015). These results are consistent with low quantities of vesicular vitriclasts determined in point counts. Lack of vesicular vitriclasts in fine-grained ash is consistent with phreatomagmatic eruptions driven by MFCl (Buttner et al., 2002; White, 1996).

\section{Fragmentation and Eruption Style Conclusions}

Convexity distribution curves comparing LPT, TM, and subsamples from West Mata, all of which are inferred to have fragmented during strombolian style eruptions (Resing et al., 2011), have different peak locations compared to HMT, and are distinctly different from Axial Seamount scoop bag subsamples inferred to have fragmented by autoclastic (non-explosive) fragmentation. This implies that the majority of vitriclasts within HMT were not fragmented by magmatic volatile overpressures or autoclastic processes.

HMT is dominated by dense angular / blocky vitriclasts, which represent a fragmented very poorly vesicular melt. Low proportions of fluidal shards in HMT suggest that magma fragmented while in a brittle state and that strombolian eruptions were not the primary eruption style responsible for vitriclasts observed in HMT. Vitriclast surface features including step-fractures and conchoidal fractures, consistent with brittle fragmentation. Surface pitting may be indicative of fresh vitriclasts interacting with hydrothermal fluids in the subsurface consistent with phreatomagmatic eruptions.

The fine-grained nature of HMT ( 100 $\mu$ m peak mode $)$ and abundance of lithics within HMT are consistent with experiments by Wohletz et al. (1986) and 
White (1996), and analysis of natural pyroclasts (Deardorff et al., 2011) indicating phreatomagmatic eruptions by MFCl. Chemical heterogeneity of vitriclasts (Portner et al., 2015) support the idea that some vitriclasts are cognate lithics, products of previous eruptions that were incorporated into the erupted plume. Additionally, the presence of accessory lithics (see non-primary volcaniclast origin - conduit wall-rock) are indicative of phreatomagmatic eruptions, where conduit walls are stripped and incorporated during magma ascent (Deardorff et al., 2011). Portner et al. (2015) estimated combined lithostatic and hydrostatic pressures on Axial Seamount to be about $29.0 \mathrm{MPa}$ above the melt lens, or 600 mbsf. Based on the provenance of accessory lithics it is estimated that fragmentation by $\mathrm{MFCl}$ on Axial Seamount would therefore be limited to a depth of $\sim 600-800$ mbsf near the critical point of seawater (Fig. 47).

\section{Deep Marine Dispersal}

Historically, maximum dispersal of pyroclastic material in submarine volcanic settings has been estimated to be only tens of meters (Head and Wilson, 2003). The intense hydrostatic pressure coupled with the relatively high viscosity of seawater in deep-marine environments relative to subaerial settings, has been though to limit dispersal of volcaniclastic material (Cashman and Fiske, 1991). However, multiple examples have recently been described where volcaniclastic deposits have been observed several kilometers away from the source in deepmarine settings (e.g. Ferguson et al., 2017; Clague et al., 2009b; Walker et al., 2007). 


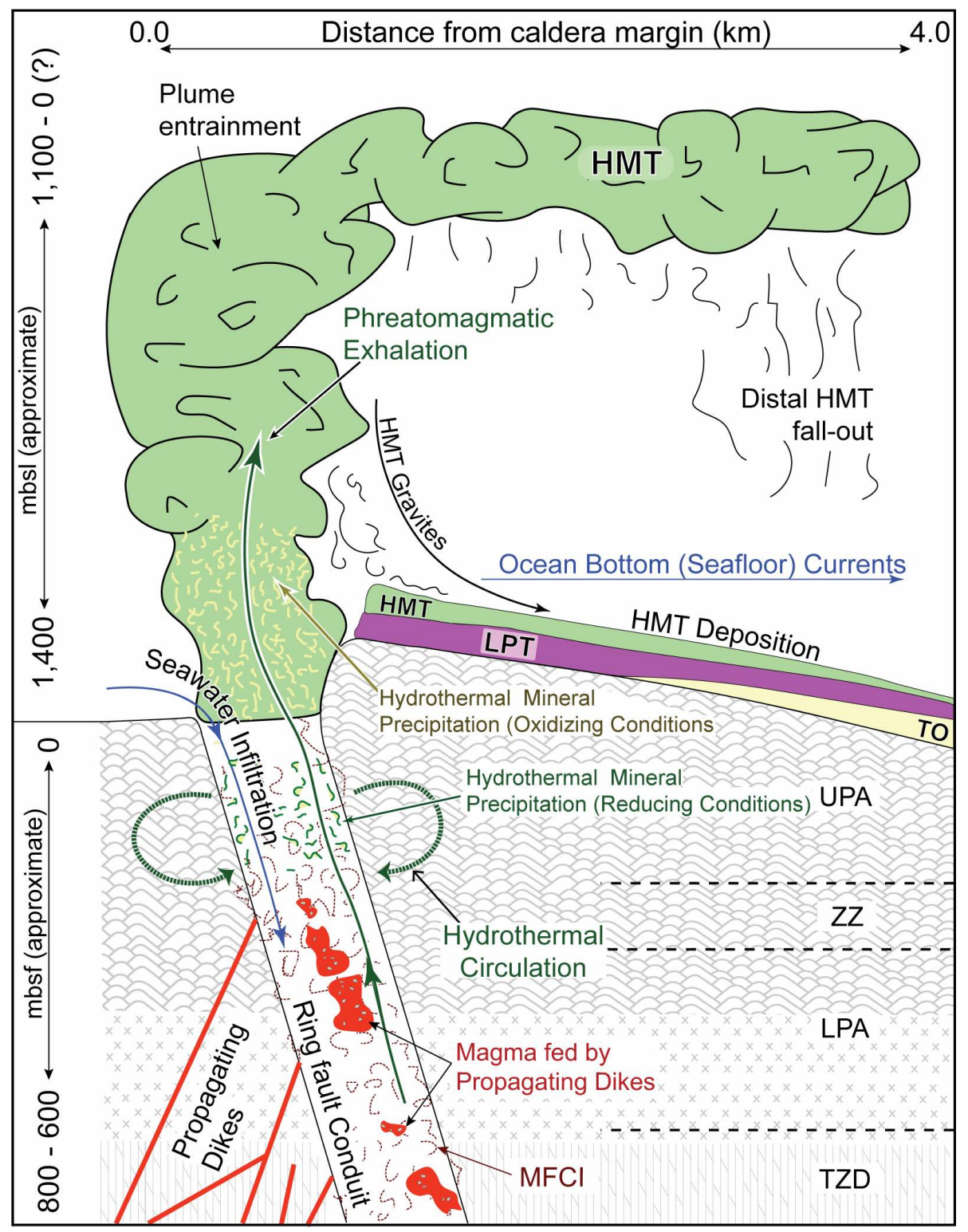

Figure 47. Conceptual model of mechanisms responsible of HMT formation and deposition. Dikes propagate to and through caldera ring fault system. Seawater infiltrates ring faults and facilitates magma-seawater interaction and $\mathrm{MFCl}$ at a depth of 600-800 mbsf (maximum depth is dependent on critical point of seawater). Phreatomagmatic exhalation (large green arrow) strips bedrock and well-rock thus incorporating accessory lithics in conduit, and authigenic minerals from circulating low-temperature hydrothermal fluids (green curved arrows) under reducing conditions. Above the vent, the phreatomagmatic plume entrains authigenic minerals precipitating in the water column under oxidizing conditions. Deposition of HMT is facilitated by bottom currents, plume-collapse gravites, and plume entrainment and fall-out over $3.5 \mathrm{~km}$ away from the source. Alteration zones (Alt et al., 1986) shown for reference. 
Three primary mechanisms have been proposed for transporting volcanic material in submarine settings and include (1) plume entrainment and subsequent fall-out (Clague et al., 2009b; Barreyre et al., 2011; Verolino et al., 2018), (2) sediment gravity flows (Doronzo and Dellino, 2012; Walker et al., 2019), and (3) bottom current transport of re-worked material (Stow and Lovel, 1979). Dispersal by plume entrainment involves an eruption launching pyroclasts into the water column where they are entrained by warm, buoyant fluids, which eventually fall-out due to gravity (Clague et al., 2009b). Settling velocity experiments by Barreyre et al., 2011 suggest that clast size and shape strongly influence the dispersal distance of particles by plume entrainment and subsequent fall-out and may result in blocky glass shards up to $1 \mathrm{~mm}$ being transported up to $1 \mathrm{~km}$, while smaller $(\sim 0.5 \mathrm{~mm})$ bubble-shards can be transported several kilometers away from the source. Plume entrainment and fall-out therefore preferentially sorts material due to different settling velocities of particles often resulting in normal grading and a decrease in grain-size with increasing distance from the source (Barreyre et al., 2011).

Based on the $100 \mu \mathrm{m}$ mean grain-size of HMT and extrapolation of settling velocity experiments by Barreyre et al. (2011), average settling velocity of HMT material is approximately $1 \mathrm{~cm} / \mathrm{s}$ which has the potential to transport material on Axial Seamount more than $3.5 \mathrm{~km}$ away from the inferred source (caldera) with a minimum plume height of $1,000 \mathrm{~m}$ above the seafloor. Ongoing unpublished work suggests that pyroclasts may have reached the ocean surface, well above 1,000 
$\mathrm{m}$ above the seafloor, by megaplume entrainment (Clague pers. Comm.). Additional work modeling volcanic plumes in deep-marine settings and vitriclast dispersal is necessary to determine whether Axial Seamount's eruptions could have facilitated plumes capable of dispersing vitriclasts to the extent observed.

Several types of gravity flows exist in submarine volcanic environments including volcanic turbidity currents, (VTC's) caused by slope failure or seismicity, and pyroclastic density currents (PDC's) where the flow is triggered by plume-collapse. Studies by Pritchard and Gladstone (2009) \& Brand and Clarke (2012) found that VTC's and PDC's have similar flow dynamics; therefore, for the purposes of this study, we use the term "gravite" (Gani, 2003) to refer to deposits generated by both mechanisms. Volcaniclastic gravites have the ability to transport sediment in excess of 5 kilometers (Brand and Clarke, 2012). Additionally, Walker et al. (2019) discussed the ability of volcaniclastic gravites to detach (liftoff), from the seafloor creating a buoyant plume by that could be transported several kilometers. As with the plume entrainment mechanism, turbulent gravity flows also preferentially sort sediment generally resulting in wellsorted material that is generally normal-graded (Bouma, 1962), but in contrast, may also exhibit reverse-graded bedding in higher density gravity flows over significantly short transport distances (tens of meters) with non-turbulent flow (e.g. grain flow; Fisher, 1971).

Relatively gentle slopes on Axial Seamount reduce the chances that VTC's are caused by slope failure (Van Andel and Komar, 1969); however, they could 
be triggered by overburden through volcaniclastic accumulation, particularly near vents. They could also be triggered by eruption plume-collapse. Although wellsorted material, well-defined ash laminations and normal grading may be indicative of gravites, the fine-grained nature of HMT coupled with the "reversenormal graded" structures in proximal and medial cores and diffuse ash laminations in distal cores argue against gravites as being the primary dispersal mechanism. While VTC's could have occurred in proximal settings, particularly near caldera margins, they do not explain the presence of HMT extending 3.5 $\mathrm{km}$.

Bottom currents on the seafloor have the potential to re-mobilize and disperse sediment resulting in contourite deposits (Stow and Lovell, 1979). Contourite deposits often exhibit normal grading, parallel laminae, and ripples, in finegrained, well-sorted sediment (Shanmugam et al., 1993; Martín-Chivelet et al., 2008; Rebesco et al., 2014). Although often described in continental slope settings, multiple examples have been described in deep-marine settings (e.g. Stow et al., 2002; Hernández-Molina et al., 2008). Xu and Lavelle (2017) modeled bottom currents on Axial Seamount suggesting the possibility of volcaniclastic dispersal by bottom currents.

The fine-grained, well sortied nature of ash laminations (well-defined and diffuse), and "reverse-normal grading" structures in HMT are all features identified in contourites deposited by bottom currents (Stow et al., 1979; Shanmugam et al., 1993; Martín-Chivelet et al., 2008). Bottom current models by 
Xu and Lavelle (2017) show significant bottom current velocities $(10-11 \mathrm{~cm} / \mathrm{s})$ extending more than $200 \mathrm{~m}$ above Axial Seamount's summit in a toroidal (anticyclonic) pattern. Bottom currents have the potential to transport HMT more than $3.5 \mathrm{~km}$ away from the source (Fig. 47).

Although grain-size analysis and visual observations of core structures and depositional / thickness trends allows us to make inferences on dispersal mechanisms, further analysis is required. Multiple mechanisms likely attributed to HMT dispersal. Future work to model plume dynamics and vitriclast dispersal on Axial Seamount is ongoing.

\section{CONCLUSION}

Phreatomagmatic eruptions during caldera collapse on Axial Seamount produced a unique volcaniclastic lithology, hydrothermal muddy tuff (HMT) lithofacies, containing fine-grained vitriclasts, and crystalline bedrock and hydrothermal lithics. The uniqueness of this lithofacies, unlike any other lithology on Axial Seamount, is due in part to magma-seawater interaction along ringfaults of the caldera system. The depth in the crust of this interaction is constrained by the formation temperatures of accessory lithics mineralogy in HMT (e.g. greenschist grade fragments) and is close to the critical point of seawater between 600-800 mbsf. Bedrock fragmentation during eruption stripped the conduit walls during ascent and incorporated parts of the basal portion of the upper oceanic crust (pillow basalt section) into the ascending eruption plume. Abundant high temperature clays at the top of HMT in proximal and medial cores 
may suggest that deeper crust was stripped during the last phase of phreatomagmatic exhalation.

Magma fragmentation during phreatomagmatic eruption was driven by $\mathrm{MFCl}$. Non-fluidal and poorly to non-vesicular textures indicates that the majority of vitriclasts fragmented while their parent magma was in a brittle state and argues against fragmentation by magmatic volatile degassing alone. Ash morphology trends of HMT compared to deposits of known autoclastic and strombolian-style fragmentation processes suggests that its erupting magma fragmented by a different mechanism. The fine grain-size of HMT (average peak mode $100 \mu \mathrm{m}$ ) implies high fragmentation energy consistent with MFCl (Wohletz et al., 1986; White, 1996). Such high energy interaction would generate the abundance of accidental lithics within HMT, further supporting a phreatomagmatic origin where conduit walls were stripped during by MFCI processes.

Upon eruption through the vent and into the ocean column, the eruption plume precipitated authigenic hydrothermal minerals at low-moderate temperatures $\left(40-170^{\circ} \mathrm{C}\right)$. This is supported by the notable absence of hightemperature hydrothermal minerals (e.g. siderite, cubanite, chalcopyrite) common in more typical black smoker deposits. Mineral precipitation near the vent is supported by the presence of unique agglutinate particles, which indicates that magma was still molten when it interacted with the hydrothermal mineral precipitates. 
The resulting phreatomagmatic eruption plume dispersed HMT over $3.5 \mathrm{~km}$ away from the caldera source. Deposition of HMT occurred by different dispersal mechanisms including plume entrainment and fall-out, ocean bottom currents, and, perhaps, localized plume-collapse-induced gravites near caldera margins. Plume fall-out in proximal and medial locations $(<2 \mathrm{~km})$, and fluctuating eruption flux or bottom currents created laminations with "reverse-to-normal graded" structures. Lack of well-defined ash laminations in distal cores supports reworking of HMT by ocean bottom currents.

In summary, this study provides insight into how caldera formation can influence deep-marine eruption processes. Lithic provenance data are critical and may be used to distinguish phreatomagmatic vs. other eruptions styles in deep-sea settings. Although work presented here distinguished accessory and accidental lithics, future geochemical work is required to identify juvenile vitriclasts from cognate lithics, which would help confirm models of primary magma fragmentation. The vitriclast morphology datasets form this study is one of the first of its kind and may be used to populate a database with standardized ash morphometric parameters, which would aid future comparison of eruption styles and environments (e.g. subaerial). Such a database will be invaluable in helping future marine volcanologists identify the fingerprints of deep-marine pyroclastic eruptions, a still highly debated topic. Combined with a spatial analysis of the associations between lithofacies to mapped fissures and lava 
flows, future workers will better understand the connection between volcaniclast dispersal processes and eruption styles in the deep sea. 


\section{References}

Airo, M., 2002, Aeromagnetic and aeroradiometric response to hydrothermal alteration: Surveys in Geophysics, v. 23, p. 273-302.

Allen, S.R., Fiske, R.S., and Tamura, Y., 2010, Effects of water depth on pumice formation in submarine domes at Sumisu, Izu-Bonin arc, western Pacific: Geology, v. 38, p. 391-394.

Alt, J.C., Honnorez, J., Laverne, C., and Emmermann, R., 1986, Hydrothermal alteration of a $1 \mathrm{~km}$ section through the upper oceanic crust, Deep Sea Drilling Project Hole 504B: Mineralogy, chemistry and evolution of seawaterbasalt interactions: Journal of Geophysical Research: Solid Earth, v. 91, p. 10309-10335.

Alt, J.C., and Jiang, W., 1991, Hydrothermally precipitated mixed-layer illitesmectite in recent massive sulfide deposits from the sea floor: Geology, v. 19, p. $570-573$.

Andrews, A.J., 1980, Saponite and celadonite in layer 2 basalts, DSDP Leg 37: Contributions to Mineralogy and Petrology, v. 73, p. 323-340.

Arevalo Jr, R., and McDonough, W.F., 2010, Chemical variations and regional diversity observed in MORB: Chemical Geology, v. 271, p. 70-85.

Barberi, F., Bertagnini, A., Landi, P., and Principe, C., 1992, A review on phreatic eruptions and their precursors: Journal of Volcanology and Geothermal Research, v. 52, p. 231-246.

Barberi, F., Cioni, R., Rosi, M., Santacroce, R., Sbrana, A., and Vecci, R., 1989, Magmatic and phreatomagmatic phases in explosive eruptions of Vesuvius as deduced by grain-size and component analysis of the pyroclastic deposits: Journal of Volcanology and Geothermal Research, v. 38, p. 287-307.

Barreyre, T., Soule, S.A., and Sohn, R.A., 2011, Dispersal of volcaniclasts during deep-sea eruptions: Settling velocities and entrainment in buoyant seawater plumes: Journal of Volcanology and Geothermal Research, v. 205, p. 84-93.

Bayliss, P., Erd, D., Mrose, M., Sabina, A., and Smith, D., 1986, Mineral Powder Diffraction File Search Manual, JCPDS: International Center for Diffraction Data, USA. 
Beaufort, D., and Meunier, A., 1994, Saponite, corrensite and chlorite-saponite mixed-layers in the Sancerre-Couy deep drill-hole (France): Clay Minerals, v. 29, p. 47-61.

Berry, L.G., 1974, Selected powder diffraction data for minerals: Joint Committee on Powder Diffraction Standards, v. 1601.

Bischoff, J.L., and Rosenbauer, R.J., 1985, An empirical equation of state for hydrothermal seawater (3.2 percent $\mathrm{NaCl}$ ). American Journal of Science, $\mathrm{v}$. 285, p. $725-763$.

Blott, S.J., and Pye, K., 2001, GRADISTAT: a grain size distribution and statistics package for the analysis of unconsolidated sediments: Earth Surface Processes and Landforms, v. 26, p. 1237-1248.

Blount, C., 1977, Barite solubilities and thermodynamic quantities up to 300 degrees $C$ and 1400 bars: American Mineralogist, v. 62, p. 942-957.

Boles, J.R., 1977, Zeolites in low-grade metamorphic rocks: Mineralogy and Geology of Natural Zeolites, v. 4, p. 103-135.

Bouma, A., 1964, Turbidites, in Developments in sedimentology: Elsevier, p. 247256.

Brand, B.D., and Clarke, A.B., 2012, An unusually energetic basaltic phreatomagmatic eruption: using deposit characteristics to constrain dilute pyroclastic density current dynamics: Journal of Volcanology and Geothermal Research, v. 243, p. 81-90.

Brindley, G.W., 1952, Identification of clay minerals by X-ray diffraction analysis: Clays and Clay Minerals, v. 1, p. 119-129.

Browne, P., 1978, Hydrothermal alteration in active geothermal fields: Annual Review of Earth and Planetary Sciences, v. 6, p. 229-248.

Browning, J., and Gudmundsson, A., 2015, Caldera faults capture and deflect inclined sheets: an alternative mechanism of ring dike formation: Bulletin of Volcanology, v. 77, p. 4.

Buckland, H.M., Eychenne, J., Rust, A.C., and Cashman, K.V., 2018, Relating the physical properties of volcanic rocks to the characteristics of ash generated by experimental abrasion: Journal of Volcanology and Geothermal Research, v. 349, p. 335-350. 
Büttner, R., Dellino, P., and Zimanowski, B., 1999, Identifying magma-water interaction from the surface features of ash particles: Nature, v. 401, p. 688.

Büttner R., Dellino P., La, V.L., Lorenz V., and Zimanowski B., 2002, Thermohydraulic explosions in phreatomagmatic eruptions as evidenced by the comparison between pyroclasts and products from Molten Fuel Coolant Interaction experiments: Journal of Geophysical Research: Solid Earth, v. 107, p. ECV 5-1; ECV 5-14, doi: 10.1029/2001JB000511.

Caress, D.W., Clague, D.A., Paduan, J.B., Martin, J.F., Dreyer, B.M., Chadwick Jr, W.W., Denny, A., and Kelley, D.S., 2012, Repeat bathymetric surveys at 1-metre resolution of lava flows erupted at Axial Seamount in April 2011: Nature Geoscience, v. 5, p. 483.

Cas, R.A.F., Yamagishi, H., Moore, L., and Scutter, C., 2003, Miocene submarine fire fountain deposits, Ryugazaki Headland, Oshoro Peninsula, Hokkaido, Japan: implications for submarine fountain dynamics and fragmentation processes: Washington DC American Geophysical Union Geophysical Monograph Series, v. 140, p. 299-316.

Cashman, K.V., and Fiske, R.S., 1991, Fallout of pyroclastic debris from submarine volcanic eruptions: Science (New York, N.Y.), v. 253, p. 275-280, doi: 253/5017/275 [pii].

Chadwick, J., Perfit, M., Ridley, I., Jonasson, I., Kamenov, G., Chadwick, W., Embley, R., Le Roux, P., and Smith, M., 2005, Magmatic effects of the Cobb hot spot on the Juan de Fuca Ridge: Journal of Geophysical Research: Solid Earth, v. 110.

Chadwick Jr, W., Clague, D., Embley, R., Perfit, M., Butterfield, D., Caress, D., Paduan, J., Martin, J.F., Sasnett, P., and Merle, S., 2013, The 1998 eruption of Axial Seamount: New insights on submarine lava flow emplacement from high-resolution mapping: Geochemistry, Geophysics, Geosystems, v. 14, p. 3939-3968.

Chen, S., Ravelo, A., and Clague, D., 2015, Constraining Seasonal and Vertical Distributions of Planktonic Foraminifera for Paleoclimate Reconstruction Since MIS3 at the Axial Seamount, Juan de Fuca Ridge, in AGU Fall Meeting Abstracts.

Cioni, R., Santacroce, R., and Sbrana, A., 1999, Pyroclastic deposits as a guide for reconstructing the multi-stage evolution of the Somma-Vesuvius Caldera: Bulletin of Volcanology, v. 61, p. 207-222. 
Clague, D.A., Davis, A.S., and Dixon, J.E., 2003, Submarine strombolian eruptions on the Gorda mid-ocean ridge: Explosive Subaqueous Volcanism, v. 140 , p. $111-128$.

Clague, D., Rubin, K., and Keller, N., 2009a, Products of submarine fountains and bubble-burst eruptive activity at $1200 \mathrm{~m}$ on West Mata Volcano, Lau Basin, in AGU Fall Meeting Abstracts, .

Clague, D.A., Paduan, J.B., and Davis, A.S., 2009b, Widespread strombolian eruptions of mid-ocean ridge basalt: Journal of Volcanology and Geothermal Research, v. 180, p. 171-188.

Clague, D.A., Dreyer, B.M., Paduan, J.B., Martin, J.F., Chadwick, W.W., Caress, D.W., Portner, R.A., Guilderson, T.P., McGann, M.L., Hans, T., Butterfield, D.A., and Embley, R.W., 2013, Geologic history of the summit of Axial Seamount, Juan de Fuca Ridge: Geochemistry, Geophysics, Geosystems, v. 14, p. 4403-4443, doi: 10.1002/ggge.20240.

Cole, J., Milner, D., and Spinks, K., 2005, Calderas and caldera structures: a review: Earth-Science Reviews, v. 69, p. 1-26.

Coombs, D., 1954, The nature and alteration of some Triassic sediments from Southland, New Zealand, in Transactions of the Royal Society of New Zealand, , p. 109.

Deardorff, N.D., Cashman, K.V., and Chadwick Jr, W.W., 2011, Observations of eruptive plume dynamics and pyroclastic deposits from submarine explosive eruptions at NW Rota-1, Mariana arc: Journal of Volcanology and Geothermal Research, v. 202, p. 47-59.

Delaney, J.R., Kelley, D.S., Marburg, A., Stoermer, M., Hadaway, H., Juniper, K., and Knuth, F., 2016, Axial Seamount-wired and restless: A cabled submarine network enables real-time, tracking of a Mid-Ocean Ridge eruption and live video of an active hydrothermal system Juan de Fuca Ridge, NE Pacific, in OCEANS 2016 MTS/IEEE Monterey, IEEE, p. 1-8.

Dellino, P., and La Volpe, L., 1996, Image processing analysis in reconstructing fragmentation and transportation mechanisms of pyroclastic deposits. The case of Monte Pilato-Rocche Rosse eruptions, Lipari (Aeolian islands, Italy): Journal of Volcanology and Geothermal Research, v. 71, p. 13-29.

Doronzo, D.M., and Dellino, P., 2013, Hydraulics of subaqueous ash flows as deduced from their deposits: 2 . Water entrainment, sedimentation, and deposition, with implications on pyroclastic density current deposit 
emplacement: Journal of Volcanology and Geothermal Research, v. 258, p. 176-186.

Dreyer, B.M., Clague, D.A., and Gill, J.B., 2013, Petrological variability of recent magmatism at Axial Seamount summit, Juan de Fuca Ridge: Geochemistry, Geophysics, Geosystems, v. 14, p. 4306-4333, doi: 10.1002/ggge.20239.

Ellis, A.J., and Mahon, W., 1977, Chemistry and geothermal systems.

Fee, D., Garces, M., and Steffke, A., 2010, Infrasound from Tungurahua volcano 2006-2008: Strombolian to Plinian eruptive activity: Journal of Volcanology and Geothermal Research, v. 193, p. 67-81.

Feely, R.A., Lewison, M., Massoth, G.J., Robert-Baldo, G., Lavelle, J.W., Byrne, R.H., Von Damm, K.L., and Curl, H.C., 1987, Composition and dissolution of black smoker particulates from active vents on the Juan de Fuca Ridge: Journal of Geophysical Research: Solid Earth, v. 92, p. 11347-11363.

Ferguson, D.J., Li, Y., Langmuir, C.H., Costa, K.M., McManus, J.F., Huybers, P., and Carbotte, S.M., 2017, A 65 ky time series from sediment-hosted glasses reveals rapid transitions in ocean ridge magmas: Geology, v. 45, p. 491-494.

Fox, C.G., 1990, Evidence of active ground deformation on the mid-ocean ridge: Axial Seamount, Juan de Fuca Ridge, April-June 1988: Journal of Geophysical Research: Solid Earth, v. 95, p. 12813-12822.

Fisher, R.V., and Schmincke, H.U., 1984, Submarine Volcaniclastic Rocks: Pyroclastic Rocks. Springer, P. 265-296.

Folk, R.L., and Ward, W.C., 1957, Brazos River bar [Texas]; a study in the significance of grain size parameters: Journal of Sedimentary Research, v. 27 , p. 3-26.

Franceschelli, M., Carcangiu, G., Caredda, A., Cruciani, G., Memmi, I., and Zucca, M., 2002, Transformation of cumulate mafic rocks to granulite and reequilibration in amphibolite and greenschist facies in NE Sardinia, Italy: Lithos, v. 63, p. 1-18.

Galley, A.G., Hannington, M.D., and Jonasson, I., 2007, Volcanogenic massive sulphide deposits: Mineral Deposits of Canada: A Synthesis of Major DepositTypes, District Metallogeny, the Evolution of Geological Provinces, and Exploration Methods: Geological Association of Canada, Mineral Deposits Division, Special Publication, v. 5, p. 141-161. 
Gani, M.R., Crisis for a general term referring to all types of sediment gravity flow deposits: gravite, in 2003 Seattle Annual Meeting, poster.

Germanovich, L.N., and Lowell, R.P., 1995, The mechanism of phreatic eruptions: Journal of Geophysical Research: Solid Earth, v. 100, p. 84178434.

Geshi, N., Shimano, T., Chiba, T., and Nakada, S., 2002, Caldera collapse during the 2000 eruption of Miyakejima Volcano, Japan: Bulletin of Volcanology, v. 64, p. 55-68.

Gilbert, L.A., McDuff, R.E., and Paul Johnson, H., 2007, Porosity of the upper edifice of Axial Seamount: Geology, v. 35, p. 49-52.

Gertisser, R., Self, S., Thomas, L.E., Handley, H.K., Van Calsteren, P., and Wolff, J.A., 2011, Processes and timescales of magma genesis and differentiation leading to the great Tambora eruption in 1815: Journal of Petrology, v. 53, p. 271-297.

Hammond, S.R., Embley, R.W., and Baker, E.T., 2015, The NOAA vents program 1983 to 2013: Thirty years of ocean exploration and research: Oceanography, v. 28, p. 160-173.

Hannington, M.D., Jonasson, I.R., Herzig, P.M., and Petersen, S., 1995, Physical and chemical processes of seafloor mineralization at mid-ocean ridges: Seafloor Hydrothermal Systems: Physical, Chemical, Biological, and Geological Interactions, v. 91, p. 115-157.

Hay, R.L., and Jones, B.F., 1972, Weathering of basaltic tephra on the island of Hawaii: Geological Society of America Bulletin, v. 83, p. 317-332.

Head III, J.W., and Wilson, L., 2003, Deep submarine pyroclastic eruptions: theory and predicted landforms and deposits: Journal of Volcanology and Geothermal Research, v. 121, p. 155-193.

Hernández-Molina, F., Maldonado, A., and Stow, D., 2008, Abyssal plain contourites: Developments in Sedimentology, v. 60, p. 345-378.

Heiken, G., 1972, Morphology and petrography of volcanic ashes: Geological Society of America Bulletin, v. 83, p. 1961-1988.

Heiken, G., and Wohletz, K., 1991, Fragmentation processes in explosive volcanic eruptions: Special Publications of SEPM. 
Helo, C., Longpré, M., Shimizu, N., Clague, D.A., and Stix, J., 2011, Explosive eruptions at mid-ocean ridges driven by $\mathrm{CO} 2$-rich magmas: Nature Geoscience, v. 4, p. 260.

Inoue, A., 1995, Formation of Clay Minerals in Hydrothermal Environments, in Velde, B., ed., Origin and Mineralogy of Clays: Clays and the Environment: Berlin, Heidelberg, Springer Berlin Heidelberg, p. 268-329.

Jamieson, J.W., Hannington, M.D., Tivey, M.K., Hansteen, T., Williamson, N.M., Stewart, M., Fietzke, J., Butterfield, D., Frische, M., and Allen, L., 2016, Precipitation and growth of barite within hydrothermal vent deposits from the Endeavour Segment, Juan de Fuca Ridge: Geochemical Et Cosmochimica Acta, v. 173, p. 64-85.

Kelley, D.S., Delaney, J.R., and Juniper, S.K., 2014, Establishing a new era of submarine volcanic observatories: Cabling Axial Seamount and the Endeavour Segment of the Juan de Fuca Ridge: Marine Geology, v. 352, p. 426-450.

Kim, K.H., and McMurtry, G.M., 1991, Radial growth rates and 210Pb ages of hydrothermal massive sulfides from the Juan de Fuca Ridge: Earth and Planetary Science Letters, v. 104, p. 299-314.

Klug, C., and Cashman, K.V., 1994, Vesiculation of May 18, 1980, Mount St. Helens magma: Geology, v. 22, p. 468-472.

Lafuente, B., Downs, R., Yang, H., and Stone, N., 2015, The power of databases: the RRUFF project. in "Highlights in mineralogical crystallography”, Armbruster, T. \& Danisi, RM, eds. W: De Gruyter, Berlin, Germany, v. 1, p. 30.

Large, R.R., 1992, Australian volcanic-hosted massive sulfide deposits; features, styles, and genetic models: Economic Geology, v. 87, p. 471-510.

Le Pennec, J., Ruiz, G.A., Ramón, P., Palacios, E., Mothes, P., and Yepes, H., 2012, Impact of tephra falls on Andean communities: The influences of eruption size and weather conditions during the 1999-2001 activity of Tungurahua volcano, Ecuador: Journal of Volcanology and Geothermal Research, v. 217, p. 91-103.

Leibrandt, S., and Le Pennec, J., 2015, Towards fast and routine analyses of volcanic ash morphometry for eruption surveillance applications: Journal of Volcanology and Geothermal Research, v. 297, p. 11-27. 
Liu, E., Cashman, K., and Rust, A., 2015, Optimizing shape analysis to quantify volcanic ash morphology: Georesj, v. 8, p. 14-30.

Liu, E., Cashman, K., Rust, A., and Gislason, S., 2015, The role of bubbles in generating fine ash during hydromagmatic eruptions: Geology, v. 43, p. 239242.

Liu, E.J., Cashman, K., Rust, A., and Höskuldsson, A., 2017, Contrasting mechanisms of magma fragmentation during coeval magmatic and hydromagmatic activity: the Hverfjall Fires fissure eruption, Iceland: Bulletin of Volcanology, v. 79, p. 68.

Luyendyk, B.P., and Melson, W.G., 1967, Magnetic properties and petrology of rocks near the crest of the Mid-Atlantic Ridge: Nature, v. 215, p. 147.

Maicher, D., White, J.D., and Batiza, R., 2000, Sheet hyaloclastite: densitycurrent deposits of quench and bubble-burst fragments from thin, glassy sheet lava flows, Seamount Six, Eastern Pacific Ocean: Marine Geology, v. 171, p. $75-94$.

Maria, A., and Carey, S., 2007, Quantitative discrimination of magma fragmentation and pyroclastic transport processes using the fractal spectrum technique: Journal of Volcanology and Geothermal Research, v. 161, p. 234246.

Martín-Chivelet, J., Fregenal-Martínez, M., and Chacón, B., 2008, Traction structures in contourites: Developments in Sedimentology, v. 60, p. 157-182.

McCave, I., Bryant, R., Cook, H., and Coughanowr, C., 1986, Evaluation of a laser-diffraction-size analyzer for use with natural sediments: Journal of Sedimentary Research, v. 56.

McPhie, J., Walker, G.P., and Christiansen, R.L., 1990, Phreatomagmatic and phreatic fall and surge deposits from explosions at Kilauea volcano, Hawaii, 1790 AD: Keanakakoi Ash Member: Bulletin of Volcanology, v. 52, p. 334354.

Moore, J.G., 1985, Structure and eruptive mechanisms at Surtsey Volcano, Iceland: Geological Magazine, v. 122, p. 649-661.

Moore, D.M., and Reynolds, R.C., 1989, X-ray Diffraction and the Identification and Analysis of Clay Minerals: Oxford university press New York, . 
Mueller, W., Stix, J., Corcoran, P., and Daigneault, R., 2009, Subaqueous calderas in the Archean Abitibi greenstone belt: An overview and new ideas: Ore Geology Reviews, v. 35, p. 4-46.

Mumpton, F.A., and Ormsby, W.C., 1976, Morphology of zeolites in sedimentary rocks by scanning electron microscopy: Clays and Clay Minerals, v. 24, p. 123.

Mumpton, F.A., 2018, Mineralogy and geology of natural zeolites: Walter de Gruyter $\mathrm{GmbH} \&$ Co KG.

Murnane, R., and Clague, D.A., 1983, Nontronite from a low-temperature hydrothermal system on the Juan de Fuca Ridge: Earth and Planetary Science Letters, v. 65, p. 343-352.

Murray, L., 2019, Deep-sea mining: plundering the seafloor's minerals: RSS, https://eandt.theiet.org/content/articles/2019/02/deep-sea-mining-plunderingthe-seafloor-s-minerals/ (accessed July 2019).

Neuhoff, P.S., Rogers, K.L., Stannius, L.S., Bird, D.K., and Pedersen, A.K., 2006, Regional very low-grade metamorphism of basaltic lavas, Disko-Nuussuaq region, West Greenland: Lithos, v. 92, p. 33-54.

Newhall, C.G., and Self, S., 1982, The volcanic explosivity index (VEI) an estimate of explosive magnitude for historical volcanism: Journal of Geophysical Research: Oceans, v. 87, p. 1231-1238.

Nisbet, E.G., Bickle, M., and Martin, A., 1977, The mafic and ultramafic lavas of the Belingwe greenstone belt, Rhodesia: Journal of Petrology, v. 18, p. 521566.

Nurfiani, D., and de Maisonneuve, C.B., 2018, Furthering the investigation of eruption styles through quantitative shape analyses of volcanic ash particles: Journal of Volcanology and Geothermal Research, v. 354, p. 102-114.

Ollier, C., 1974, Phreatic eruptions and maars, in Developments in Solid Earth Geophysics: Elsevier, p. 289-311.

Papale, P., 1999, Strain-induced magma fragmentation in explosive eruptions: Nature, v. 397, p. 425.

Paytan, A., Kastner, M., Martin, E., Macdougall, J., and Herbert, T., 1993, Marine barite as a monitor of seawater strontium isotope composition: Nature, v. 366, p. 445. 
Paytan, A., Moore, W., and Kastner, M., 1996a, Sedimentation rate as determined by 226Ra activity in marine barite: Geochimica Et Cosmochimica Acta, v. 60, p. 4313-4319.

Paytan, A., Kastner, M., and Chavez, F., 1996b, Glacial to interglacial fluctuations in productivity in the equatorial Pacific as indicated by marine barite: Science, v. 274, p. 1355-1357.

Peacock, M.A., 1926, The petrology of Iceland, part 1. The basic tuffs: Transactions of the Royal Society of Edinburgh, v. 55, p. 53-76.

Poppe, L., Paskevich, V., Hathaway, J., and Blackwood, D., 2001, A laboratory manual for X-ray powder diffraction: US Geological Survey Open-File Report, v. 1, p. $1-88$.

Porreca, M., Cifelli, F., Soriano, C., Giordano, G., Romano, C., Conticelli, S., and Mattei, M., 2014, Hyaloclastite fragmentation below the glass transition: An example from El Barronal submarine volcanic complex (Spain): Geology, v. 42 , p. $87-90$.

Portner, R.A., Clague, D.A., and Paduan, J.B., 2014, Caldera formation and varied eruption styles on North Pacific seamounts: The clastic lithofacies record: Bulletin of Volcanology, v. 76, p. 845.

Portner, R.A., Clague, D.A., Helo, C., Dreyer, B.M., and Paduan, J.B., 2015, Contrasting styles of deep-marine pyroclastic eruptions revealed from Axial Seamount push core records: Earth and Planetary Science Letters, v. 423, p. 219-231.

Pritchard, D., and Gladstone, C., 2009, Reversing buoyancy in turbidity currents: developing a hypothesis for flow transformation and for deposit facies and architecture: Marine and Petroleum Geology, v. 26, p. 1997-2010.

Rebesco, M., Hernández-Molina, F.J., Van Rooij, D., and Wåhlin, A., 2014, Contourites and associated sediments controlled by deep-water circulation processes: state-of-the-art and future considerations: Marine Geology, v. 352, p. 111-154.

Resing, J.A., Rubin, K.H., Embley, R.W., Lupton, J.E., Baker, E.T., Dziak, R.P., Baumberger, T., Lilley, M.D., Huber, J.A., and Shank, T.M., 2011, Active submarine eruption of boninite in the northeastern Lau Basin: Nature Geoscience, v. 4, p. 799. 
Riley, C.M., Rose, W.I., and Bluth, G.J., 2003, Quantitative shape measurements of distal volcanic ash: Journal of Geophysical Research: Solid Earth, v. 108.

Schiffman, P., and Fridleifsson, G.O., 1991, The smectite-chlorite transition in drillhole NJ-15, Nesjavellir geothermal field, Iceland: XRD, BSE and electron microprobe investigations: Journal of Metamorphic Geology, v. 9, p. 679-696.

Schipper, C.I., and White, J.D., 2010, No depth limit to hydrovolcanic limu o Pele: analysis of limu from Lōihi Seamount, Hawaii: Bulletin of Volcanology, v. 72, p. $149-164$.

Sclater, J.G., Parsons, B., and Jaupart, C., 1981, Oceans and continents: similarities and differences in the mechanisms of heat loss: Journal of Geophysical Research: Solid Earth, v. 86, p. 11535-11552.

Shanmugam, G., Spalding, T., and Rofheart, D., 1993, Process sedimentology and reservoir quality of deep-marine bottom-current reworked sands (sandy contourites): an example from the Gulf of Mexico: AAPG Bulletin, v. 77, p. 1241-1259.

Skilling, I., White, J., and McPhie, J., 2002, Peperite: a review of magmasediment mingling: Journal of Volcanology and Geothermal Research, v. 114, p. 1-17.

Smith, K.L., Milnes, A.R., and Eggleton, R.A., 1987, Weathering of basalt: formation of iddingsite: Clays and Clay Minerals, v. 35, p. 418-428.

Sparks, S.R., Sigurdsson, H., and Wilson, L., 1977, Magma mixing: a mechanism for triggering acid explosive eruptions: Nature, v. 267, p. 315.

Stewart, R.J., 1974, Zeolite facies metamorphism of sandstone in the Western Olympic Peninsula, Washington: Geological Society of America Bulletin, v. 85, p. 1139-1142.

Stow, D., and Lovell, J., 1979, Contourites: their recognition in modern and ancient sediments: Earth-Science Reviews, v. 14, p. 251-291.

Stow, D.A., Faugères, J., Howe, J.A., Pudsey, C.J., and Viana, A.R., 2002, Bottom currents, contourites and deep-sea sediment drifts: current state-ofthe-art: Geological Society, London, Memoirs, v. 22, p. 7-20.

Stroncik, N.A., and Schmincke, H., 2001, Evolution of palagonite: Crystallization, chemical changes, and element budget: Geochemistry, Geophysics, Geosystems, v. 2. 
Stroncik, N.A., and Schmincke, H., 2002, Palagonite-a review: International Journal of Earth Sciences, v. 91, p. 680-697.

Sun, S., 1982, Chemical composition and origin of the Earth's primitive mantle: Geochimica Et Cosmochimica Acta, v. 46, p. 179-192.

Utada, M., 1980, Hydrothermal alterations related to igneous activity in Cretaceous and Neogene formations in Japan: Mining Geol., Spec. Issue, v. 8, p. 67-83.

Van Andel, T.H., and Komar, P.D., 1969, Ponded sediments of the Mid-Atlantic Ridge between 22 and 23 North latitude: Geological Society of America Bulletin, v. 80, p. 1163-1190.

Van Ark, E.M., Detrick, R.S., Canales, J.P., Carbotte, S.M., Harding, A.J., Kent, G.M., Nedimovic, M.R., Wilcock, W.S., Diebold, J.B., and Babcock, J.M., 2007, Seismic structure of the Endeavour Segment, Juan de Fuca Ridge: Correlations with seismicity and hydrothermal activity: Journal of Geophysical Research: Solid Earth, v. 112.

Van Otterloo, J., Cas, R.A., and Scutter, C.R., 2015, The fracture behaviour of volcanic glass and relevance to quench fragmentation during formation of hyaloclastite and phreatomagmatism: Earth-Science Reviews, v. 151, p. 79116.

Verolino, A., White, J., and Zimanowski, B., 2018, Particle transport in subaqueous eruptions: An experimental investigation: Journal of Volcanology and Geothermal Research, v. 349, p. 298-310.

Walker, J., 2007, Introduction to computer modeling of X-ray powder diffraction patterns of clay minerals--a guided tour of NEWMOD, in CMS Workshop Lecture, , p. 1-18.

Walker, S.L., Baker, E.T., Lupton, J.E., and Resing, J.A., 2019, Patterns of fine ash dispersal related to volcanic activity at West Mata volcano, NE Lau basin: Frontiers in Marine Science, v. 6, p. 593.

Welton, J.E., 2003, SEM petrology atlas.

White, J.D., 1996, Impure coolants and interaction dynamics of phreatomagmatic eruptions: Journal of Volcanology and Geothermal Research, v. 74, p. 155170. 
White, J.D., Smellie, J.L., and Clague, D.A., 2003, Explosive subaqueous volcanism: American Geophysical Union Washington, DC.

Wilcock, W.S., Dziak, R.P., Tolstoy, M., Chadwick Jr, W.W., Nooner, S.L., Bohnenstiehl, D.R., Caplan-Auerbach, J., Waldhauser, F., Arnulf, A.F., and Baillard, C., 2018, The recent volcanic history of Axial Seamount: Geophysical insights into past eruption dynamics with an eye toward enhanced observations of future eruptions: Oceanography, v. 31, p. 114-123.

Wilson, L., Sparks, R.S.J., and Walker, G.P., 1980, Explosive volcanic eruptions-IV. The control of magma properties and conduit geometry on eruption column behaviour: Geophysical Journal International, v. 63, p. 117148.

Wirsching, U., 1981, Experiments on the hydrothermal formation of calcium zeolites: Clays and Clay Minerals, v. 29, p. 171-183.

Wohletz, K.H., 1986, Explosive magma-water interactions: Thermodynamics, explosion mechanisms, and field studies: Bulletin of Volcanology, v. 48, p. 245-264.

Wohletz, K.H., 1983, Mechanisms of hydrovolcanic pyroclast formation: grainsize, scanning electron microscopy, and experimental studies: Journal of Volcanology and Geothermal Research, v. 17, p. 31-63.

Wohletz, K., and Krinsley, D., 1982, Scanning electron microscopy of basaltic hydromagmatic ash: Los Alamos Scientific Laboratory, .

Xu, G., and Lavelle, J.W., 2017, Circulation, hydrography, and transport over the summit of Axial Seamount, a deep volcano in the Northeast Pacific: Journal of Geophysical Research: Oceans, v. 122, p. 5404-5422.

Yeniyol, M., 2007, Characterization of a Mg-rich and low-charge saponite from the Neogene lacustrine basin of Eskişehir, Turkey: Clay Minerals, v. 42, p. 541-548.

Yuan, H., and Bish, D.L., 2010, NEWMOD , a new version of the NEWMOD program for interpreting $X$-ray powder diffraction patterns from interstratified clay minerals: Clays and Clay Minerals, v. 58, p. 318-326.

Zhang, L., Xie, S., Xin, W., Li, X., Liu, S., and Xu, L., 2011, Crystallization and morphology of mordenite zeolite influenced by various parameters in organicfree synthesis: Materials Research Bulletin, v. 46, p. 894-900. 
Zimanowski, B., Büttner, R., Dellino, P., White, J.D., and Wohletz, K.H., 2015, Magma-water interaction and phreatomagmatic fragmentation, in The encyclopedia of volcanoes: Elsevier, p. 473-484.

Zimanowski, B., Büttner, R., Lorenz, V., and Häfele, H., 1997, Fragmentation of basaltic melt in the course of explosive volcanism: Journal of Geophysical Research: Solid Earth, v. 102, p. 803-814. 


\section{APPENDICES}

\section{Appendix A: Core Descriptions}

\begin{tabular}{|c|c|c|c|}
\hline Unit & $\begin{array}{l}\text { Thickness } \\
\text { (cm) }\end{array}$ & Lithofacies & Description \\
\hline 1 & 2.0 & HMT & $\begin{array}{l}\text { Sandy mud - fine-grained ash. Glass is sporadic and mostly } \\
\text { appears blocky. Orange Fe oxides are abundant and white } \\
\text { mystery mineral is present. Hydrothermal clays present but } \\
\text { not green (orange color). No biogenics or volcanic minerals. } \\
\text { Contact is gradational with underlying unit (possibly artificial } \\
\text { mixing by coring). Color: Light Olive Grey ( } 5 \text { Y } 5 / 2 \text { ). }\end{array}$ \\
\hline 2 & 5.0 & LPT & $\begin{array}{l}\text { Ash - Coarse Ash to fine lapilli containing both fluidal and } \\
\text { blocky grains. Additionally, Fe oxides are abundant within } \\
\text { ash. Plagioclase and other feldspar crystals are present. } \\
\text { Olivine crystals also present. Sample taken from } 4 \mathrm{~cm} \text { depth } \\
\text { with oxidized contamination (since removed) from metal pin. } \\
\text { Sharp basal contact with below unit. }\end{array}$ \\
\hline 3 & 13.0 & TM & $\begin{array}{l}\text { Ashy mud - Fine grained to medium grained ash that is } \\
\text { predominantly blocky. Top } 10 \mathrm{~cm} \text { contains about } 15 \% \text { glass } \\
\text { whereas bottom } 2 \mathrm{~cm} \text { is very fine-grained ash mixed with } \\
\text { biogenics and similar componentry. Contains abundant } \\
\text { orange Fe oxides and biogenic material is present. } \\
\text { Feldspars mixed with glass. Possibly some diffuse } \\
\text { laminations, but unit has samples removed previously } \\
\text { making it difficult to tell. Samples previously taken at } 1,3.5 \text {, } \\
5 \text {, and } 8 \mathrm{~cm} \text { within unit. The samples at } 1 \mathrm{~cm} \text { and } 5 \mathrm{~cm} \text { had } \\
\text { oxidation contamination (since removed). Sharp basal } \\
\text { contact with } \sim 5 \text {-degree angle. Color: Moderate Brown } \\
\text { (10YR } 5 / 4 \text { ). }\end{array}$ \\
\hline 4 & 24.0 & HMT & $\begin{array}{l}\text { Sandy mud - Fine-grained ash that is mostly blocky and } \\
\text { about } 10 \% \text {. Contains orange Fe oxides, green hydrothermal } \\
\text { clay particles, and unknown white mineral. Feldspar and } \\
\text { olivine crystals appear present within thicker glassy } \\
\text { laminations. Diffuse laminations at } 2.5 \mathrm{~cm} \text { and } 9.5 \mathrm{~cm} \text { of } \\
\text { about } 0.5 \mathrm{~cm} \text { thickness that is predominantly blocky ash. } \\
\text { Thicker pronounced laminations at } 18.5 \text { and } 24 \mathrm{~cm} \text { (base of } \\
\text { core) of about } 1 \mathrm{~cm} \text { thickness also containing predominantly } \\
\text { blocky ash. Laminations Unit is mostly massive with some } \\
\text { glassy laminations. Color: Light Olive Grey (5Y } 5 / 2 \text { ). }\end{array}$ \\
\hline
\end{tabular}


D516-PC61XL

\begin{tabular}{|c|c|c|c|}
\hline Unit & $\begin{array}{l}\text { Thickness } \\
\text { (cm) }\end{array}$ & Lithofacies & Description \\
\hline 1 & 11.0 & TM & $\begin{array}{l}\text { Ashy mud - Ash is mixed with both fluidal and angular, } \\
\text { medium lapilli and approximately } 40-50 \% \text { modality. } \\
\text { Components: Orange Fe oxides are present, biogenics are } \\
\text { sparse, hydrothermal clays are absent. Plagioclase is } \\
\text { present, no other volcanic material was observed. Unit has } \\
\text { several pulses of ash throughout unit where ash is } \\
\text { concentrated, but no laminations. Top of unit contains } \\
\text { slightly more ash and larger sized particles and thins out } \\
\text { near the bottom, reversely graded. Sharp contact with } \\
\text { underlying unit. Color: Moderate Yellowish Brown (10YR } \\
5 / 4) \text {. }\end{array}$ \\
\hline 2 & 4.5 & HMT & $\begin{array}{l}\text { Sandy mud - Ash style appears angular, but is very fine- } \\
\text { grained and sparse, fine-grained ash with about } 25 \% \\
\text { modality. Components: Orange Fe oxides are present, } \\
\text { hydrothermal clays are present (more yellow colored), } \\
\text { biogenics are absent, volcanic material and plagioclase } \\
\text { appears absent, but may be sparse within mud. Unit } \\
\text { contains a lamination at very top, } \sim 1 \mathrm{~cm} \text { thick that is more } \\
\text { yellowish grey in color than the overall unit and only about } \\
1 \% \text { modality of ash. Gradational contact with underlying } \\
\text { HMT unit. Color: Pale Yellowish Brown (10YR } 6 / 2 \text { ). }\end{array}$ \\
\hline 3 & 13.5 & HMT & $\begin{array}{l}\text { Sandy mud - Ash is predominantly blocky/angular, but does } \\
\text { contain some fluidal ash, fine-grained ash approximately } \\
50 \% \text { modality. Components: Orange Fe oxides are present, } \\
\text { hydrothermal clays are present, altered zeolite minerals are } \\
\text { abundant, plagioclase is present, no sulfides or biogenics } \\
\text { observed. Unit contains one ash lamination approximately } \\
11 \mathrm{~cm} \text { depth and about } 1 \mathrm{~cm} \text { thick, contains mostly thin, } \\
\text { platy fluidal ash with some blocky material that is fine lapilli. } \\
\text { Plagioclase and crystalline basalt is also present in } \\
\text { lamination Sharp contact with underlying ash unit. Color: } \\
\text { Light Olive Grey ( } 5 \text { Y } 5 / 2) \text {. }\end{array}$ \\
\hline 4 & 18.5 & LPT & $\begin{array}{l}\text { Ash - Predominantly blocky/angular, with some fluidal } \\
\text { vitriclasts present. Grain size is medium lapilli. Contains a } \\
\text { wide variety of ash morphologies. Contains abundant } \\
\text { feldspars including plagioclase both as single crystals and } \\
\text { that appear attached to glass. Crystalline basalt fragments } \\
\text { are present. Olivine appears sparse. Orange Fe oxides are } \\
\text { absent, other than contamination from metal pushpins. No } \\
\text { other material is present. Lamination at approximately } 1 \mathrm{~cm} \\
\text { depth and about } 1 \mathrm{~cm} \text { thick that is muddier, but still } \sim 70 \% \\
\text { ash modality. Lamination is mixed with hydrothermal } \\
\text { material and components similar to above unit (HMT). Unit } \\
\text { is normally graded with a sharp contact with underlying unit. }\end{array}$ \\
\hline
\end{tabular}

Notes:

Samples previously taken at the following depths $(\mathrm{cm})$ : 
$0.0 ; 5.0 ; 9.0 ; 13.5 ; 17.5 ; 21.5 ; 27.0 ; 29.5 ; 30.5 ; 32.5 ; 44.0$. . All metal pushpins were removed, heavy oxidation contamination was present and was removed as best as possible.

Used to describe thickness of units near rim of caldera, do not sample as already heavily sampled. 
D522-PPC1

\begin{tabular}{|c|c|c|c|}
\hline Unit & $\begin{array}{l}\text { Thickness } \\
\text { (cm) }\end{array}$ & Lithofacies & Description \\
\hline 1 & 8.5 & TM & $\begin{array}{l}\text { Ashy mud - Ash is predominantly blocky but also contains } \\
\text { some fluidal shards. Grain size is coarse ash and modal } \\
\text { percent is about } 30-35 \% \text { ash. Contains abundant orange } \\
\text { Fe oxides - Unit appears heavily oxidized - Plagioclase and } \\
\text { crystalline basalt fragments appear sparse. Hydrothermal } \\
\text { lithics also appear sparse, but some are present near } \\
\text { bottom of unit, likely mixed in from underlying HMT. Unit is } \\
\text { structureless. Gradational contact with underlying unit. } \\
\text { Color: Moderate Brown (10YR 5/4). }\end{array}$ \\
\hline 2 & 10.5 & HMT & $\begin{array}{l}\text { Sandy mud - Ash is a mixture of fluidal and angular, fine- } \\
\text { grained ash. Modal percent is about } 25 \% \text { ash. Components: } \\
\text { Orange Fe oxides are present, hydrothermal lithics are } \\
\text { abundant. Plagioclase is present. Crystalline basalt appears } \\
\text { sparse. Biogenics are absent. Unit contains a lamination at } \\
\text { very top of unit, about } 1.0 \mathrm{~cm} \text { thick that is the distinct } \\
\text { yellow/green/grey color and contains fewer ash modality. } \\
\text { Second lamination at } \sim 3.0 \text { depth and about } 1 / 2 \mathrm{~cm} \text { thickness } \\
\text { containing "stacked" platy vitriclasts that appear heavily } \\
\text { oxidized. Two diffuse laminations of more ash at } 7.0 \text { and } 8.5 \\
\text { cm depth. Contact is sharp with underlying unit and at } \sim 15- \\
\text { degree angle. Color: Light Olive Grey }(5 Y 5 / 2) \text {. }\end{array}$ \\
\hline 3 & 2.5 & LPT & $\begin{array}{l}\text { Ash, Predominantly blocky/Angular with some fluidal } \\
\text { vitriclasts present. Ash is medium lapilli. Contains abundant } \\
\text { feldspar crystals, crystalline basalt is present. Sparse olivine } \\
\text { crystals. Orange Fe oxides are present. Some clay material } \\
\text { mixed with very top of unit, likely from overlying HMT. } \\
\text { Overall unit is normally graded. Contact is sharp at } \sim 15- \\
\text { degree angle. }\end{array}$ \\
\hline 4 & $8.0-10.0$ & HMT & $\begin{array}{l}\text { Sandy mud - Overall unit is very similar in terms of ash size } \\
\text { and style and components as unit \#2 (HMT). Ash is a } \\
\text { mixture of fluidal and angular, fine-grained ash. Modal } \\
\text { percent } ~ 35 \% \text { ash. Components: Orange Fe oxides are } \\
\text { present, hydrothermal lithics are abundant. Plagioclase is } \\
\text { present. Crystalline basalt appears sparse. Biogenics are } \\
\text { absent. No laminations; however, there is a weird-shaped } \\
\text { bulge of ash at } \sim 6 \mathrm{~cm} \text { depth within unit that is } 3 \mathrm{~cm} \text { thick on } \\
\text { sides of core and pinches out near the middle of the core. } \\
\text { Weird shape could be artificial coring artifact? Ash within } \\
\text { bulb is a mix of angular and fluidal and contains plagioclase, } \\
\text { abundant crystalline basalt - medium to coarse lapilli. Basal } \\
\text { contact of unit is sharp at no angle. Color of overall unit: } \\
\text { Light Olive Grey (5Y } 5 / 2) \text {. }\end{array}$ \\
\hline 5 & 3.0 & LPT & $\begin{array}{l}\text { Ash - Predominantly blocky / angular. Grain size is coarse } \\
\text { lapilli. Contains abundant plagioclase, abundant crystalline } \\
\text { basalt lithics, orange Fe oxides are present mostly as a fine } \\
\text { surficial coating on vitriclasts. No hydrothermal clay lithics or } \\
\text { other components. Lamination at } 1.0 \mathrm{~cm} \text { depth of } \\
\text { approximately } 1 / 2 \mathrm{~cm} \text { thickness of highly oxidized volcanic } \\
\text { glass. }\end{array}$ \\
\hline
\end{tabular}


D522-PC62L

\begin{tabular}{|c|c|c|c|}
\hline Unit & $\begin{array}{l}\text { Thickness } \\
(\mathrm{cm})\end{array}$ & Lithofacies & Description \\
\hline 1 & 9.0 & TM & $\begin{array}{l}\text { Ashy mud - Ash is predominantly blocky but does contain } \\
\text { some fluidal vitriclasts. Ash grain size is medium lapilli. } \\
\text { Modal percent is } 35-40 \% \text { ash. Contains orange Fe oxides } \\
\text { present, plagioclase is sparse, crystalline basalt is sparse, } \\
\text { biogenics are also sparse. Hydrothermal lithics are absent. } \\
\text { Unit is intermixed with fine mud and coarser ash without } \\
\text { true laminations. Gradational contact with underlying unit. } \\
\text { Color: Moderate Yellowish Brown (10YR 5/4). }\end{array}$ \\
\hline 2 & 21.0 & HMT & $\begin{array}{l}\text { Sandy mud - Ash style appears to contain both blocky and } \\
\text { fluidal ash and varies within unit. Ash is fine-grained ash } \\
\text { and is approximately } 5-30 \% \text { modal percent. Contains } \\
\text { orange Fe oxides are present, hydrothermal lithics are } \\
\text { abundant. Plagioclase and crystalline basalt is present. Unit } \\
\text { contains a lamination at very top of unit that is } \sim 1 / 2 \mathrm{~cm} \text { thick } \\
\text { and more yellowish, greenish grey color. The top } 16 \mathrm{~cm} \text { of } \\
\text { the unit is relatively ash-poor and finer-grained } \\
\text { hydrothermal clays whereas the bottom } 5 \mathrm{~cm} \text { of the unit is } \\
\text { more ash-rich ( } 30 \% \text { ash modality) and coarser-grained ash } \\
\text { containing predominantly fluidal ash. Overall unit is normally } \\
\text { graded, particularly the bottom } 5 \mathrm{~cm} \text {. Color: Light Olive Grey } \\
(5 \mathrm{Y} 5 / 2) \text {. }\end{array}$ \\
\hline 3 & 3.0 & LPT & $\begin{array}{l}\text { Ash - Predominantly angular/blocky ash with some fluidal } \\
\text { shards present. Grain size is medium lapilli. Contains } \\
\text { abundant feldspars including plagioclase. Crystalline basalt } \\
\text { fragments are also present. Olivine appears sparse. Orange } \\
\text { Fe oxides are absent. Some hydrothermal clays are mixed } \\
\text { into top of unit likely from overlying HMT. Overall unit is } \\
\text { normally graded. Contact is sharp and at } \sim 15 \text {-degree } \\
\text { angle. }\end{array}$ \\
\hline 4 & 16.0 & HMT & $\begin{array}{l}\text { Sandy mud - Ash appears predominantly fluidal, fine- } \\
\text { grained ash and approximately } 5 \% \text { modality. Contains } \\
\text { orange Fe oxides are present, hydrothermal clays and } \\
\text { lithics are abundant. Plagioclase is present. Sulfides may be } \\
\text { sparse. Unit contains several diffuse laminations at } \sim 15- \\
\text { degree angles. First lamination is at } 5.0 \mathrm{~cm} \text {, another at } 7.0 \\
\mathrm{~cm} \text {, and a third at } 12.0 \mathrm{~cm} \text {. All of these diffuse laminations } \\
\text { are normally graded. Sharp contact with underlying unit at } \\
\sim 10 \text {-degree angle. Color: Light Olive Grey (5Y } 5 / 2) \text {. }\end{array}$ \\
\hline 5 & 2.5 & LPT & $\begin{array}{l}\text { Ash - Predominantly blocky / angular. Grain size is medium } \\
\text { lapilli. Contains abundant plagioclase, olivine is present. } \\
\text { Orange Fe oxides are absent. Hydrothermal lithics and } \\
\text { other components are also absent. Unit is normally graded. }\end{array}$ \\
\hline
\end{tabular}


D522-PC66

\begin{tabular}{|c|c|c|c|}
\hline Unit & $\begin{array}{l}\text { Thickness } \\
\text { (cm) }\end{array}$ & Lithofacies & Description \\
\hline 1 & 7.0 & TM & $\begin{array}{l}\text { Ashy mud - Ash is primarily fluidal with some small blocky } \\
\text { particles, coarse ash and about } 40 \% \text { modality. } \\
\text { Components: Biogenics are sparse, orange Fe oxides } \\
\text { present. No plagioclase crystals visible. Clay aggregates } \\
\text { are sparse. Slight color variation and mottling within overall } \\
\text { unit. Lamination at } 6.5 \mathrm{~cm} \text { depth of a muddy, olive-grey color } \\
\text { about } 2-3 \mathrm{~mm} \text { thickness. Sharp basal contact at bottom of } \\
\text { glass lamination with next unit. Color: Dark Yellowish } \\
\text { Orange }(10 \mathrm{YR} 6 / 6) \text {. }\end{array}$ \\
\hline 2 & 4.0 & HMT & $\begin{array}{l}\text { Ashy mud - Ash fine-grained ash and about } 30 \% \text { modality. } \\
\text { Components: Orange Fe oxides are present. Sulfide } \\
\text { minerals are present. Near top of unit, small amount of ash } \\
\text { settled from overlying unit. Biogenics are absent. Clay } \\
\text { particles are present. At } 2 \mathrm{~cm} \text { depth, } 3 \mathrm{~mm} \text { thick glassy } \\
\text { lamination composed of fluidal ash and also containing } \\
\text { plagioclase. At } 3.5 \mathrm{~cm} \text { depth, } 5 \mathrm{~mm} \text { thick ash lamination } \\
\text { containing both fluidal and blocky ash, plagioclase crystals } \\
\text { and crystalline basalt present. Sharp contact with underlying } \\
\text { unit marked by glassy lamination. Color: Light Olive Grey } \\
\text { (5Y 5/2). }\end{array}$ \\
\hline 3 & 6.0 & HMT & $\begin{array}{l}\text { Sandy mud - Ash contains both fluidal and blocky fine- } \\
\text { grained ash. Ash modality is approximately } 10-15 \% \text {. } \\
\text { Components: Biogenics are sparse. Orange Fe oxides are } \\
\text { present, green hydrothermal clay particles are abundant. } \\
\text { Sulfides also present. Plagioclase crystals are absent. } \\
\text { Overall unit is structureless. Sharp contact based on ash } \\
\text { content. Color: Light Olive Grey }(5 \mathrm{Y} 5 / 2) \text {. }\end{array}$ \\
\hline 4 & 3.0 & HMT & $\begin{array}{l}\text { Ashy mud - Ash contains both fluidal and blocky fine- } \\
\text { grained ash with approximately } 30 \% \text { ash. Components: } \\
\text { Biogenic material is present, orange Fe oxides are present, } \\
\text { green clay material is present, sparse plagioclase crystals, } \\
\text { very sparse crystalline basalt fragments. Possibly some } \\
\text { sulfides near top of unit. Very diffuse lamination at top of } \\
\text { unit } \sim 2 \mathrm{~mm} \text { thick which includes more fluidal and stacked } \\
\text { platy vitriclasts and includes more plagioclase within the } \\
\text { lamination. Color: Light Olive Grey ( } 5 Y 5 / 2 \text { ). }\end{array}$ \\
\hline
\end{tabular}


D524-PC47XL

\begin{tabular}{|c|c|c|c|}
\hline Unit & $\begin{array}{l}\text { Thickness } \\
(\mathrm{cm})\end{array}$ & Lithofacies & Description \\
\hline 1 & 1.0 & Artificial & $\begin{array}{l}\text { Sandy mud/silt }- \text { Mix of glass and hydrothermal fragments. } \\
\text { Massive (no structures). Edges taper down } \sim 3 \mathrm{~cm} \text { and } \\
\text { mostly sand. Layer is likely artificial from coring process. } \\
\text { Color: Moderate Yellowish Brown (10 YR } 5 / 4 \text { ). }\end{array}$ \\
\hline 2 & $1.0-4.0$ & Artificial & $\begin{array}{l}\text { Muddy ash - mostly glass particles mixed with mud brought } \\
\text { up from underlying unit. Irregular orientation as it is pulled } \\
\text { down the sides of the core. Layer is likely artificial from } \\
\text { coring process. Color: Mostly ash (Black). }\end{array}$ \\
\hline 3 & 6.5 & TM & $\begin{array}{l}\text { Ashy mud - Ash is fine ash to fine lapilli with blocky and } \\
\text { angular ash particles. Few fluidal vitriclasts present. Ash is } \\
\text { evenly distributed. Mud is mottled slightly with areas of } \\
\text { lighter/darker mud. Biogenic material is present. Orange Fe- } \\
\text { oxides area also present. Layer is structureless (no } \\
\text { laminations). Sharp basal contact Sample previously pulled } \\
\text { at } 5.0 \mathrm{~cm} \text { within unit. Color: Light Brown (5YR 5/6). }\end{array}$ \\
\hline 4 & 10.0 & TM & $\begin{array}{l}\text { Ashy mud - Ashy laminations. Ash is very coarse ash - fine } \\
\text { lapilli and is mostly blocky with few fluidal shards. } \\
\text { Laminations } 0.5-1.5 \mathrm{~cm} \text { thick with alternating mud/ash } \\
\text { laminations. Ash laminations are diffuse (not obvious). Mud } \\
\text { within laminations is similar to mud above laminations. No } \\
\text { volcanic crystals observed. Biogenic chunks present. } \\
\text { Mottling within unit is present. Sharp basal contact at } ~ 10- \\
\text { degree angle. Color: Pale Yellow-Brown (10YR } 5 / 2 \text { ). }\end{array}$ \\
\hline 5 & 7.0 & HMT & $\begin{array}{l}\text { Sandy mud. Ash is fine-grained ash, but coarser than } \\
\text { surrounding sandy material. Contains orange Fe-oxides and } \\
\text { green hydrothermal clay material with white mystery } \\
\text { mineral. At } \sim 2 \mathrm{~cm} \text { depth, a much lighter color horizon } \\
\text { (whitish -pale yellow) with a lack of ash. No biogenics } \\
\text { observed. Some mottling within unit. Gradational basal } \\
\text { contact with increasing sand \& ash. Color: Moderately } \\
\text { Yellowish Brown (10YR } 5 / 4) \text {. }\end{array}$ \\
\hline 6 & 3.5 & HMT & $\begin{array}{l}\text { Muddy sand (similar to above unit) - Ash is fine grained ash } \\
\text { in top of unit and medium ash near bottom. Componentry is } \\
\text { same as above includes Fe-oxides and green hydrothermal } \\
\text { clay material with white mystery mineral. Increase in } \\
\text { percent of sand and ash. No biogenics or visible volcanic } \\
\text { minerals within mud. Unit is normally graded (coarser near } \\
\text { bottom fining upward). Sample taken from } 1.0 \mathrm{~cm} \text { depth } \\
\text { within sample. Color: Olive Grey (5Y } 3 / 2) \text {. }\end{array}$ \\
\hline 7 & 5.0 & LPT & $\begin{array}{l}\text { Ash - Medium to coarse grained lapilli. Fluidal shards } \\
\text { concentrated near top and blocky shards near bottom. } \\
\text { Contains plagioclase crystals, and some olivine. Notable } \\
\text { proportion of feldspar. Crystalline basalt fragments also } \\
\text { present. Morphology and grainsize are crudely graded. } \\
\text { Sharp basal contact with below. }\end{array}$ \\
\hline 8 & 5.0 & LPT & $\begin{array}{l}\text { Muddy Ash - Medium to coarse grained lapilli with mostly } \\
\text { blocky ash. Mud present in rip-ups the entire width of the } \\
\text { core. Crystalline basalt and feldspars are present. Similar to } \\
\text { overlying unit with slightly more mud from rip-ups. Orange }\end{array}$ \\
\hline
\end{tabular}




\begin{tabular}{|l|l|l|l|}
\hline & & $\begin{array}{l}\text { Oxidation is artificial from metal thumbtack left in unit. } \\
\text { Gradational contact with underlying unit. }\end{array}$ \\
\hline 9 & 11.0 & LPT & $\begin{array}{l}\text { Ash - Coarse grained lapilli. Ash is mostly blocky/angular } \\
\text { with a few fluidal shards that are thick. Some have "primary } \\
\text { surfaces (stepped fragment pattern - brittle, smooth - } \\
\text { ductile). Plagioclase crystals present, no good orientation } \\
\text { on glassy blocks. Plagioclase crystals appear part of } \\
\text { phenocrysts (larger crystals). }\end{array}$ \\
\hline
\end{tabular}




\begin{tabular}{|c|c|c|c|}
\hline Unit & $\begin{array}{l}\text { Thickness } \\
\text { (cm) }\end{array}$ & Lithofacies & Description \\
\hline 1 & 16.5 & TM & $\begin{array}{l}\text { Ashy Mud - Medium-grained ash that is mostly fluidal. } \\
\text { Approximate ash modality is about } 30 \% \text {. Contains orange } \\
\text { Fe oxides present, green hydrothermal clays are sparse, } \\
\text { and biogenics are also sparse. Several laminations within } \\
\text { unit: At } 6.0 \mathrm{~cm} \text { below base, lamination of } 1 / 2 \mathrm{~cm} \text { containing } \\
\text { both fluidal and angular ash that is fine-medium ash. } \\
\text { Second lamination at } 14 \mathrm{~cm} \text { that is diffuse (not obvious) } \\
\text { and about } 0.2 \mathrm{~cm} \text { thick containing ash that is fluidal/platy } \\
\text { appearing stacked together, or on top of each other. Finer } \\
\text { lamination at base of unit about } 0.5 \mathrm{~cm} \text { thick that contains a } \\
\text { lighter/pale yellow/green color, is sandy mud with lack of } \\
\text { ash and includes Fe-oxides. Samples taken at } 6.5 \mathrm{~cm}, 12.5 \\
\mathrm{~cm} \text { below the base. Color: Light Brown (5YR } 5 / 6 \text { ). }\end{array}$ \\
\hline 2 & 13.5 & HMT & $\begin{array}{l}\text { Sandy mud - Coarse to fine-grained ash. Contains } \\
\text { abundant orange Fe oxides and white mystery minerals, } \\
\text { and hydrothermal clays are present. Plagioclase and } \\
\text { olivine crystals relatively abundant. Several laminations: at } \\
5 \mathrm{~cm} \text { depth, find-grained ashy lamination about } 1 \mathrm{~cm} \text { thick } \\
\text { that contains about } 7 \% \text { ash. Second lamination angled at } \\
\text { about } 25 \text { degrees at } 11 \mathrm{~cm} \text {, that is about } 1 \mathrm{~cm} \text { thick } \\
\text { containing medium-grained fluidal ash and few blocky } \\
\text { grains and also contains orange Fe oxides, white mineral } \\
\text { and green hydrothermal material. Sample taken from } 5.5 \\
\mathrm{~cm} \text { and } 11.0 \mathrm{~cm} \text {. Mottling of color within mud of this unit. } \\
\text { Gradational structure with increasing ash towards bottom } \\
\text { of unit. Contact with underlying unit is sharp and angled at } \\
\sim 30 \text { degrees. Color: Moderate Yellowish Brown (10YR } \\
5 / 4) \text {. }\end{array}$ \\
\hline 3 & $3-4$ & LPT & $\begin{array}{l}\text { Ash - Fine to medium-grained lapilli that contains both } \\
\text { fluidal and blocky vitriclasts. Contains plagioclase that is } \\
\text { abundant, and olivine crystals are present. Sample } \\
\text { previously taken at } 0.5 \mathrm{~cm} \text { depth of unit with artificial } \\
\text { oxidation (now removed) from metal pin. }\end{array}$ \\
\hline
\end{tabular}




\begin{tabular}{|c|c|c|c|}
\hline Unit & $\begin{array}{l}\text { Thickness } \\
\text { (cm) }\end{array}$ & Lithofacies & Description \\
\hline 1 & 11.5 & TM & $\begin{array}{l}\text { Ashy mud - Medium to fine-grained ash with some medium- } \\
\text { grained ash. Ash is angular/blocky. Contains Fe oxides } \\
\text { present, minute amount of plagioclase, no visible } \\
\text { hydrothermal clays or biogenics. Lamination of muddy glass } \\
\text { at } 2.5 \mathrm{~cm} \text { depth. Mostly massive. Glass is homogenous. } \\
\text { Samples previously collected at } 2.5 \& 10 \mathrm{~cm} \text { depths. Color: } \\
\text { Moderate Brown (10 YR 5/4) }\end{array}$ \\
\hline 2 & 7.5 & HMT & $\begin{array}{l}\text { Sandy Mud - Ash is fine-grained ash. Glass is } \\
\text { homogenous. Mud and sand is very fine-grained. Large } \\
\text { abundance of plagioclase, orange Fe-oxides and } \\
\text { hydrothermal clays also abundant. Samples previously } \\
\text { taken from } 1.0 \& 7.0 \mathrm{~cm} \text { depth. Some possible glass } \\
\text { contamination from underlying unit. Contact is gradational } \\
\text { with underlying LPT layer at } \sim 15 \text { degrees. Color: Moderate } \\
\text { Yellowish Brown (10YR 5/4). }\end{array}$ \\
\hline 3 & 2.5 & LPT & $\begin{array}{l}\text { Ash - medium lapilli contains both blocky and fluidal ash. } \\
\text { Orange Fe-oxides and green hydrothermal material present } \\
\text { in top portion of the unit and is likely fall-out from above unit. } \\
\text { Small amounts of plagioclase crystals. Sample previously } \\
\text { taken from } 1.0 \mathrm{~cm} \text { depth and contains artificial oxidation } \\
\text { from metal pushpin. Sharp basal contact. }\end{array}$ \\
\hline 4 & 8.0 & TO & $\begin{array}{l}\text { Ashy mud - Ash is both angular and fluidal and is medium- } \\
\text { grained ash. Ash modality is approximate } 15 \% \text {. Top } 3 \mathrm{~cm} \text { of } \\
\text { unit is muddy ash with about } 50 \% \text { ash and abundant } \\
\text { biogenics. Overall unit contains abundant biogenics with a } \\
\text { sparse amount of ash. No other minerals or crystals } \\
\text { observed within unit. Two samples collected at } 0.5 \& 2.0 \mathrm{~cm} \\
\text { depth in unit with heavy artificial oxidation contamination } \\
\text { (removed) from metal pins. Basal contact not well defined } \\
\text { (gradational) but marked by change in color. Color: Greyish } \\
\text { Orange (10YR } 7 / 4 \text { ). }\end{array}$ \\
\hline 5 & 12.5 & TO & $\begin{array}{l}\text { Ashy Mud - Coarse-grained ash that is poorly sorted with } \\
\text { some larger vitriclasts. Ash is mostly blocky and } \\
\text { approximately } 5-7 \text { modal percent. No Fe oxides, } \\
\text { hydrothermal material or volcanic crystals. Abundant } \\
\text { biogenic material. Samples collected at } 6 \mathrm{~cm} \text { and } 9.5 \mathrm{~cm} \\
\text { depth within unit and contained heavy artificial oxidation } \\
\text { from metal pins (since removed). Bottom } 4.0 \mathrm{~cm} \text { of core is } \\
\text { only } \sim 3 \% \text { glass. Section contains more ash percent at top } \\
\text { and less near bottom. Color: Greyish Orange (10YR } 7 / 4) \text {. }\end{array}$ \\
\hline
\end{tabular}




\begin{tabular}{|c|c|c|c|}
\hline Unit & $\begin{array}{l}\text { Thickness } \\
\text { (cm) }\end{array}$ & Lithofacies & Description \\
\hline 1 & 6.5 & TM & $\begin{array}{l}\text { Ashy mud - Predominantly blocky, fine lapilli with } \\
\text { approximately } 30-40 \% \text { modality. Components: Orange Fe } \\
\text { oxides are present, feldspars are present, hydrothermal } \\
\text { material is absent, biogenics are absent, sulfides also } \\
\text { absent. Unit is reversely graded containing finer ash near } \\
\text { bottom and coarser ash near top. Gradational contact with } \\
\text { next unit. Color: Moderate Yellowish Brown (10YR 5/4). }\end{array}$ \\
\hline 2 & 12.5 & HMT & $\begin{array}{l}\text { Sandy mud - Ash is mostly fluidal that is fine-grained ash } \\
\text { and approximately } 10 \% \text { modality. Components: Orange Fe } \\
\text { oxides are present, green hydrothermal clays are abundant, } \\
\text { sparse plagioclase, sulfides present, biogenics are absent. } \\
\text { Two diffuse laminations of ash: First is about } 1 \mathrm{~cm} \text { from the } \\
\text { top and } \sim 1 / 2 \mathrm{~cm} \text { thick. Second is at about } 2.5 \mathrm{~cm} \text { depth and } \\
\sim 1 / 2 \mathrm{~cm} \text { thick. Large lamination of ash at } 6.5 \mathrm{~cm} \text { depth and } \\
\text { about } \sim 1 \mathrm{~cm} \text { thick, predominantly block medium lapilli, } \\
\text { feldspars are abundant, other volcanic material is also } \\
\text { abundant. Entire unit is normally graded and has a sharp } \\
\text { contact with underlying unit. Color: Light Olive Grey ( } 5 \mathrm{Y} \\
5 / 2 \text { ). }\end{array}$ \\
\hline 3 & 9.0 & LPT & $\begin{array}{l}\text { Ash - Ash is mixed with both blocky and fluidal, medium } \\
\text { lapilli. Components: Abundant plagioclase, olivine is } \\
\text { present, oxidized glass shards may be due to exposure ex } \\
\text { situ. Wide range of glass morphologies. Lamination at } \sim 2.5 \\
\mathrm{~cm} \text { depth that is about } 1.5 \mathrm{~cm} \text { thick that is ashy mud, } \\
\text { containing blocky, fine-grained ash containing orange Fe } \\
\text { oxides and plagioclase, no clays or biogenics (similar to TM } \\
\text { unit with a Moderate Yellowish Brown color 10YR } 5 / 4 \text { within } \\
\text { the lamination). }\end{array}$ \\
\hline
\end{tabular}


D655-PPC49

\begin{tabular}{|l|l|l|l|}
\hline Unit & $\begin{array}{l}\text { Thickness } \\
(\mathrm{cm})\end{array}$ & Lithofacies & Description \\
\hline 1 & 11 & TM & $\begin{array}{l}\text { Muddy ash - Predominantly blocky, with some fluidal } \\
\text { shards, size is coarse ash with approximately } 30-40 \% \\
\text { modality. Components: Orange Fe oxides are present, } \\
\text { feldspars are present, hydrothermal material is absent, } \\
\text { biogenics are absent, sulfides also absent. Unit is } \\
\text { structureless. Sharp contact with next unit. Color: Moderate } \\
\text { Yellowish Brown (10YR 5/4). }\end{array}$ \\
\hline 2 & 2.5 & TM & $\begin{array}{l}\text { Sandy mud - mostly angular ash fragments. Grain size is } \\
\text { fine-grained ash with 10\% modality. Components: } \\
\text { abundant orange Fe-oxides, plagioclase is absent, } \\
\text { hydrothermal lithics are sparse, biogenics are absent. Unit } \\
\text { is structureless but some orange color mottling is present. } \\
\text { Sharp contact with underlying unit (although some } \\
\text { disturbance due to settling). Color: Light brown (5YR 5/6). }\end{array}$ \\
\hline 3 & 4.5 & $\begin{array}{l}\text { Sandy Mud - Fluidal, medium ash fragments with 15\& ash } \\
\text { modality. Components: Sparse orange Fe-oxides, green } \\
\text { hydrothermal lithics present. Sulfides are present, } \\
\text { plagioclase present in areas with higher ash modality. } \\
\text { Biogenics are absent. Lamination near top of unit about } 1 / 2 \\
\text { cm thick, noted for yellow-pale grey color and contains very } \\
\text { fine-grained ash with 1-5 ash modality, abundant orange } \\
\text { Fe-oxides and green lithics while volcanic lithics are absent } \\
\text { from lamination. Diffuse lamination of increased ash at } \\
\sim 3 \text { 3cm depth. Color: Light olive grey (5Y 5/2). }\end{array}$ \\
\hline
\end{tabular}




\begin{tabular}{|c|c|c|c|}
\hline Unit & $\begin{array}{l}\text { Thickness } \\
\text { (cm) }\end{array}$ & Lithofacies & Description \\
\hline 1 & 4.5 & TM & $\begin{array}{l}\text { Muddy ash - Ash is mostly fluidal that is fine lapilli. Modality } \\
\text { of ash is approximately } 40 \% \text {. Components: Orange Fe } \\
\text { oxides are present, sparse biogenics, plagioclase is } \\
\text { present, hydrothermal clay material is sparse, although } \\
\text { more clays appear near the bottom of the unit. Entire unit is } \\
\text { structureless. Gradational contact with } \sim 10 \text {-degree angle. } \\
\text { Color: Greyish Brown (5YR 3/2). }\end{array}$ \\
\hline 2 & $1.0-3.0$ & TM & $\begin{array}{l}\text { Sandy mud - Ash is mostly fluidal with grain size being } \\
\text { medium ash and modal percent is about } 15 \% \text {. Components: } \\
\text { Abundant orange Fe oxides, biogenics are present, } \\
\text { hydrothermal clays are present. Plagioclase is present. } \\
\text { Entire unit is structureless. Sharp contact with underlying } \\
\text { unit. Color: Light Brown (5YR 5/6). }\end{array}$ \\
\hline 3 & 8.0 & HMT & $\begin{array}{l}\text { Sandy mud - Predominantly fluidal ash with fine-grained } \\
\text { ash and approximately } 35 \% \text { ash modality. Components: } \\
\text { Orange Fe oxides are present. Green hydrothermal clay } \\
\text { aggregates are abundant. Plagioclase is sparse, white } \\
\text { zeolite mineral is present. Biogenics are absent, Sulfides } \\
\text { appear abundant. Entire unit is normally graded with coarse } \\
\text { ash near bottom and fining upwards. Lamination at top of } \\
\text { the unit defines the upper contact. Lamination is } \sim 1 \mathrm{~cm} \\
\text { thick, volcanic ash-rich containing fluidal medium-grained } \\
\text { ash containing orange Fe oxides present, abundant } \\
\text { plagioclase and volcanic material, clays and biogenics } \\
\text { appear absent. Color of entire unit: Light Olive Grey (5Y } \\
5 / 2) \text {. }\end{array}$ \\
\hline
\end{tabular}

Notes:

Entire core is dried out making colors appear different than other cores 


\begin{tabular}{|c|c|c|c|}
\hline Unit & $\begin{array}{l}\text { Thickness } \\
\text { (cm) }\end{array}$ & Lithofacies & Description \\
\hline 1 & $0.5-2.5$ & Artificial & $\begin{array}{l}\text { Artificial - Disturbed layer, drags along the edges of the } \\
\text { core. Contains ash, hydrothermal material, biogenics all } \\
\text { likely brought up \& disturbed from coring process. }\end{array}$ \\
\hline 2 & 9.5 & TM & $\begin{array}{l}\text { Ashy mud - Predominantly fluidal, fine lapilli that appears } \\
\text { platy. Modal percent of ash is approximately } 35 \% \text {. } \\
\text { Components: Orange Fe oxides present, biogenic material } \\
\text { is present. Plagioclase is present and olivine absent. } \\
\text { Crystalline basalt is present. Entire unit is structureless. } \\
\text { Gradational contact marked by a reduction of ash modality } \\
\text { and grain size. Color: Light Brown (5YR 5/6). }\end{array}$ \\
\hline 3 & $5.0-6.0$ & HMT & $\begin{array}{l}\text { Sandy mud - Mostly blocky ash that is medium-grained ash } \\
\text { and approximately } 15 \% \text { modality. Components: Abundant } \\
\text { orange Fe oxides and abundant clay aggregates. Sparse } \\
\text { biogenics, possible presence of sulfides, sparse } \\
\text { plagioclase. Unit is structureless. Contains a variation of } \\
\text { color/mottling with an orange hue. Sharp contact at } \sim 20- \\
\text { degree angle. Color: Light Brown (5Y } 5 / 6) \text {. }\end{array}$ \\
\hline 4 & $\begin{array}{l}12.0- \\
13.5\end{array}$ & HMT & $\begin{array}{l}\text { Muddy Ash - mix of angular and fluidal ash with slightly } \\
\text { more fluidal shards. Grain size is fine-grained ash and } \\
\text { approximately } 40 \% \text { modal percent. Components: Sparse } \\
\text { orange Fe oxides, abundant green hydrothermal clay } \\
\text { aggregates, sulfides are sparse, crystalline basalt } \\
\text { fragments sparse, plagioclase is present and biogenics are } \\
\text { absent. Top of unit contains a lamination about } 1 / 2 \mathrm{~cm} \text { thick } \\
\text { that has pale-yellowish grey color. Within the lamination, } \\
\text { there is approximately } 10 \% \text { modality of ash that is fine- } \\
\text { grained, abundant orange Fe oxides, sulfides present, clays } \\
\text { present, plagioclase and crystalline basalt is absent, } \\
\text { biogenics also absent. Second lamination at } \sim 2 \mathrm{~cm} \text { depth } \\
\text { that is } 1 \mathrm{~cm} \text { thick ashy lamination containing mostly fluidal, } \\
\text { coarse ash with abundant plagioclase, sparse clays and } \\
\text { sparse Fe oxides and no biogenics. A third lamination at } ~ \\
\text { cm depth and thickness of about } 1 \mathrm{~cm} \text { containing } \\
\text { predominantly fluidal, coarse-grained ash and composed of } \\
\text { similar material to entire unit (highly variable) with Fe oxides } \\
\text { present, clays present, clays present, biogenics absent, } \\
\text { sulfides present, and plagioclase sparse. Fourth lamination } \\
\text { at } ~ 8-9 \mathrm{~cm} \text { that is } 1 \mathrm{~cm} \text { thick that is an ashy lamination } \\
\text { containing fluidal and angular, fine lapilli vitriclasts with Fe } \\
\text { oxides, sparse clays, abundant plagioclase and absent } \\
\text { biogenics. Color of entire unit: Light Olive Grey (5Y } 5 / 2 \text { ). }\end{array}$ \\
\hline
\end{tabular}




\begin{tabular}{|c|c|c|c|}
\hline Unit & $\begin{array}{l}\text { Thickness } \\
\text { (cm) }\end{array}$ & Lithofacies & Description \\
\hline 1 & 6.0 & TM & $\begin{array}{l}\text { Sandy mud - Ash is very hard to determine shape. Ash } \\
\text { grain size is very fine-grained ash and modality is } \\
\text { approximately } 1 \% \text {. Contains very sparse orange Fe oxides } \\
(<1 \%) \text {. No other volcanic material is present. Biogenics are } \\
\text { absent - sparse. Most of the unit is just mud. Sharp contact } \\
\text { based on color. Unit is structureless. Color: Moderate } \\
\text { Brown (5YR 5/6). }\end{array}$ \\
\hline 2 & 18.0 & TO & $\begin{array}{l}\text { Sandy mud - Ash shape hard to determine. Ash grain size } \\
\text { is very fine-fine grained ash and modality is approximately } \\
<1 \% \text { (nearly absent). Contains abundant biogenic material } \\
\text { (forams) and that is it. No structures in unit, but color } \\
\text { variation \& mottling is present, includes darker brown } \\
\text { (similar to above unit color) with lighter brown of this unit. } \\
\text { Darker brown material has slightly more ash and may be } \\
\text { distal fall-out from previous eruptions. Color: Greyish } \\
\text { Orange (10YR } 7 / 4 \text { ). }\end{array}$ \\
\hline
\end{tabular}

Notes:

Off Ridge, Very far south (furthest south of all cores) $\sim 149 \mathrm{~km}$ 
D876-PC66

\begin{tabular}{|c|c|c|c|}
\hline Unit & $\begin{array}{l}\text { Thickness } \\
(\mathrm{cm})\end{array}$ & Lithofacies & Description \\
\hline 1 & 7.5 & TM & $\begin{array}{l}\text { Ashy mud - Contains both blocky and fluidal ash that is } \\
\text { medium lapilli and approximately } 40 \% \text { modality. } \\
\text { Components: Orange Fe oxides abundant, biogenics are } \\
\text { present, plagioclase crystals are present, hydrothermal clay } \\
\text { aggregates are absent. Lamination near bottom of the unit } \\
\text { at } \sim 6 \mathrm{~cm} \text { depth and about } 1 \mathrm{~cm} \text { thick containing more ash } \\
\text { than surrounding unit with similar composition and ash } \\
\text { morphology. Gradational contact. Color: Moderate } \\
\text { Yellowish Brown (10YR 5/4). }\end{array}$ \\
\hline 2 & 3.5 & TM & $\begin{array}{l}\text { Sandy mud - Ash is a mix of both blocky and fluidal, } \\
\text { medium-grained ash that is approximately } 30 \% \text { modality. } \\
\text { Components: Abundant orange Fe oxides, hydrothermal } \\
\text { clays are present and more yellow in color. Biogenics are } \\
\text { sparse and fragmented near top of the unit. Plagioclase is } \\
\text { present. Diffuse lamination at } \sim 2 \mathrm{~cm} \text { depth approximately } 1 / 2 \\
\mathrm{~cm} \text { thick that is more ashy, fine-grained fluidal and blocky } \\
\text { with similar composition with surrounding unit but } \sim 40 \% \text { ash } \\
\text { modality. Gradational contact. Color: Light Brown (5YR } 5 / 6 \text { ). }\end{array}$ \\
\hline 3 & 10.0 & HMT & $\begin{array}{l}\text { Sandy mud - Ash is predominantly fluidal, fine-grained ash } \\
\text { that is approximately } 15 \% \text { modality. Components: Orange } \\
\text { Fe oxides are present, hydrothermal clays are present, } \\
\text { sparse plagioclase. Lamination at } \sim 1.5 \mathrm{~cm} \text { depth that is } \\
\text { yellowish grey in color and } \sim 2 \mathrm{~mm} \text { thick, similar composition } \\
\text { but with finer ash than surrounding unit ( } \sim 10 \% \text { ash } \\
\text { modality). Sharp contact with underlying unit. Color: Light } \\
\text { Olive Grey (5YR 5/2). }\end{array}$ \\
\hline 4 & 2.5 & $\begin{array}{l}\text { LPT } \\
\end{array}$ & $\begin{array}{l}\text { Ash - Mostly fluidal vitriclasts but also contains some blocky } \\
\text { particles and is medium lapilli. Components: Plagioclase is } \\
\text { abundant, olivine and crystalline basalt is present. Wide } \\
\text { range of glass morphologies. Normally graded and sharp } \\
\text { contact with underlying unit. }\end{array}$ \\
\hline 5 & 1.0 & TO & $\begin{array}{l}\text { Sandy mud - Predominantly blocky, fine-grained ash with } \\
\text { about } 10 \% \text { modality. Overall unit contains abundant } \\
\text { biogenics with a sparse amount of ash. No other minerals or } \\
\text { crystals observed within unit. Color: Greyish Orange (10YR } \\
7 / 4 \text { ). }\end{array}$ \\
\hline
\end{tabular}




\begin{tabular}{|c|c|c|c|}
\hline Unit & $\begin{array}{l}\text { Thickness } \\
\text { (cm) }\end{array}$ & Lithofacies & Description \\
\hline 1 & 7.5 & TM & $\begin{array}{l}\text { Ashy mud - Ash is fluidal, medium lapilli with approximately } \\
30 \% \text { modality. Components: Orange Fe oxides are } \\
\text { abundant, biogenics are present, hydrothermal clays are } \\
\text { absent. Feldspars are present. Some pulses of ash } \\
\text { throughout unit but no laminations. Gradational contact with } \\
\text { underlying unit. Color: Moderate Yellowish Brown (10YR } \\
5 / 4) \text {. }\end{array}$ \\
\hline 2 & 8.0 & TM & $\begin{array}{l}\text { Ashy mud - Ash is a mix of angular and fluidal, fine-grained } \\
\text { ash with about } 10 \% \text { modality. Components: Abundant } \\
\text { orange Fe oxides, abundant hydrothermal clays (more } \\
\text { yellow colored), sulfides present, biogenics are absent, } \\
\text { white altered zeolite minerals are present, plagioclase is } \\
\text { sparse. Unit is structureless. Gradational contact. Color: } \\
\text { Dark Yellowish Orange (10YR 6/6). }\end{array}$ \\
\hline 3 & 4.0 & HMT & $\begin{array}{l}\text { Sandy mud - Mostly fluidal, fine-grained ash with } \\
\text { approximately } 15 \% \text { modal percent. Components: Orange } \\
\text { Fe oxides are present, hydrothermal clays are present, } \\
\text { plagioclase is sparse, white altered zeolite minerals are } \\
\text { present, biogenics are absent. Unit is structureless. Sharp } \\
\text { contact with underlying unit. Color: Light Olive Grey (5Y } \\
5 / 2 \text { ). }\end{array}$ \\
\hline 4 & 2.5 & LPT & $\begin{array}{l}\text { Ash - Mostly fluidal with some blocky, medium lapilli sized } \\
\text { vitriclasts. Contains a wide variety of ash morphologies. } \\
\text { Plagioclase and feldspars are abundant, orange Fe oxides } \\
\text { are present. Crystalline basalt fragments are present. Unit is } \\
\text { normally graded with a sharp contact with underlying unit. }\end{array}$ \\
\hline 5 & 1.0 & HMT & $\begin{array}{l}\text { Sandy mud - Ash is predominantly fluidal, fine-grained ash } \\
\text { with approximately } 30 \% \text { modality. Components: Orange Fe } \\
\text { oxides are present, hydrothermal clays are present, } \\
\text { feldspars are present, biogenic material is absent. Unit is } \\
\text { structureless. Color: Light Olive Grey (5Y } 5 / 2 \text { ). }\end{array}$ \\
\hline
\end{tabular}




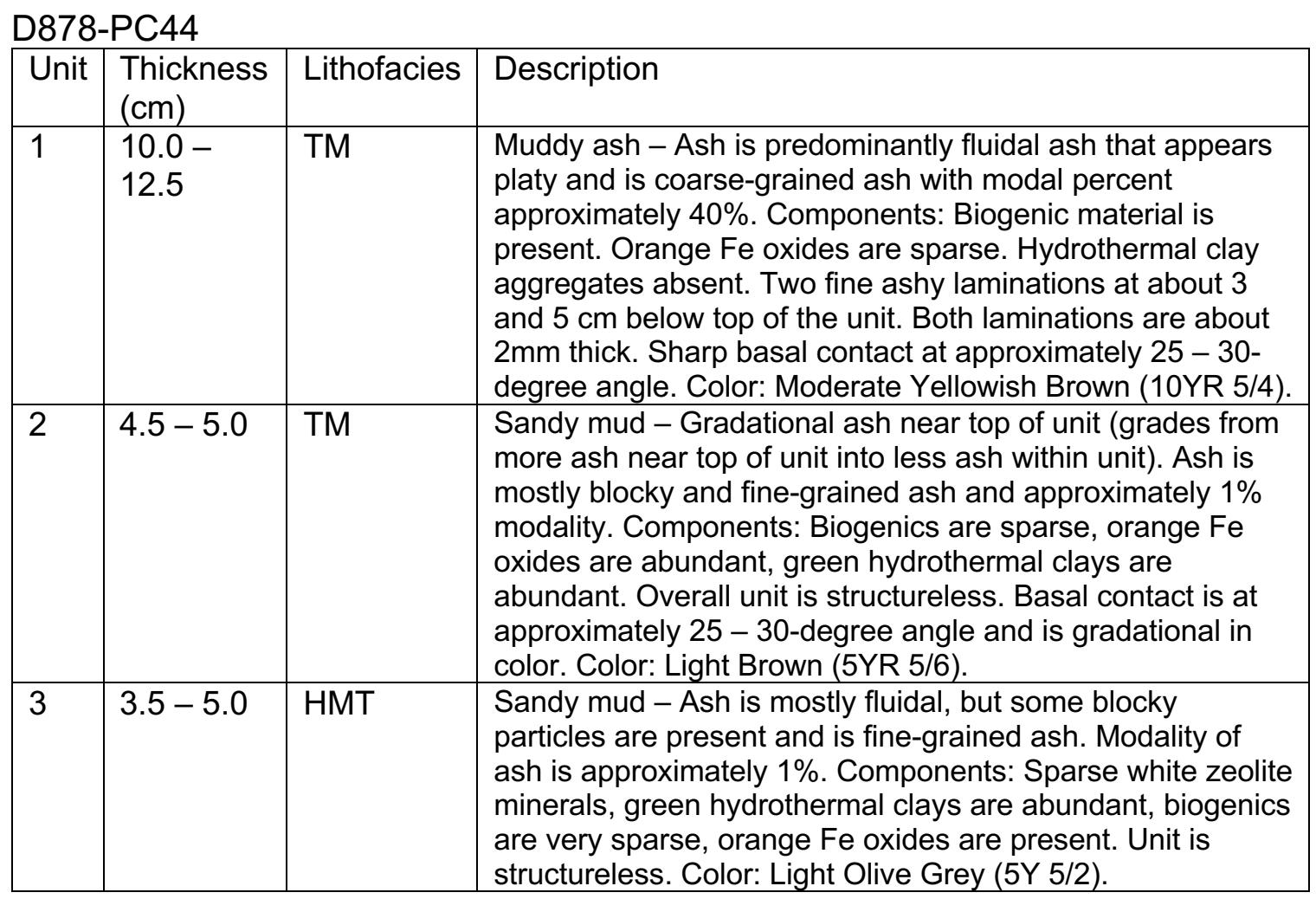




\begin{tabular}{|c|c|c|c|}
\hline \multicolumn{4}{|c|}{ ग878-PC } \\
\hline Unit & $\begin{array}{l}\text { Thickness } \\
(\mathrm{cm})\end{array}$ & Lithofacies & Description \\
\hline 1 & 8.0 & TM & $\begin{array}{l}\text { Ashy mud - Ash contains both fluidal and blocky coarse- } \\
\text { grained ash with a modality of approximately } 30 \% \text {. } \\
\text { Components: Plagioclase crystals are present, biogenics } \\
\text { are present, orange Fe oxides are present, green } \\
\text { hydrothermal clays are sparse. Lamination of light mud, } \\
\text { about } 1 \mathrm{~cm} \text { thick, separating an upper ashy layer from a } \\
\text { muddy layer. Basal contact is gradational based on change } \\
\text { of ash content. Color: Moderate Brown (5YR 4/4). }\end{array}$ \\
\hline 2 & 4.0 & HMT & $\begin{array}{l}\text { Sandy Mud - Ash is mostly fluidal, fine-grained ash with a } \\
\text { modality of approximately } 1 \% \text {. Components: Orange Fe } \\
\text { oxides are present, biogenics are sparse. Bulbous clay } \\
\text { particles present to abundant. Composition changes from } \\
\text { orange oxides to more greenish clays with increasing depth. } \\
\text { Plagioclase crystals sparse. Overall unit is structureless. } \\
\text { Gradational contact marked by modal abundance of ash } \\
\text { and no angle. Overall color: Light Olive Grey (5Y } 5 / 2) \text {. }\end{array}$ \\
\hline 3 & 8.0 & HMT & $\begin{array}{l}\text { Ashy Mud - Ash contains both fluidal and blocky but with } \\
\text { higher proportion of blocky vitriclasts. Grain size of ash is } \\
\text { medium ash and modal percent is approximately } 25 \% \text {. } \\
\text { Components: Biogenics are sparse, plagioclase crystals } \\
\text { sparse, crystalline basalt fragments are present, orange Fe } \\
\text { oxides abundant. Clay particles are abundant, sulfides are } \\
\text { present. At } \sim 3 \mathrm{~cm} \text { depth, lamination of lighter mud of about } \\
1 \mathrm{~mm} \text { thickness with abundant Fe oxides and overall less } \\
\text { ash. Color: Dark Yellowish Brown (10YR } 4 / 2 \text { ). }\end{array}$ \\
\hline
\end{tabular}




\begin{tabular}{|c|c|c|c|}
\hline \multicolumn{4}{|c|}{ D878-PC58 } \\
\hline Unit & $\begin{array}{l}\text { Thickness } \\
(\mathrm{cm})\end{array}$ & Lithofacies & Description \\
\hline 1 & 5.5 & TM & $\begin{array}{l}\text { Ashy mud - Ash is mostly fluidal, coarse-grained ash with } \\
\text { modal percent approximately } 5-7 \% \text {. Components: } \\
\text { Biogenics are present, orange Fe oxides are sparse, } \\
\text { plagioclase crystals and clay particles both absent. } \\
\text { Laminated overall with glass laminations starting at } \sim 2 \mathrm{~cm} \\
\text { depth, very fine at about } 1 \mathrm{~mm} \text { thickness. Basal contact is } \\
\text { gradational and difficult to differentiate with underlying unit. } \\
\text { Color: Moderate Yellowish Brown (10YR } 5 / 4) \text {. }\end{array}$ \\
\hline 2 & 2.5 & TM & $\begin{array}{l}\text { Sandy mud - Predominantly fluidal, fine-grained ash with } \\
\text { about } 1 \% \text { modality. Components: Orange Fe oxides are } \\
\text { present, biogenics are sparse, Hydrothermal clays are } \\
\text { present. Plagioclase is absent, sulfides also present. } \\
\text { Overall unit is structureless with a } 1 \mathrm{~cm} \text {-thick "lamination" } \\
\text { near base of the unit which appears artificial due to core } \\
\text { splitting process. Unit contains some mottling of red/brown } \\
\text { colors. Basal contact is sharp. Color: Light Brown (5YR 5/6). }\end{array}$ \\
\hline 3 & 1.5 & TM & $\begin{array}{l}\text { Ashy mud - predominantly fluidal, fine-grained ash with } \\
\text { about } 10 \% \text { modality. Components: Biogenics are present, } \\
\text { orange Fe oxides are sparse, plagioclase is absent. Clay } \\
\text { aggregates are found near top of the unit which may be } \\
\text { from overlying HMT unit. Overall unit is structureless - but } \\
\text { so thin it is difficult to see much else. Color: Dark Yellowish } \\
\text { Brown (10YR 5/2). }\end{array}$ \\
\hline
\end{tabular}


D878-PC62

\begin{tabular}{|c|c|c|c|}
\hline Unit & $\begin{array}{l}\text { Thickness } \\
\text { (cm) }\end{array}$ & Lithofacies & Description \\
\hline 1 & 4.0 & TM & $\begin{array}{l}\text { Ashy mud - Ash is mostly blocky (with some fluidal) } \\
\text { medium-grained ash with a modal percent of approximately } \\
30-40 \% \text {. Components: White biogenic material is present. } \\
\text { Crystalline basalt fragments are present. Plagioclase } \\
\text { crystals are abundant. Orange Fe oxides are present. Clay } \\
\text { minerals are absent. Inter-fingering of mud and ash without } \\
\text { true laminations. Basal contact is gradational and marked } \\
\text { by disappearance of ash. Color: Moderate Brown (5YR - } \\
3 / 4 \text { ). }\end{array}$ \\
\hline 2 & 13.0 & TM & $\begin{array}{l}\text { Ashy mud - Ash is predominantly fluidal fine-grained ash } \\
\text { with a modality of about } 1-2 \% \text {. Components: Orange Fe } \\
\text { oxides are abundant. Plagioclase crystals present, } \\
\text { biogenics are present, clay hydrothermal material is sparse. } \\
\text { At approximately } 9 \mathrm{~cm} \text { fine lamination about } 2 \mathrm{~mm} \text { thick, } \\
\text { pale-grey color but similar to overall unit in composition, } \\
\text { may be bioturbation. At approximately } 10 \mathrm{~cm} \text { depth, a } \\
\text { second lamination about } 5 \mathrm{~mm} \text { thick consisting of fine- } \\
\text { grained orange material that contains less ash (fluidal), } \\
\text { plagioclase absent, orange Fe oxides abundant, sparse clay } \\
\text { particles (looks similar to above lamination). Below orange } \\
\text { lamination is another lamination approximately } 1 \mathrm{~cm} \text { thick of } \\
\text { ashy mud consisting of fluidal and platy ash, possibly } \\
\text { stacked and includes crystalline basalt, biogenics, and } \\
\text { plagioclase. Remaining layer similar to upper portion of unit. } \\
\text { Color: Light Brown (5YR 5/6). }\end{array}$ \\
\hline 3 & 4.0 & TM & $\begin{array}{l}\text { Ashy mud - Ash contains both blocky and fluidal ash and is } \\
\text { fine-grained ash of approximately } 30 \% \text { modal percent. } \\
\text { Components: Plagioclase crystals present, sparse } \\
\text { crystalline basalt fragments. Orange Fe oxide particles are } \\
\text { present. Clay particles are absent. Biogenic material is } \\
\text { sparse. Entire unit is normally graded with coarser ash near } \\
\text { the base fining upwards. Color: Moderate Brown (5YR 3/4). }\end{array}$ \\
\hline
\end{tabular}

Notes:

Furthest core from caldera in the 878 transect. 


\begin{tabular}{|c|c|c|c|}
\hline \multicolumn{4}{|c|}{ Ј878-PC63 } \\
\hline Unit & $\begin{array}{l}\text { Thickness } \\
\text { (cm) }\end{array}$ & Lithofacies & Description \\
\hline 1 & 6.5 & TM & $\begin{array}{l}\text { Muddy ash - Mostly fluidal ash containing approximately } \\
30-40 \% \text { ash modality \& fine -medium lapilli ash size. } \\
\text { Contains orange Fe oxides, biogenic material present, } \\
\text { plagioclase crystals present within ash. At approximately } \\
2 \mathrm{~cm} \text { depth, lamination of } \sim 1 \mathrm{~cm} \text { thickness where reduced } \\
\text { ash content }(\sim 15 \%) \text {. Color: Dark Yellowish Brown (10YR } \\
4 / 2) .\end{array}$ \\
\hline 2 & 5.0 & TM & $\begin{array}{l}\text { Sandy mud - Ash is predominantly blocky and is fine ash } \\
\text { size. Modal percent ash is approximately } 1 \% \text { with } \\
\text { gradational ash content near the top. Contains orange Fe } \\
\text { oxides are abundant, hydrothermal clay material is present, } \\
\text { biogenic material are sparse. No other visible volcanic } \\
\text { material. Unit is structureless. Basal contact is at } \sim 25- \\
\text { degree angle and is gradational into unit below. Color: Light } \\
\text { Brown (5YR 5/6). }\end{array}$ \\
\hline 3 & $2.0-4.0$ & HMT & $\begin{array}{l}\text { Sandy mud - Ash is predominantly fluidal and fine-grained } \\
\text { ash with some blocky and approximately } 1-2 \% \text { modality. } \\
\text { Contains orange Fe oxides present, white altered mineral } \\
\text { are sparse, hydrothermal aggregates are abundant, } \\
\text { biogenics are very sparse. Unit is structureless. Color: Dark } \\
\text { Yellowish Brown (10YR 4/2). }\end{array}$ \\
\hline
\end{tabular}


D878-PC66

\begin{tabular}{|l|l|l|l|}
\hline Unit & $\begin{array}{l}\text { Thickness } \\
(\mathrm{cm})\end{array}$ & Lithofacies & Description \\
\hline 1 & $2.0-3.5$ & TM & $\begin{array}{l}\text { Ashy mud- Predominantly block ash with coarse ash to fine } \\
\text { lapilli size with average modality of } 40 \% \text {. Contains } \\
\text { abundant biogenic material, abundant orange Fe oxides, } \\
\text { sparse hydrothermal clays. Entire unit is structureless. } \\
\text { Basal contact is gradational and dependent on decrease of } \\
\text { ash modality. Contact is also at an angle of about 25-30 } \\
\text { degrees. Color: Dark Yellowish Brown (10YR 4/2). }\end{array}$ \\
\hline 2 & $2.5-3.0$ & TM & $\begin{array}{l}\text { Ashy mud - Ash is predominantly fluidal with medium } \\
\text { grained ash and approximately 3-5\% modality. Unit contains } \\
\text { abundant orange Fe oxides, biogenics are present, sparse } \\
\text { hydrothermal clay material. Basal contact is marked by a 1/2 } \\
\text { cm thick lamination containing 30-40\% modality ash at } 25- \\
\text { 30-degree angle. Overall unit is more orange than overlying } \\
\text { unit. Within bottom lamination contains feldspar crystals } \\
\text { mixed with ash, Fe oxides present, hydrothermal material } \\
\text { also present. Color: Moderate Brown (5YR 4/4). }\end{array}$ \\
\hline 3 & $2.5-3.5$ & TM & $\begin{array}{l}\text { Sandy mud - Ash is mostly fluidal and fine-grained ash with } \\
\text { approximately 1-2 modal percent ash. Contains orange Fe } \\
\text { oxides present, biogenic material is present, hydrothermal } \\
\text { clay aggregates are present. Two 3-5mm circular zones or } \\
\text { bulbs containing 30\% ash, likely bioturbation related. } \\
\text { Orange mottling near basal contact is present. Gradational } \\
\text { contact into the next unit with about a 20-degree angle and } \\
\text { marked by abundance of ash but not sharply delineated. } \\
\text { Color: Moderate Yellowish Brown (10YR 4/2). }\end{array}$ \\
\hline 4 & $2.0-3.5$ & HMT & $\begin{array}{l}\text { Ashy mud - Ash is mostly fluidal and fine-grained ash with } \\
\text { approximately 20-25\% ash. Contains abundant orange Fe } \\
\text { oxides, biogenic material is present, green hydrothermal } \\
\text { clays are present. Unit is structureless although there is } \\
\text { some color variation and mottling near top of unit similar to } \\
\text { unit \#3 above. Color: Dark Yellowish Brown (10YR 4/2). }\end{array}$ \\
\hline
\end{tabular}




\begin{tabular}{|c|c|c|c|}
\hline Unit & $\begin{array}{l}\text { Thickness } \\
\text { (cm) }\end{array}$ & Lithofacies & Description \\
\hline 1 & 6.0 & TM & $\begin{array}{l}\text { Ashy mud - Contains both angular and fluidal, coarse- } \\
\text { grained ash with approximately } 30 \% \text { modality. Components: } \\
\text { Orange FE oxides are present, biogenics are present, } \\
\text { hydrothermal material is absent, plagioclase is sparse. Unit } \\
\text { is structureless with a gradational contact with underlying } \\
\text { unit. Color: Moderate Yellowish Brown (10YR 5/4). }\end{array}$ \\
\hline 2 & 7.0 & TM & $\begin{array}{l}\text { Sandy mud - Predominantly fluidal, medium-grained ash } \\
\text { with approximately } 10 \% \text { modal percent ash. Components: } \\
\text { Orange Fe oxides are present, hydrothermal clays are } \\
\text { present and appear more yellow in color. Plagioclase is } \\
\text { sparse, biogenic material is sparse and fragmented, sulfides } \\
\text { appear to be present. Unit is structureless. Sharp contact } \\
\text { with underlying unit. Color: Dark Yellowish Orange (10YR } \\
6 / 6) \text {. }\end{array}$ \\
\hline 3 & $3.0-4.0$ & HMT & $\begin{array}{l}\text { Sandy mud - Predominantly angular, fine-grained ash with } \\
\text { approximately } 10 \% \text { modal percent ash. Components: } \\
\text { Orange Fe oxides are present, green hydrothermal clay } \\
\text { aggregates are abundant, white zeolite minerals present, } \\
\text { sulfides are absent (none observed). Plagioclase is present } \\
\text { near bottom of unit; biogenic material is absent. Unit is } \\
\text { normally graded with sharp contact at } \sim 10 \text {-degree angle. } \\
\text { Color: Light Olive Grey (5YR } 5 / 2) \text {. }\end{array}$ \\
\hline 4 & 2.0 & LPT & $\begin{array}{l}\text { Ash - Predominantly fluidal, medium lapilli sized vitriclasts. } \\
\text { Contains: Abundant plagioclase, crystalline basalt } \\
\text { fragments are present, wide range of glass morphologies. } \\
\text { Unit is normally graded. Sharp contact with underlying unit. }\end{array}$ \\
\hline 5 & 5.0 & TO & $\begin{array}{l}\text { Ashy mud - Mix of both angular and fluidal, coarse-grained } \\
\text { ash with approximately } 40 \% \text { modality. Components: } \\
\text { Biogenic material is abundant. Plagioclase is sparse and } \\
\text { only in glass-rich areas. Other components are absent. Unit } \\
\text { is entirely ash and biogenic material. Color: Yellowish Grey } \\
\text { (5Y } 7 / 2 \text { ). }\end{array}$ \\
\hline
\end{tabular}




\begin{tabular}{|c|c|c|c|}
\hline \\
\hline Unit & $\begin{array}{l}\text { Thickness } \\
(\mathrm{cm})\end{array}$ & Lithofacies & Description \\
\hline 1 & 8.0 & TM & $\begin{array}{l}\text { Ashy mud - Ash is mostly blocky but also contains some } \\
\text { fluidal shards. Ash is coarse ash - fine lapilli size and } \\
\text { approximately } 20-25 \% \text { modality of ash. Contains orange Fe } \\
\text { oxides present, abundant biogenic material, green } \\
\text { hydrothermal aggregates are sparse. Small amounts of } \\
\text { layering without defined laminations or structures. Sharp } \\
\text { contact with underlying unit. Color: Yellowish Brown (5YR } \\
5 / 6) \text {. }\end{array}$ \\
\hline 2 & 2.0 & TM & $\begin{array}{l}\text { Sandy mud - Ash is predominantly blocky and is sub- } \\
\text { millimeter (medium ash) and approximately } 3 \% \text { modality. } \\
\text { Contains abundant orange Fe oxides, biogenics are } \\
\text { present, yellowish hydrothermal material is also present. } \\
\text { Overall unit is structureless. Color grades from darker } \\
\text { orange (top) to yellow-orange (bottom). Sharp basal contact } \\
\text { with unit below. Color: Light Brown (5YR 5/6). }\end{array}$ \\
\hline 3 & 1.5 & HMT & $\begin{array}{l}\text { Ashy mud - Ash is both blocky and fluidal (platy) with } \\
\text { blocky being the predominant shape. Ash is fine-grained } \\
\text { ash and approximately } 15 \% \text { modality. Contains orange Fe } \\
\text { oxides present, abundant green hydrothermal material, } \\
\text { feldspar crystals present among vitriclasts. Overall unit is } \\
\text { structureless. Sharp contact with underlying unit with } \sim 5- \\
\text { degree angle. Color: Yellowish Grey (5YR } 7 / 2) \text {. }\end{array}$ \\
\hline 4 & 2.0 & LPT & $\begin{array}{l}\text { Ash - Ash is mostly fluidal with largest ash Medium lapilli } \\
\text { near bottom \& coarse ash near top. Feldspar crystals are } \\
\text { present among ash. Tachylite crystals sparse. Normally } \\
\text { graded with finer ash near top \& coarser ash near bottom. } \\
\text { Sharp contact with basal unit at } \sim 5 \text {-degree angle and } \\
\text { parallel with contact above. }\end{array}$ \\
\hline 5 & 1.5 & TO & $\begin{array}{l}\text { Ashy mud - Ash is mostly fluidal and medium-grained ash } \\
\text { with a modal percent ash of approximately } 50 \% \text {. Orange Fe } \\
\text { oxides are sparse, absent hydrothermal material. Biogenic } \\
\text { material is abundant }(\sim 90 \%) \text {. Lamination at } 1 / 2 \mathrm{~cm} \text { depth that } \\
\text { is about } 1 / 2 \mathrm{~cm} \text { thick containing slightly more ash. Color: } \\
\text { Greyish Orange (10YR } 7 / 4) \text {. }\end{array}$ \\
\hline
\end{tabular}


D878 PC78

\begin{tabular}{|l|l|l|l|}
\hline Unit & $\begin{array}{l}\text { Thickness } \\
(\mathrm{cm})\end{array}$ & Lithofacies & Description \\
\hline 1 & 6.5 & TM & $\begin{array}{l}\text { Ashy mud - Ash is predominantly fluidal and grain size is } \\
\text { medium to coarse ash and modal percent is approximately } \\
15 \% \text {. Edges of core in this unit are likely contaminated with } \\
\text { more ash as there is a bulge along the sides (40\% ash near } \\
\text { edges). Contains orange Fe oxides present. Biogenic } \\
\text { material is present. Hydrothermal material is sparse-absent. } \\
\text { No other volcanic material (feldspars) observed. Mottling of } \\
\text { yellow and orange colors but no distinct laminations. Sharp } \\
\text { basal contact with below unit. Color: Light Brown (5YR 5/6). }\end{array}$ \\
\hline 2 & 7.5 & HMT & $\begin{array}{l}\text { Sandy mud - Very small amounts of ash and too difficult to } \\
\text { determine ash shape. Very fine-fine grained ash with 1\% } \\
\text { modal percent. Contains no biogenic material, abundant } \\
\text { hydrothermal material, no orange Fe oxides present, no } \\
\text { ofther volcanic material present. Two laminations present: } \\
\text { First is about 1/2 cm below base approximately 2-3 cm thick. } \\
\text { Second lamination is approximately 1.5 cm below base and } \\
\text { 2-3 mm. Both laminations contain slightly higher ash } \\
\text { content that is fine-grained, fluidal ash. Color: Yellowish } \\
\text { Grey (5YR 7/2). }\end{array}$ \\
\hline & &
\end{tabular}


D881-PC72L

\begin{tabular}{|l|l|l|l|}
\hline Unit & $\begin{array}{l}\text { Thickness } \\
(\mathrm{cm})\end{array}$ & Lithofacies & Description \\
\hline 1 & 7.0 & TM & $\begin{array}{l}\text { Ashy mud - Ash is both angular and fluidal. Largest particle } \\
\text { is } \sim / 2 \text { cm (medium lapilli). Ash modality is approximately } \\
40 \% \text { ash surrounded by orange/brown mud. Contains } \\
\text { orange Fe oxides sparse }(\sim 1 \%), \text { plagioclase is present. } \\
\text { Hydrothermal clays \& altered minerals absent. Biogenics } \\
\text { sparse-present. Top of unit is structureless. Reverse-graded } \\
\text { (more ash near the top and ash thins out near bottom of } \\
\text { unit). Mottling of color with underlying unit. Gradational } \\
\text { contact. Color: Moderate Brown (5YR 5/6). }\end{array}$ \\
\hline 2 & 5.0 & TM & $\begin{array}{l}\text { Ashy mud - Ash is mostly blocky/angular. Largest particle } \\
\text { 年m (fine lapilli). Modal percent ash is approximately } \\
\text { 10\%. Contains orange Fe oxides very sparse - absent. } \\
\text { Plagioclase \& volcanic minerals absent. Biogenics are } \\
\text { present to abundant. Hydrothermal clays absent. Layer is } \\
\text { structureless but noticeable variation where mix of TO \& } \\
\text { TM. This unit is more of a gradational transition layer from } \\
\text { underlying ooze and overlying mud units. Gradational } \\
\text { contact. Color: Greyish orange (10YR 7/4). }\end{array}$ \\
\hline 3 & 44.0 & TO & $\begin{array}{l}\text { Sandy mud - Ash is blocky and fine-grained ash and is <1\% } \\
\text { modality. Contains only <1\% ash and the rest is biogenic } \\
\text { material. Unit is very fine-grained. Entire unit is } \\
\text { structureless. Very slight color variation but mostly massive. } \\
\text { Color: Yellowish Grey (5Y 7/2). }\end{array}$ \\
\hline
\end{tabular}

Notes:

Core is $\sim 47 \mathrm{~km}$ south of caldera

3 previous samples taken from core @ 13.0, 31.0, \& 61.0 (very bottom of core) cm. 


\section{Appendix B: Core Logs}

The following core logs were compiled primarily based off of core descriptions (Appendix A). Core images have been enhanced for better contrast. Lithofacies boundaries, structures, color, modal ash percent, and grain size represent visual observations and not quantitative measurements (e.g. PSA). Color is based on the Munsell color system. Location of subsamples used for analysis in this study are indicated. Geophysical characteristics including $P$-wave velocity, bulk density, and magnetic susceptibility, which were measured at USGS in Santa Cruz, are also included. The D655 series of cores were not measured for geophysics. For information regarding symbols, see the core log key below:

\begin{tabular}{|c|c|c|c|c|c|}
\hline \multicolumn{6}{|c|}{ Core Log Key } \\
\hline \multicolumn{2}{|c|}{ Material: } & \multicolumn{2}{|c|}{ Structures: } & \multicolumn{2}{|c|}{ Contacts: } \\
\hline 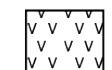 & Ash & $\Rightarrow$ & Massive (structureless) & & Sharp Contact \\
\hline & & & & - & Gradational Contact \\
\hline $\begin{array}{l}v^{v}-v-v-v \\
-v-v-v\end{array}$ & Muddy Ash & 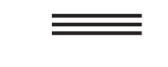 & Muddy Laminations & $n$ & Undulose Contact \\
\hline$F \overline{v^{v}-\overline{v v}}$ & & 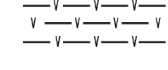 & Ashy Mud Lamination & Subsan & ples: \\
\hline 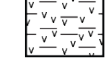 & Ashy Mud & 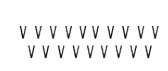 & Ash Lamination & $\triangle$ & PSA (Granulometry) \\
\hline 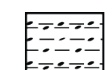 & Sandy Mud & $\bullet \bullet \bullet$ & Normal grading & 0 & XRD (Bulk Mineralogy) \\
\hline & & $\bullet \bullet \bullet$ & Reverse aradina & (b) & $\begin{array}{l}\text { XRD (Bulk \& Clay } \\
\text { Mineralogy) }\end{array}$ \\
\hline = & 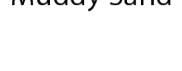 & $\approx$ & Color Motteling & $\diamond$ & Point Counts \\
\hline 地 & Artificial & & & $\square$ & MGS \\
\hline
\end{tabular}




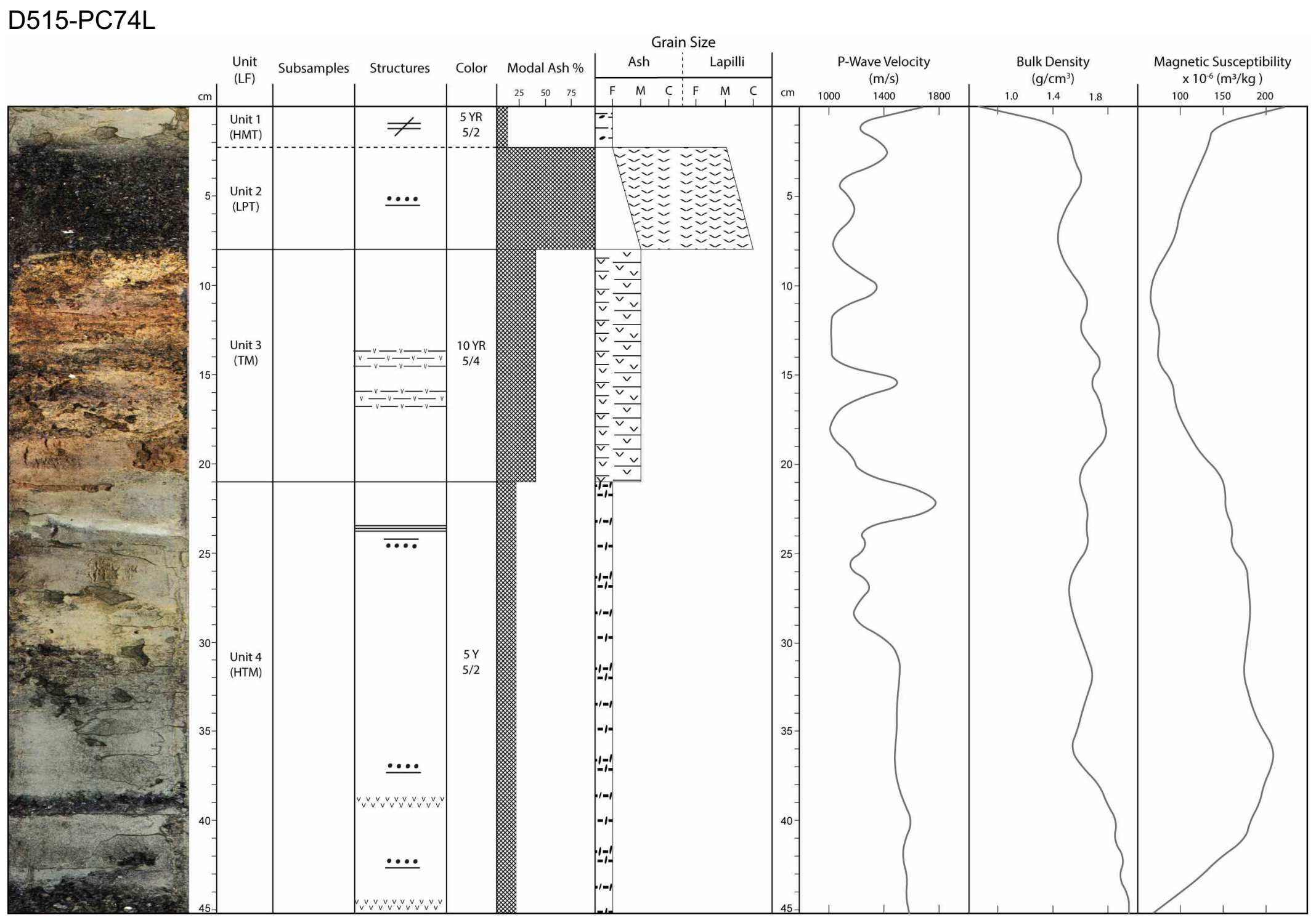




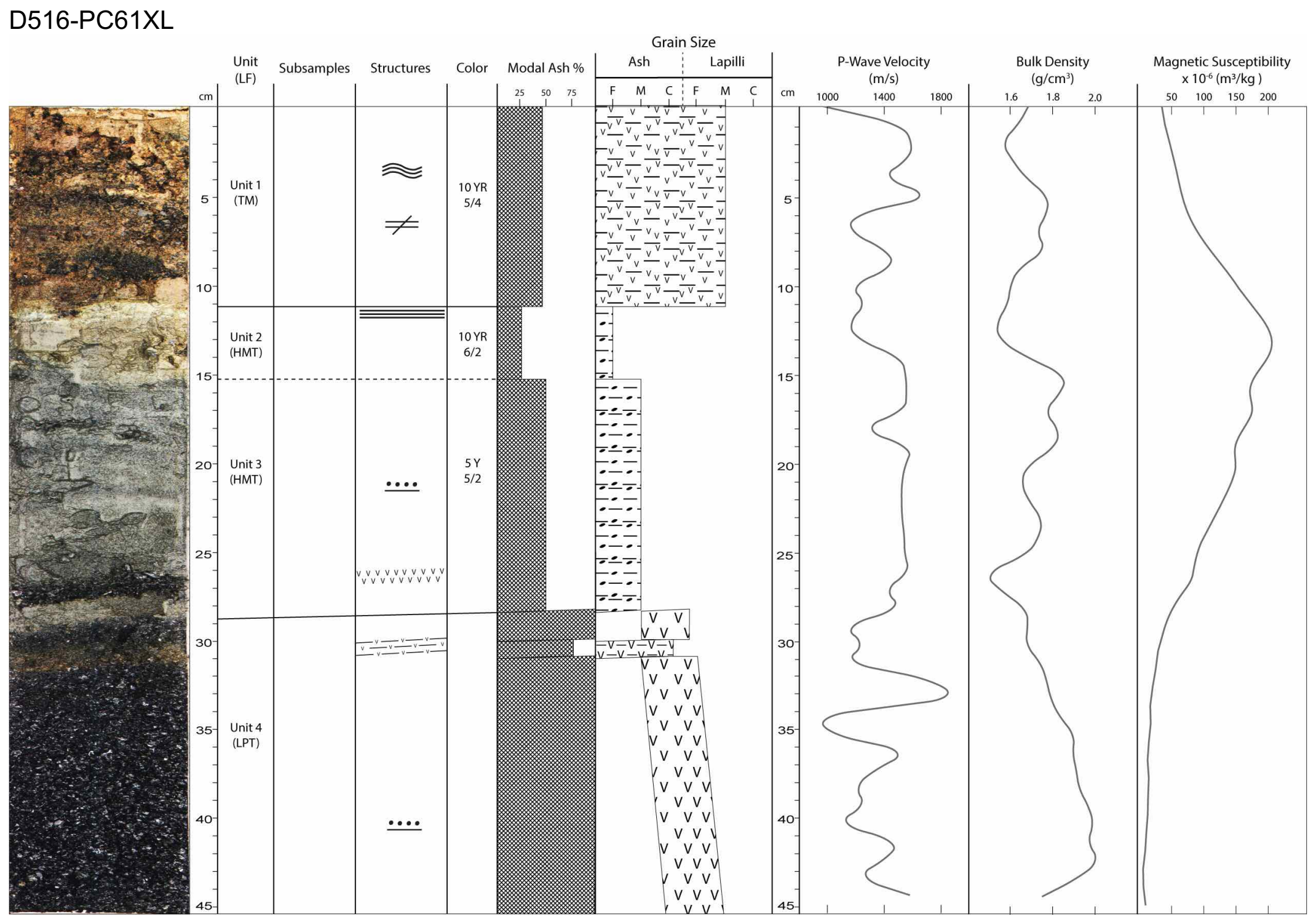




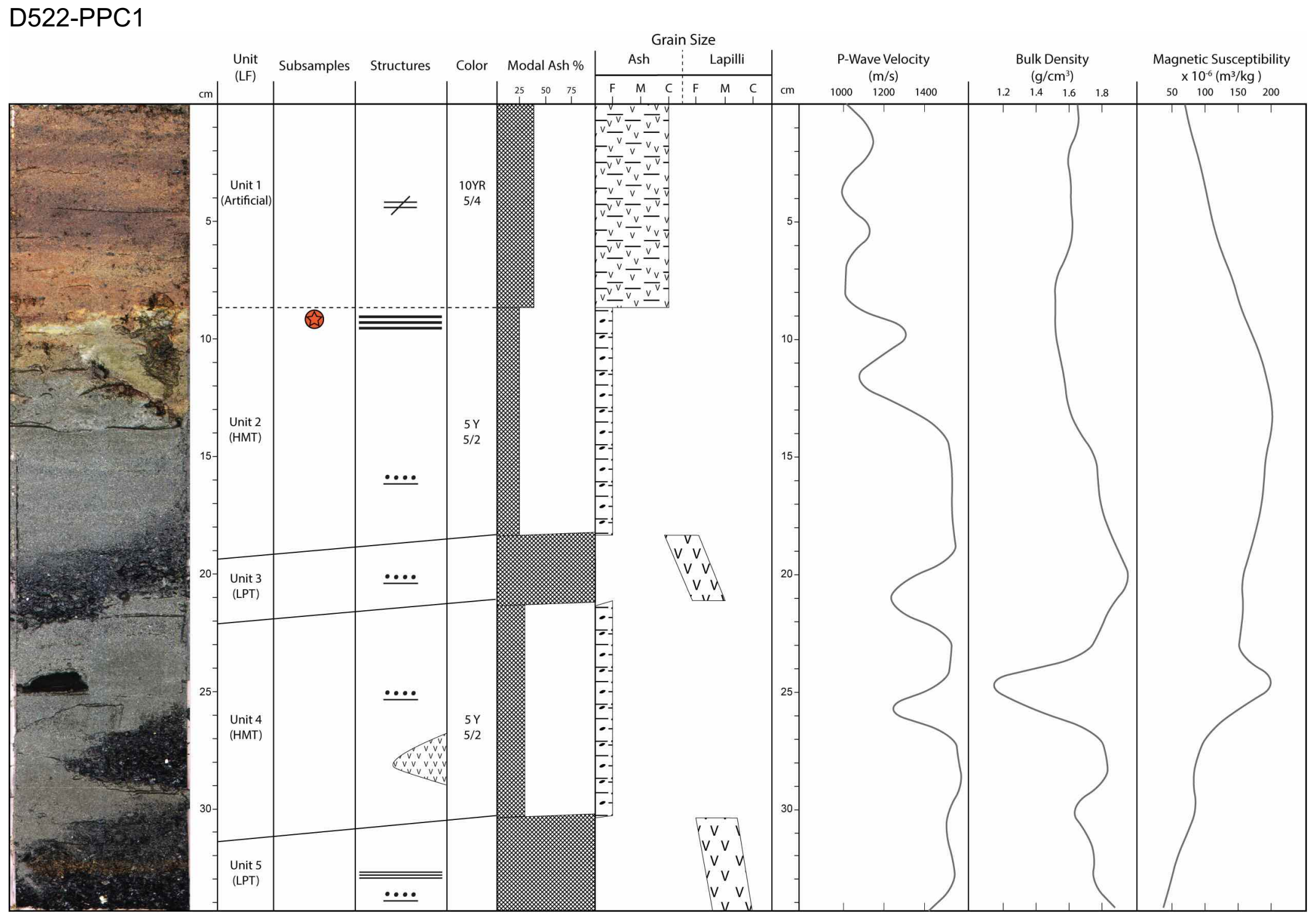




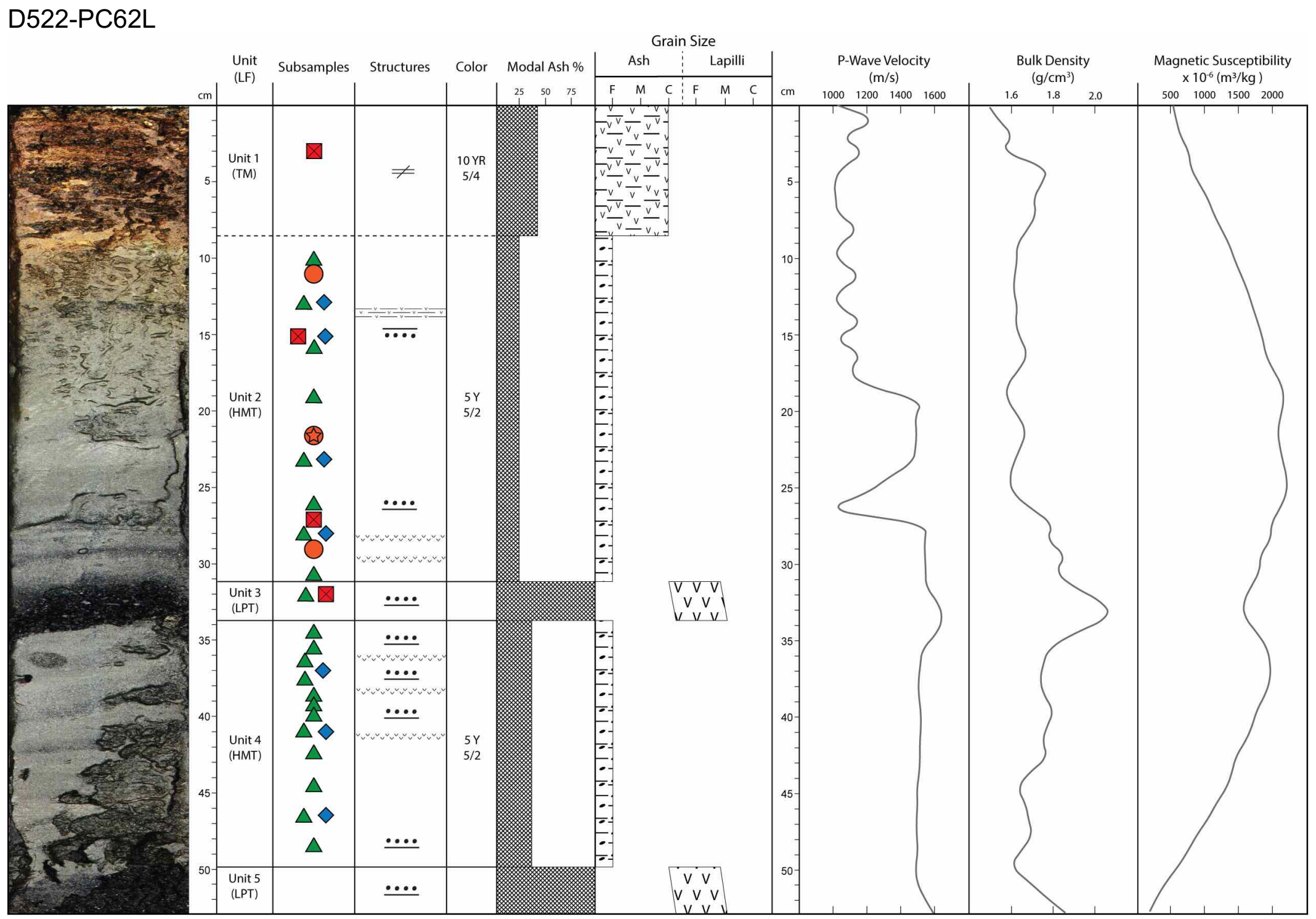




\section{D522-PC66}

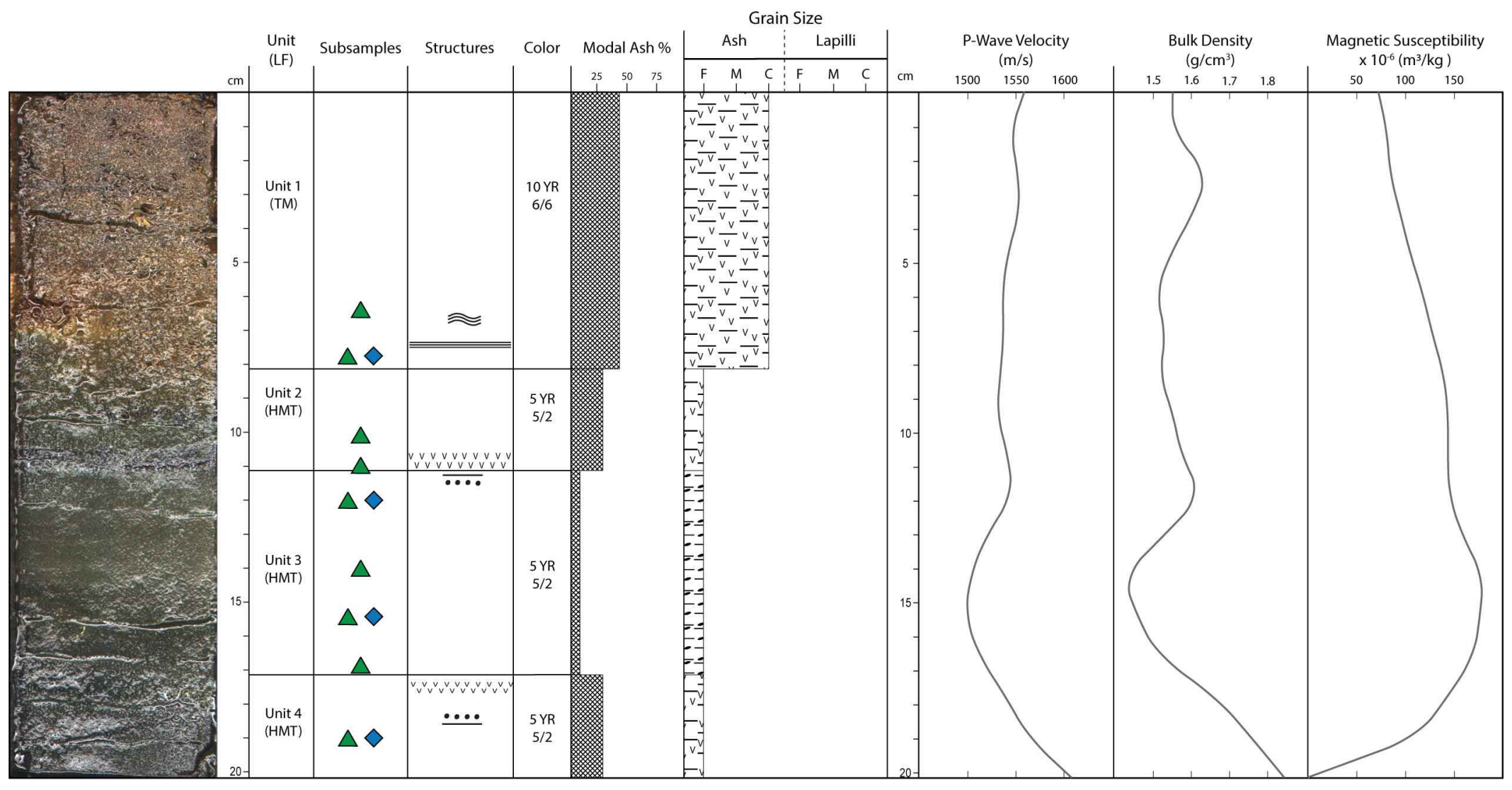




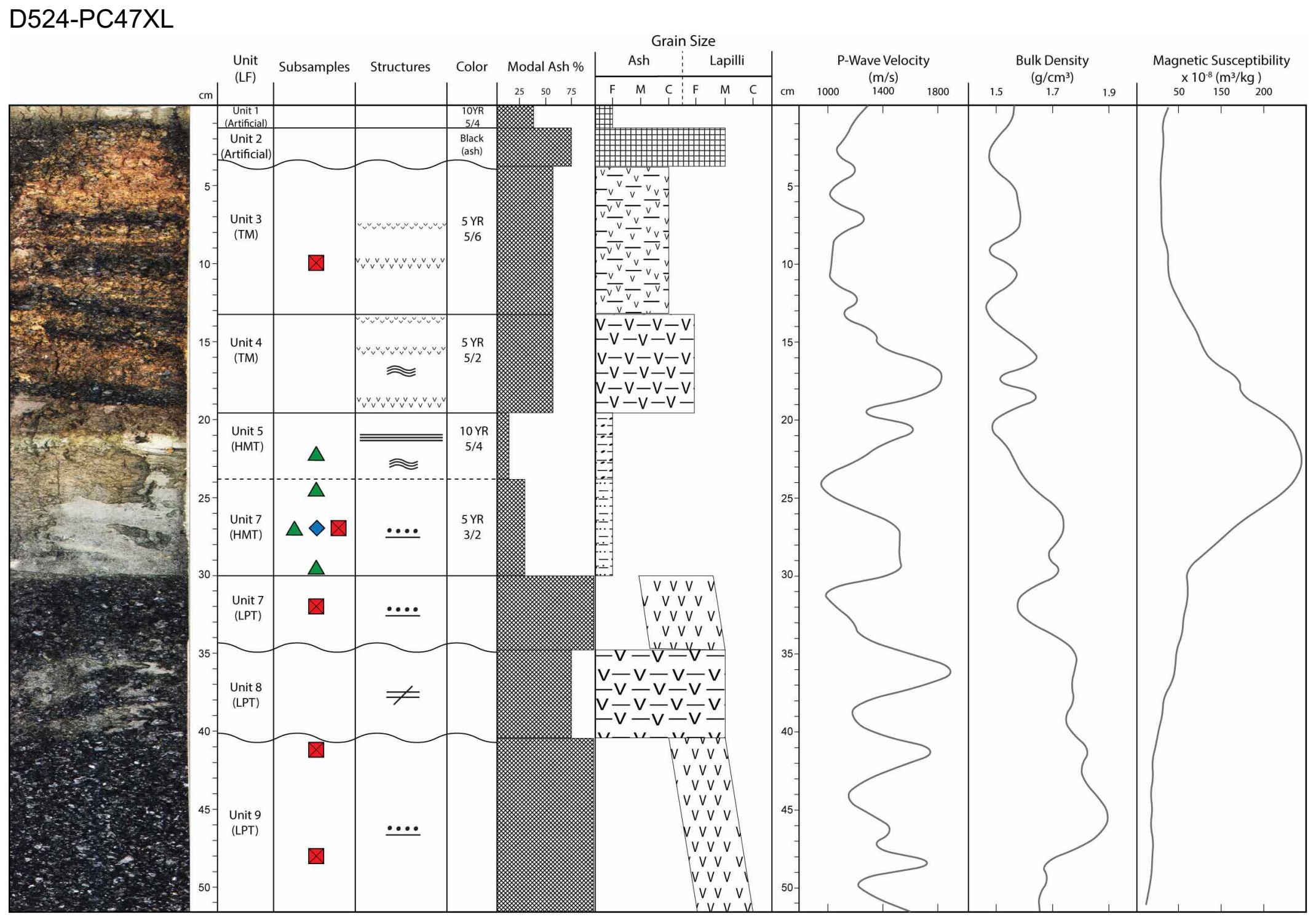




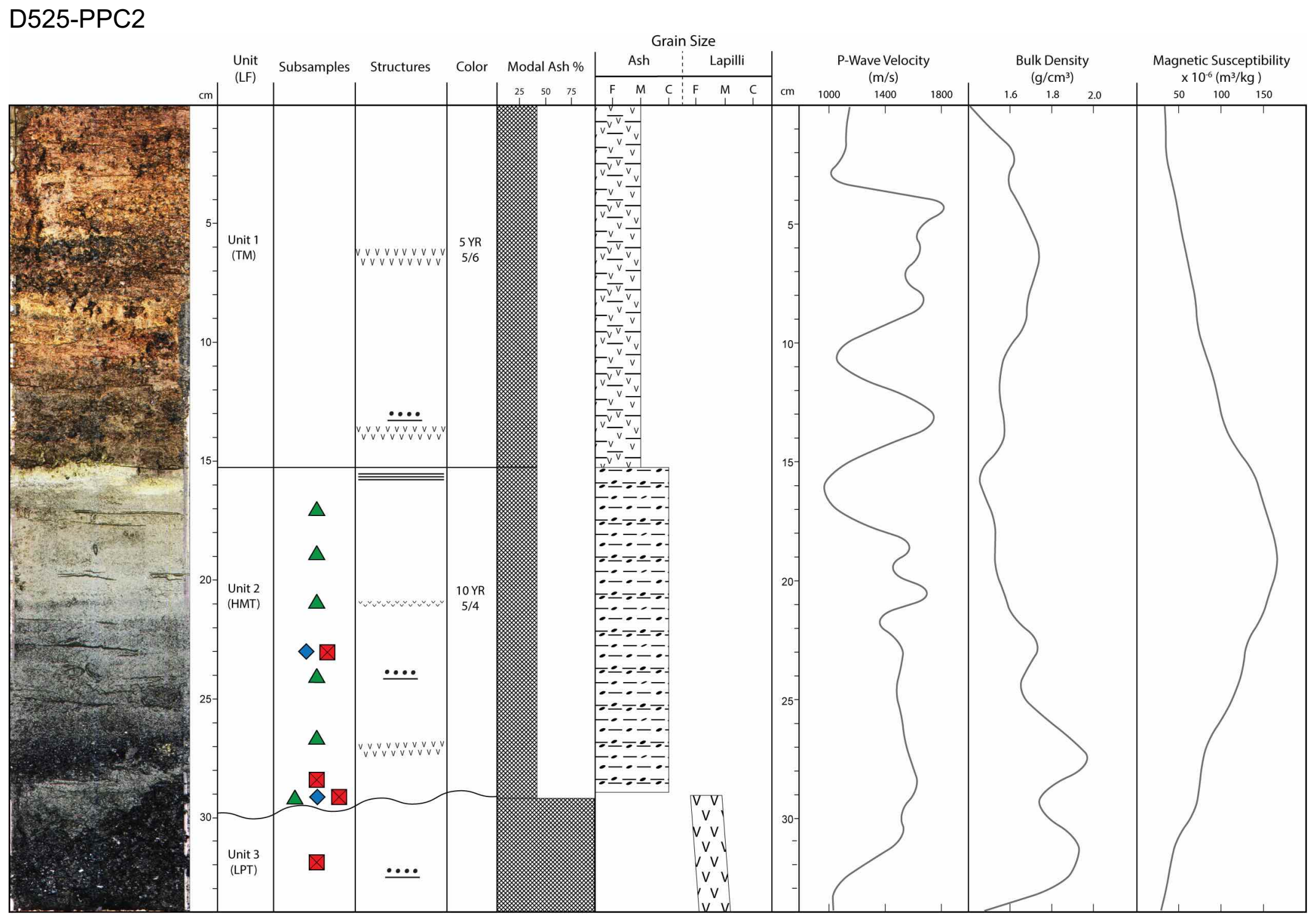




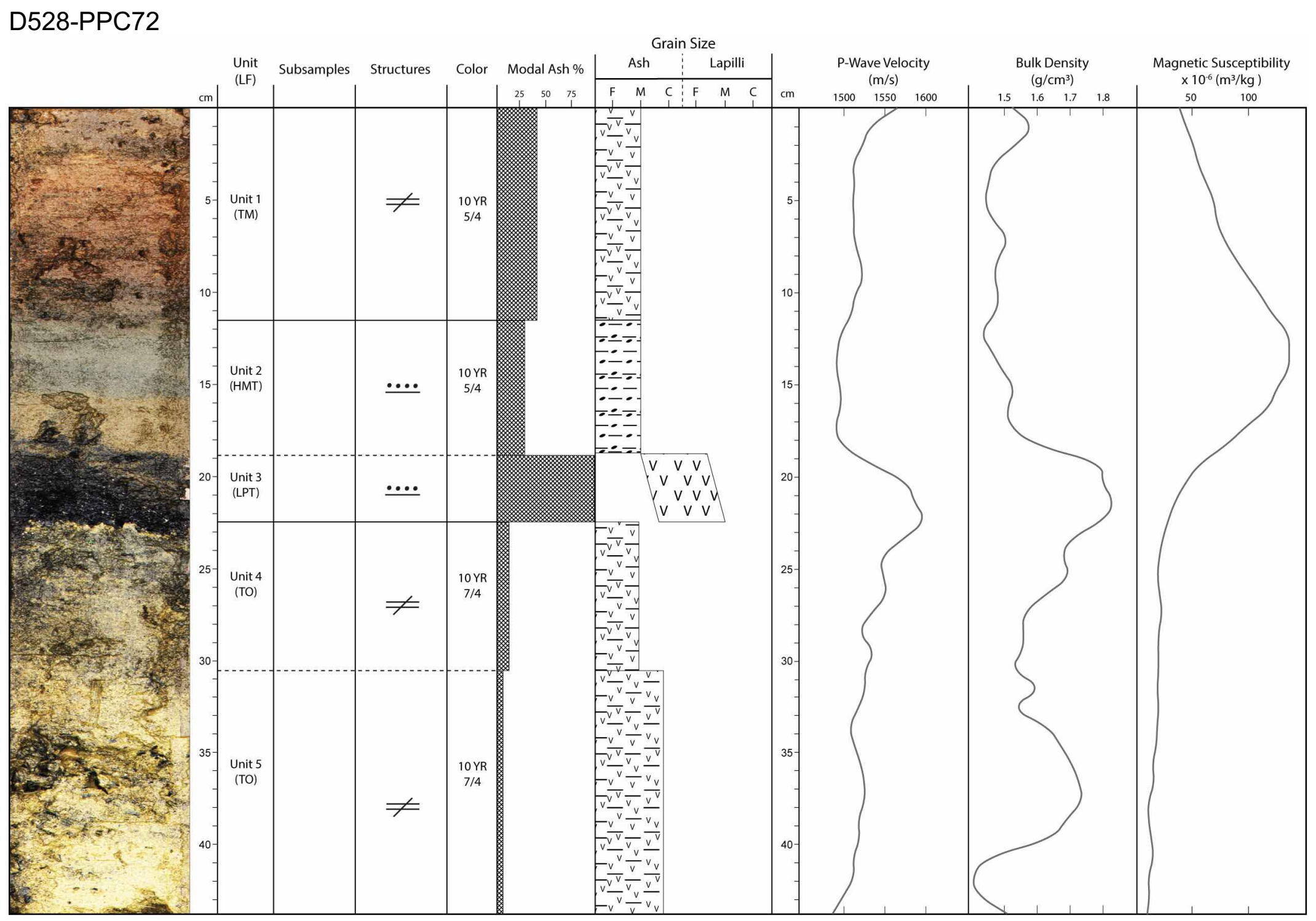




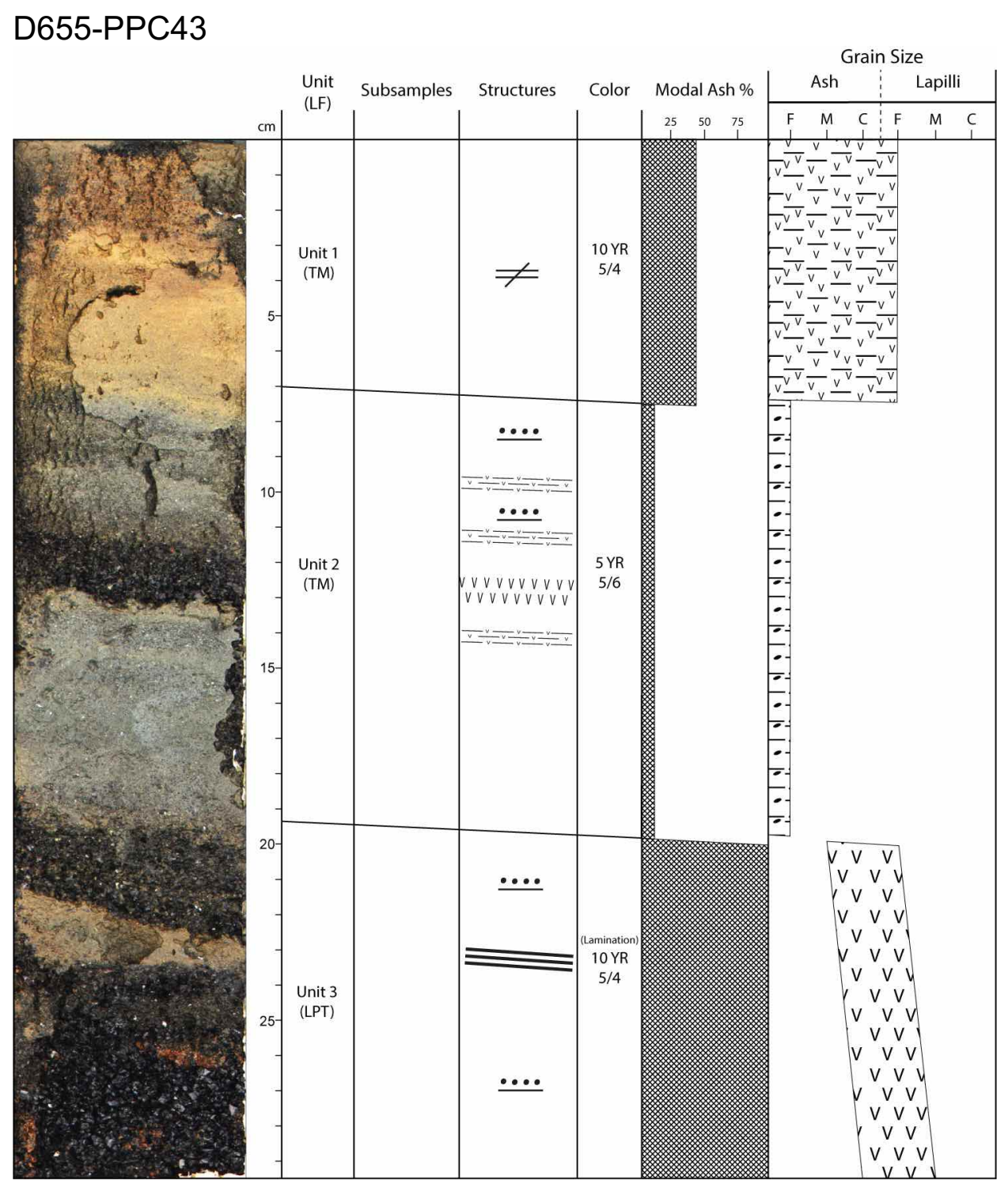




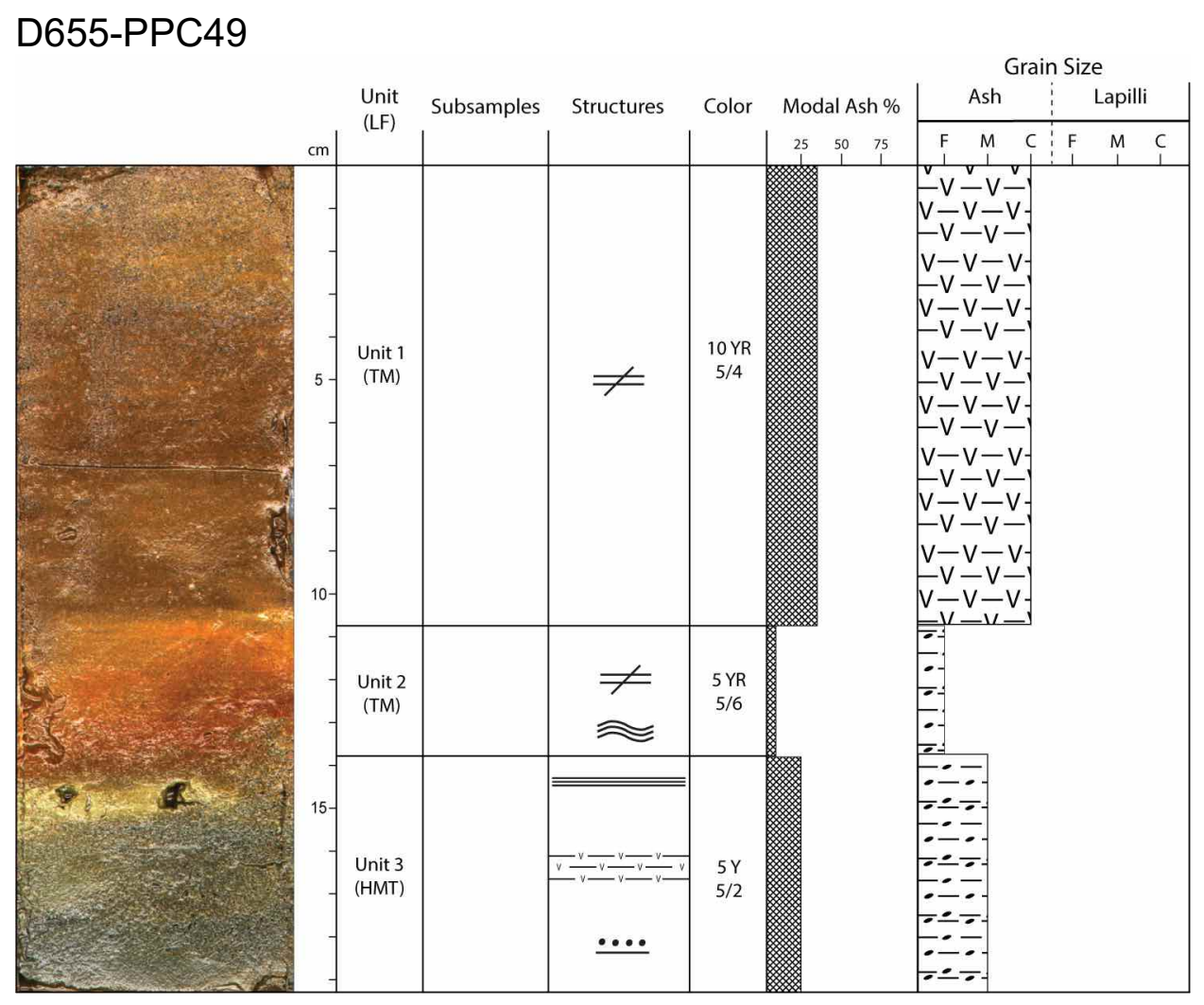




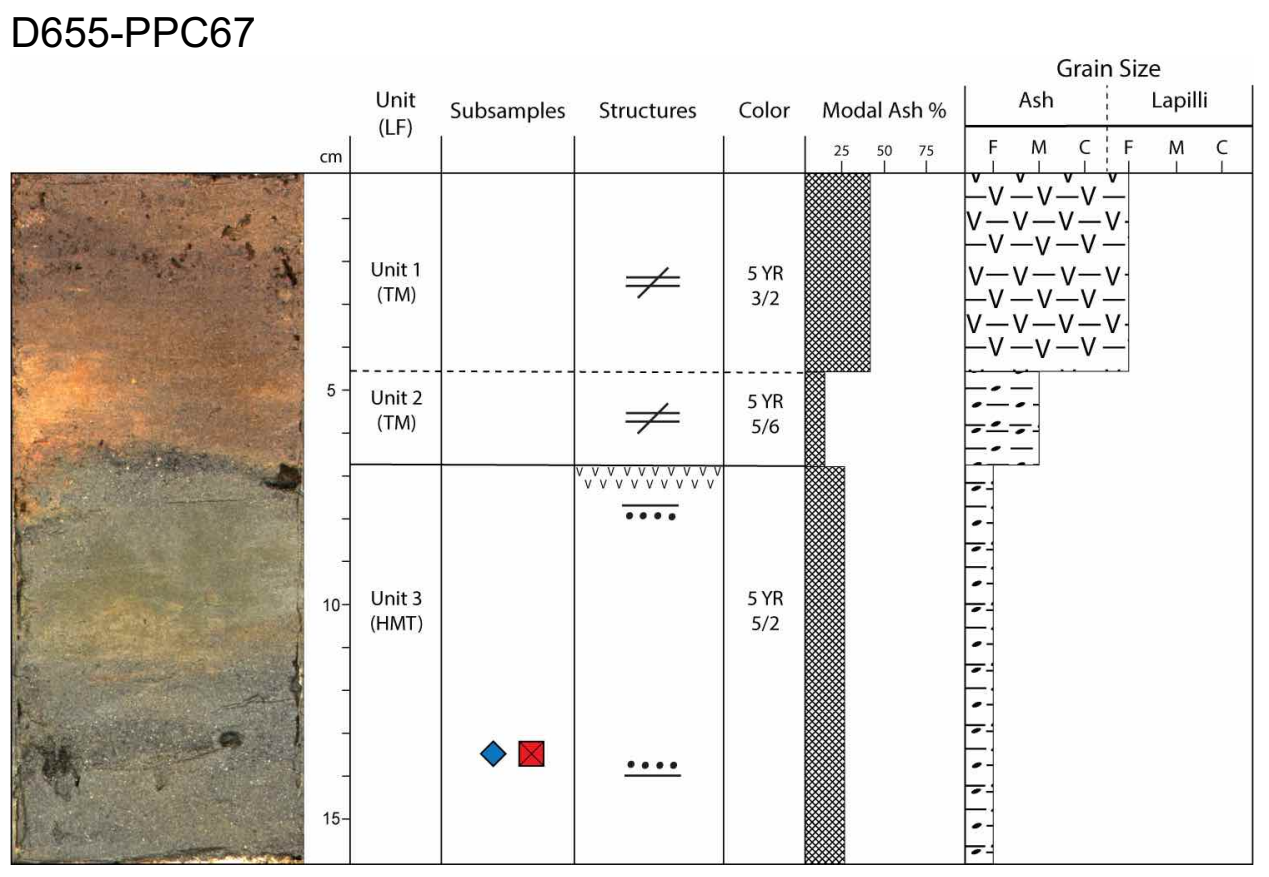




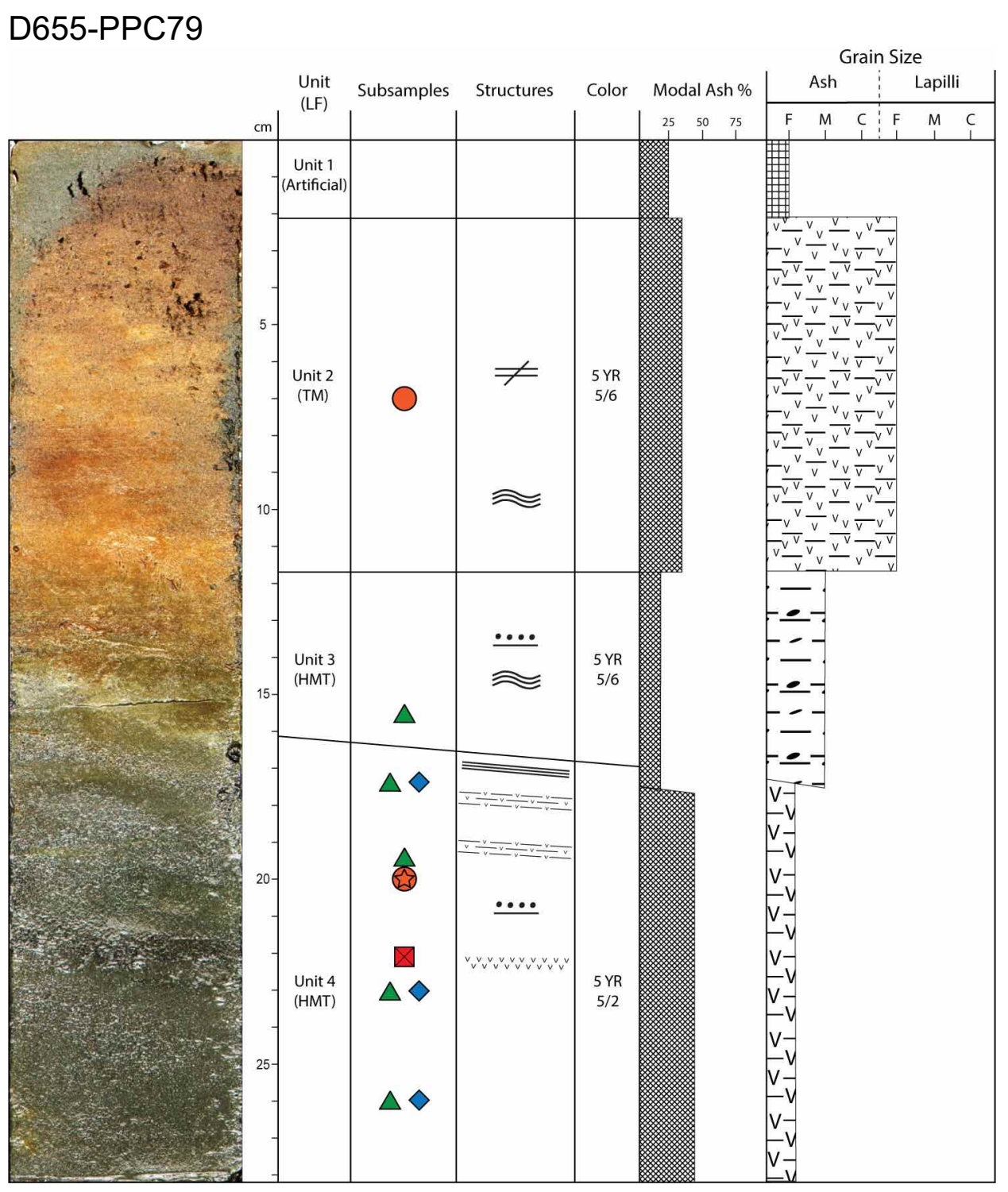




\section{D875-PC75}

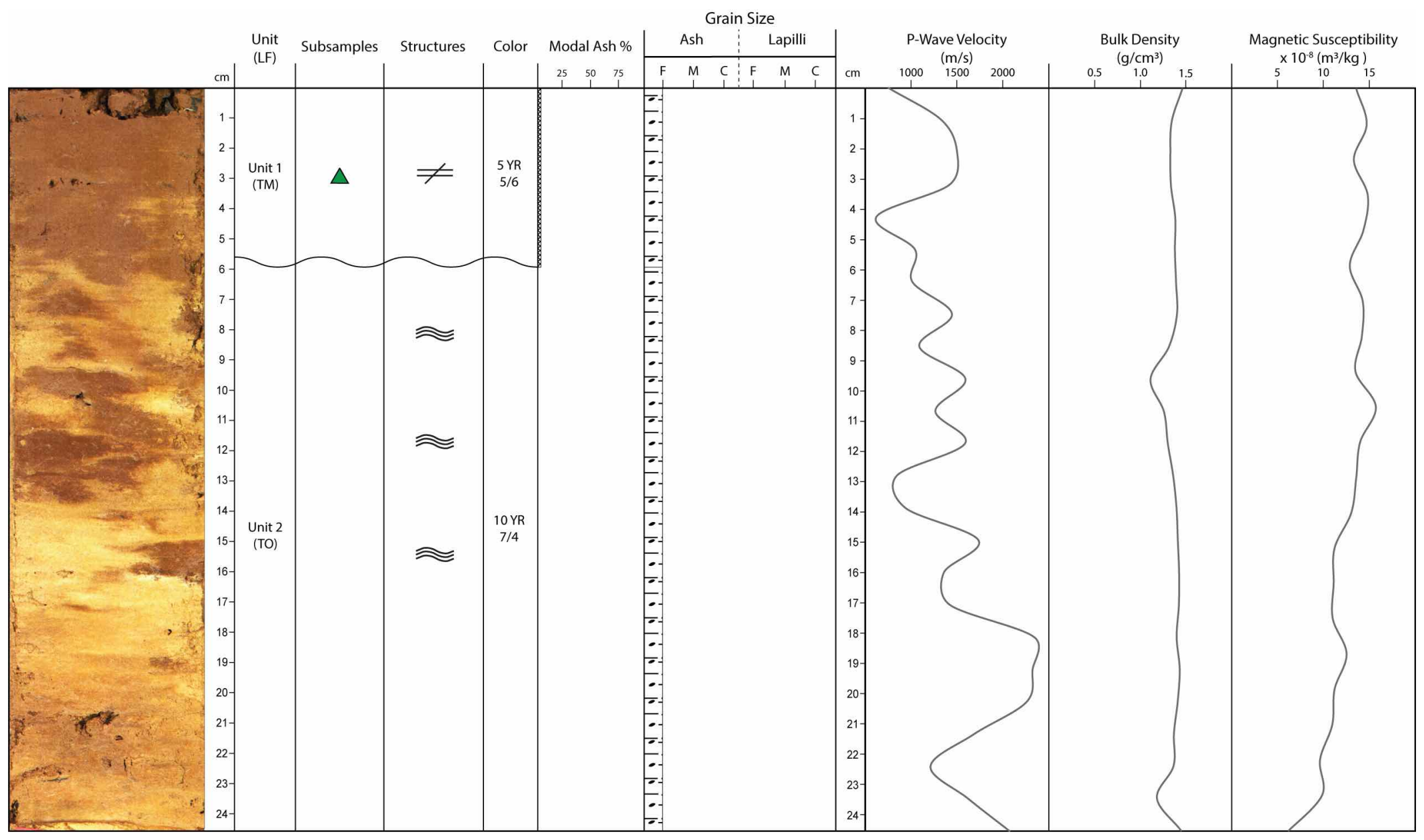




\section{D876-PC66}

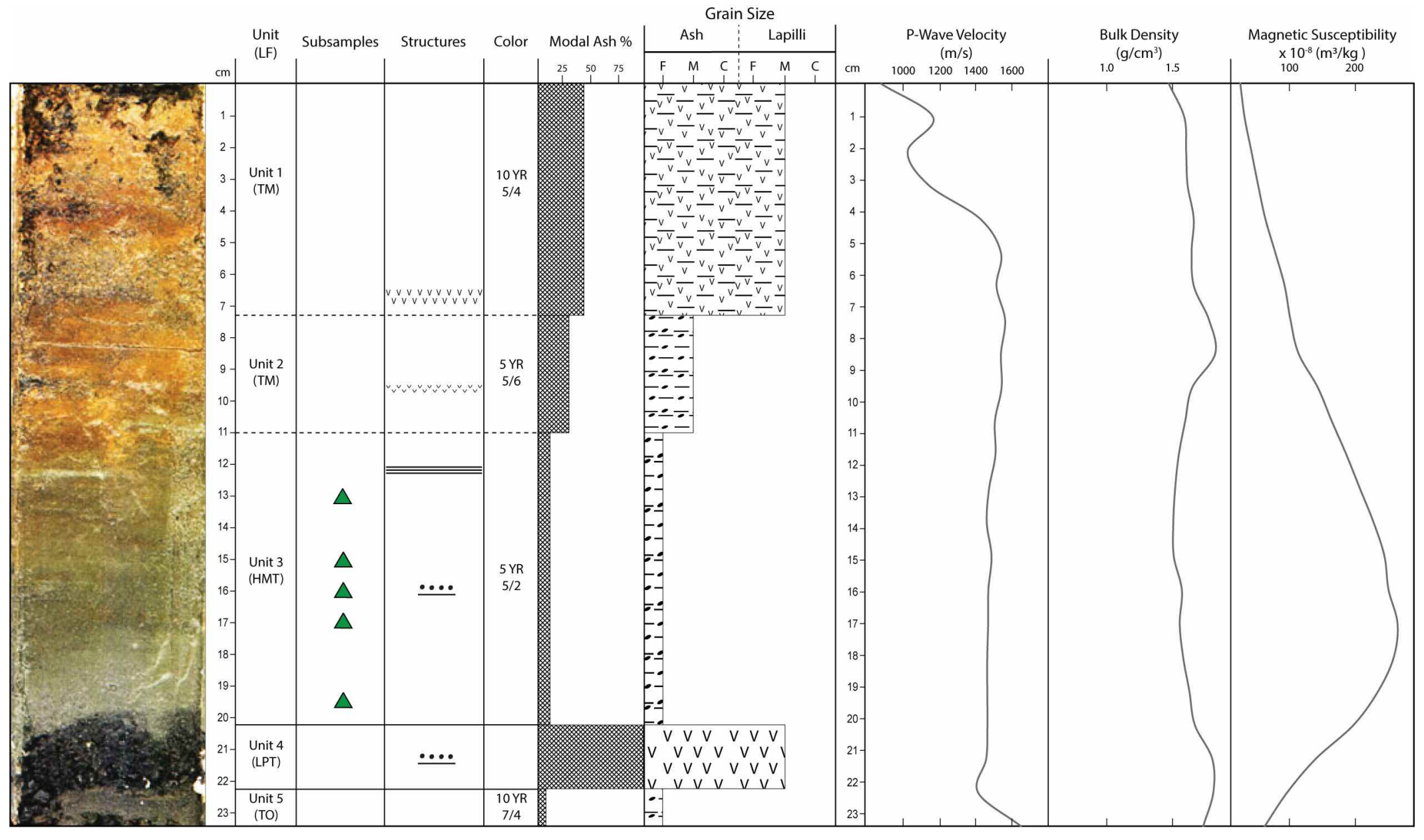




\section{D876-PC75}

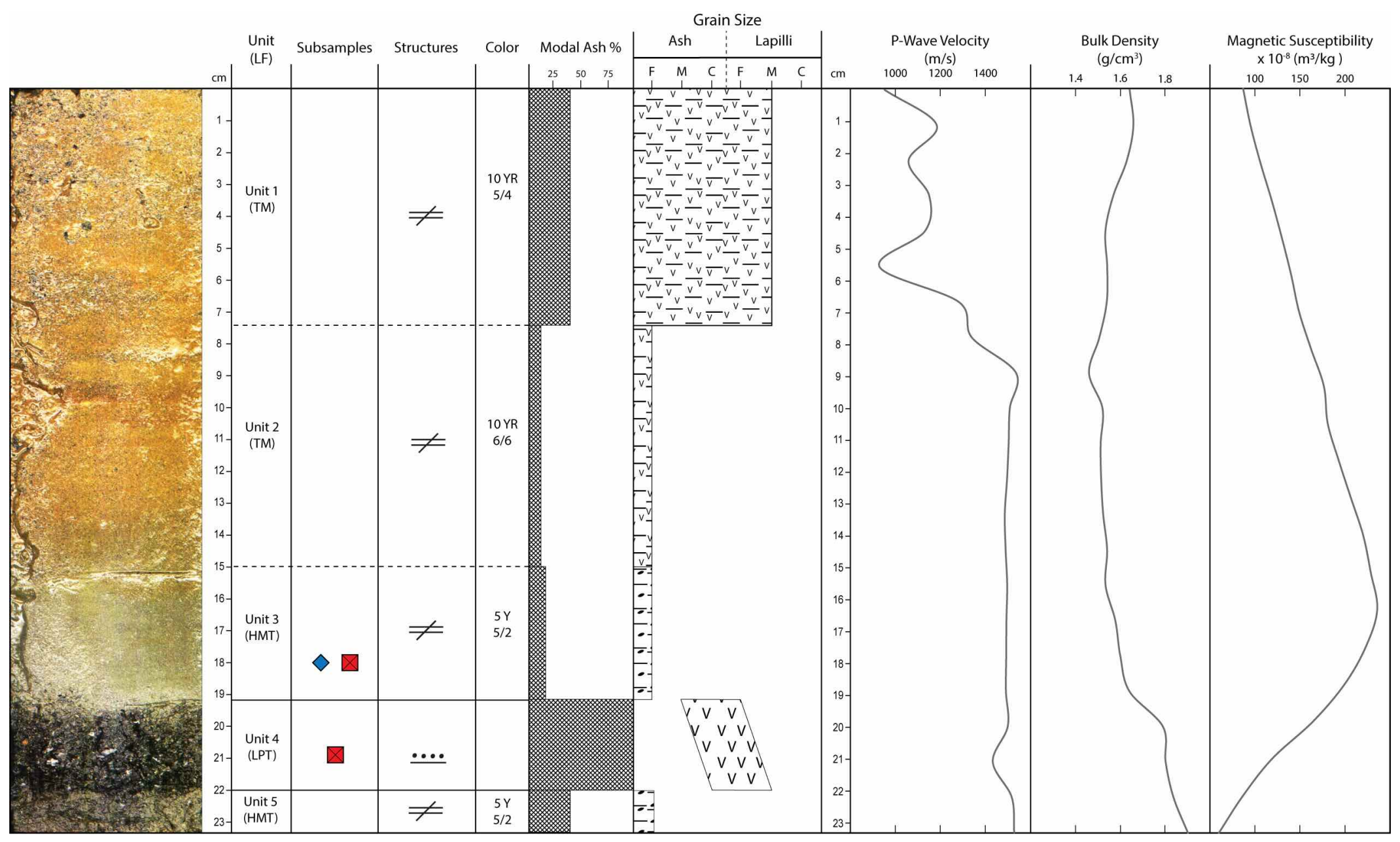




\section{D878-PC44}

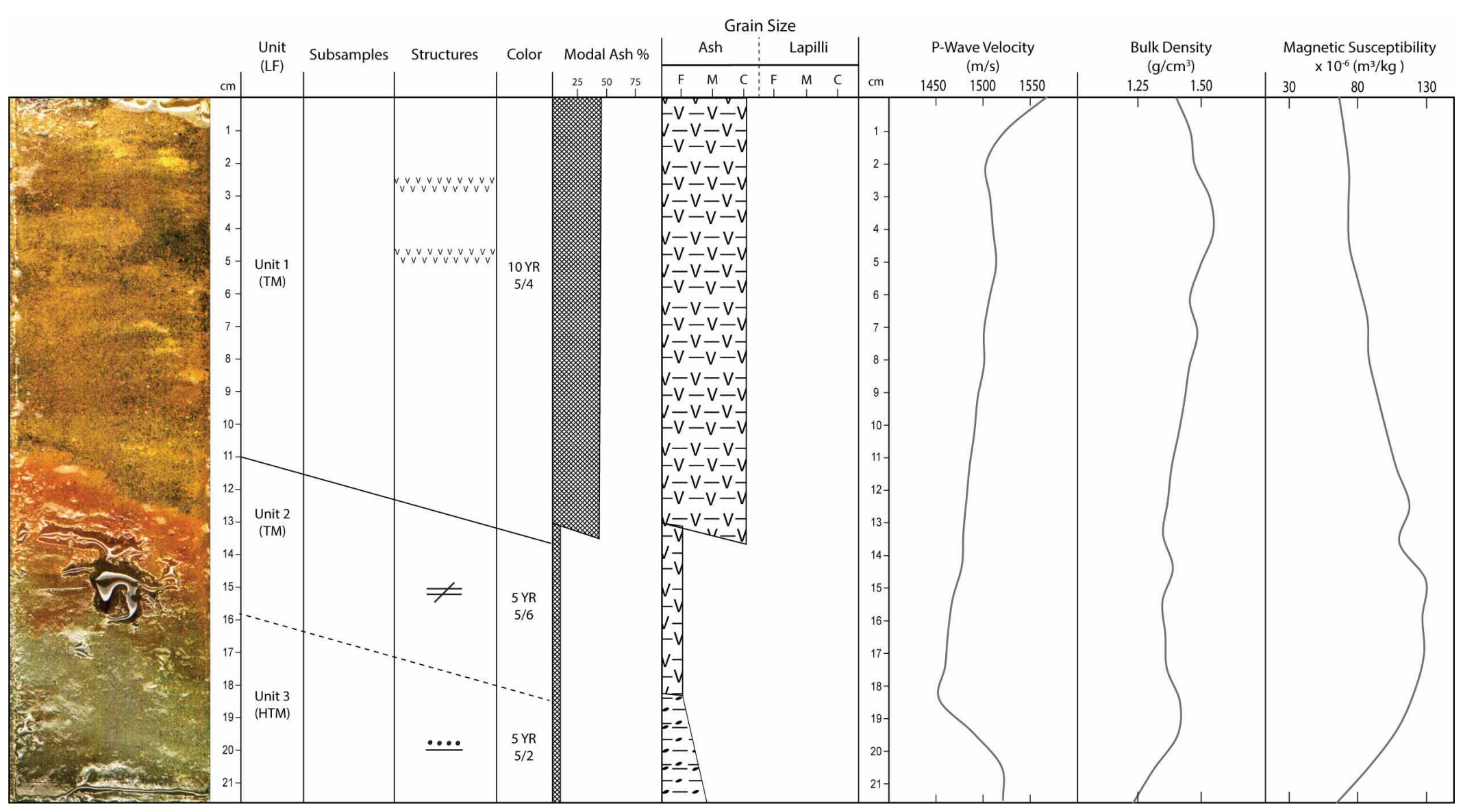




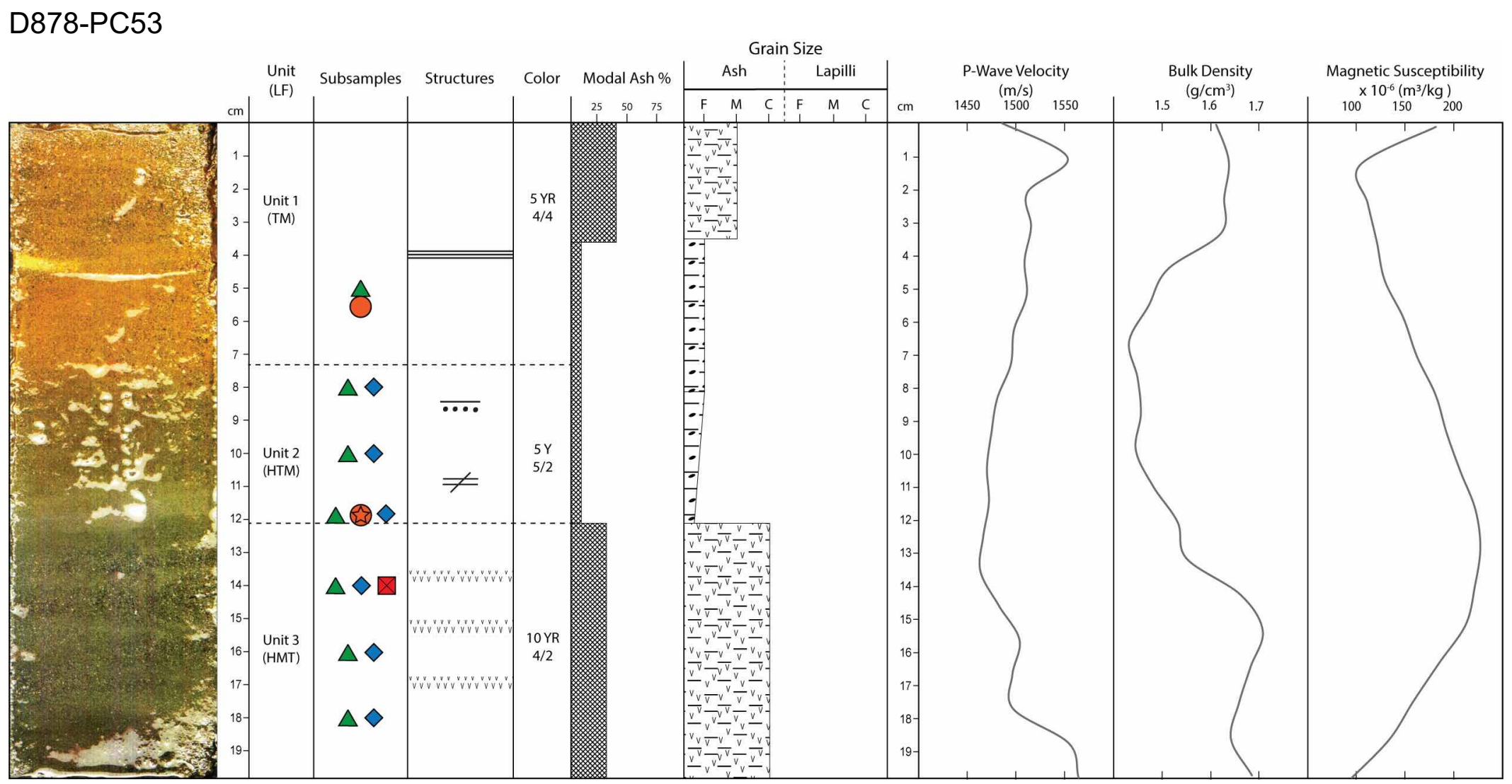




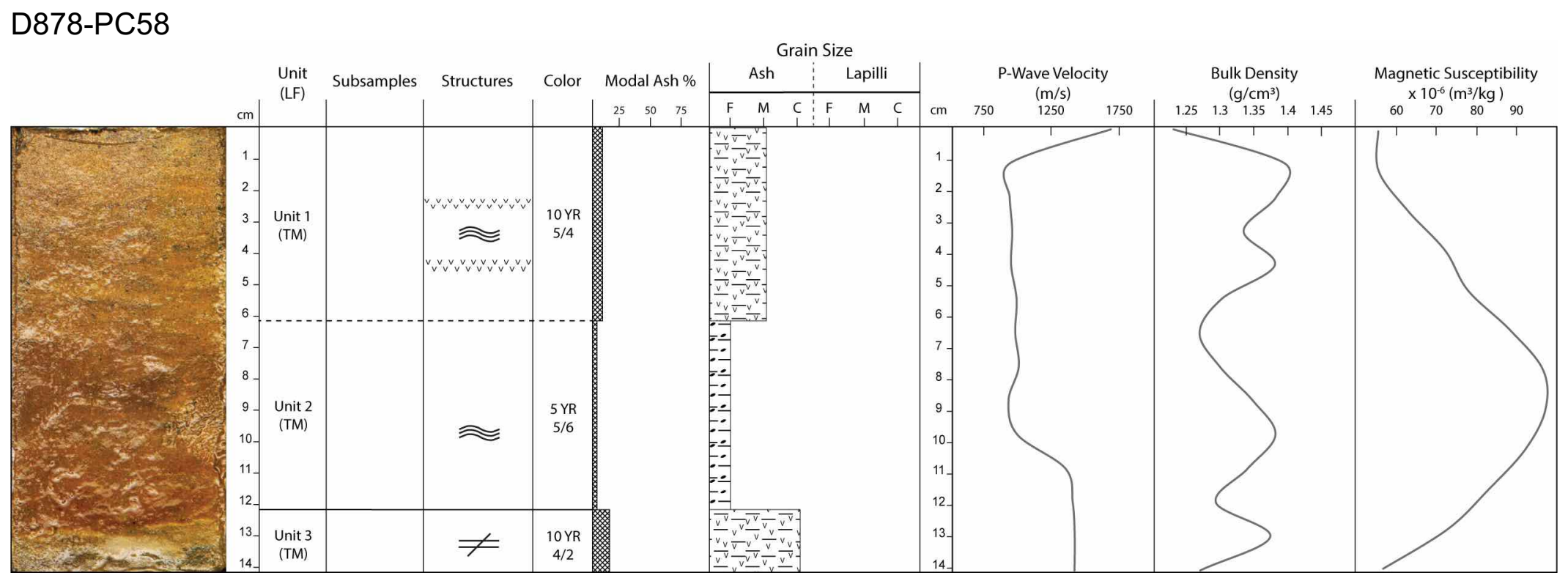




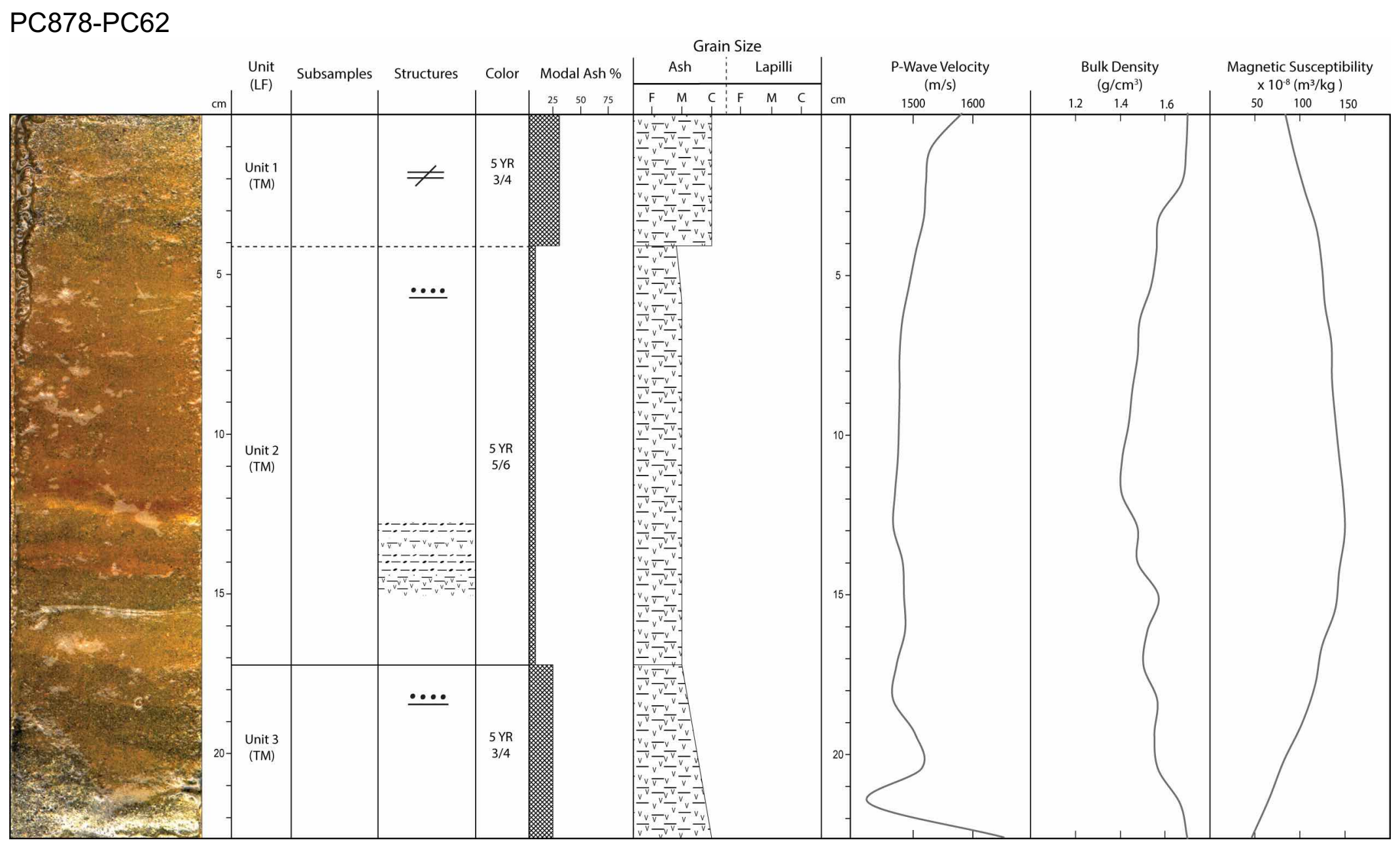




\section{D878-PC63}

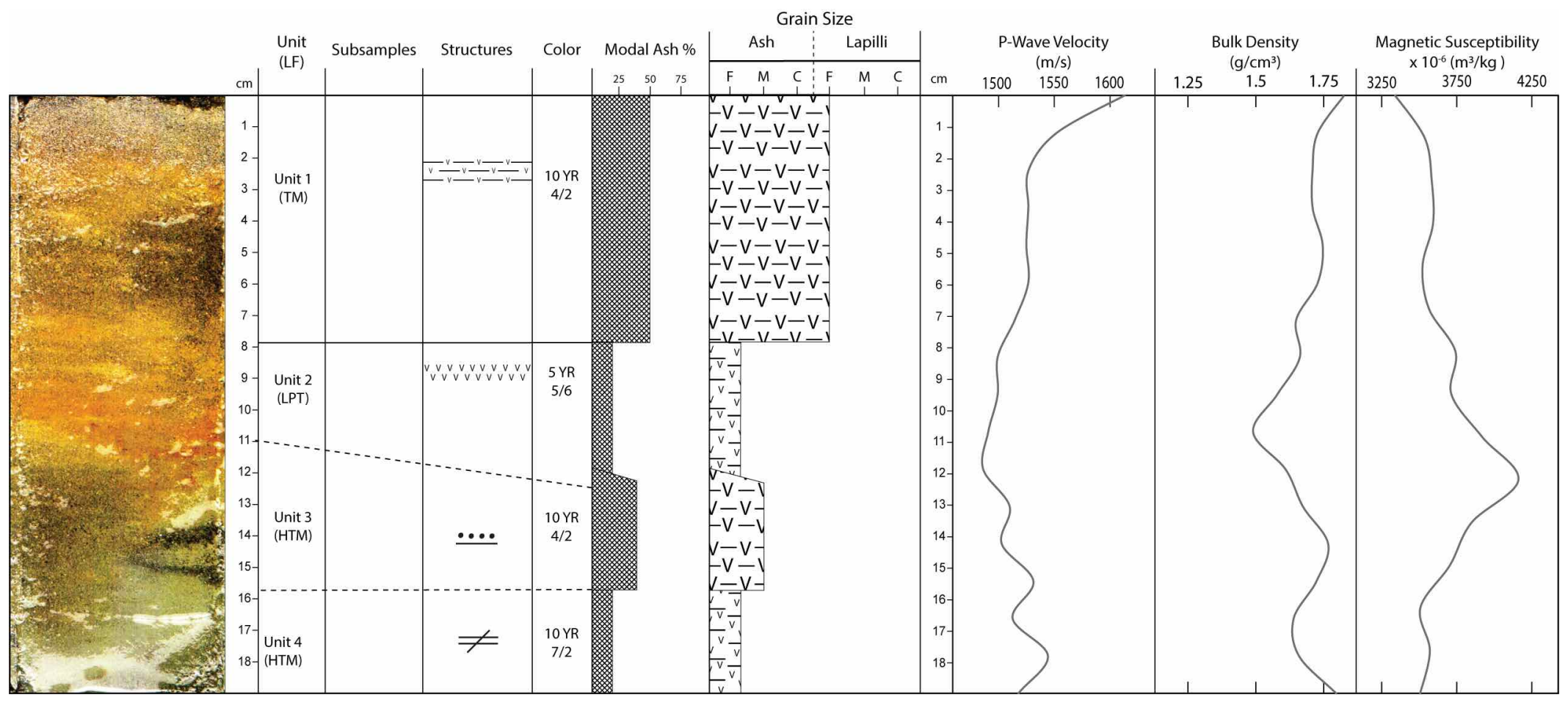




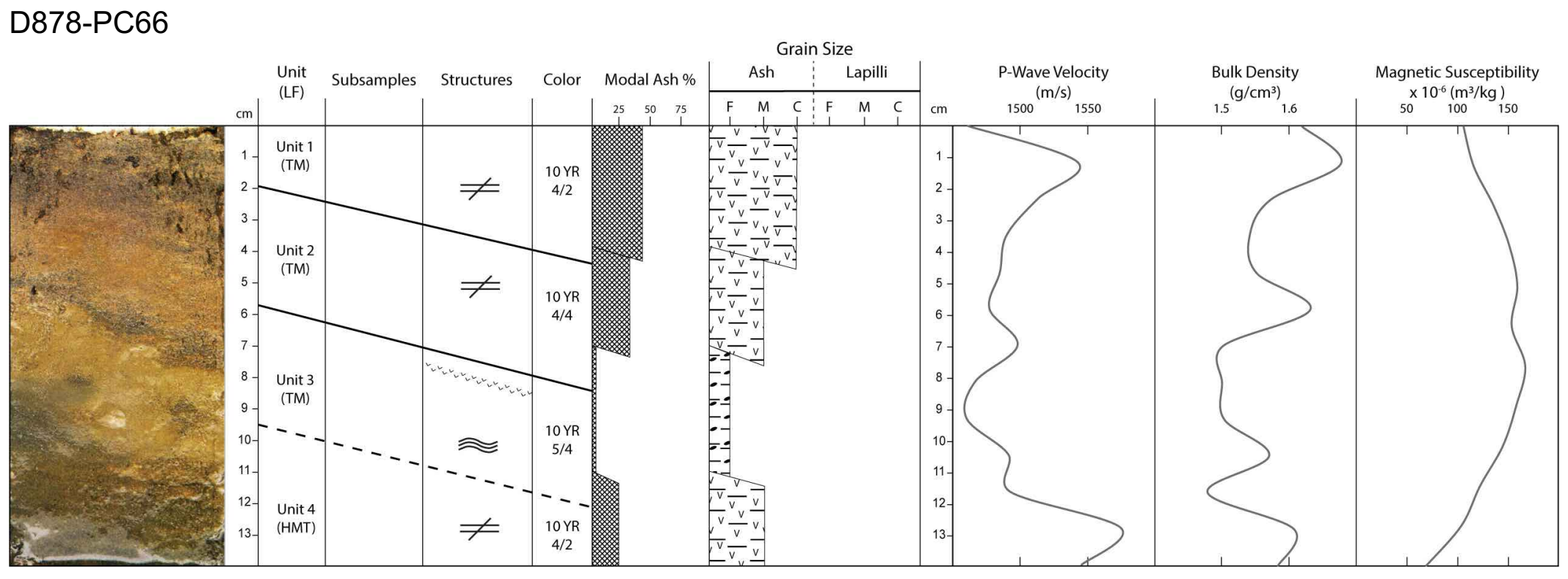




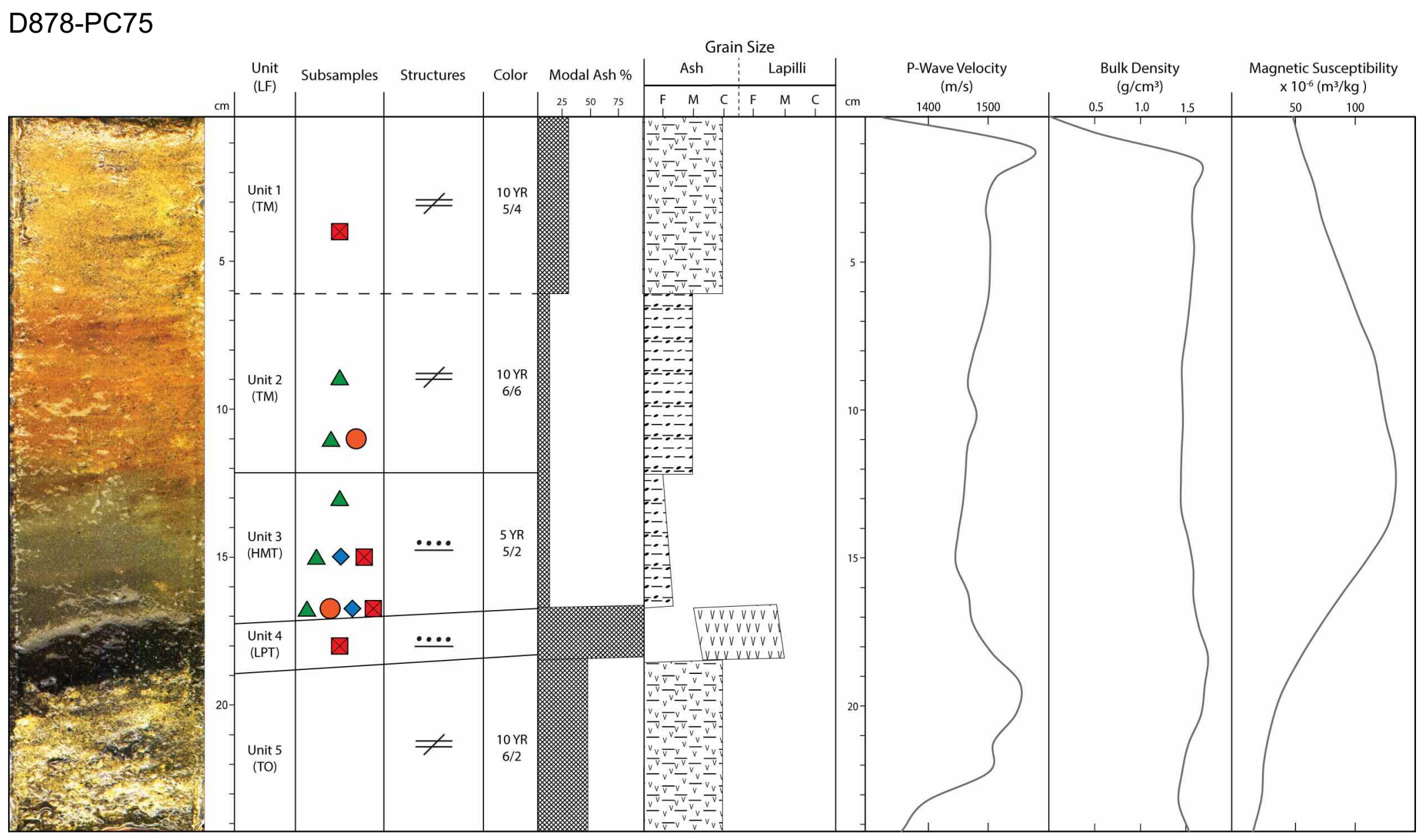




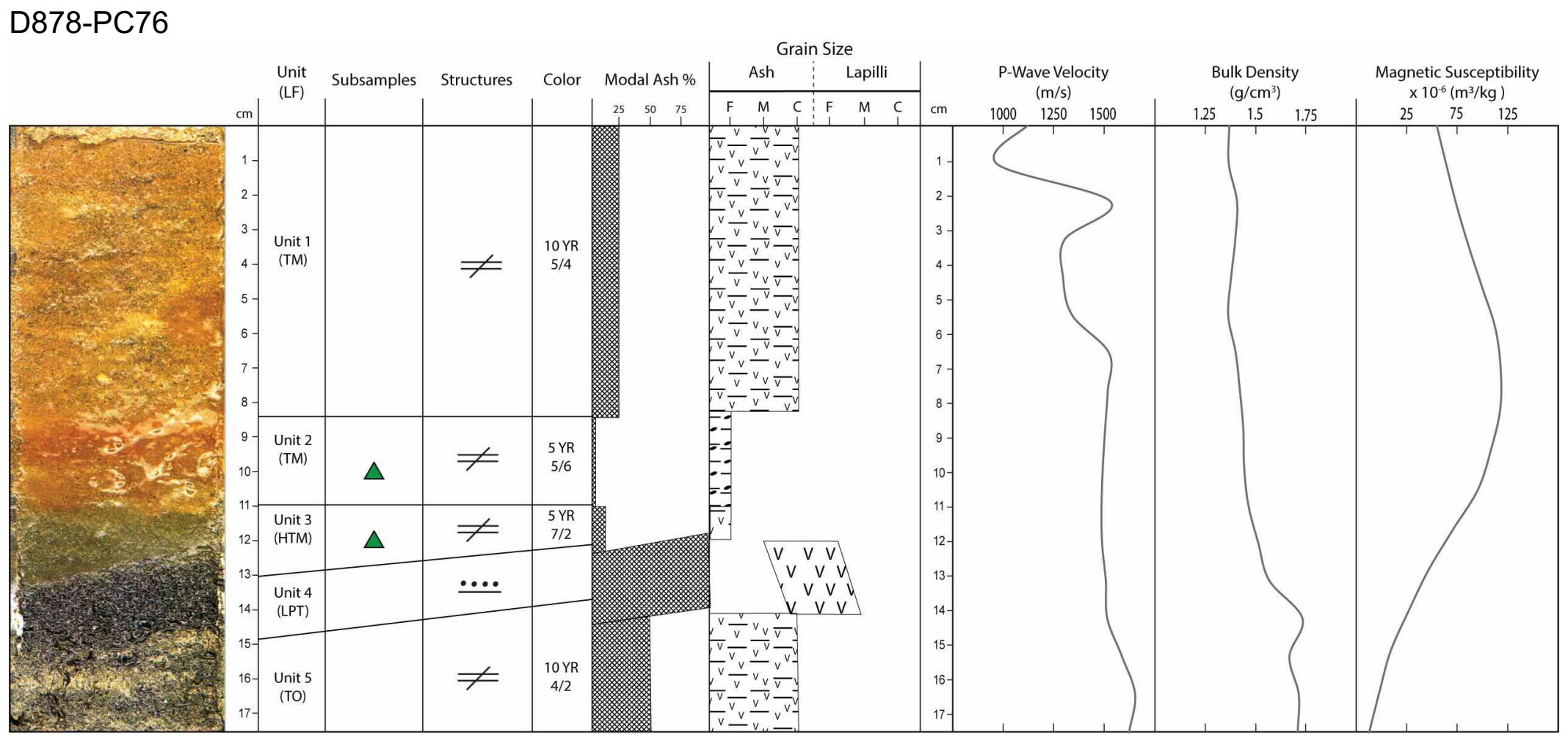




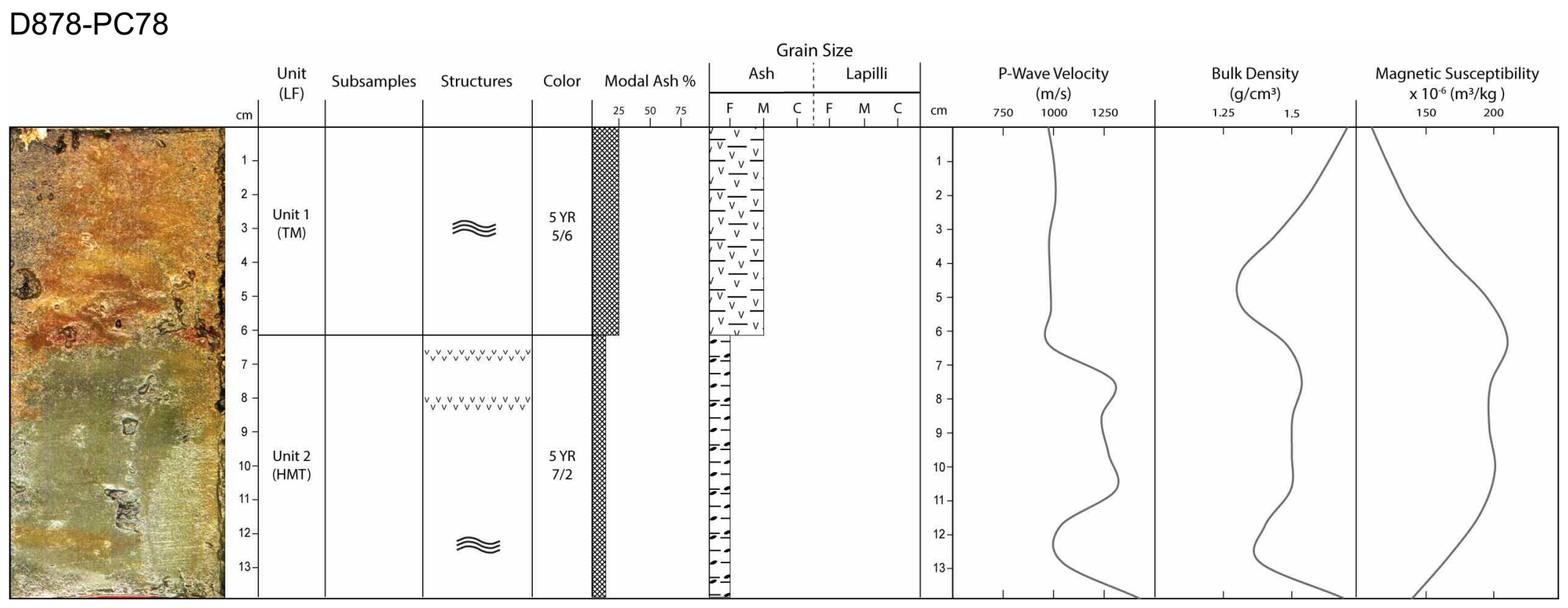




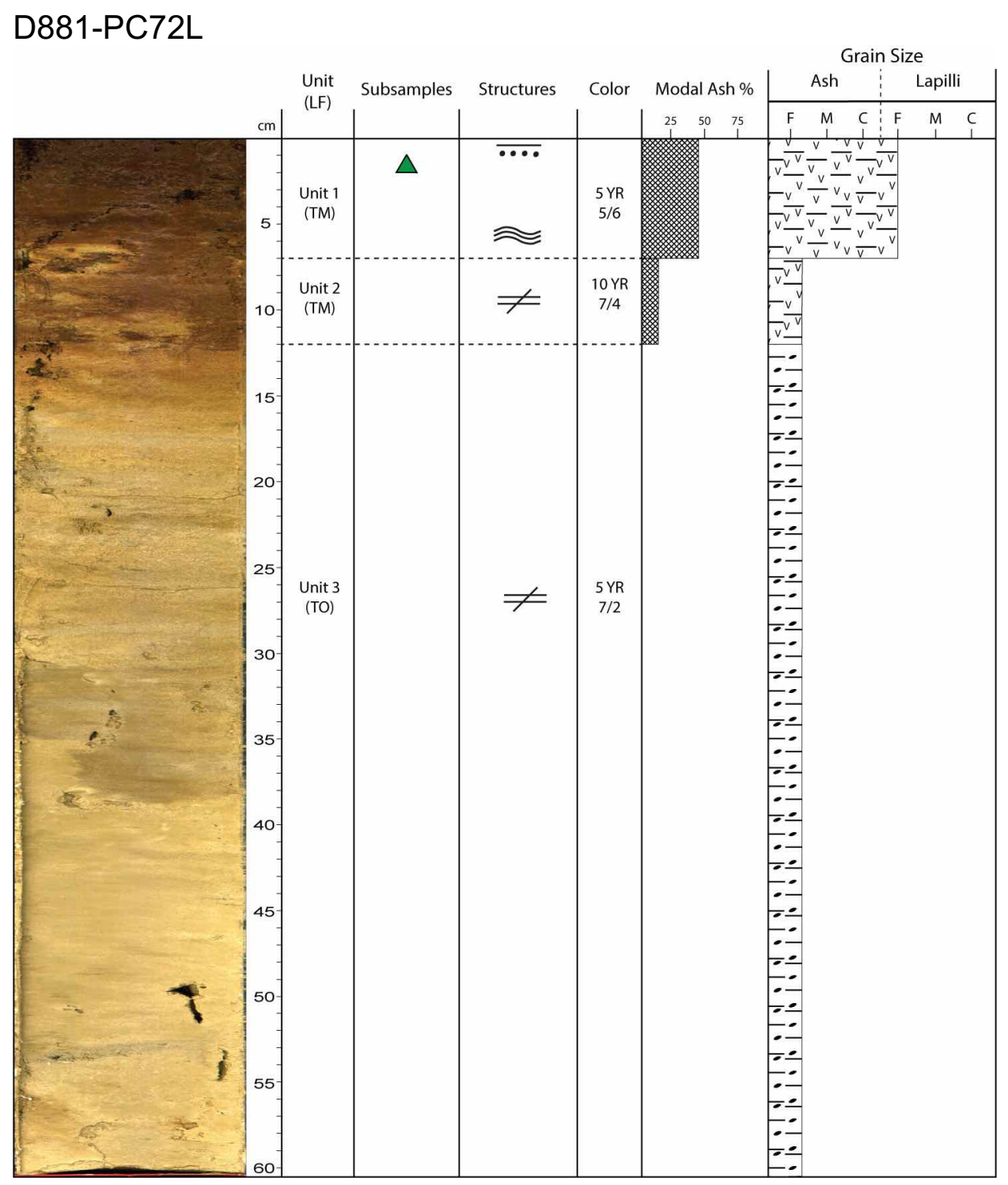

